\title{
Bringing two worlds closer together : addressing methodological challenges in the economic evaluation of public health programs
}

Citation for published version (APA):

Alayli-Goebbels, A. F. G. (2013). Bringing two worlds closer together : addressing methodological challenges in the economic evaluation of public health programs. [Doctoral Thesis, Maastricht University]. Datawyse / Universitaire Pers Maastricht. https://doi.org/10.26481/dis.20131210aa

Document status and date:

Published: 01/01/2013

DOI:

10.26481/dis.20131210aa

Document Version:

Publisher's PDF, also known as Version of record

Please check the document version of this publication:

- A submitted manuscript is the version of the article upon submission and before peer-review. There can be important differences between the submitted version and the official published version of record.

People interested in the research are advised to contact the author for the final version of the publication, or visit the DOI to the publisher's website.

- The final author version and the galley proof are versions of the publication after peer review.

- The final published version features the final layout of the paper including the volume, issue and page numbers.

Link to publication

\footnotetext{
General rights rights.

- You may freely distribute the URL identifying the publication in the public portal. please follow below link for the End User Agreement:

www.umlib.nl/taverne-license

Take down policy

If you believe that this document breaches copyright please contact us at:

repository@maastrichtuniversity.nl

providing details and we will investigate your claim.
}

Copyright and moral rights for the publications made accessible in the public portal are retained by the authors and/or other copyright owners and it is a condition of accessing publications that users recognise and abide by the legal requirements associated with these

- Users may download and print one copy of any publication from the public portal for the purpose of private study or research.

- You may not further distribute the material or use it for any profit-making activity or commercial gain

If the publication is distributed under the terms of Article 25fa of the Dutch Copyright Act, indicated by the "Taverne" license above, 


\section{Bringing two worlds closer together}

Addressing methodological challenges in the economic evaluation of public health programs 
Layout: Tiny Wouters

Cover design: Omar Alayli

Printed by: Datawyse | Universitaire Pers Maastricht

ISBN: 9789461592781

(C) Adrienne Alayli-Goebbels, Maastricht 2013

No part of this book may be reproduced or transmitted in any form or by any means, without prior permission in writing by the author, or when appropriate, by the publishers of the publications.

The research in this dissertation was mainly funded by a Toptalent grant of the Netherlands Organisation for Scientific Research (NWO), project number 0.21.001.034. Additional financial support was provided by the School of Public Health and Primary Care (Caphri). The study described in Chapter 3 was funded by ROCHE Netherlands BV.

Financial support for printing this dissertation was kindly provided provided by the Health Technology Assessment Program of the School for Public Health and Primary Care (Caphri), Maastricht University. 


\section{Bringing two worlds closer together}

Addressing methodological challenges in the economic evaluation of public health programs

\section{Proefschrift}

Ter verkrijging van de graad van doctor aan de Universiteit Maastricht, op gezag van de Rector Magnificus, Prof. dr. L. L. G. Soete, volgens het besluit van het College van Decanen, in het openbaar te verdedigen op dinsdag 10 december 2013 om 16.00 uur

door

\section{Adrienne Alayli-Goebbels}

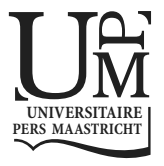




\section{Promotores}

Prof. dr. J. L. Severens (Erasmus Universiteit Rotterdam)

Prof. dr. N. K. de Vries

\section{Copromotor}

Dr. A. A. J. H. Ament

\section{Beoordelingscommissie}

Prof. dr. D. Ruwaard (voorzitter)

Prof. dr. C. D. Dirksen

Prof. dr. M. W. van Tulder (Vrije Universiteit Amsterdam)

Prof. dr. H. de Vries

Dr. G. A. de Wit (Universitair Medisch Centrum Utrecht) 


\section{Contents}

$\begin{array}{lll}\text { Chapter } 1 & \text { Introduction } & 7\end{array}$

Chapter 2 A review of economic evaluations of behavior change interventions: 27 setting an agenda for research methods and practice

Chapter 3 Estimating the implicit value of statistical life based on public interventions implemented in the Netherlands

Chapter 4 Exploring non-health outcomes of health promotion: the perspective of participants in a lifestyle behavior change intervention

Chapter 5 Consumer preferences for health and non-health outcomes of health promotion: results from a discrete choice experiment

Chapter 6 Consumer willingness to invest money and time for benefits of lifestyle behavior change: an application of the contingent valuation method

Chapter 7 General discussion

Summary

Acknowledgements

Curriculum Vitae

List of publications and presentations 


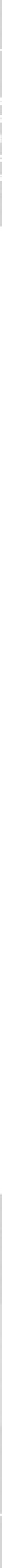
\begin{tabular}{l}
8 \\
\hline-1 \\
$\frac{1}{d}$ \\
$\frac{0}{0}$ \\
$\frac{0}{U}$
\end{tabular} 
This dissertation focuses on methodological challenges in the economic evaluation of public health programs. Chapter 1 provides a general background on the topic and outlines the objectives and methods of this research.

\section{What is public health?}

Public Health has been defined as the science and art of preventing disease, prolonging life and promoting health, through organized efforts of society. ${ }^{1}$ The methods and practice of public health are in continuous development, adapting to the prevailing and evolving health risks and problems. The changing focus of Public Health from its origins to the Modern or New Public Health has been described in terms of six eras. ${ }^{2}$

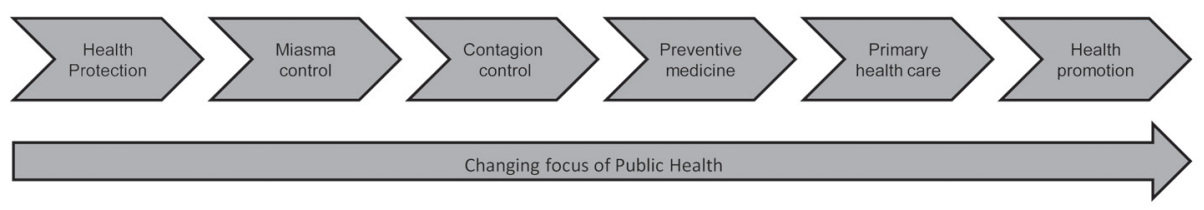

Figure 1.1 Six generations of Public Health (based on Awofeso) ${ }^{2}$

In the first era (antiquity to the 1830s), public health was characterized mainly by health protection. It was an integral part of societies' social structures and consisted of enforced regulation of behavior through religious and cultural rules as well as quarantine measures. Typical measures included hand washing rules, theologically sanctioned quarantine of leprosy sufferers and societal responses to the Black Death plague (e.g. isolating plague victims, tracing and incarcerating their contacts as well as restrictions on travelling and shipping). ${ }^{2,3}$ The discovery of highly developed sewer and water supply systems built by civilizations in antiquity is also worth noting, as it documents early public health engineering efforts. ${ }^{4}$

In the second era (1840s to 1870 ) public health was primarily concerned with miasma control. Miasma, originally meaning stain or pollution of sin, which offended the gods, was considered a poisonous vapor or mist filled with particles from decomposed matter that caused disease. ${ }^{5}$ Measures included centralized activities to tackle unsanitary environmental conditions (e.g. provision of clean water) and legislation regarding sewage and waste disposal. ${ }^{2,4}$

The next era (1880s-1930), referred to as the contagion control era, was characterized by an improved understanding of the pathogenesis of infectious diseases, like cholera. This drew the attention somewhat away from the sanitary problems of water supply, 
street cleaning, housing and living conditions of the poor, and opened the door for new ways to control infectious diseases, such as the development of vaccines against diphtheria and cholera. Another significant public health achievement in this era included the development of methods to measure bacteria in air, water and milk. ${ }^{2,4}$

The preventive medicine era (1940s to 1960s) was an extension of the contagion control era in that it continued to improve scientific understanding of the pathogenesis of infectious diseases, including the role of nutrient deficiencies and disease vectors. Public health became more disease-oriented during this era focusing on prevention and cure of infectious diseases among the ill and high-risk groups, such as pregnant women, factory workers, school children and the elderly. ${ }^{2}$ Due to growing successes in infectious disease control, life expectancy increased considerably and chronic diseases became the new frontier of public health in the last half of the $20^{\text {th }}$ century. ${ }^{6}$ New challenges involved tobacco-related diseases, unhealthy diet, physical activity, lack of access to preventive care, injuries, violence, as well as sexual and substance abuse behaviors. ${ }^{4,7}$

In response to these challenges, the primary care era (1970s -1980s) took a largely preventive approach. The WHO Alma Ata Declaration in 1978 formalized the key elements and goals of this approach, including (a) primary health care as backbone of the public health strategy, with an emphasis on health promotion and disease prevention strategies (b) global cooperation and piece as important aspects of primary health care, (c) adaptation of health services to countries and communities, (d) the recognition that healthcare reflects broader social and economic development, (e) the achievement of equity in health status and (d) involvement of all sectors in the promotion of health. ${ }^{2}$

Modern public health (1990 - present) is referred to as the health promotion era. It can be regarded as a continuation of the primary care era: several of its core principles remain relevant today, including the emphasis on multi-sector collaboration, achieving health equity and attention for the impact of social and economic conditions. ${ }^{2,6}$ Due to a modified definition of health and recognition of the need to increase opportunities for people to make healthy choices the scope of public health has been broadened during the health promotion era. ${ }^{2,6}$ As documented by WHO's 1986 Ottawa Charter for Health Promotion, modern public health is based on a positive health concept, perceiving health as a resource for everyday life and not the objective of living. Consequently, modern public health programs go beyond disease control towards improving quality of life and wellbeing. ${ }^{6}$ Actions take place in five key areas (i.e. building healthy public policy, creating supportive environments, strengthening of community action, developing personal skills and reorienting health services) and consist of three core activities (i.e. health education, prevention and protection).

Modern public health activities incorporate components of previous eras, which have been further developed or reframed. To give an example, quarantine practices from the 
health protection era and vaccination methods from the contagion era continue to be a part of the modern public health. The original quarantine practices have been replaced however by more targeted, humane and less stigmatizing measures, and contemporary vaccination programs use social marketing and persuasion techniques rather than legal enforcement to achieve necessary vaccination coverage. ${ }^{2}$

Modern public health programs are challenging for evaluation, because they often address multiple factors, consist of multiple strategies and take place on multiple analytical levels. Table 1.1 provides an overview of the different factors and analytical levels that may be targeted by modern public health programs alongside with several example interventions.

Table 1.1 Analytical levels targeted by modern public health interventions

\begin{tabular}{|c|c|c|}
\hline Level & Factors addressed & Interventions \\
\hline Intrapersonal & $\begin{array}{l}\text { Characteristics of the } \\
\text { individual, such as } \\
\text { knowledge, attitudes, } \\
\text { behavior, self-concept and } \\
\text { skills. Includes the } \\
\text { developmental history of } \\
\text { the individual. }\end{array}$ & $\begin{array}{l}\text { Aim to change individuals and may include } \\
\text { educational programs, mass media, support groups, } \\
\text { organizational incentives or peer counselling. } \\
\text { Example: Training adolescents to resist peer pressure } \\
\text { related to smoking. }\end{array}$ \\
\hline Interpersonal & $\begin{array}{l}\text { Interpersonal processes } \\
\text { and primary groups, such } \\
\text { as formal and informal } \\
\text { social network and social } \\
\text { support systems (e.g. } \\
\text { family, work group and } \\
\text { friendship networks). }\end{array}$ & $\begin{array}{l}\text { Aim to change social influences on individuals by } \\
\text { addressing social norms and social groups to which } \\
\text { individuals belong. } \\
\text { Example: Changing norms about drug use within } \\
\text { existing networks or creating alternative networks. }\end{array}$ \\
\hline Institutional & $\begin{array}{l}\text { Social institutions with } \\
\text { organizational } \\
\text { characteristics and both } \\
\text { formal and informal rules } \\
\text { as well as regulations for } \\
\text { operation. }\end{array}$ & $\begin{array}{l}\text { Directed at creating an organizational culture and } \\
\text { structures supportive of health issues and healthy } \\
\text { behavior. Organizational context may also be used } \\
\text { for the diffusion of health promotion programs. } \\
\text { Example: Changing food offerings in cafeterias or } \\
\text { implementing stress reduction interventions that } \\
\text { improve worker supervisor relationships. }\end{array}$ \\
\hline Community & $\begin{array}{l}\text { Relationships among } \\
\text { organizations, institutions } \\
\text { and informal networks } \\
\text { within defined boundaries. }\end{array}$ & $\begin{array}{l}\text { Seek to increase coordination among community } \\
\text { agencies to improve delivery of services, encourage } \\
\text { coalition building to influence community awareness } \\
\text { and local health policies, and to improve access to } \\
\text { community political and power structures. } \\
\text { Example: Strategies to include representation from } \\
\text { disadvantaged populations on community boards. }\end{array}$ \\
\hline Public policy & $\begin{array}{l}\text { Local, state and national } \\
\text { laws and policies. }\end{array}$ & $\begin{array}{l}\text { Include regulatory policies, procedures and laws to } \\
\text { promote and protect health of the community, as } \\
\text { well as the establishment of health promotion centres } \\
\text { in universities and health promotion offices/agencies } \\
\text { in federal and state government. } \\
\text { Example: Restrictions on alcohol sales, increased } \\
\text { taxes on alcohol and cigarettes. }\end{array}$ \\
\hline
\end{tabular}




\section{Evidence-informed decision-making on public health}

Due to innovation and research, interventions with the potential to improve public health are continuously introduced and further developed. However, not every innovation leads to improved population wellbeing and not all effective interventions can be implemented due to limited public resources. ${ }^{9}$ Therefore, it is important to distribute resources wisely, considering available evidence.

Health Technology Assessment (HTA) encourages evidence-informed decision-making by building a bridge between scientific research and policy-making. ${ }^{10}$ It has been defined as "a multidisciplinary process that summarizes information about the medical, social, economic and ethical issues related to the use of a health technology in a systematic, transparent, unbiased, robust manner" ${ }^{11}$

The term 'technology' in HTA is defined very broadly, comprising actual technologies, like medical devices or diagnostic tests, but also organizational changes, rehabilitation, prevention and health promotion programs. Although countries differ regarding the structure of HTA agencies and specific HTA procedures, the general elements of the HTA process are quite similar across countries. ${ }^{12}$

The HTA process may be regarded as a continuous and interdependent flow of twelve activities. ${ }^{13}$ It begins with the (1) assessment of health needs of a population and the (2) prioritization of health needs to concentrate on. Then (3) technologies are identified that could be used or are in use to treat, prevent or manage the priority health needs. From the available technologies (4) a selection is made of technologies to be further assessed. This decision may be based on preliminary literature review and/or consultation with experts. In the next step (5) external specialists/researchers are identified and asked to participate in the assessment of the selected technologies. In consultation with the external specialists the (6) assessment objectives and target audience for the technology are defined. Then (7) specific research questions are formulated, defining the clinical, social and economic impacts of the technology that will be assessed. These questions guide the actual assessment of the technology, which consists of the (8) identification and collection of relevant evidence, (9) the analysis and synthesis of the evidence, (10) preparing a draft report for assessment by internal and external reviewers, and (11) writing and editing the final HTA report. The report is then (12) disseminated to the appropriate people who make decisions regarding the use of the technology. When a technology is implemented in practice, the assessment process does not finish. It is recommended that the performance of the technology is regularly examined and if necessary, the technology may re-enter the assessment process. ${ }^{14}$ 
Although a broad number of aspects of health technologies are regarded relevant to consider during the technology assessment process (e.g. effectiveness, costeffectiveness, psychological, social and ethical issues, organizational and professional implications ${ }^{12}{ }^{12}$ in practice the systematic assessment of technologies, is often limited to a few aspects (i.e. efficacy, safety, and cost-effectiveness). ${ }^{15,16}$ This appears for instance from the Measurement Interactive Loop, also referred to as Technology Assessment Iterative Loop, which is frequently used as a framework to guide the technology assessment process (see Figure 1.2). ${ }^{17}$

1

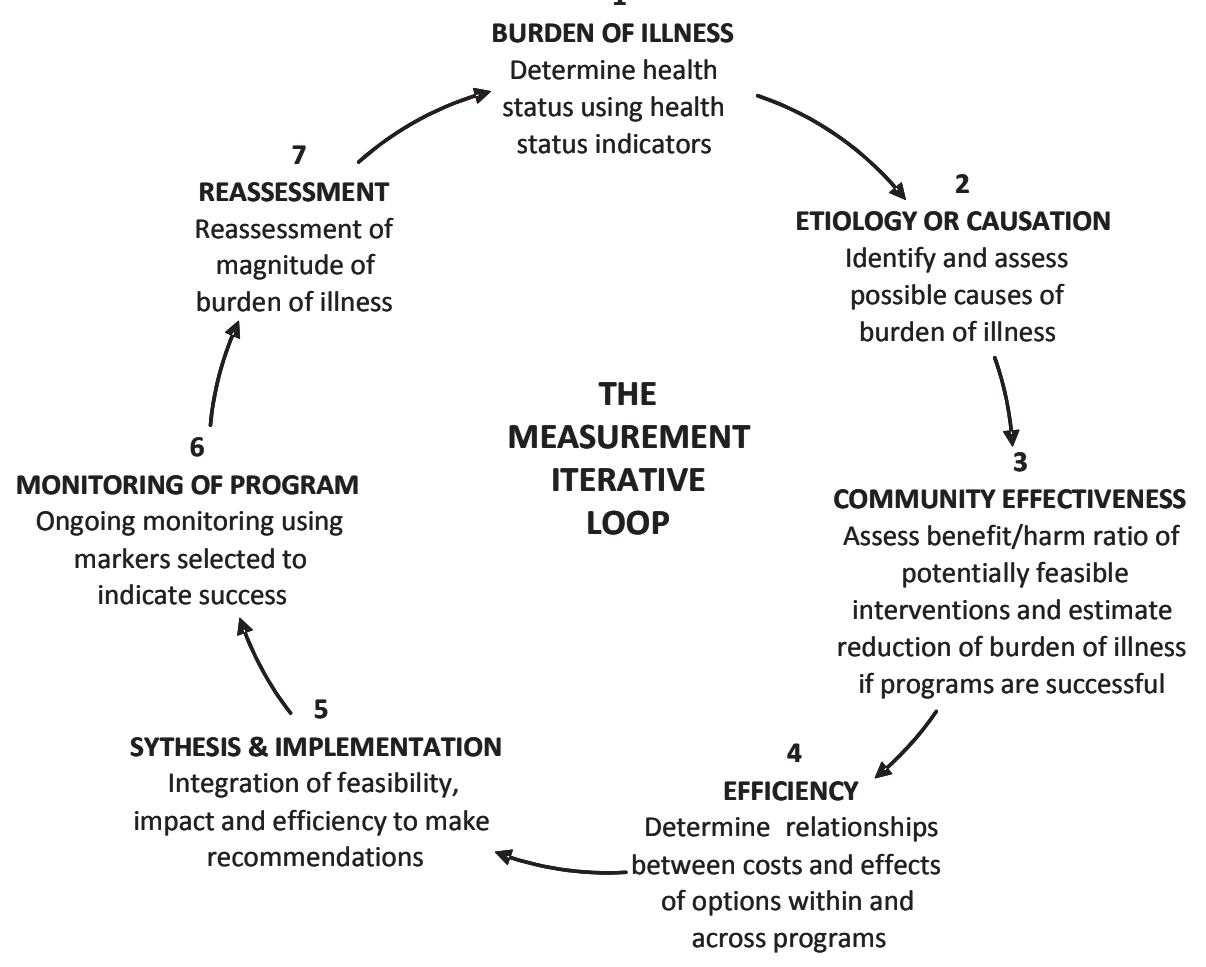

Figure 1.2 Measurement Iterative Loop

The framework links evaluation questions defined during the technology assessment process with research methods that can be used to answer the questions. It describes a sequence of scientific methods that may used to inform decisions about health technologies starting from methods to quantify the burden of illness and identify likely causes, through methods for evaluating community effectiveness and efficiency of 
interventions, and back again to methods determining whether disease burden has been reduced by the technology. After a technology has been identified, the framework suggests performing scientific assessment of two major pieces of evidence: (1) community effectiveness, which incorporates information about efficacy, safety (e.g. side effects), screening and diagnostic accuracy, coverage, as well as compliance; and (2) efficiency, which integrates evidence on efficacy or community effectiveness with evidence on costs. ${ }^{17}$ Systematic methods for considering social, ethical, cultural or organizational aspects of the technology are not described by the framework. The authors only mention briefly that such aspects should be assessed to determine the feasibility of implementing the technology, when synthesizing information in step five. ${ }^{17}$ Methods to consider such broader societal impacts are not well developed and rely more on qualitative rather than quantitative information. ${ }^{18}$ For this reason several countries, including The Netherlands, divide the technology assessment process into two distinct phases. ${ }^{19,20}$ The first phase, referred to as 'assessment phase', focuses on 'hard' quantitative measures, such as burden of disease and costs per Quality Adjusted Life Year (QALY) gained. ${ }^{19}$ Based on these measures recommendations are made for decision-making, which are reassessed in the second phase, referred to as 'appraisal phase'. In contrast to the research-based assessment phase, the appraisal phase relies on social value judgments. The information considered in the appraisal phase is more qualitative and collected in a less systematic manner than the information considered during the assessment phase. It relates to issues, such as social justice and solidarity. ${ }^{19,21}$ The National Institute for Health and Care Excellence, which is responsible for conducting technology assessments and appraisals in the United Kingdom, notes that in practice the dividing line between the appraisal and assessment phase is not always very clear. ${ }^{22}$

\section{Economic evaluation}

Cost-effectiveness evidence can be a useful tool for decisions about health technologies because it can provide clear policy guidance as to which investments provide the largest health gain for a given budget. Cost-effectiveness or efficiency of health technologies can be assessed by means of economic evaluation studies. The methods used in economic evaluation studies and their application to public health are the primary focus of this research. An economic evaluation is a comparative analysis of alternative courses of action or interventions in terms of both their costs and consequences. ${ }^{23}$ It can take five different forms, referred to as cost-effectiveness analysis (CEA), cost-utility analysis (CUA), cost-benefit analysis (CBA), cost-consequence analysis (CBA) and costminimization analysis (CMA). The identification and measurement of costs is similar 
across all forms of economic evaluation. The difference lies in the nature of the consequences being considered and the way consequences are measured. ${ }^{23}$

In CEA consequences are measured in terms of a single, common unit of effect that may differ in size between the alternatives. Results of a CEA are expressed in terms of the cost per unit of effect, such as for instance the cost per life-year gained, cost per infection averted, cost per disability day avoided or cost per person who quits smoking. ${ }^{23}$ CUAs also compare alternatives in terms of their cost per unit of effect. The unit of effect in CUA is a single measure accounting for both changes in life expectancy and quality of life. The most frequently used measure is the QALY. It is calculated by multiplying a person's life expectancy with a weight for the health-related quality of life (HRQOL) experienced in that period. The HRQOL weight is a number between 0 and 1 , which represents a value ascribed to a specific health state relative to full health (weight $=1$ ) and death (weight $=0$ ). This weight is mostly derived by means of generic preference based instruments, such as the EQ-5D, which describe health states in terms of different HRQOL dimensions that can take several levels. The health state descriptions are usually derived from patients or program participants, while the corresponding weight or value is derived from a general population sample. ${ }^{24}$ The advantage of CUAs compared to CEAs, is that they go beyond specific intervention outcomes and allow for a comparison of a broad number of health programs.

CBAs use an even broader measure of effect than CUAs. They express program consequences in monetary terms. As monetary values can in principle be attached to all types of consequences, there is no need to restrict the analysis to health outcomes only. Expressing program consequences in monetary terms also has the advantage that it allows for a direct comparison of program costs and consequences. Hence, the analyst can assess whether the program is worthwhile (i.e. net monetary benefit $>0$ ). Despite these advantages, CBA is not used very much in the health sector, because attaching a monetary value to health and life is not a straightforward operation. There are several methods available for monetary valuation, such as the human capital approach and revealed and stated preference methods, but these are controversial and sometimes even regarded as unethical. ${ }^{23}$

Analysts who seek to consider various types of outcomes, but do not want to attach a monetary value to them or present them in one aggregate measure (like a QALY or a cost-effectiveness ratio) can use a CCA approach. In CCA relevant costs and consequences of alternatives are presented separately, for example in a tabular format. This has the advantage that the policy maker can consider components of special interest separately and decide about their relative importance. ${ }^{23-25} \mathrm{~A}$ weakness of this approach is however, that there is no clear decision rule. It is for example difficult to 
determine the overall impact of the program when some outcomes improve and others get worse. ${ }^{26,27}$

CMA can be used in situations, where previous research suggests that consequences of two or more programs are broadly equivalent. The analysis is then reduced to a comparison of costs of the alternatives. It has been argued that this form of economic evaluation is only justifiable when the alternatives under comparison are nearly identical, which is for example the case when comparing drugs in the same pharmacological class. ${ }^{23}$ CMA is unlikely to be useful for the comparison of public health programs, because these programs are targeted to specific contexts and populations, and thus seldom identical.

The five forms of economic evaluation described here can be designed in two major ways: they can be either trial- or model-based. Trial-based studies involve the collection of new primary data alongside a randomized controlled trial, a pragmatic trial or another study design used to examine program effectiveness. Trial-based designs provide specific data on the level of intervention participants, which is attractive for both dataanalysis and internal validity. ${ }^{23}$ Model-based studies use mathematical relationships to define possible consequences resulting from alternative options being evaluated. They make use of secondary data, which are synthesized from different sources. This allows for instance to compare more alternatives and subsamples than what is feasible in a trial. Models can also be used to extrapolate costs and consequences of an alternative over time, for example by linking an intermediate measure of effect (e.g. reduction in cholesterol) to long-term health outcomes. ${ }^{28}$ Hence, model and trial-based studies can be regarded as complementary rather than mutually exclusive and may be combined in one study.

\section{Methodological standards for economic evaluation}

To enhance the credibility and usefulness of economic evaluation studies for decisionmaking the International Society for Pharmacoeconomics and Outcomes Research (ISPOR) and the Society of Medical Decision Making (SMDM) have established good practice guidelines for designing, conducting and reporting both trial- and model based economic evaluation studies. ${ }^{29,30}$ A number of key methodological standards addressed in these guidelines are discussed in the following chapters and therefore briefly outlined below. 


\section{Study endpoints}

It is recommended to directly measure program consequences in either QALYs or monetary terms and to avoid intermediate outcome measures, such as for instance percentage LDL cholesterol reduction. However, the stronger the relationship between intermediate outcomes and long-term disease outcomes, the more it is justified to rely on intermediate endpoints. ${ }^{29}$

\section{Time horizon}

The time horizon of an economic evaluation should be sufficiently long to capture all health effects and costs relevant to the decision problem. Ideally this includes lifetime costs and consequences of the alternatives under evaluation. ${ }^{29,30}$

\section{Appropriate trial design}

Generally pragmatic effectiveness trials are regarded the best vehicle for economic evaluation studies. ${ }^{29}$ The study design of these trials is equal to that of randomized controlled trials (RCTs), but the study protocol is somewhat relaxed to allow providers of the health program and patients or participants to behave as they would under real world (i.e. routine practice) circumstances. ${ }^{31}$ However, pragmatic effectiveness trials are usually not feasible in an early stage of the development process, before the health program or drug has been approved for marketing. Therefore, RCT studies assessing effectiveness under ideal circumstances (i.e. efficacy) may also be acceptable for use in economic evaluation. ${ }^{29}$

\section{Discounting}

Economists generally assume that individuals and society have a positive rate of time preference. This means that they prefer to experience additional benefits today rather than in the future. For costs it is assumed that people prefer to incur costs later rather than sooner. To account for time preference in economic evaluation it is recommended to apply discounting, a method to adjust costs and consequences incurred in the future to their present value, using a common real discount rate..$^{23,29}$

\section{Summary measures}

For a meaningful comparison of costs and consequences between alternatives, it is recommended to report a measure, which summarizes the additional value of one alternative compared to another. For this incremental comparison, three types of summary measures may be used: ratio measures, difference measures or probability measures. 
Ratio measures are obtained by dividing the incremental costs by the incremental benefit of one alternative compared to another alternative. An incremental cost-effectiveness ratio (ICER) can take the form of an additional cost per QALY or an additional cost for any other unit of effect (e.g. averting one case of HIV infection). ${ }^{29}$

The net monetary benefit (NMB) of a program is a commonly used difference measure. It can be calculated when a monetary value has been attached to program outcomes. According to this approach a program is cost-effective when the ICER is lower than the maximum willingness to pay (WTP) for a QALY or other unit of effect employed in the ICER. A positive NMB $(>0)$ suggests that the incremental benefits of the program exceed its costs, which is for example the case when the WTP for a QALY gained by a new program is higher than the incremental costs per QALY. NMB measures can be used when willingness to pay is estimated within a cost-benefit framework using for example revealed or stated preference methods. ${ }^{23,29}$

Cost-effectiveness acceptability curves are a frequently used probability measure. They characterize the likelihood that a program is more cost-effective than an alternative, given different possible WTP values. WTP is varied, because WTP for a QALY or another unit of effect is considered an arbitrary societal value. ${ }^{23,29}$

\section{Sensitivity analyses}

Results of economic evaluation are subject to uncertainty from a number or sources. Parameter estimates, such as unit costs, event probabilities and the discount rate are a key source of uncertainty. It is therefore recommended to use sensitivity analysis to assess the impact of parameter uncertainty on incremental cost-effectiveness results. ${ }^{29}$ Sensitivity analyses can be either deterministic (where values are varied using point estimates) or probabilistic (where values are varied using probability distributions). It is often appropriate to use both types of sensitivity analyses within a single economic evaluation study. 23,30

\section{Costs and resource use}

The measurement of costs and resource use has to be consistent with the time horizon and the perspective of the study. If the study is conducted from a societal perspective the costs considered should also reflect social opportunity costs. ${ }^{29}$ 


\section{Applying economic evaluation methods to public health}

The vast majority of economic evaluation studies focus on biomedical health interventions, such as pharmaceuticals, medical devices and surgical procedures, but applications of economic evaluations to public health programs are increasing. ${ }^{32-34}$ This is especially the case for clinical preventive programs, such as screening and vaccination, and for programs directed at lifestyle behavior changes. Economic evaluations of public health programs addressing wider environmental and socio-economic determinants of health, such as poverty and unemployment, are still very rare. ${ }^{32,33}$

The relative lack of economic evaluation evidence in public health can be attributed to three major factors. First, there are very limited resources available for evaluating public health interventions. ${ }^{33,35,36}$ There is little opportunity to generate profit from public health programs. Therefore, these studies are generally not funded by large multinational companies, as is often the case for economic evaluations of clinical or pharmaceutical interventions. Consequently, these studies have to rely on limited funding from government, charitable organizations and private foundations. ${ }^{33,37}$

Second, systematic decision-making mechanisms for priority setting in public health are not well developed in most countries. ${ }^{36,37}$ Consequently, there are usually no clear requirements for the use of economic evaluation evidence in decision-making on public health programs, unlike the requirements that are in place for pharmaceuticals. For instance, the Health Care Insurance Board (College voor Zorgverzekeringen), which provides advice to the Dutch government regarding reimbursement of pharmaceuticals by the social health insurance scheme, has published guidelines for economic evaluation studies that need to be followed by companies, requesting reimbursement of pharmaceuticals. ${ }^{38}$ In the Netherlands and most other countries such guidelines do not exist for public health programs.

Third, modern public health programs pose a number of challenges to evaluation methods, which are described in more detail in the next paragraph.

\section{Methodological challenges for economic evaluation of public health programs}

Based on the scientific literature we identified seven methodological challenges for the economic evaluation of public health programs. First, they tend to have a long time horizon. The health impacts of behavior changes and changes to broader environmental or economic conditions take so long to accrue, that they are usually not measured within effectiveness trials. Although extension of follow-up periods is theoretically possible, it is 
very expensive and often not feasible in practice. Hence, alternatives to actual measurement are needed, such as mathematical modeling, which may be used to translate intermediate outcomes (e.g. behavior changes) to final outcomes (e.g. changes to life expectancy or quality of life). ${ }^{33,39}$

Second, modern public health programs do not only focus on improving health. They also aim to impact on broader domains of wellbeing ${ }^{6}$. A typical objective is for instance empowerment of individuals. This may include increasing their self-esteem, health literacy, communication and problem solving skills. ${ }^{1,40,41}$ Changes to these outcomes are not captured by standard measures of health outcomes, such as QALYs. Intended broader outcomes are however not well-defined and theoretically underpinned outcome measures for use in economic evaluation are currently lacking. ${ }^{42}$

Third, public health programs address determinants of health and wellbeing on multiple operational levels. At the individual level, educational interventions are for example implemented to promote healthy lifestyle choices and enhance people's life skills. At the community level, interventions may be directed at developing systems to strengthen public participation in health matters, ${ }^{43}$ and interventions at the societal level may address social, economic and environmental determinants of wellbeing by means of fiscal measures (e.g. alcohol tax), legislation (e.g. smoke free work place legislation) or organizational changes (e.g. changing food offerings in schools) ${ }^{8,44,45}$ As a consequence of this multi-level approach, outcomes may also be produced on multiple levels. ${ }^{46}$ Outcome measurement in economic evaluation studies however tends to focus only on individual level outcomes. ${ }^{47}$

Fourth, reducing health inequities is an important objective of public health programs, while economic evaluation studies usually do not account for equity outcomes. ${ }^{48}$ They are based on a utilitarian framework and seek to compare which of the programs under evaluation achieves the highest degree of overall utility or health benefit. For example, for each Euro invested, evaluators compare which program achieves the largest number of QALYs possible, regardless of whom the QALYs accrue to. ${ }^{48}$

Fifth, the most preferred forms of effectiveness evidence for use in economic evaluations are (pragmatic) RCTs and meta-analyses of RCTs. The evidence base in the field of public health does not always fit into this framework, because RCT designs are often not an appropriate and feasible option. ${ }^{35}$ Randomization into different experimental conditions may not possible due to practical reasons (e.g. in case of policy or structural interventions) or ethical reasons (e.g. in studies of the effects of environmental tobacco smoke $)^{49}$ and when evaluating mass-media interventions it is difficult to use an appropriate control group, because people cannot be excluded from participation. Another problem is that public health interventions are not standardized, but often tailored to local contexts. Hence, effects may not be transferable to other settings. RCT 
designs are not sufficient to examine interaction with local context and transferability of effectiveness findings to other contexts. ${ }^{50}$

Sixth, public health interventions often require multi-sector collaboration. ${ }^{37,51}$ For example an intervention to create bicycle paths to stimulate more physical activity requires collaboration between the sectors health, transport and spatial planning. As a result multiple societal sectors contribute financial and other resources to public health programs. ${ }^{51,52}$ It is currently unclear what kind of non-health sector resources these exactly are and how to consider these within economic evaluation. ${ }^{34,53}$

Finally, multi-sector collaboration also creates the need for decision-makers to compare possible investments in the area of public health with investments in other areas. The methods to compare efficiency of public health interventions with efficiency of interventions in for example transport and the environmental sector are however not well developed, and it is unclear which measures to use in the comparison. Economic evaluation studies in public health have mainly adopted cost-effectiveness and costutility analysis frameworks. These frameworks are not used in other societal sectors, which hampers comparability. A potential way to increase comparability across sectors would be to use a cost-benefit analysis framework. But, there is still uncertainty about feasibility and validity of methods, which can be used to assign monetary values to intervention outcomes (e.g. contingent valuation)..$^{54,55}$

\section{Objectives and scope}

This research had two objectives. First, to provide a general overview of the methodological quality of economic evaluations of public health programs and the progress that has been made regarding the seven challenges for evaluation described above. Second, to contribute to potential solutions to overcome the challenges associated with comparing efficiency across multiple societal sectors and the impacts public health programs may have on broader domains of wellbeing at the individual level. With respect to public health, this research focuses primarily on lifestyle behavior change interventions (LBCIs), which constitute a key attention area of modern public health/health promotion and an area of public health where a relative large number of economic evaluation studies are available. Additionally, progress is likely to occur in this area because some methodological challenges may be overcome more easily for LBCIs than for other public health programs. For example due to increasing availability of epidemiological data, which allow for translation of behavior changes into long-term health outcomes. ${ }^{56}$ 


\section{Outline}

In Chapter 2 a systematic literature review provides insights into how economic evaluation studies of lifestyle behavior change interventions addressed methodological challenges for evaluation and their methodological quality. Chapter 3 describes a study exploring the possibility to use the Value of Statistical Life as a common parameter of efficiency in a multi-sector comparison of life saving public health interventions and life saving interventions implemented in three other societal sectors in the Netherlands.

Chapter 4 reports on a qualitative study conducted among participants of a lifestyle intervention trial to identify experienced broader outcomes of public health that are not captured by typical measures of health outcome used in economic evaluation. For consideration of such broader outcomes in decision-making, it is crucial to understand their importance to society. This question is addressed in Chapter 5, which describes the results of a discrete choice experiment, examining the relative importance of health outcomes usually considered within economic evaluations and broader non-health outcomes that were identified by the qualitative research described in Chapter 4 .

Chapter 6 illustrates an application of contingent valuation to value both health and broader outcomes of public health in monetary terms. Questions regarding the feasibility and validity of the method to derive willingness to pay from an individual consumer perspective are also addressed.

In Chapter 7 the research findings presented in the previous chapters are discussed with respect to their implications for practice, policy making and future research. 


\section{References}

1. WHO. Health Promotion Glossary. Geneva: World Health Organization; 1998.

2. Awofeso N. What's New About the "New Public Health"? American Journal of Public Health. 2004;94:705-709.

3. Slack P. Responses to plague in early modern Europe: The implications of public health. Social Research. 1988;55:433-453.

4. Novick LF, Morrow CB, Mays GP. Public Health Administration: Principles for population-based management. Sudbury: Jones and Bartlett Publishers; 2008.

5. Curtis VA. Dirt, disgust and disease: A natural history of hygiene. Journal of Epidemiology and Community Health. 2007;61:660-664.

6. Fielding JE, Teutsch S, Breslow L. A Framework for public health in the United States. Public Health Reviews. 2010;32:174-189.

7. Halpin HA, Morales-Suárez-Varela MM, Martin-Moreno JM. Chronic disease prevention and the new public health. Public Health Reviews. 2010;32:120-154.

8. McLeroy KR, Bibeau D, Steckler A, Glanz K. An ecological perspective on health promotion programs. Health Education Quarterly. 1988;15:351-377.

9. Garrido V, Kristensen FB, Nielsen CP, Busse R. Health technology assessment and healthpolicy making in Europe. Observatory Studies Series No14. 2008.

10. Battista RN, Hodge MJ. The development of health care technology assessment: An international perspective. International Journal of Technology Assessment in Health Care. 1995; 11:287-300.

11. Kristensen FB. EunetHTA and health policy-decision making in Europe. Eurohealth. 2006;12:36-38.

12. Busse R. Best practice in undertaking and reporting health technology assessments. International Journal of Technology Assessment in Health Care 2002;18:361-422.

13. WHO Collaborating Center for Knowledge Translation and Health Technology Assessment in Health Equity. Health Technology Assessment Process. 2004 [December 5th 2012]; Available from: http://www.cgh.uottawa.ca/whocc/projects/eo_toolkit/hta.htm.

14. Rosenkötter $\mathrm{N}$, Vondeling $\mathrm{H}$, Blancquaert I, Mekel $\mathrm{OCL}$, Kristensen FB. The contribution of health technology assessment, health needs assessment, and health impact assessment to the assessment and translation of technologies in the field of public health genomics. Public Health Genomics. 2011;14:43-52.

15. Marsh K, Dolan P, Kempster J, Lugon M. Prioritizing investments in public health: a multicriteria decision analysis. Journal of Public Health. 2012; doi:10.1093/pubmed /fds099.

16. Stephens JM, Handke B, Doshi JA. International survey of methods used in health technology assessment (HTA): Does practice meet the principles proposed for good research? Comparative Effectiveness Research. 2012;2:29-44.

17. Tugwell $P$, Bennett $K$, Sacket DL, Haynes RB. The measurement iterative loop: A framework for the critical appraisal of need, benefits and costs of health interventions. Journal of Chronic Diseases. 1985;38:4.

18. Banta HD, Luce BR. Health care technology and its assessment: An international perspective Oxford: University Press; 1993.

19. RVZ. Zinnige en duurzame zorg. Zoetermeer: Raad voor de Volksgezondheid en Zorg; 2006.

20. Walley T. Health technology assessment in England: Assessment and appraisal. Medical Journal of Australia 2007;187:283-285.

21. NICE. Guide to the methods of technology appraisal 2013. London: National Institute for Health and Care Excellence; 2013.

22. NICE. Guide to the methods of technology appraisal. London: National Institute for Health and Clinical Excellence; 2008.

23. Drummond MF, Sculpher MJ, Torrance W, O'Brien BJ, Stoddard GL. Methods for the Economic Evaluation of Health Care Programmes New York: Oxford University Press; 2005. 
24. Brazier J, Ratcliffe J, Salomon JA, Tsuchiya A. Measuring and valuing health benefits for economic evaluation. New York: Oxford University Press; 2007.

25. Mauskopf JA, Paul JE, Grant DM, Stergachis A. The role of cost-consequence analysis in healthcare decision-making. Pharmacoeconomics. 1998;13:277-288.

26. Fox-Rushby J, Cairns J. Economic Evaluation. New York: Open University Press; 2005.

27. De Salazar L, Jackson S, Shiell A, Rice M. Guide to economic evaluation in health promotion. Washington: Pan American Health Organization; 2007.

28. Briggs A, Claxton K, Sculpher M. Decision Modelling for health economic evaluation. New York: Oxford University Press; 2006.

29. Ramsey S, Willke R, Briggs A, Brown R, Buxton M, Chawla A, et al. Good research practices for cost-effectiveness analysis alongside clinical trials: The ISPOR RCT-CEA Task Force Report. Value in Health 2005;8:521-533.

30. Caro JJ, Briggs A, Siebert U, Kuntz KM. Modeling good research practices - Overview: A report of the ISPOR-SMDM modeling good research practices task force-1. Medical Decision Making 2012;32:667-677.

31. O'Brien BJ. Economic evaluation of pharmaceuticals: Frankenstein's monster or vampire of trials? Medical Care. 1996;34:DS99-DS108 Supplement.

32. Rush B, Shiell A, Hawe P. A census of economic evaluations in health promotion. Health Education Research 2004 19:707-719.

33. McDaid $D$, Needle J. What use has been made of economic evaluation in public health? A systematic review of the literature. In: Dawson S, Morris ZS, editors. Future Public Health: Burdens, Challenges and Opportunities. Basingstone: Palgrave Macmillan; 2009:248-264.

34. Weatherly H, Drummond M, Claxton K, Cookson R, Ferguson B, Godfrey C, et al. Methods for assessing the cost-effectiveness of public health interventions: Key challenges and recommendations. Health Policy. 2009;93:85-92.

35. Victora CG, Habicht J, Bryce J. Evidence-based public health: Moving beyond randomized trials. American Journal of Public Health 2004;94:400-405.

36. Wanless D. Securing good health for the whole population. Final Report London: HM Treasury; 2004.

37. Allin S, Mossialos E, McKee M, Holland W. Making decisions on public health: A review of eight countries. Copenhagen: WHO Regional Office for Europe; 2004.

38. CVZ. Guidelines for pharmacoeconomic research, updated version. Diemen: College voor Zorgverzekeringen; 2006.

39. Prenger R, Pieterse ME, Braakman-Jansen LMA, van der Palen J, Christenhusz LCA, Seydel ER. Moving beyond a limited follow-up in cost-effectiveness analyses of behavioural interventions. European Journal of Health Economics. 2012; DOI 10.1007/s10198-011-0371-6.

40. Peerson A, Saunders M. Health literacy revisited: What do we mean and why does it matter? Health Promotion International. 2009;24:285-295.

41. Rissel C. Empowerment: The holy grail of health promotion? Health Promotion International. 1994;9:39-47.

42. Rootman I, Goodstadt M, Potvin L, Springett J. A framework for health promotion evaluation. WHO Regional Publications European Series No 92. 2001:7-38.

43. WHO. Milestones in health promotion: Statements from globel conferences. Geneva: World Health Organization; 2009.

44. Allwright S, Paul G, Greiner B, Pursell L, Kelly A, Bonner B, et al. Legislation for smoke-free workplaces and health of bar workers in Ireland: Before and after study. British Medical Journal 2005;331:1117.

45. Wagenaar AC, Tobler AL, Komro KA. Effects of alcohol tax and price policies on morbidity and mortality: A Systematic Review. American Journal of Public Health. 2010;100:2270-2278.

46. Smith RD, Petticrew M. Public health evaluation in the twenty-first century: Time to see the wood as well as the trees. Journal of Public Health. 2010;32:2-7.

47. Shiell A, Hawe P. Health promotion community development and the tyranny of individualism. Health Economics. 1996;5:241-247. 
48. Cookson R, Drummond $M$, Weatherly $H$. Explicit incorporation of equity considerations into economic evaluation of public health interventions. Health Economics Policy and Law. 2009;4:231-245.

49. West SG, Duan N, Pequegnat W, Gaist P, Des Jarlais DC, Holtgrave D, et al. Alternatives to the randomized controlled trial. American Journal of Public Health. 2008;98:1359-1366.

50. Rychetnik L, Frommer M, Hawe P, Shiell A. Criteria for evaluating evidence on public health interventions. Journal of Epidemiology and Community Health 2002;56:119-127.

51. Aarts M, Jeurissen MPJ, van Oers HAM, Schuit AJ, van de Goor IAM. Multi-sector policy action to create activity-friendly environments for children: A multiple-case study. Health Policy. 2011;101:11-19.

52. Ziglio E, Hagard S, Levin LS. Investment for health: Developing a multifaceted appraisal approach. WHO Regional Publications European Series. 2001;No. 92:493-513.

53. Claxton K, Walker S, Palmer S, Sculpher M. Appropriate perspectives for health care decisions. Centre for Health Economics (CHE) Research Paper 2010;54.

54. Venkatachalam L. The contingent valuation method: A review. Environmental Impact Assessment Review. 2004;24:89-124.

55. de Meijer C, Brouwer W, Koopmanschap M, van den Berg B, van Exel J. The value of informal care - a further investigation of the feasibility of contingent valuation in informal caregivers. Health Economics. 2010;19:755-771.

56. Ezzati M, Lopez AD, L. MCJ. Comparative quantification of health risks: global and regional burden of disease attributable to selected major risk factors. Geneva: World Health Organization; 2004. 


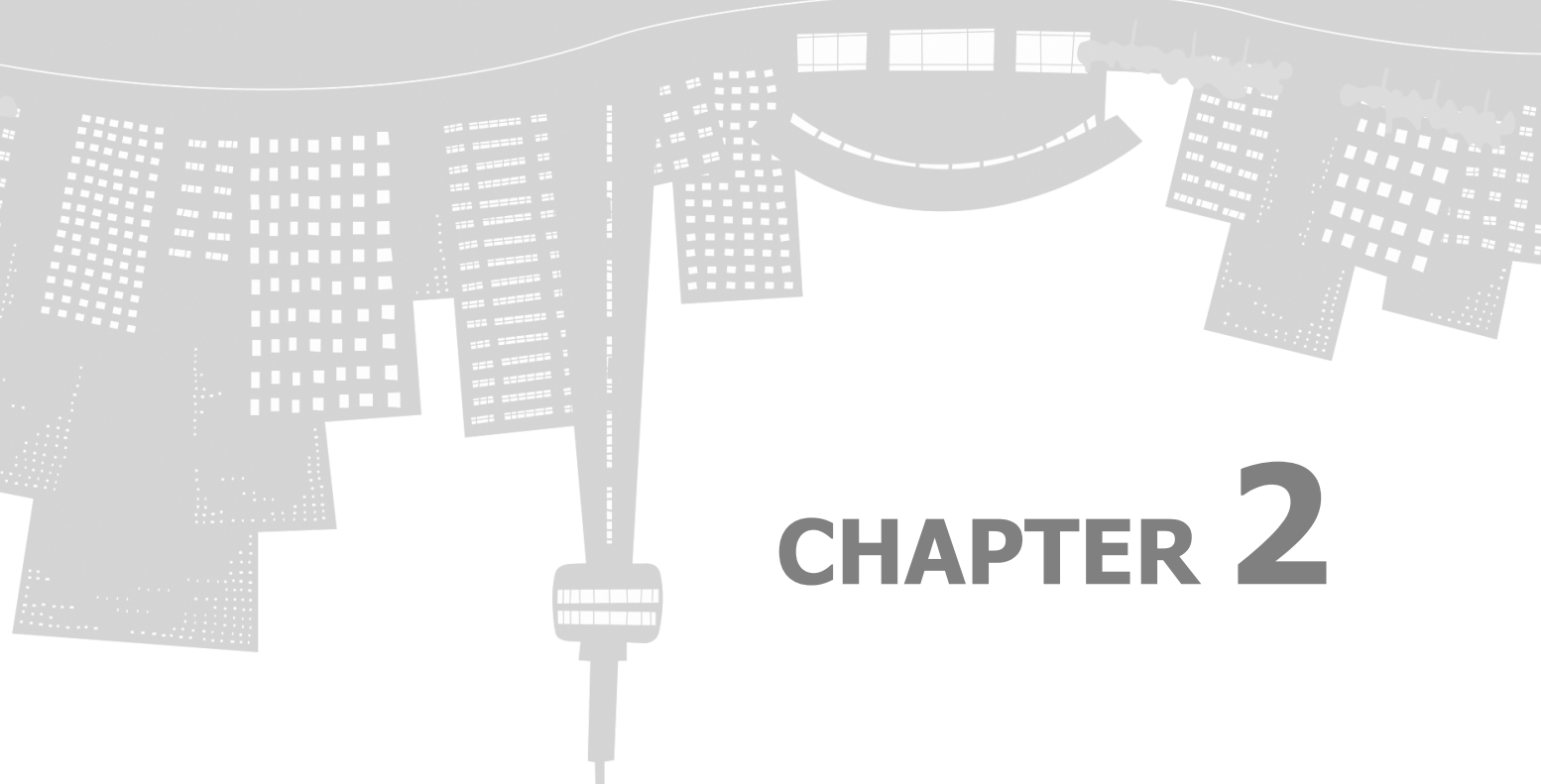

A review of economic evaluations of behavior change interventions: setting an agenda for research methods and practice

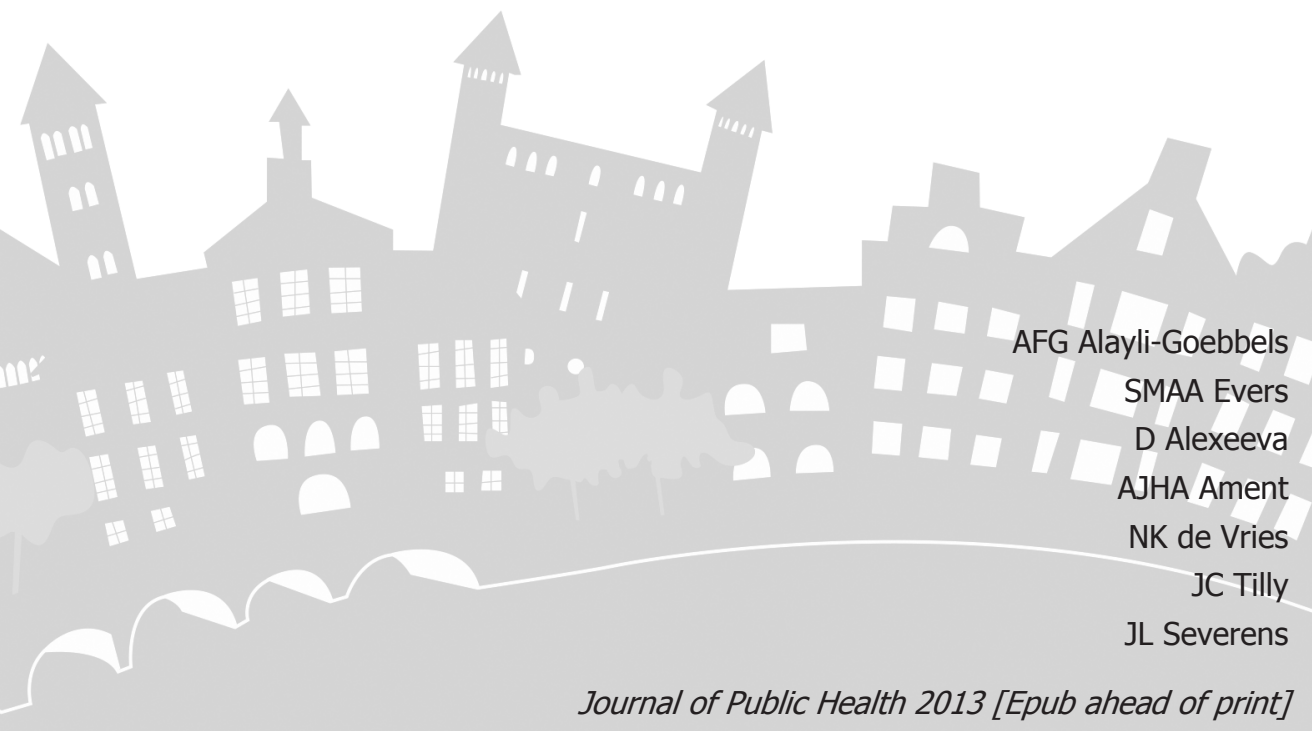




\section{Abstract}

\section{Objective}

To review methodological quality of economic evaluations of lifestyle behavior change interventions (LBCIs) and to examine how they address methodological challenges for public health economic evaluation identified in the literature.

\section{Methods}

Pubmed and the NHS economic evaluation database were searched for published studies in six key areas for behavior change: smoking, physical activity, dietary behavior, (illegal) drug use, alcohol use and sexual behavior. From included studies $(n=142)$, we extracted data on general study characteristics, characteristics of the LBCIs, methodological quality and handling of methodological challenges.

\section{Results}

Economic evaluation evidence for LBCIs showed a number of weaknesses: methods, study design and characteristics of evaluated interventions were not well reported; methodological quality showed several shortcomings; and progress with addressing methodological challenges remained limited.

\section{Conclusion}

Based on the findings of this review we propose an agenda for improving future evidence to support decision-making. Recommendations for practice include improving reporting of essential study details and increasing adherence with good practice standards. Recommendations for research methods focus on mapping out complex causal pathways for modeling, developing measures to capture broader domains of wellbeing and community outcomes, testing methods for considering equity, identifying relevant non-health sector costs, and advancing methods for evidence synthesis. 


\section{Introduction}

Lifestyle behavior is responsible for a large part of the disease burden to society. Therefore, interventions to change lifestyle behaviors, such as smoking, physical activity, diet and alcohol use, are increasingly developed. ${ }^{1}$ As public resources are limited, policymakers should give priority to lifestyle behavior change interventions (LBCIs) that produce the largest benefit per dollar invested. Economic evaluation studies can assist in this process by providing insights into the relative costs and benefits of interventions. ${ }^{2}$ Such studies become increasingly available for $\mathrm{LBCIs}_{1}^{3,4}$ but their methodological quality has been questioned ${ }^{5}$ and there is increasing recognition that methods, which have been developed to evaluate bio-medical health interventions, need amendments to deal with the challenges posed by public health interventions, such as LBCIs. ${ }^{6-8}$

Six key challenges have been identified in the literature. Four of these concern the measurement of intervention outcomes: (i) as health benefits of LBCIs take a long time to accrue, lengthy follow up periods are needed or intermediate outcomes need to be translated to final outcomes (e.g. survival); (ii) LBCIs may produce a broad number of outcomes, which are not fully captured by standard measures of health outcome, such as Quality Adjusted Life Years (QALYs); ${ }^{8,9}$ (iii) LBCIs may have consequences for people, who are not directly targeted by the intervention or the community at large. ${ }^{7,10}$ Outcome measurement in economic evaluation, however, tends to focus on individual intervention participants only; (iv) many LBCIs are designed to achieve more health equity, but

methods to account for equity outcomes in economic evaluation are not well developed. ${ }^{11,12}$

The identification and measurement of costs create a fifth challenge. LBCIs take place in a wide range of settings and often produce costs outside the health sector. How to deal with non-health sector costs in economic evaluations is still unclear., ${ }^{73}$ Finally, there is discussion about the study design for evaluating effectiveness. Most economic evaluation guidelines indicate a preference for randomized controlled trials (RCTs), which are not always feasible in the context of LBCIs. ${ }^{7,12-14}$

The aim of this research was 2-fold: (i) to examine the general methodological quality of economic evaluations of LBCIs and (ii) to examine how they addressed the six challenges for public health economic evaluation.

\section{Methods}

A systematic literature review was conducted focusing on six key areas for behavior change: smoking, physical activity, dietary behavior, (illegal) drug use, alcohol use and sexual behavior. Relevant references $(n=5798)$ were identified through PubMed and the 
NHS Economic Evaluation Database (see Supplementary data, Appendix 2.1 for the search strategy). From these we selected 142 for inclusion in this study (see Figure 2.1 for the selection strategy and Supplementary data, Appendix 2.2 for full references).

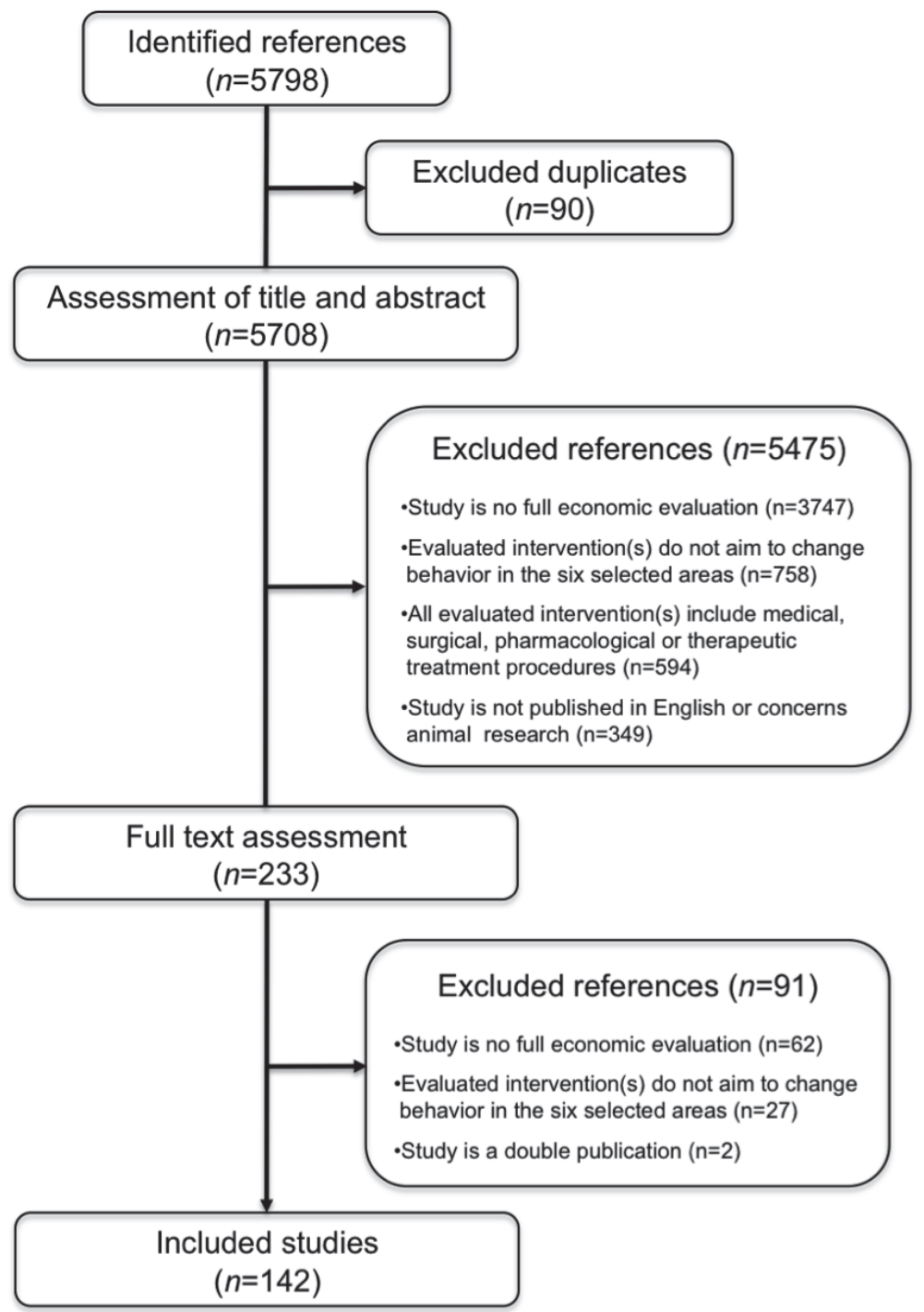

Figure 2.1 Study selection procedure 


\section{Data extraction and analysis}

Included studies were divided between six reviewers (A.G., S.E., D.A., A.A., J.T. and J.S.). One reviewer assessed each study using a data extraction form, piloted by the research team, on 20 randomly selected articles. Data were extracted on general study characteristics, characteristics of the LBCIs evaluated, methodological quality and handling of methodological challenges. Methodological quality was examined using the 10 main questions of a checklist for assessing economic evaluations developed by Drummond et al. ${ }^{2}$ (see Table 2.2). Due to ongoing discussion about the types of costs and consequences to be considered in public health economic evaluations, we further specified question 4 and focused only on program costs, survival and health-related quality of life outcomes. Question 10 was discarded, because examples and instructions regarding this question did not provide specific criteria for assessment.

To assess handling of the six methodological challenges, we extracted data about study design and time horizon. Outcome measures used were identified and classified into the following categories: (i) intermediate outcomes, such as behavior changes (e.g. smoking cessation) or biomedical health indicators (e.g. body mass index); (ii) health outcomes, measured in terms of morbidity or disease occurrence (e.g. HIV infections prevented); (iii) final outcomes, including survival; health-related quality of life (HRQOL) and general quality of life (GQOL) or wellbeing; and (iv) equity outcomes (i.e. the impact of the intervention on distribution of health and wellbeing across socio-economic groups). Outcome measures were also classified according to measurement level (i.e. intervention participants, people not directly targeted or the community/society as a whole). Finally, we examined cost types included (i.e. program costs, health sector costs and non-health sector costs) and study designs used to determine intervention effectiveness. To reach consensus about questions arising during the data extraction and analysis process, regular meetings were held.

\section{Results}

General study characteristics of the economic evaluation studies and LBCIs evaluated are displayed in Table 2.1. 
Table 2.1 Study characteristics of the economic evaluations ( $n_{\text {total }}=142$ )

\begin{tabular}{|c|c|c|}
\hline \multicolumn{2}{|l|}{ Study characteristic } & n (\%) \\
\hline \multirow[t]{3}{*}{ Year of publication } & $1981-1990$ & $7(4.9)$ \\
\hline & $1991-2000$ & $43(30.3)$ \\
\hline & 2001-2009 & $92(64.8)$ \\
\hline \multirow[t]{6}{*}{ Country of study } & US & $84(59.2)$ \\
\hline & UK & $10(7.0)$ \\
\hline & Australia & $10(7.0)$ \\
\hline & Sweden & $5(3.5)$ \\
\hline & Netherlands & $5(3.5)$ \\
\hline & Other & $28(19.8)$ \\
\hline \multirow[t]{7}{*}{ Behavior area } & Smoking & $36(25.4)$ \\
\hline & Physical activity & 17 (11.9) \\
\hline & Diet & $18(12.7)$ \\
\hline & Sexual behavior & $19(13.4)$ \\
\hline & Alcohol abuse & $11(7.7)$ \\
\hline & Illegal drug use & $1(0.7)$ \\
\hline & Several behavior areas & $40(28.2)$ \\
\hline \multirow[t]{6}{*}{ Prevention level } & Universal & $24(16.9)$ \\
\hline & Selective & $36(25.4)$ \\
\hline & Indicated & $54(38.0)$ \\
\hline & Care related & $18(12.7)$ \\
\hline & Combination of prevention levels & $6(4.2)$ \\
\hline & Not described & $4(2.8)$ \\
\hline \multirow[t]{6}{*}{ Type of economic evaluation } & Cost-effectiveness analysis & $68(47.9)$ \\
\hline & Cost-utility analysis & $15(10.6)$ \\
\hline & Cost-benefit analysis & $8(5.6)$ \\
\hline & Cost-consequence analysis & $12(8.5)$ \\
\hline & Cost-minimization analysis & $4(2.8)$ \\
\hline & Multiple types combined & $35(24.6)$ \\
\hline \multirow[t]{4}{*}{ Comparators used } & Doing nothing & $49(34.5)$ \\
\hline & Usual care/standard intervention & $29(20.4)$ \\
\hline & Pharmacotherapy & $11(7.7)$ \\
\hline & Other & $56(39.4)$ \\
\hline \multirow[t]{4}{*}{ Study design } & Trial & $58(40.9)$ \\
\hline & Modeling & $56(39.4)$ \\
\hline & Combination & $23(16.2)$ \\
\hline & Not described & $5(3.5)$ \\
\hline \multirow[t]{6}{*}{ Time horizon } & $\leq 2$ years & $53(37.3)$ \\
\hline & $\leq 5$ years & $8(5.6)$ \\
\hline & $\leq 10$ years & $8(5.6)$ \\
\hline & $>10$ years & $12(8.5)$ \\
\hline & Lifetime & $30(21.1)$ \\
\hline & Not described & $31(21.8)$ \\
\hline \multirow[t]{4}{*}{ Effectiveness data derived from } & RCT & $80(56.3)$ \\
\hline & Quasi experiment & $18(12.7)$ \\
\hline & Other & $27(19.0)$ \\
\hline & Not described & $17(12.0)$ \\
\hline \multirow[t]{3}{*}{ Costs included } & Intervention costs & $133(93.7)$ \\
\hline & Health-care costs & $90(63.4)$ \\
\hline & Costs in other societal sectors & $11(7.7)$ \\
\hline
\end{tabular}




\section{Methodological quality}

Table 2.2 displays several methodological shortcomings. Only two thirds of the economic evaluations reported a well-defined research question. The perspective of the analysis was for example only explicitly stated by $57 \%$ of the studies ( $n=81$ ). Less than half of the studies described the alternatives under evaluation in sufficient detail and specific behavior change techniques could only be determined for 11 studies $(7.7 \%)$. Relevant costs and consequences were identified by only $41 \%(n=58)$ of the studies, despite the fact that we restricted ourselves to considering program costs, survival and HRQOL outcomes. Measurement and valuation of costs and consequences were rated as accurate in more than two-thirds of the studies. From studies with a time horizon exceeding 1 year $(n=89)$ only $78.7 \%(n=70)$ used discounting to adjust for differential timing of costs and consequences. Incremental analysis was conducted by less than twothirds of the studies (59.8\%). Studies performing sensitivity analyses ( $n=98,69 \%)$ to account for uncertainty in estimated parameters usually did this consistently for both costs and consequences $(n=73,74.5 \%)$. But in less than half of the cases $(n=43$, $43.9 \%$ ) authors gave justifications for the value ranges or distributions used. Likewise, relatively few studies performed sensitivity analyses on the discount rate ( $n=41,41.8 \%)$. Economic evaluations scored better regarding program effectiveness, which was either established beforehand or examined simultaneously with the economic evaluation by $93 \%$ of the studies $(n=132)$. Methodological quality of more recently published studies (2001-09) was comparable with the total sample.

Table 2.2 Methodological quality scores

\begin{tabular}{|c|c|c|c|c|}
\hline & \multirow[t]{2}{*}{ Checklist questions } & \multicolumn{3}{|c|}{ n (\%) } \\
\hline & & Yes & No & Can't tell \\
\hline 1. & $\begin{array}{l}\text { Was a well-defined question posed in an } \\
\text { answerable form? }\end{array}$ & $92(64.8)$ & $50(35.2)$ & - \\
\hline 2. & $\begin{array}{l}\text { Was a comprehensive description of competing } \\
\text { alternatives given? }\end{array}$ & $63(44.4)$ & $79(55.6)$ & - \\
\hline 3. & $\begin{array}{l}\text { Was the effectiveness of the programs or services } \\
\text { established? }\end{array}$ & $132(93.0)$ & $4(2.8)$ & $6(4.2)$ \\
\hline 4. & $\begin{array}{l}\text { Were all the important and relevant costs and } \\
\text { consequences for each alternative identified? }\end{array}$ & $58(40.8)$ & $83(58.5)$ & $1(0.7)$ \\
\hline 5. & $\begin{array}{l}\text { Were costs and consequences measured accurately } \\
\text { in appropriate physical units? }\end{array}$ & $107(75.4)$ & $17(12.0)$ & $18(12.7)$ \\
\hline 6. & Were costs and consequences valued credibly? & $97(68.3)$ & $17(12.0)$ & $28(19.7)$ \\
\hline 7. & $\begin{array}{l}\text { Were costs and consequences adjusted for } \\
\text { differential timing? }\end{array}$ & $77(54.2)$ & $59(41.6)$ & $6(4.2)$ \\
\hline 8. & $\begin{array}{l}\text { Was an incremental analysis of costs and } \\
\text { consequences of alternatives performed? }\end{array}$ & $85(59.8)$ & $39(27.5)$ & $18(12.7)$ \\
\hline 9. & $\begin{array}{l}\text { Was allowance made for uncertainty in the } \\
\text { estimates of costs and consequences? }\end{array}$ & $98(69.0)$ & $44(31.0)$ & - \\
\hline 10. & $\begin{array}{l}\text { Did the presentation and discussion of results } \\
\text { include all issues of concern to users of the } \\
\text { economic evaluation? }\end{array}$ & - & - & - \\
\hline
\end{tabular}




\section{Handling of challenges}

\section{Design and time horizon of economic evaluations}

Model-based studies ( $n=56$ ) were equally represented as trial-based $(n=58)$ studies and 23 studies (16.2\%) used a combination of both approaches (Table 2.1). Five studies did not describe study design. Trial-based studies generally had a follow-up of two years or less ( $n=48)$. Only six studies had longer follow-up periods (up to 5 years). This is long for a trial, but insufficient to assess long-term health consequences of LBCIs. Modeling is a useful approach to extrapolate study findings beyond the trial period. From the 79 studies with a modeling component, only $38 \%(n=30)$ calculated lifetime intervention consequences, as recommended by good practice guidelines. ${ }^{15}$

\section{Scope of outcomes considered}

Outcomes incorporated in the studies are summarized in Table 2.3 . Two studies $(1.4 \%)$ did not specify outcome measures. More than one-third of the studies ( $n=52,36.6 \%$ ) only incorporated intermediate outcome measures. Fourteen studies $(9.9 \%)$ incorporated health outcomes, but no final outcomes, and 74 studies $(52.1 \%)$ incorporated final outcomes. Survival (48.6\%) and HRQOL (36.6\%) were the most common final outcome measures and often used simultaneously $(33.8 \%)$, for example when authors calculated QALYs. Only two studies (1.4\%) used measures of GQOL or wellbeing. Johannesson et al. ${ }^{16}$ applied contingent valuation (CV) to value changes in subjective wellbeing and Quist Paulsen et al. ${ }^{17}$ used a measure of life satisfaction in sensitivity analyses to examine whether cost-effectiveness results alter when adjusted for quality of life.

Measures of behavior change ( $n=60,42.3 \%)$, such as the number of people who quit smoking or the number of drinks per day, were the most common intermediate outcome measures. Biomedical health indicators (e.g. reductions in weight, blood pressure or cholesterol) were incorporated by 33 studies (23.2\%). Twelve (8.5\%) studies incorporated other intermediate measures (e.g. increased health knowledge, ${ }^{18}$ improved daily stress management, increased problem solving ability and self-efficacy, ${ }^{19}$ unwanted pregnancies prevented, ${ }^{20,21}$ increased endurance levels, ${ }^{22}$ intervention recall, ${ }^{23}$ reduced sick leave, ${ }^{24,25}$ hospital admissions ${ }^{26}$ and outpatient visits ${ }^{26,27}$ ).

None of the studies examined the impact of LBCIs on equity outcomes or explored whether cost-effectiveness varied for different socio-economic groups. 
Table 2.3 Outcomes of LBCIs incorporated in economic evaluations by measurement level $\left(n_{\text {total }}=142\right)$

\begin{tabular}{|c|c|c|c|c|c|c|c|c|c|}
\hline \multirow[b]{2}{*}{$\begin{array}{l}\text { Measurement } \\
\text { level }(n)\end{array}$} & \multicolumn{4}{|c|}{$\begin{array}{c}\text { Intermediate outcomes } \\
\mathrm{n}(\%)\end{array}$} & \multirow{2}{*}{$\begin{array}{c}\text { Health } \\
\text { outcomes } \\
\mathrm{n}(\%)\end{array}$} & \multicolumn{4}{|c|}{$\begin{array}{c}\text { Final outcomes } \\
\mathrm{n}(\%)\end{array}$} \\
\hline & Behavior & $\begin{array}{c}\text { Biomedical } \\
\text { health } \\
\text { indicators }\end{array}$ & Other & Any & & Survival & HRQOL & $\begin{array}{c}\text { General } \\
\text { QOL/ } \\
\text { wellbeing }\end{array}$ & Any \\
\hline $\begin{array}{l}\text { Targeted } \\
\text { individuals } \\
(n=140)\end{array}$ & $\begin{array}{c}60 \\
(42.3)\end{array}$ & $\begin{array}{c}33 \\
(23.2)\end{array}$ & $\begin{array}{c}11 \\
(7.7)\end{array}$ & $\begin{array}{c}84 \\
(59.2)\end{array}$ & $\begin{array}{c}41 \\
(28.9)\end{array}$ & $\begin{array}{c}69 \\
(48.6)\end{array}$ & $\begin{array}{c}52 \\
(36.6)\end{array}$ & $\begin{array}{c}2 \\
(1.4)\end{array}$ & $\begin{array}{c}74 \\
(52.1)\end{array}$ \\
\hline $\begin{array}{l}\text { Not directly } \\
\text { targeted } \\
\text { individuals } \\
(n=12)\end{array}$ & $\begin{array}{c}0 \\
(0.0)\end{array}$ & $\begin{array}{c}1 \\
(0.7)\end{array}$ & $\begin{array}{c}0 \\
(0.0)\end{array}$ & $\begin{array}{c}1 \\
(0.7)\end{array}$ & $\begin{array}{c}5 \\
(3.5)\end{array}$ & $\begin{array}{c}7 \\
(4.9)\end{array}$ & $\begin{array}{c}6 \\
(4.2)\end{array}$ & $\begin{array}{c}0 \\
(0)\end{array}$ & $\begin{array}{c}7 \\
(4.9)\end{array}$ \\
\hline $\begin{array}{l}\text { Community/ } \\
\text { society } \\
(n=1)\end{array}$ & $\begin{array}{c}0 \\
(0.0)\end{array}$ & $\begin{array}{c}0 \\
(0.0)\end{array}$ & $\begin{array}{c}1 \\
(0.7)\end{array}$ & $\begin{array}{c}1 \\
(0.7)\end{array}$ & $\begin{array}{c}0 \\
(0.0)\end{array}$ & $\begin{array}{c}0 \\
(0.0)\end{array}$ & $\begin{array}{c}0 \\
(0.0)\end{array}$ & $\begin{array}{c}0 \\
(0.0)\end{array}$ & $\begin{array}{c}0 \\
(0.0)\end{array}$ \\
\hline $\begin{array}{l}\text { Total } \\
(n=140)\end{array}$ & $\begin{array}{c}60 \\
(42.3)\end{array}$ & $\begin{array}{c}33 \\
(23.2)\end{array}$ & $\begin{array}{c}12 \\
(8.5)\end{array}$ & $\begin{array}{c}86 \\
(60.6)\end{array}$ & $\begin{array}{c}42 \\
(29.6)\end{array}$ & $\begin{array}{c}69 \\
(48.6)\end{array}$ & $\begin{array}{c}52 \\
(36.6)\end{array}$ & $\begin{array}{c}2 \\
(1.4)\end{array}$ & $\begin{array}{c}74 \\
(52.1)\end{array}$ \\
\hline
\end{tabular}

Notes: The total number of studies incorporating outcomes at any of the measurement levels is lower than the total number of studies, because two studies did not specify outcome measures. Some studies considered the same outcome on more than one measurement level. Therefore, numbers in columns do not always add up.

Twelve studies (8.5\%) incorporated outcomes for not directly targeted individuals. Most of these $(n=10)$ evaluated interventions addressing sexual behaviors. ${ }^{21,28-36}$ They incorporated either health outcomes (i.e. HIV and other STD infections averted) or final outcomes (i.e. life years and QALYs gained) among sexual partners of targeted individuals. Two studies evaluated interventions in other behavior change areas. One evaluated a nutrition education intervention and accounted for education spillovers and external benefits to people in the environment of targeted individuals. ${ }^{37}$ The other study evaluated a prenatal health education program and described how the program affected children's birth weight of participating mothers. ${ }^{38}$

Community level outcomes were only incorporated by one study evaluating an intervention for problem drinkers. ${ }^{39}$ The authors ascribed a monetary value to reduced quality of life caused by crimes and accidents based on jury compensations paid for pain and suffering caused by physical injuries and fear.

Nineteen studies (13.4\%) identified potentially relevant outcomes of LBCIs not incorporated in the economic evaluation due to a lack of adequate methods or limited scope of the research. These mostly concerned outcomes for individuals not directly targeted (i.e. health outcomes, survival, behavior changes and other intermediates, such as empowerment of staff delivering the intervention) and outcomes for intervention 
participants not captured by standard measures of health outcome (e.g. changes in quality of life due to withdrawal symptoms or psychological wellbeing resulting from physical activity). Few studies $(n=5)$ identified community level outcomes, such as a better sense of community, increased community support and the emergence of a black market due to changes in smoking legislation.

\section{Costs included}

Table 2.1 shows that the majority of studies included direct program costs $(n=133$, $93.7 \%)$, health-care costs $(n=90,63.4 \%)$ or both $(n=84,59.2 \%)$. Eleven studies $(7.7 \%)$ included costs in other societal sectors, ${ }^{20,39-48}$ such as costs of motor-vehicle accidents, violent crimes, incarceration, personal injury, property damage, fire destruction, law enforcement (e.g. roadside breath testing and handling legal challenges in court) and costs to industry, commerce and the voluntary sector. Detailed descriptions of identification, measurement and valuation of these costs were not provided. Out of pocket payments and time investments for behavior changes by participants were accounted for by $11.3 \%(n=16)$ and $20.4 \%(n=29)$ of the studies, respectively.

\section{Study designs to determine effectiveness of $\mathrm{LBCls}$}

Table 2.1 shows that effectiveness data were mostly derived from RCTs ( $n=80,56.3 \%$ ). This included single RCTs $(n=62)$ and meta-analyses of RCTs $(n=18)$. Eighteen studies $(12.7 \%)$ derived effectiveness data from quasi-experiments, which provide an alternative design to the RCT, when randomization is not possible (e.g. in community-based interventions). In some cases it may even be difficult to use an appropriate control group, because people cannot be excluded from participation in the intervention. Two studies evaluating mass media interventions to encourage smoking cessation therefore used historical data as comparator, which were collected among the same population. ${ }^{49,50}$ Other sources of effectiveness data were expert opinion, systematic literature research (not further specified), hypothetical data or combinations of the study designs above.

\section{Discussion}

\section{Main finding of this study}

Economic evaluations of LBCIs identified in this study $(n=142)$ are characterized by a number of weaknesses. Methods, study design, and characteristics of LBCIs are not always reported in sufficient detail to assess relevance and quality of the evidence. 
Methodological quality showed several areas for improvement and methodological challenges still need to be addressed.

\section{What is already known on this topic}

The Wanless reports in the UK pointed out that cost-effectiveness evidence to support decision-making about LBCIs is scarce and that applying economic evaluation methods to complex public health interventions, such as LBCIs, is difficult. ${ }^{51,52}$ Influenced by these reports, the National Institute for Health and Care Excellence (NICE) was one of the first organizations worldwide to introduce a systematic and transparent approach to producing guidance for evidence-informed decision-making about public health interventions, including LBCIs. ${ }^{53}$ Kelly et al. $^{6}$ described methodological challenges emerging during the first years of developing this guidance. Several other researchers also identified methodological challenges ${ }^{7-9,12,54,55}$ and a systematic review by Weatherly et al. ${ }^{7}$ showed that few empirical studies tackled these in practice.

\section{What this study adds}

This study provides a further exploration of the progress made with addressing methodological challenges in the area of behavior change. It adds to the work of Weatherly et al. ${ }^{7}$ by (i) considering economic evaluation studies published before 2000 and after 2005, and (ii) by examining their methodological quality.

Based on our findings several priority areas for improving future evidence were identified.

(i) Essential study details should be better reported. Quality assessment checklists, such as Drummond et al. ${ }^{2}$, Evers et al. ${ }^{56}$ and Philips et al. ${ }^{57}$ can provide guidance on reporting of methodological aspects of the study. Davidson et al. ${ }^{58}$ can be used to identify intervention characteristics essential to report, while Abraham and Michie $^{59}$ can assist in describing behavior change techniques.

(ii) To increase compliance with methodological standards, such as performing an incremental analysis, sensitivity analyses and the use of discounting, we suggest that evaluators use good practice guidelines (e.g. Ramsey et al, $2005^{15}$, Caro et al., $2012^{60}$ ) when planning and designing new studies.

(iii) Long-term costs and outcomes should be incorporated more often. This requires availability of (better) data and more use of mathematical models adopting a lifetime horizon. To improve availability of data for modeling, future research should map out social diffusion effects of LBCIs, as well as relationships between final and intermediate outcomes, in particular for intermediates other than behavior changes and bio-medical health indicators. ${ }^{61,62}$ Alternatives to Markov 
models may be needed to model some of these relationships (e.g. interactions between individuals). ${ }^{63,64}$ More use of long-term modeling may also be encouraged through building modeling skills and reducing costs by using models in multiple applications. ${ }^{65}$

(iv) Measures of final outcome need to be developed that allow for incorporation and valuation of broader domains of wellbeing relevant for LBCIs. Such measures are currently not available, but first steps to develop instruments are on their way. For example Lorgelly et al. ${ }^{66}$ explored the possibility to develop an outcome measure based on Sen's capability approach. Willingness to pay is an alternative measure for capturing broader domains of wellbeing. ${ }^{8,54}$ One study in this review applied contingent valuation (CV) to value broader outcomes in willingness to pay, but did not specify which aspects of wellbeing were valued. ${ }^{16}$ More experiences with CV are needed to examine feasibility and validity of the method for evaluating LBCIs.

(v) Incorporating outcomes for individuals who are not directly targeted is relevant in all behavior change areas examined. Progress was, however, mainly limited to studies evaluating interventions directed at sexual behaviors. These studies can give direction to methods development in other areas (e.g. to consider health impacts of smoking cessation for people exposed to second-hand smoke). ${ }^{67,68}$

(vi) Future research should focus on developing measures of community level change for use within economic evaluation. Hawe, Shiell and Gold ${ }^{55,69}$ propose to build these on system-based approaches to evaluation increasingly used in public health, which describe complex relationships between process and long-term outcomes on multiple levels (e.g. individual, family, institutions, neighborhood and policy level) using logic models and examine intervention impacts by means of a combination of qualitative and quantitative methods. ${ }^{70,71}$

(vii) Reducing health inequities is an important public health objective and therefore relevant to consider in decision-making. Future research should test systematic methods to consider equity outcomes both directly within economic evaluation and alongside economic evaluation results. Suggested methods for use within economic evaluation, include for example reviewing background information on equity, presenting cost-effectiveness for equity-relevant subgroups and systematic assessment of expected distributional effects of implementing interventions under evaluation. ${ }^{11,72}$ The equity effectiveness loop framework can help identify equity evidence relevant to consider in decision-making and the Equity Methods Group of the Cochrane collaboration is a good source for finding such evidence. ${ }^{73}$ 
(viii) It is important that future studies consider relevant non-health sector costs. To increase consistency in the costs considered, research should compile an overview of broader costs in each behavior change area and develop guidance on how to identify, measure and value these.

(ix) RCTs designs ensure the highest degree of internal validity and are an important source of efficacy evidence. They are however not always feasible or ethical. In these situations natural experiments can be a useful alternative. ${ }^{74,75}$ RCTs also provide limited insights into intervention processes, contextual factors, participant experiences and implementation fidelity. ${ }^{14,76}$ Hence, augmenting RCTs with another study component (e.g. a discrete choice experiment, qualitative study or observational study) may be helpful. ${ }^{76,77}$ Methods to synthesize diverse forms of evidence for decision-making, such as cost-consequence analysis, multi-criteria decision analysis or logic frameworks should be further developed and tested. ${ }^{14,78}$

Finally, to support decision-making using limited evidence, we suggest that evaluators clearly identify costs and outcomes not considered in the study and their expected impact on cost-effectiveness.

\section{Limitations}

This review only included full economic evaluations. Hence, it is possible that studies with very low quality (e.g. simple pre-post designs) were excluded and that methodological quality has even been overestimated. Our search strategy was limited to studies included by PubMed and the NHS economic evaluation database before April 2009. Therefore, we cannot preclude the possibility that we have missed relevant studies and that our conclusions do not apply to the most recent years.

\section{Conclusion}

Weak evidence on cost-effectiveness currently hampers priority setting between LBCIs. Our study identified a number of steps to improve future evidence, but decisions about allocation of public resources to LBCIs still need to be taken using available evidence. The methods NICE applies to make best use of existing evidence (e.g. adapting existing models from other decision contexts) can provide directions to policy makers in other countries. $^{79}$ 


\section{References}

1. World Health Organization. 2008-2013 Action Plan for the Global Strategy for the Prevention and Control of Noncommunicable Diseases. Geneva: WHO; 2008.

2. Drummond MF, Sculpher MJ, Torrance W, O'Brien BJ, Stoddard GL. Methods for the Economic Evaluation of Health Care Programmes. New York: Oxford University Press; 2005.

3. Rush B, Shiell A, Hawe P. A census of economic evaluations in health promotion. Health Education Research 2004;19:707-719.

4. McDaid D, Needle J. What use has been made of economic evaluation in public health? A systematic review of the literature. In: Dawson S, Morris ZS, editors. Future Public Health: Burdens, Challenges and Opportunities. Basingstone: Palgrave Macmillan 2009:248-264.

5. Schwappach DLB, Boluarte TA, Suhrcke M. The economics of primary prevention of cardiovascular disease - a systematic review of economic evaluations. Cost Effectiveness and Resource Allocation. 2007;5:5.

6. Kelly M, Morgan A, Ellis S, Younger T, Huntley J, Swann C. Evidence based public health: A review of the experience of the National Institute of Health and Clinical Excellence (NICE) of developing public health guidance in England. Social Science \& Medicine 2010;71:1056-1062.

7. Weatherly H, Drummond M, Claxton K, Cookson R, Ferguson B, Godfrey C, Rice N, Sculpher $M$, Sowden A. Methods for assessing the cost-effectiveness of public health interventions: Key challenges and recommendations. Health Policy 2009;93:85-92.

8. Godfrey C. Economic evaluation of health promotion. WHO Regional Publications European Series No 922001 2001:149-170.

9. Goebbels AFG, Lakerveld J, Ament AJHA, Bot SDM, Severens JL. Exploring non-health outcomes of health promotion: The perspective of participants in a lifestyle behaviour change intervention. Health Policy 2012;106:177-186.

10. Smith RD, Petticrew M. Public health evaluation in the twenty-first century: time to see the wood as well as the trees. Journal of Public Health 2010;32:2-7.

11. Cookson R, Drummond $M$, Weatherly $H$. Explicit incorporation ofequity considerations into economic evaluation of public health interventions. Health Economics Policy and Law 2009;4:231-245.

12. Chalkidou K, Culyer A, Naidoo B, Littlejohns P. Cost-effective Public Health Guidance: Asking questions from the Decision-Maker's viewpoint. Health Economics 2008;17:441-448.

13. Godfrey C. Economic evaluation of health promotion and disease prevention: Issues and challenges. Eurohealth 2000;6:40-42.

14. Baxter S, Killoran A, Goyder E. Synthesizing diverse evidence: the use of primary qualitative data analysis methods and logic models in public health reviews. Public Health 2010;124: 99-106.

15. Ramsey S, Willke R, Briggs A, Brown R, Buxton M, Chawla A, Cook J, Glick H, Bengt L, Petitti D, Reed S. Good Research Practices for Cost-Effectiveness Analysis Alongside Clinical Trials: The ISPOR RCT-CEA Task Force Report. Value in Health 2005;8:521-533.

16. Johannesson $M$, Aberg $H$, Agreus $L$, Borgquist $L$, Jonsson B. Cost-benefit analysis of nonpharmacological treatment of hypertension. Journal of Internal Medicine 1991;230:307-312.

17. Quist Paulsen P, Lydersen S, Bakke PS, Gallefoss F. Cost effectiveness of a smoking cessation program in patients admitted for coronary heart disease. European Journal of Cardiovascular Prevention \& Rehabilitation 2006;13:274-280.

18. DuShaw ML. A comparative study of three model comprehensive elementary school health education programs. Journal of School Health 1984;54:397-400.

19. Toobert DJ, Glasgow RE, Strycker LA, Barrera M, Ritzwoller DP, Weidner G. Long-term effects of the Mediterranean lifestyle program: a randomized clinical trial for postmenopausal women with type 2 diabetes. International Journal of Behavioral Nutrition and Physical Activity. 2007;4:1.

20. Downs SM, Klein JD. Clinical preventive services efficacy and adolescents' risky behaviors. Archives of Pediatrics \& Adolescent Medicine 1995;149:374-379. 
21. Wang LY, Davis M, Robin L, Collins J, Coyle K, Baumler E. Economic evaluation of Safer Choices: a school-based human immunodeficiency virus, other sexually transmitted diseases, and pregnancy prevention program. Archives of Pediatrics \& Adolescent Medicine 2000;154:1017-1024.

22. Ginsberg GM, Viskoper JR, Fuchs Z, Drexler I, Lubin F, Berlin S, Nitzan H, Zulty L, Chetrit A, Bregman $L$, et al. Partial cost-benefit analysis of two different modes of nonpharmacological control of hypertension in the community. Journal of Human Hypertension 1993;7:593-597.

23. O'Loughlin J, Paradis G, Meshefedjian G. Evaluation of two strategies for heart health promotion by direct mail in a low-income urban community. Preventive Medicine 1997;26:745753.

24. Proper KI, de Bruyne MC, Hildebrandt VH, van der Beek AJ, Meerding WJ, van Mechelen W. Costs, benefits and effectiveness of worksite physical activity counseling from the employer's perspective. Scandinavian Journal of Work, Environment and Health 2004;30:36-46.

25. Molde Hagen E, Grasdal A, Eriksen HR. Does early intervention with a light mobilization program reduce long-term sick leave for low back pain: a 3-year follow-up study. Spine 2003; 28:2309-2315.

26. Munro J, Brazier J, Davey R, Nicholl J. Physical activity for the over-65s: could it be a costeffective exercise for the NHS? Journal of Public Health Medicine 1997;19:397-402.

27. Chen IJ, Chou CL, Yu S, Cheng SP. Health services utilization and cost utility analysis of a walking program for residential community elderly. Nursing Economics 2008;26:263-269.

28. Rahman M, Fukui T, Asai A. Cost-effectiveness analysis of partner notification program for human immunodeficiency virus infection in Japan. Journal of Epidemiology 1998;8:123-128.

29. Sweat M, O'Donnell C, O'Donnell L. Cost-effectiveness of a brief video-based HIV intervention for African American and Latino sexually transmitted disease clinic clients. AIDS 2001;15: 781-787.

30. Holtgrave DR, Kelly JA. Cost-effectiveness of an HIV/AIDS prevention intervention for gay men. AIDS and Behavior 1997;1:173-180.

31. Pinkerton SD, Holtgrave DR, DiFranceisco WJ, Stevenson LY, Kelly JA. Cost-effectiveness of a community-level HIV risk reduction intervention. American Journal of Public Health 1998;88:1239-1242.

32. Pinkerton SD, Johnson-Masotti AP, Otto-Salaj LL, Stevenson LY, Hoffmann RG. Costeffectiveness of an HIV prevention intervention for mentally ill adults. Mental Health Services Research 2001;3:45-55.

33. Tao GY, Remafedi G. Economic evaluation of an HIV prevention intervention for gay and bisexual male adolescents. Journal of Acquired Immune Deficiency Syndromes 1998;17:83-90.

34. Marseille E, Kahn JG, Billinghurst K, Saba J. Cost-effectiveness of the female condom in preventing HIV and STDs in commercial sex workers in rural South Africa. Social Science \& Medicine 2001; 52:135-148.

35. Richter A, Loomis B. Health and economic impacts of an HIV intervention in out of treatment substance abusers: evidence from a dynamic model. Health Care Management Science 2005;8:67-79.

36. Vickerman P, Kumaranayake L, Balakireva O, Guinness L, Artyukh O, Semikop T, Yaremenko $\mathrm{O}$, Watts $\mathrm{C}$. The cost-effectiveness of expanding harm reduction activities for injecting drug users in Odessa, Ukraine. Sexually Transmitted Diseases 2006;33(10 Suppl):S89-102.

37. Scharff RL, McDowell J, Medeiros L. Evaluation of an educational intervention using the enhanced food safety cost-of-illness model. Journal of Food Protection 2009;72:137-141.

38. Ershoff DH, Aaronson NK, Danaher BG, Wasserman FW. Behavioral, health, and cost outcomes of an HMO-based prenatal health education program. Public Health Reports 1983; 98:536-547.

39. Fleming MF, Mundt MP, French MT, Manwell LB, Stauffacher EA, Barry KL. Benefit-cost analysis of brief physician advice with problem drinkers in primary care settings. Medical Care 2000;38:7-18.

40. Phillips $\mathrm{CJ}$, Prowle MJ. Economics of a reduction in smoking: case study from Heartbeat Wales. Journal of Epidemiology \& Community Health 1993;47:215-223. 
41. Mundt MP, French MT, Roebuck MC, Manwell LB, Barry KL. Brief physician advice for problem drinking among older adults: an economic analysis of costs and benefits. Journal of Studies on Alcohol 2005;66:389-394.

42. Ahmad S. The cost-effectiveness of raising the legal smoking age in California. Medical Decision Making 2005;25:330-340.

43. Spoth RL, Guyll M, Day SX. Universal family-focused interventions in alcohol-use disorder prevention: cost-effectiveness and cost-benefit analyses of two interventions. Journal of Studies on Alcohol 2002;63:219-228.

44. Solberg LI, Maciosek MV, Edwards NM. Primary care intervention to reduce alcohol misuse ranking its health impact and cost effectiveness. American Journal of Preventive Medicine 2008;34:143-152.

45. Lock CA, Kaner E, Heather N, Doughty J, Crawshaw A, McNamee P, Purdy S, Pearson P. Effectiveness of nurse-led brief alcohol intervention: a cluster randomized controlled trial. Journal of Advanced Nursing 2006;54:426-439.

46. Lai T, Habicht J, Reinap M, Chisholm D, Baltussen R. Costs, health effects and costeffectiveness of alcohol and tobacco control strategies in Estonia. Health Policy 2007;84: 75-88.

47. DiFranza JR, Peck RM, Radecki TE, Savageau JA. What is the potential cost-effectiveness of enforcing a prohibition on the sale of tobacco to minors? Preventive Medicine 2001;32:168174.

48. Lindholm L, Rosen M, Weinehall L, Asplund K. Cost effectiveness and equity of a community based cardiovascular disease prevention programme in Norsjo, Sweden. Journal of Epidemiology \& Commmunity Health 1996;50:190-195.

49. Bauer JE, Carlin-Menter SM, Celestino PB, Hyland A, Cummings KM. Giving away free nicotine medications and a cigarette substitute (Better Quit) to promote calls to a quitline. Journal of Public Health Management and Practice 2006;12:60-67.

50. Mosbaek CH, Austin DF, Stark MJ, Lambert LC. The association between advertising and calls to a tobacco quitline. Tobacco Control 2007;16 Suppl 1:i24-29.

51. Wanless D. Securing Our Future Health: Taking a Long-Term View. Final Report. London: HM Treasury 2002.

52. Wanless D. Securing Good Health for the Whole Population. Final Report London: HM Treasury; 2004.

53. Kelly MP. Public health guidance and the role of new NICE. Public Health 2005;119:960-968.

54. Borghi J, Jan S. Measuring benefits of health promotion programmes: Application of the contingent valuation method. Health Policy 2008;87:235-248.

55. Shiell A, Hawe P. Health promotion community development and the tyranny of individualism. Health Economics 1996;5:241-247.

56. Evers S, Goosens M, de Vet H, van Tulder M, Ament A. Criteria list for assessment of methodological quality of economic evaluations: Consensus on Health Economic Criteria. International Journal of Technology Assessment in Health Care 2005;21:240-245.

57. Philips Z, Bojke L, Sculpher M, Claxton K, Golder S. Good practice guidelines for decisionanalytic modelling in health technology assessment: a review and consolidation of quality assessment. Pharmacoeconomics 2006;24:355-371.

58. Davidson KW, Goldstein M, Kaplan RM, Kaufmann PG, Knatterud GL, Orleans CT, Spring B, Trudeau KJ, Whitlock EP. Evidence-Based Behavioral Medicine: What is it and how do we achieve it? Annals of Behavioral Medicine 2003;26:161-171.

59. Abraham C, Michie S. A taxonomy of behavior change techniques used in interventions. Health Psychology 2008;27:379-387.

60. Caro JJ, Briggs A, Siebert U, Kuntz KM. Modeling Good Research Practices - Overview: A Report of the ISPOR-SMDM Modeling Good Research Practices Task Force-1. Medical Decision Making 2012;32:667-677.

61. McCormack G, Shiell A. In search of causality: a systematic review of the relationship between the built environment and physical activity among adults. International Journal of Behavioral Nutrition and Physical Activity 2011;8: 1-11. 
62. Prenger R, Pieterse ME, Braakman-Jansen LMA, van der Palen J, Christenhusz LCA, Seydel ER. Moving beyond a limited follow-up in cost-effectiveness analyses of behavioural interventions. European Journal of Health Economics. 2013;14:297-306.

63. Barton P, Bryan S, Robinsion S. Modelling in the economic evaluation of health care: selecting the appropriate approach. Journal of Health Services Research \& Policy 2004;9:110-118.

64. Stahl JE. Modelling methods for pharmacoeconomics and health technology assessment: An Overview and Guide. Pharmacoeconomics 2008;26:131-148.

65. Eddy DM, Hollingworth W, Caro JJ, Tsevat J, M. MK, Wong JB. Model Transparency and Validation: A Report of the ISPOR_SMDM Modeling Good Research Practices Task Force- 7. Medical Decision Making 2012;32:733-743.

66. Lorgelly PK, Lawson KD, Fenwick EAL, Briggs AH. Outcome measurement in economic evaluationds of public health interventions: a role for the capability approach?. International Journal of Environmental Research and Public Health 2010;7:2274-2289.

67. Taylor R, Najafi F, Dobson A. Meta-analysis of studies of passive smoking and lung cancer: effects of study type and continent. International Journal of Epidemiolgy 2007;36:1048-1059.

68. International Agency for Research on Cancer. IARC monographs on the evaluation of carcinogenic risks to humans. Volume 83 . Tobacco and involuntary smoking. Lyon: IARC; 2004.

69. Shiell A, Hawe P, Gold L. Complex interventions or complex systems: Implications for health economic evaluation. British Medical Journal 2008;336:1281-1283.

70. Cheadle A, Samuels SE, Rauzon S, Yoshida SC, Schwartz PM, Beery WL, Craypo. L, Solomon L. Approaches to Measuring the Extent and Impact of Environmental Change in Three California Community-Level Obesity Prevention Initiatives. American Journal of Public Health 2010;100:2129-2136.

71. Kreger M, Brindis CD, Manuel DM, Sassoubre L. Lessons learned in systems change initiatives: benchmarks and indicators. American Journal of Community Psychology 2007;39:301-320.

72. Sassi F, Archard L, Le Grand J. Equity and the economic evaluation of healthcare. Health Technology Assessment 2001;5:1-138.

73. Tugwell P, de Savigny D, Hawker G, Robinsion V. Applying clinical epidemiological methods to health equity: the equity effectiveness loop. British Medical Journal 2006;322:358-361.

74. Craig P, Cooper C, Gunnell D, Haw S, Lawson K, Macintyre S, Ogilvie D, Petticrew M, Reeves $B$, Sutton M. Using natural experiments to evaluate population health interventions: new Medical Research Council guidance. Journal of Epidemiology \& Community Health 2012;66:1182-1186.

75. Craig P, Cooper C, Gunnel D, Haw S, Lawson K, Macintyre S, Oglivie D, Petticrew M, Reeves B, Sutton $M$, Thompson $S$. Using natural experiments to evaluate population health interventions: guidance for producers and users of evidence. London: Medical Research Council; 2011.

76. Rychetnik L, Frommer M, Hawe P, Shiell A. Criteria for evaluating evidence on public health interventions. Journal of Epidemiology \& Community Health 2002;56:119-127.

77. Victora CG, Habicht J, Bryce J. Evidence-Based Public Health: Moving Beyond Randomized Trials. American Journal of Public Health 2004;94:400-405.

78. Marsh K, Dolan P, Kempster J, Lugon M. Prioritizing investments in public health: a multicriteria decision analysis. Journal of Public Health 2012;doi: 10.1093/pubmed/fds099.

79. NICE. Methods for the development of NICE public health guidance (third edition). London NHS; 2012. 


\section{Appendix 2.1 Search strategies}

To retrieve economic evaluation studies, we developed separate search strategies for PubMed and the NHS Economic Evaluation Database (EED). Records in the NHS EED are based on rigorous weekly searches in four other databases: Medline, EMBASE, PsychINFO and CINAHL. Our search strategy consisted of MeSH terms and free text covering the topics economic evaluation, public health and the six behavior change areas. Search terms for economic evaluation and the choice of the two databases were based on recommendations for retrieving economic evaluation studies ${ }^{1,2}$. Search terms for public health were based on those used in previous reviews of public health interventions $s^{3,4}$ and search terms for the six behavior change areas were developed in consultation with experts in each area. Combining these search terms, resulted in the following two search strategies.

PubMed

("drug use"[Title/Abstract] OR "Substance Abuse, Intravenous"[Mesh] OR "Opioid-Related Disorders"[Mesh] OR "Marijuana Abuse"[Mesh] OR "Amphetamine-Related Disorders"[Mesh] OR "Cocaine-Related Disorders"[Mesh] OR "Needle Sharing"[Mesh] OR "needle sharing"[Title/Abstract] OR "drug addiction"[Title/Abstract]) ("Alcohol-Induced Disorders"[Mesh] OR "alcohol drinking"[MeSH Terms] OR "alcohol" [Title/Abstract]) OR ("acquired immunodeficiency syndrome"[Title/Abstract] OR "aids"[Title/Abstract] OR "Hiv Infections"[MeSH] OR "Hiv"[MeSH] OR "hiv"[Title/Abstract] OR "Hiv Seropositivity"[MeSH] OR "Condoms"[MeSH] OR condom [Title/Abstract] OR "Sexual Behavior"[MeSH Terms] OR "sexual behavior"[Title/Abstract] OR "sexual behaviour"[Title/Abstract] OR "Safe sex"[Title/Abstract] OR "Safer sex"[Title/Abstract] OR "Sexually Transmitted Diseases"[MeSH] OR "sexually transmitted"[Title/Abstract]) OR ("Smoking"[MeSH] OR "Tobacco use cessation"[MeSH] OR "Tobacco Use Disorder"[MeSH] OR "tobacco use cessation"[Title/Abstract] OR "smoking cessation"[Title/Abstract]) OR ("Locomotion"[MeSH] OR "Exercise"[MeSH] OR "Physical Fitness"[MeSH Terms] OR "Exercise Movement Techniques"[MeSH] OR "motor activity"[Title/Abstract] OR "workout"[Title/Abstract] OR "motion"[ Title/Abstract] OR "training"[Title/Abstract] OR "physical activity" [Title/Abstract] OR "motor activity"[Title/Abstract]) OR ("feeding behavior"[MeSH] OR "Nutrition Assessment"[MeSH] OR "Nutritional Support"[MeSH] OR "Nutrition Therapy"[MeSH] OR "Diet"[MeSH] OR "Bottle Feeding"[MeSH] OR "Breast Feeding"[MeSH] OR "Eating"[MeSH] OR "Nutritional Requirements"[MeSH] OR "Nutritional Status"[MeSH] OR "nutritional support"[Title/Abstract] OR "five a day" [Title/Abstract] OR "weight control"[Title/Abstract] OR "nutrition"[Title/Abstract])

AND

("Life Style"[Mesh] OR "Health Behavior"[Mesh] OR "Public Health Practice"[Mesh] OR "Preventive Health Services"[Mesh] OR "Prevention and Control"[Subheading] OR "Harm Reduction"[Mesh] OR "Risk Reduction Behavior"[Mesh])

AND

("Costs and Cost Analysis"[MeSH] $\quad$ OR "cost analysis"[Title/Abstract] OR "cost utility"[Title/Abstract] OR "cost effectiveness"[Title/Abstract] OR "Quality-Adjusted Life Year"[Title/Abstract] OR "Quality-Adjusted Life Years"[MeSH] OR "QALY"[Title/Abstract] OR "Economic analysis"[Title/Abstract] OR "cost-consequence"[Title/Abstract] OR "Cost minimization"[Title/Abstract] OR "Cost minimisation"[All Fields] OR "Economic evaluation"[Title/Abstract] OR "Cost benefit"[Title/Abstract] OR "Economic" [Title])

Limits

Language: English' and 'Species: humans' 
NHS Economic Evaluation Database

"drug use" [Any field] OR "Substance Abuse, Intravenous"[Mesh] OR "Opioid-Related Disorders"[Mesh] OR "Marijuana Abuse"[Mesh] OR "Amphetamine-Related Disorders"[Mesh] OR "Cocaine-Related Disorders"[Mesh] OR "Needle Sharing"[Mesh] OR "needle sharing" [Any field] OR "drug addiction" [Any field] OR "Alcohol-Induced Disorders"[Mesh] OR "alcohol drinking"[MeSH] OR alcohol drinking [Any field] OR alcohol consumption [Any Field] OR "Acquired Immunodeficiency Syndrome"[MeSH] OR "acquired AND immunodeficiency AND syndrome" [Any field] OR "aids" [Any Field] OR "Hiv Infections"[MeSH] OR "hiv"[MeSH] OR "hiv" [Any field] OR "hiv seropositivity"[MeSH]" OR Condoms"[MeSH] OR "condom" [Any Field] OR "Sexual Behavior"[MeSH Terms] OR "sexual AND behavior" [Any Field] OR "sexual AND behaviour" OR "Safe sex" [Any Field] OR "Safer sex" [Any Field] OR "Sexually Transmitted Diseases"[MeSH] OR "sexually AND transmitted" [Any Field] OR "Smoking"[MeSH] OR "Tobacco use cessation"[MeSH] OR "Tobacco Use Disorder"[MeSH] OR "tobacco use cessation"[Any Field] OR "smoking cessation"[Any Field] OR "Locomotion"[MeSH] OR "Exercise"[MeSH] OR "Physical Fitness"[MeSH] OR "Exercise Movement Techniques"[MeSH] OR "motor activity"[Any Field] OR "workout"[Any Field] OR "motion"[Any Field] OR "training"[Title/Abstract] OR "physical activity" [Any Field] OR "motor activity"[Any Field] OR "Feeding Behavior"[MeSH] OR "Nutrition Assessment"[MeSH] OR "Nutritional Support"[MeSH] OR "Nutrition Therapy"[MeSH] OR "Diet"[MeSH] OR "Bottle Feeding"[MeSH] OR "Breast feeding"[MeSH] OR "Eating"[MeSH] OR "Nutritional Requirements"[MeSH] OR "Nutritional Status"[MeSH] OR "Nutritional Support"[Any Field] OR "five a day" [Any Field] OR "weight control"[Any Field] OR "nutrition"[Any Field]

AND

"Life Style"[Mesh] OR "Health Behavior"[Mesh] OR "Public Health Practice"[Mesh] OR "Preventive Health Services"[Mesh] OR "prevention and control" [Any Field] "Harm Reduction"[Mesh] OR "Risk Reduction Behavior"[Mesh].

\section{References}

1. Alton V, Eckerlund I, Norlund A. Health economic evaluations: How to find them. International Journal of Technology Assessment in Health Care 2006;22:512-517.

2. Sassi F, Archard L, McDaid D. Searching literature databases for health care economic evaluations: How systematic can be afford to be. Medical Care 2002;40:387-394.

3. Rush B, Shiell A, Hawe P. A census of economic evaluations in health promotion. Health Education Research 2004;19:707-719.

4. Schwappach DLB, Boluarte TA, Suhrcke M. The economics of primary prevention of cardiovascular disease - a systematic review of economic evaluations. Cost Effectiveness and Resource Allocation 2007;5;doi:10.1186/1478-7547-5-5. 


\section{Appendix 2.2 References included in the review}

1. Ackermann RT, Marrero DG, Hicks KA, Hoerger TJ, Sorensen S, Zhang P, et al. An evaluation of cost sharing to finance a diet and physical activity intervention to prevent diabetes. Diabetes Care 2006;29:1237-1241.

2. Ahmad S. The cost-effectiveness of raising the legal smoking age in California. Medical Decision Making 2005;25:330-340.

3. Altman DG, Flora JA, Fortmann SP, Farquhar JW. The cost-effectiveness of three smoking cessation programs. American Journal of Public Health 1987;77:162-165.

4. Alwyn T, John B, Hodgson RJ, Phillips CJ. The addition of a psychological intervention to a home detoxification programme. Alcohol \& Alcoholism 2004;39:536-541.

5. Annemans L, Lamotte M, Clarys P, Van den Abeele E. Health economic evaluation of controlled and maintained physical exercise in the prevention of cardiovascular and other prosperity diseases. European Journal of Cardiovascular Prevention \& Rehabilitation 2007; 14:815-824.

6. Avants SK, Margolin A, Sindelar JL, Rounsaville BJ, Schottenfeld R, Stine S, et al. Day treatment versus enhanced standard methadone services for opioid-dependent patients: a comparison of clinical efficacy and cost. American Journal of Psychiatry 1999;156:27-33.

7. Babor TF, Higgins Biddle JC, Dauser D, Burleson JA, Zarkin GA, Bray J. Brief interventions for at-risk drinking: patient outcomes and cost-effectiveness in managed care organizations. Alcohol \& Alcoholism 2006;41:624-631.

8. Bauer JE, Carlin-Menter SM, Celestino PB, Hyland A, Cummings KM. Giving away free nicotine medications and a cigarette substitute (Better Quit) to promote calls to a quitline. Journal of Public Health Management and Practice 2006;12:60-67.

9. Baxter T, Milner P, Wilson K, Leaf M, Nicholl J, Freeman J, et al. A cost effective, community based heart health promotion project in England: prospective comparative study. British Medical Journal 1997;315:582-585.

10. Brannon SD, Tershakovec AM, Shannon BM. The cost-effectiveness of alternative methods of nutrition education for hypercholesterolemic children. American Journal of Public Health 1997;87:1967-1970.

11. Broadhead RS, Heckathorn DD, Weakliem DL, Anthony DL, Madray H, Mills RJ, et al. Harnessing peer networks as an instrument for AIDS prevention: results from a peer-driven intervention. Public Health Reports 1998;113 (Suppl 1):42-57.

12. Brun JF, Bordenave S, Mercier J, Jaussent A, Picot MC, Prefaut C. Cost-sparing effect of twiceweekly targeted endurance training in type 2 diabetics: a one-year controlled randomized trial. Diabetes and Metabolism 2008;34:258-265.

13. Burney J, Haughton B. EFNEP: a nutrition education program that demonstrates cost-benefit. Journal of the American Dietetic Association 2002;102:39-45.

14. Byers T, Mullis R, Anderson J, Dusenbury L, Gorsky R, Kimber C, et al. The costs and effects of a nutritional education program following work-site cholesterol screening. Am J Public Health 1995;85:650-655.

15. Chen IJ, Chou CL, Yu S, Cheng SP. Health services utilization and cost utility analysis of a walking program for residential community elderly. Nursing Economics 2008;26:263-269.

16. Chesson HW, Greenberg JB, Hennessy M. The cost-effectiveness of the WINGS intervention: a program to prevent HIV and sexually transmitted diseases among high-risk urban women. BMC Infectious Diseases 2002;2:24.

17. Chirikos TN, Herzog TA, Meade CD, Webb MS, Brandon TH. Cost-effectiveness analysis of a complementary health intervention: the case of smoking relapse prevention. International Journal of Technology Assessment in Health Care 2004;20:475-480.

18. Clarke P, Gray A, Adler A, Stevens R, Raikou M, Cull C, et al. Cost-effectiveness analysis of intensive blood-glucose control with metformin in overweight patients with Type II diabetes. Diabetologia 2001;44:298-304. 
19. Cohen DA, Wu S, Farley TA. Structural interventions to prevent HIV/sexually transmitted disease: are they cost-effective for women in the Southern United States? Sexually Transmitted Diseases 2006;33(7 Suppl):S46-S49.

20. Cohen DA, Wu SY, Farley TA. Comparing the cost-effectiveness of HIV prevention interventions. Journal of Acquired Immune Deficiency Syndromes 2004;37:1404-1414.

21. Cromwell J, Bartosch WJ, Fiore MC, Hasselblad V, Baker T. Cost-effectiveness of the clinical practice recommendations in the AHCPR guideline for smoking cessation. Journal of the American Medical Association 1997;278:1759-1766.

22. Cummings SR, Rubin SM, Oster G. The cost-effectiveness of counseling smokers to quit. Journal of the American Medical Association 1989;261:75-79.

23. Dalziel K, Segal L. Time to give nutrition interventions a higher profile: cost-effectiveness of 10 nutrition interventions. Health Promotion International 2007;22:271-283.

24. Davis AL, Faust R, Ordentlich M. Self-help smoking cessation and maintenance programs: a comparative study with 12-month follow-up by the American Lung Association. American Journal of Public Health 1984;74:1212-1217.

25. DiFranza JR, Peck RM, Radecki TE, Savageau JA. What is the potential cost-effectiveness of enforcing a prohibition on the sale of tobacco to minors? Preventive Medicine 2001;32: 168-174.

26. Dollahite J, Kenkel D, Thompson CS. An economic evaluation of the expanded food and nutrition education program. Journal of Nutrition Education and Behavior 2008;40:134-143.

27. Doran CM, Shakeshaft AP, Fawcett JE. General practitioners' role in preventive medicine: scenario analysis using alcohol as a case study. Drug and Alcohol Review 2004;23:399-404.

28. Dornelas EA, Magnavita J, Beazoglou $T$, Fischer EH, Oncken $C$, Lando $H$, et al. Efficacy and cost-effectiveness of a clinic-based counseling intervention tested in an ethnically diverse sample of pregnant smokers. Patient Education and Counseling 2006;64:342-349.

29. Dowdy DW, Sweat MD, Holtgrave DR. Country-wide distribution of the nitrile female condom (FC2) in Brazil and South Africa: a cost-effectiveness analysis. AIDS 2006;20:2091-2098.

30. Downs SM, Klein JD. Clinical preventive services efficacy and adolescents' risky behaviors. Archives of Pediatrics \& Adolescent Medicine 1995;149:374-379.

31. DuShaw ML. A comparative study of three model comprehensive elementary school health education programs. Journal of School Health 1984;54:397-400.

32. Dzator JA, Hendrie $D$, Burke $V$, Gianguilio N, Gillam HF, Beilin $L$, et al. A randomized trial of interactive group sessions achieved greater improvements in nutrition and physical activity at a tiny increase in cost. Journal of Clinical Epidemiology 2004;57:610-619.

33. Eddy DM, Schlessinger L, Kahn R. Clinical outcomes and cost-effectiveness of strategies for managing people at high risk for diabetes. Annals of Internal Medicine 2005;143:251-264.

34. Elder JP, Campbell NR, Mielchen SD, Hovell MF, Litrownik AJ. Implementation and evaluation of a community-sponsored smoking cessation contest. American Journal of Health Promotion 1991;5:200-207.

35. Elley R, Kerse N, Arroll B, Swinburn B, Ashton T, Robinson E. Cost-effectiveness of physical activity counselling in general practice. New Zealand Medical Journal 2004;117:U1216.

36. Emmons KM, Puleo E, Park E, Gritz ER, Butterfield RM, Weeks JC, et al. Peer-delivered smoking counseling for childhood cancer survivors increases rate of cessation: the Partnership for Health Study. Journal of Clinical Oncology 2005;23:6516-6523.

37. Erfurt JC, Foote A, Heirich MA. The cost-effectiveness of work-site wellness programs for hypertension control, weight loss, and smoking cessation. Journal of Occupational Medicine 1991;33:962-970.

38. Ershoff DH, Aaronson NK, Danaher BG, Wasserman FW. Behavioral, health, and cost outcomes of an HMO-based prenatal health education program. Public Health Reports 1983;98:536-547.

39. Feenstra TL, Hamberg van Reenen HH, Hoogenveen RT, Rutten van Molken MP. Costeffectiveness of face-to-face smoking cessation interventions: a dynamic modeling study. Value in Health 2005;8:178-190. 
40. Finkelstein EA, Troped PJ, Will JC, Palombo R. Cost-effectiveness of a cardiovascular disease risk reduction program aimed at financially vulnerable women: the Massachusetts WISEWOMAN project. Journal of Women's Health and Gender Based Medicine 2002;11: 519-526.

41. Fleming MF, Mundt MP, French MT, Manwell LB, Stauffacher EA, Barry KL. Benefit-cost analysis of brief physician advice with problem drinkers in primary care settings. Medical Care 2000;38:7-18.

42. Franco $\mathrm{OH}$, der Kinderen $\mathrm{AJ}$, De Laet $\mathrm{C}$, Peeters $\mathrm{A}$, Bonneux L. Primary prevention of cardiovascular disease: cost-effectiveness comparison. International Journal of Technology Assessment in Health Care 2007;23:71-79.

43. Galani $\mathrm{C}$, Schneider $\mathrm{H}$, Rutten FF. Modelling the lifetime costs and health effects of lifestyle intervention in the prevention and treatment of obesity in Switzerland. International Journal of Public Health 2007; 52:372-382.

44. Gentilello LM, Ebel BE, Wickizer TM, Salkever DS, Rivara FP. Alcohol interventions for trauma patients treated in emergency departments and hospitals: a cost benefit analysis. Annals of Surgery 2005;241:541-550.

45. Ginsberg GM, Viskoper JR, Fuchs Z, Drexler I, Lubin F, Berlin S, et al. Partial cost-benefit analysis of two different modes of nonpharmacological control of hypertension in the community. Journal of Human Hypertension 1993;7:593-597.

46. Glasgow RE, La Chance PA, Toobert DJ, Brown J, Hampson SE, Riddle MC. Long term effects and costs of brief behavioural dietary intervention for patients with diabetes delivered from the medical office. Patient Education and Counseling 1997;32:175-184.

47. Gusi N, Reyes MC, Gonzalez Guerrero JL, Herrera E, Garcia JM. Cost-utility of a walking programme for moderately depressed, obese, or overweight elderly women in primary care: a randomised controlled trial. BMC Public Health 2008;8:231.

48. Herman WH, Hoerger TJ, Brandle M, Hicks $\mathrm{K}$, Sorensen S, Zhang $\mathrm{P}$, et al. The costeffectiveness of lifestyle modification or metformin in preventing type 2 diabetes in adults with impaired glucose tolerance. Annals of Internal Medicine 2005;142:323-332.

49. Hollis JF, McAfee TA, Fellows JL, Zbikowski SM, Stark M, Riedlinger K. The effectiveness and cost effectiveness of telephone counselling and the nicotine patch in a state tobacco quitline. Tobacco Control 2007; 16 (Suppl 1):i53-59.

50. Holtgrave DR, Kelly JA. Preventing HIV/AIDS among high-risk urban women: the costeffectiveness of a behavioral group intervention. American Journal of Public Health 1996;86:1442-1445.

51. Holtgrave DR, Kelly JA. Cost-effectiveness of an HIV/AIDS prevention intervention for gay men. AIDS and Behavior 1997;1:173-180.

52. Hutton G, Wyss K, N'Diekhor Y. Prioritization of prevention activities to combat the spread of HIV/AIDS in resource constrained settings: a cost-effectiveness analysis from Chad, Central Africa. International Journal of Health Planning and Management 2003;18:117-136.

53. Jacobs van der Bruggen MA, Bos G, Bemelmans WJ, Hoogenveen RT, Vijgen SM, Baan CA. Lifestyle interventions are cost-effective in people with different levels of diabetes risk: results from a modeling study. Diabetes Care 2007;30:128-134.

54. Johannesson M, Aberg H, Agreus L, Borgquist L, Jonsson B. Cost-benefit analysis of nonpharmacological treatment of hypertension. Journal of Internal Medicine 1991;230:307-312.

55. Johnson Masotti AP, Pinkerton SD, Kelly JA, Stevenson LY. Cost-effectiveness of an HIV risk reduction intervention for adults with severe mental illness. AIDS Care 2000;12:321-332.

56. Johnson Masotti AP, Pinkerton SD, Sikkema KJ, Kelly JA, Wagstaff DA. Cost-effectiveness of a community-level HIV risk reduction intervention for women living in low-income housing developments. Journal of Primary Prevention 2005;26:345-362.

57. Jones TF, Eaton CB. Cost-benefit analysis of walking to prevent coronary heart disease. Arch Fam Med 1994;3:703-710.

58. Kahn JG, Kegeles SM, Hays R, Beltzer N. Cost-effectiveness of the Mpowerment Project, a community-level intervention for young gay men. Journal of Acquired Immune Deficiency Syndromes 2001;27: 482-491. 
59. Kaplan RM, Atkins CJ, Wilson DK. The cost-utility of diet and exercise interventions in noninsulin-dependent diabetes mellitus. Health Promotion 1988;2:331-340.

60. Krumholz HM, Cohen BJ, Tsevat J, Pasternak RC, Weinstein MC. Cost-effectiveness of a smoking cessation program after myocardial infarction. Journal of the American College of Cardiology 1993;22:1697-1702.

61. Kumpusalo E, Neittaanmaki L, Halonen P, Pekkarinen H, Penttila I, Parviainen M. Finnish healthy village study: impact and outcomes of a low-cost local health promotion programme. Health Promotion International 1996;11:105-115.

62. Kunz FM, Jr., French MT, Bazargan Hejazi S. Cost-effectiveness analysis of a brief intervention delivered to problem drinkers presenting at an inner-city hospital emergency department. Journal of Studies on Alcohol 2004;65:363-370.

63. Lacey LA, Wolf A, O'Shea D, Erny S, Ruof J. Cost-effectiveness of orlistat for the treatment of overweight and obese patients in Ireland. International Journal of Obesity 2005;29:975-982.

64. Lai T, Habicht J, Reinap M, Chisholm D, Baltussen R. Costs, health effects and costeffectiveness of alcohol and tobacco control strategies in Estonia. Health Policy 2007;84: 75-88.

65. Laufer FN. Cost-effectiveness of syringe exchange as an HIV prevention strategy. Journal of Acquired Immune Deficiency Syndromes 2001;28:273-278.

66. Levy DT, Friend K. A simulation model of policies directed at treating tobacco use and dependence. Medical Decision Making 2002;22:6-16.

67. Lindgren $\mathrm{P}$, Fahlstadius $\mathrm{P}$, Hellenius $\mathrm{ML}$, Jonsson B, de Faire $\mathrm{U}$. Cost-effectiveness of primary prevention of coronary heart disease through risk factor intervention in 60-year-old men from the county of Stockholm: a stochastic model of exercise and dietary advice. Preventive Medicine 2003;36:403-409.

68. Lindgren $\mathrm{P}$, Lindstrom J, Tuomilehto J, Uusitupa M, Peltonen M, Jonsson B, et al. Lifestyle intervention to prevent diabetes in men and women with impaired glucose tolerance is costeffective. International Journal of Technology Assessment in Health Care 2007;23:177-183.

69. Lindholm L, Rosen M, Weinehall L, Asplund K. Cost effectiveness and equity of a community based cardiovascular disease prevention programme in Norsjo, Sweden. Journal of Epidemiology \& Commmunity Health 1996;50:190-195.

70. Lock CA, Kaner E, Heather N, Doughty J, Crawshaw A, McNamee P, et al. Effectiveness of nurse-led brief alcohol intervention: a cluster randomized controlled trial. Journal of Advanced Nursing 2006;54:426-439.

71. Lowensteyn I, Coupal L, Zowall H, Grover SA. The cost-effectiveness of exercise training for the primary and secondary prevention of cardiovascular disease. Journal of Cardiopulmonary Rehabilitation 2000;20:147-155.

72. Lwegaba A. Field trial to test and evaluate primary tobacco prevention methods in clusters of elementary schools in Barbados. West Indian Medical Journal 2005;54:283-291.

73. Marseille E, Kahn JG, Billinghurst K, Saba J. Cost-effectiveness of the female condom in preventing HIV and STDs in commercial sex workers in rural South Africa. Social Science \& Medicine 2001;52:135-148.

74. Molde Hagen E, Grasdal A, Eriksen HR. Does early intervention with a light mobilization program reduce long-term sick leave for low back pain: a 3-year follow-up study. Spine 2003; 28:2309-2315.

75. Mosbaek $\mathrm{CH}$, Austin DF, Stark MJ, Lambert LC. The association between advertising and calls to a tobacco quitline. Tobacco Control 2007;16 (Suppl 1):i24-29.

76. Mundt MP, French MT, Roebuck MC, Manwell LB, Barry KL. Brief physician advice for problem drinking among older adults: an economic analysis of costs and benefits. Journal of Studies on Alcohol 2005;66:389-394.

77. Munro J, Brazier J, Davey R, Nicholl J. Physical activity for the over-65s: could it be a costeffective exercise for the NHS? Journal of Public Health Medicine 1997;19:397-402.

78. Munro JF, Nicholl JP, Brazier JE, Davey R, Cochrane T. Cost effectiveness of a community based exercise programme in over 65 year olds: cluster randomised trial. Journal of Epidemiology \& Community Health 2004;58:1004-1010. 
79. Naglak M, Mitchell DC, Kris Etherton P, Harkness W, Pearson TA. What to consider when conducting a cost-effectiveness analysis in a clinical setting. Journal of the American Dietetic Association 1998;98: 1149-1154.

80. O'Loughlin J, Paradis G, Meshefedjian G. Evaluation of two strategies for heart health promotion by direct mail in a low-income urban community. Preventive Medicine 1997;26:745753.

81. Ong MK, Glantz SA. Free nicotine replacement therapy programs vs implementing smoke-free workplaces: a cost-effectiveness comparison. American Journal of Public Health 2005;95: 969-975.

82. Osland EJ, Powell EE, Banks M, Jonsson JR, Hickman IJ. Obesity management in liver clinics: translation of research into clinical practice. Journal of Gastroenterology and Hepatology 2007;22:504-509.

83. Palmer AJ, Roze S, Valentine WJ, Spinas GA, Shaw JE, Zimmet PZ. Intensive lifestyle changes or metformin in patients with impaired glucose tolerance: modeling the long-term health economic implications of the diabetes prevention program in Australia, France, Germany, Switzerland, and the United Kingdom. Clinical Therapeutics 2004;26:304-321.

84. Parker DR, Windsor RA, Roberts MB, Hecht J, Hardy NV, Strolla LO, et al. Feasibility, cost, and cost-effectiveness of a telephone-based motivational intervention for underserved pregnant smokers. Nicotine and Tobacco Research 2007;9:1043-1051.

85. Peterson M, Chandlee M, Abraham A. Cost-effectiveness analysis of a statewide media campaign to promote adolescent physical activity. Health Promotion Practice 2008;9:426-433.

86. Phillips $\mathrm{CJ}$, Prowle MJ. Economics of a reduction in smoking: case study from Heartbeat Wales. Journal of Epidemiology \& Community Health 1993;47:215-223.

87. Pinkerton SD, Holtgrave DR, DiFranceisco WJ, Stevenson LY, Kelly JA. Cost-effectiveness of a community-level HIV risk reduction intervention. American Journal of Public Health 1998;88:1239-1242.

88. Pinkerton SD, Holtgrave DR, Jemmott JB, 3rd. Economic evaluation of HIV risk reduction intervention in African-American male adolescents. Journal of Acquired Immune Deficiency Syndromes 2000;25: 164-172.

89. Pinkerton SD, Holtgrave DR, Valdiserri RO. Cost-effectiveness of HIV-prevention skills training for men who have sex with men. AIDS 1997;11:347-357.

90. Pinkerton SD, Johnson-Masotti AP, Otto-Salaj LL, Stevenson LY, Hoffmann RG. Costeffectiveness of an HIV prevention intervention for mentally ill adults. Mental Health Services Research 2001;3:45-55.

91. Plans Rubio P. Cost-effectiveness analysis of treatments to reduce cholesterol levels, blood pressure and smoking for the prevention of coronary heart disease: evaluative study carried out in Spain. Pharmacoeconomics 1998;13:623-643.

92. Prah Ruger J, Weinstein MC, Hammond SK, Kearney MH, Emmons KM. Cost-effectiveness of motivational interviewing for smoking cessation and relapse prevention among low-income pregnant women: a randomized controlled trial. Value in Health 2008;11:191-198.

93. Pritchard DA, Hyndman J, Taba F. Nutritional counselling in general practice: a cost effectiveness analysis. Journal of Epidemiology \& Commmunity Health 1999;53:311-316.

94. Proper KI, de Bruyne MC, Hildebrandt VH, van der Beek AJ, Meerding WJ, van Mechelen W. Costs, benefits and effectiveness of worksite physical activity counseling from the employer's perspective. Scandinavian Journal of Work, Environment \& Health 2004;30:36-46.

95. Quist Paulsen P, Lydersen S, Bakke PS, Gallefoss F. Cost effectiveness of a smoking cessation program in patients admitted for coronary heart disease. European Journal of cardiovascular prevention and rehabilitation 2006;13:274-280.

96. Rahman M, Fukui T, Asai A. Cost-effectiveness analysis of partner notification program for human immunodeficiency virus infection in Japan. Journal of Epidemiology 1998;8:123-128.

97. Ranson MK, Jha P, Chaloupka FJ, Nguyen SN. Global and regional estimates of the effectiveness and cost-effectiveness of price increases and other tobacco control policies. Nicotine and Tobacco Research 2002;4:311-319. 
98. Ratcliffe J, Cairns J, Platt S. Cost effectiveness of a mass media-led anti-smoking campaign in Scotland. Tobacco Control 1997;6:104-110.

99. Richter A, Loomis B. Health and economic impacts of an HIV intervention in out of treatment substance abusers: evidence from a dynamic model. Health Care Management Science 2005;8:67-79.

100. Roux L, Pratt M, Tengs TO, Yore MM, Yanagawa TL, Van Den Bos J, et al. Cost effectiveness of community-based physical activity interventions. American Journal of Preventive Medicine 2008;35:578-588.

101. Salkeld G, Phongsavan $\mathrm{P}$, Oldenburg B, Johannesson M, Convery $\mathrm{P}$, Graham-Clarke $\mathrm{P}$, et al. The cost-effectiveness of a cardiovascular risk reduction program in general practice. Health Policy 1997;41:105-119.

102. Salvetti XM, Oliveira JA, Servantes DM, Vincenzo de Paola AA. How much do the benefits cost? Effects of a home-based training programme on cardiovascular fitness, quality of life, programme cost and adherence for patients with coronary disease. Clinical Rehabilitation 2008;22: 987-996.

103. Scharff RL, McDowell J, Medeiros L. Evaluation of an educational intervention using the enhanced food safety cost-of-illness model. Journal of Food Protection 2009;72:137-141.

104. Secker-Walker RH, Worden JK, Holland RR, Flynn BS, Detsky AS. A mass media programme to prevent smoking among adolescents: costs and cost effectiveness. Tobacco Control 1997;6:207-212.

105. Segal L, Dalton AC, Richardson J. Cost-effectiveness of the primary prevention of diabetes mellitus. Health Promotion International 1998;13:197-209.

106. Sevick MA, Dunn AL, Morrow MS, Marcus BH, Chen GJ, Blair SN. Cost-effectiveness of lifestyle and structured exercise interventions in sedentary adults: results of project ACTIVE. American Journal of Preventive Medicine 2000;19:1-8.

107. Sevick MA, Napolitano MA, Papandonatos GD, Gordon AJ, Reiser LM, Marcus BH. Costeffectiveness of alternative approaches for motivating activity in sedentary adults: results of Project STRIDE. Preventive Medicine 2007;45:54-61.

108. Shearer J, Shanahan M. Cost effectiveness analysis of smoking cessation interventions. Australian and New Zealand Journal of Public Health 2006;30:428-434.

109. Shi L. A cost-benefit analysis of a California county's back injury prevention program. Public Health Reports 1993;108:204-211.

110. Smith MY, Cromwell J, DePue J, Spring B, Redd W, Unrod M. Determining the costeffectiveness of a computer-based smoking cessation intervention in primary care. Managed Care 2007; 16:48-55.

111. Solberg LI, Maciosek MV, Edwards NM. Primary care intervention to reduce alcohol misuse ranking its health impact and cost effectiveness. American Journal of Preventive Medicine 2008;34:143-152.

112. Solberg LI, Maciosek MV, Edwards NM, Khanchandani HS, Goodman MJ. Repeated tobaccouse screening and intervention in clinical practice: health impact and cost effectiveness. American Journal of Preventive Medicine 2006;31:62-71.

113. Southard BH, Southard DR, Nuckolls J. Clinical trial of an Internet-based case management system for secondary prevention of heart disease. J Cardiopulmonary Rehabilitation 2003;23:341-348.

114. Spoth RL, Guyll M, Day SX. Universal family-focused interventions in alcohol-use disorder prevention: cost-effectiveness and cost-benefit analyses of two interventions. Journal of Studies on Alcohol 2002;63:219-228.

115. Stevens W, Hillsdon M, Thorogood M, McArdle D. Cost-effectiveness of a primary care based physical activity intervention in 45-74 year old men and women: a randomised controlled trial. British Journal of Sports Medicine 1998;32:236-241.

116. Sweat M, O'Donnell C, O'Donnell L. Cost-effectiveness of a brief video-based HIV intervention for African American and Latino sexually transmitted disease clinic clients. AIDS 2001;15: 781-787. 
117. Tao GY, Remafedi G. Economic evaluation of an HIV prevention intervention for gay and bisexual male adolescents. Journal of Acquired Immune Deficiency Syndromes 1998;17:83-90.

118. Tengs TO, Osgood ND, Chen LL. The cost-effectiveness of intensive national school-based anti-tobacco education: results from the tobacco policy model. Preventive Medicine 2001;33:558-570.

119. Thavorn K, Chaiyakunapruk N. A cost-effectiveness analysis of a community pharmacist-based smoking cessation programme in Thailand. Tobacco Control 2008;17:177-182.

120. Thorsen N, Khalil L. Cost savings associated with smoking cessation for low-income pregnant women. Wisconsin Medical Journal 2004;103:67-69.

121. Tillgren $P$, Rosen $M$, Haglund $B$ J, Ainetdin $T$, Lindholm L, Holm LE. Cost-effectiveness of a tobacco 'quit and win' contest in Sweden. Health Policy 1993;26:43-53.

122. Toobert DJ, Glasgow RE, Strycker LA, Barrera M, Ritzwoller DP, Weidner G. Long-term effects of the Mediterranean lifestyle program: a randomized clinical trial for postmenopausal women with type 2 diabetes. International Journal of Behavioral Nutrition and Physical Activity 2007;4:1.

123. Tosteson AN, Weinstein MC, Hunink MG, Mittleman MA, Williams LW, Goldman PA, et al. Costeffectiveness of populationwide educational approaches to reduce serum cholesterol levels. Circulation 1997;95:24-30.

124. Trento M, Passera P, Bajardi M, Tomalino M, Grassi G, Borgo E, et al. Lifestyle intervention by group care prevents deterioration of Type II diabetes: a 4-year randomized controlled clinical trial. Diabetologia 2002;45:1231-1239.

125. Trento $M$, Passera $P$, Borgo E, Tomalino M, Bajardi M, Brescianini A, et al. A 3-year prospective randomized controlled clinical trial of group care in type 1 diabetes. Nutrition, Metabolism, and Cardiovascular Diseases 2005;15:293-301.

126. Tuli K, Kerndt PR. Preventing sexually transmitted infections among incarcerated men who have sex with men: a cost-effectiveness analysis. Sexually Transmitted Diseases 2009;36 (2 Suppl): S41-48.

127. Vickerman P, Kumaranayake L, Balakireva O, Guinness L, Artyukh O, Semikop T, et al. The cost-effectiveness of expanding harm reduction activities for injecting drug users in Odessa, Ukraine. Sexually Transmitted Diseases 2006;33(10 Suppl):S89-102.

128. Vijgen SM, Van Baal PH, Hoogenveen RT, De Wit GA, Feenstra TL. Cost-effectiveness analyses of health promotion programs: a case study of smoking prevention and cessation among Dutch students. Health Education Research 2008;23:310-318.

129. Wake M, Gold L, McCallum Z, Gerner B, Waters E. Economic evaluation of a primary care trial to reduce weight gain in overweight/obese children: the LEAP trial. Ambulatory Pediatrics 2008;8:336-341.

130. Wang G, Macera CA, Scudder Soucie B, Schmid T, Pratt M, Buchner D. A cost-benefit analysis of physical activity using bike/pedestrian trails. Health Promotion Practice 2005;6:174-179.

131. Wang LY, Crossett LS, Lowry R, Sussman S, Dent CW. Cost-effectiveness of a school-based tobacco-use prevention program. Archives of Pediatrics and Adolescent Medicine 2001;155: 1043-1050.

132. Wang LY, Davis M, Robin L, Collins J, Coyle K, Baumler E. Economic evaluation of Safer Choices: a school-based human immunodeficiency virus, other sexually transmitted diseases, and pregnancy prevention program. Archives of Pediatrics and Adolescent Medicine 2000; 154:1017-1024.

133. Wang LY, Gutin B, Barbeau P, Moore JB, Hanes J, Johnson MH, et al. Cost-effectiveness of a school-based obesity prevention program. Journal of School Health 2008;78:619-624.

134. Wang LY, Yang Q, Lowry R, Wechsler H. Economic analysis of a school-based obesity prevention program. Obesity Research 2003;11:1313-1324.

135. Warren $E$, Brennan A, Akehurst R. Cost-effectiveness of sibutramine in the treatment of obesity. Medical Decision Making 2004;24:9-19.

136. Windsor RA, Lowe JB, Perkins LL, Smith Yoder D, Artz L, Crawford M, et al. Health education for pregnant smokers: its behavioral impact and cost benefit. American Journal of Public Health 1993;83: 201-206. 
137. Windsor RA, Warner KE, Cutter GR. A cost-effectiveness analysis of self-help smoking cessation methods for pregnant women. Public Health Reports 1988;103:83-88.

138. Wootan MG, Reger Nash B, Booth Butterfield S, Cooper L. The cost-effectiveness of $1 \%$ or less media campaigns promoting low-fat milk consumption. Preventing Chronic Disease 2005;2:A05.

139. Wutzke SE, Shiell A, Gomel MK, Conigrave KM. Cost effectiveness of brief interventions for reducing alcohol consumption. Social Science \& Medicine 2001;52:863-870.

140. Wylie-Rosett J, Swencionis C, Ginsberg M, Cimino C, Wassertheil-Smoller S, Caban A, et al. Computerized weight loss intervention optimizes staff time: the clinical and cost results of a controlled clinical trial conducted in a managed care setting. Journal of the American Dietetic Association 2001;101:1155-1166.

141. Yu CM, Lau CP, Chau J, McGhee S, Kong SL, Cheung BM, et al. A short course of cardiac rehabilitation programme is highly cost effective in improving long-term quality of life in patients with recent myocardial infarction or percutaneous coronary intervention. Archives of Physical Medicine and Rehabilitation 2004;85:1915-1922.

142. Zarkin GA, Lindrooth RC, Demiralp B, Wechsberg W. The cost and cost-effectiveness of an enhanced intervention for people with substance abuse problems at risk for HIV. Health Services Research 2001;36:335-355. 


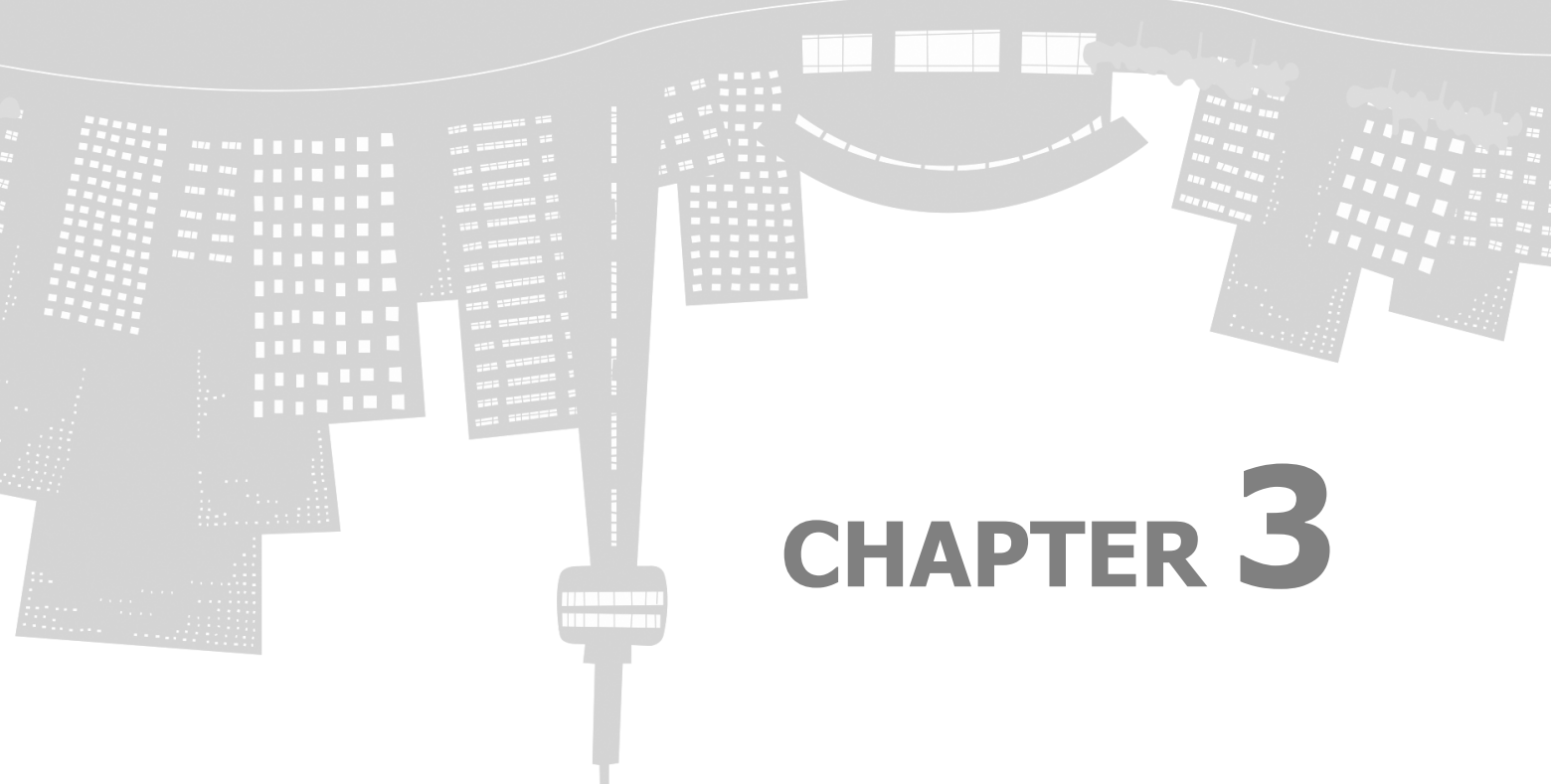

Estimating the implicit value of statistical
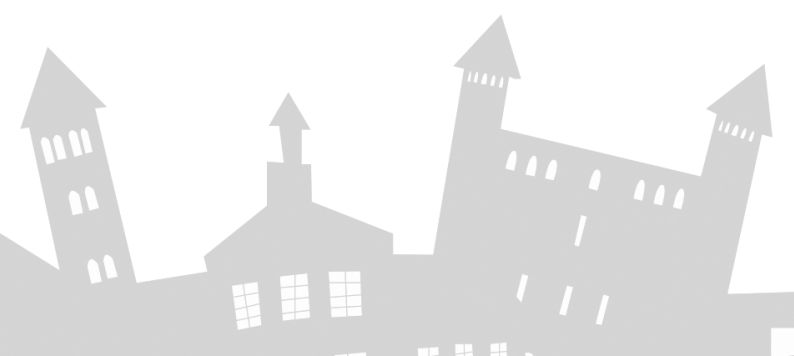

mene

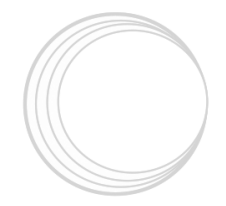

\section{life based on public interventions implemented in the Netherlands}




\section{Abstract}

\section{Objective}

In the Netherlands allocation decisions have not yet been explicitly based on the Value of Statistical Life. However, when policy makers decide whether or not to implement life saving interventions this trade-off is made implicitly. This study aimed to gain insights into this trade-off, hereafter referred to as Implicit Value of Statistical Life (IVSL), by means of a retrospective investment analysis of life saving interventions implemented in the Netherlands.

\section{Methods}

A literature search was conducted to find life saving intervention cases meeting the requirements for IVSL calculation. A final sample of ten cases was included in the study concerning interventions implemented in different societal sectors. For each case, an IVSL estimate was calculated according to a uniform method.

\section{Results}

IVSL estimates derived from the intervention cases differed considerably and ranged from $€ 1$ to almost $€ 11$ million. Differences were most extreme when comparing IVSL estimates concerning interventions implemented in different societal sectors. However, IVSL estimates also varied greatly between interventions in the same sector and even within the same interventions when critical assumptions were altered.

\section{Conclusion}

Our findings suggest that there are great imbalances between societal investments for preventing a statistical death. This highlights the need for further deliberation about how to improve transparency of policy decisions. An approach ex ante determining the Value of Statistical Life by means of empirical methods and based on societal preferences might circumvent the problems associated with the IVSL and needs further exploration. 


\section{Introduction}

Human life is the most valuable good we have and protecting it has high priority. The belief has even been expressed that costs should not play a role in saving human lives. ${ }^{1}$ In different societal sectors, such as health care, transport, consumer safety and the environment, regular efforts are made to develop interventions reducing mortality risk. However, because public resources are limited implementing all of these interventions is impossible and choices have to be made between competing intervention options.

In the healthcare sector decisions about the allocation of scarce resources are increasingly based on economic evaluations. ${ }^{2}$ In these evaluations, efficiency is often expressed in terms of costs per quality-adjusted life-year (QALY). The QALY integrates life expectancy and health-related quality of life in a single outcome measure. ${ }^{3}$ It can be used to compare different types of healthcare interventions, including screening, diagnosis, treatment, monitoring or a combination of these and as such contributes to allocative efficiency. Due to these advantages, in the Netherlands guidelines were formulated that explicitly recommend the application of the QALY in economic evaluations of pharmaceuticals that come into consideration for reimbursement. ${ }^{4}$

For interventions directed at mortality risk reduction, the economic literature suggests the Value of Statistical Life (VSL) as a common measure of efficiency. The VSL refers to the value that an individual or society would be willing to pay to avoid a statistical death (i.e. the risk of an anonymous premature death). It is a measure of the marginal rate of substitution of wealth for risk of death, due to a specific cause. ${ }^{5-7}$ Empirically, it can be determined by dividing an individual's willingness to pay (WTP) for a change in initial mortality risk, by the change in risk. WTP estimates can be determined by means of revealed or stated preference techniques. ${ }^{8}$ Revealed preference techniques draw on actual market behaviour, whereas stated preference techniques are survey-based approaches. ${ }^{9}$ Both methods result in individual WTP estimates that can be aggregated to determine a societal VSL.

As the VSL can be used to evaluate all kinds of mortality risk reducing interventions, it may assist policy makers in their assessment of competing intervention options across societal sectors. Hence, the VSL has the potential to support allocation decisions on a more central level, similar to the role the QALY plays for allocation decisions in the healthcare sector. However, to our knowledge policy decisions in the Netherlands have not been explicitly based on VSL estimates. Instead, the trade-off between wealth and mortality risk is made implicitly when policy makers decide whether or not to implement certain life saving interventions. ${ }^{10-11}$ These policy decisions give the best available indication of societal willingness to pay for reductions in mortality risk. As there is no scientific evidence regarding this Implicit Value of Statistical Life (IVSL), the present 
study had the objective to gain insights into its magnitude based on life saving interventions implemented in different societal sectors in the Netherlands.

\section{Methods}

For the purpose of this study, the IVSL was defined as the monetary value society commits to preventing one statistical death as revealed by public life saving interventions that have already been implemented. According to this definition, the IVSL can be calculated by dividing the total investment made for an intervention by the total number of lives saved by that intervention, where the number of lives saved equals the difference between the expected number of deaths before and after the intervention. This method has previously been referred to as Cost per Life saved. ${ }^{9}$

To allow for the calculation of IVSL estimates based on implementation decisions of the Dutch government, we defined the following selection criteria for life saving interventions to be included in this study. First, the interventions concern a measure or strategy reducing the probability of premature death among a specified target population. Secondly, the decision to implement the interventions has been taken by the Dutch central government, whereas the implementation itself and the costs may also be the responsibility of private parties. Finally, the literature reports estimates of the investment made and the number of lives saved by the intervention or provides sufficient information to allow for a belated calculation of these estimates.

To find suitable cases of life saving interventions, the authors initially reviewed interventions implemented or planned for implementation in the Netherlands that play(ed) a central role in the public debate of governmental policy and met the above selection criteria. Literature regarding economic evaluations conducted with respect to these interventions was searched using governmental and related websites. Furthermore, we contacted experts in different sectors of public policy working in ministries and research institutes that operate on behalf of the Dutch government. They were asked whether they were aware of policy documents regarding these particular interventions and other life saving interventions that might meet the inclusion criteria.

The majority of the reports and policy documents collected by this method initially did not meet the selection criteria. In several cases, however, additional information could be obtained from original authors and literature regarding the projected investment, the expected number of lives saved and the implementation status of the interventions. This process resulted in a final sample of 10 life saving intervention cases included in the study.

For each of these cases, first the investment made and the number of lives saved were determined. In case that these estimates were reported directly, the original calculations 
were reconstructed in order to gain insights into the comparability of estimates across the intervention cases. Subsequently, the IVSL was calculated according to the above described definition. With respect to the calculations, the following choices were made. To make IVSL estimates comparable across cases, annual estimates were transferred to total estimates. Furthermore, when uncertainty was reported around the estimates of the investment and/or number of lives saved (e.g. in terms of sensitivity analyses or minimum and maximum estimates), an IVSL was calculated for each of the possible values of the estimates.

\section{Results}

First, the intervention cases analyzed in this study are described according to the societal sector in which they were implemented and with particular emphasis on how the investment and number of lives saved were estimated. Subsequently, the IVSL estimates derived from these cases are discussed.

\section{Water control: Measures to reduce mortality risk from flooding}

In 2003 the Dutch Ministry of Transport, Public Works and Water Management commissioned the Netherlands Environment Assessment Agency (MNP) to evaluate the previous governmental policy of managing flooding risk. ${ }^{12}$ In the framework of this evaluation the cost-effectiveness of two water control measures was assessed aiming to improve the Dutch populations' protection against flooding risk: (i) the water barriers built in the southwestern part of the Netherlands after the flooding disaster in 1953 and (ii) the water barriers built in Central Holland based on the recommendations of the socalled "Delta Commission" made in $1960 .{ }^{12}$ The MNP report did not explicitly mention the perspective from which the economic analyses were performed, but as it concerned an evaluation of governmental policy, it is assumed that a public payer perspective was used.

For both interventions the investment and number of life saved estimates were directly reported. However the calculations underlying these estimates could not be reconstructed, due to unpublished literature and/ or inaccessible data. From the descriptions in the MNP report the following information could only be derived. In the Central Holland case the investment estimate was only based on the investment directly associated with the water control measures, whereas in the South West Netherlands case the investment estimate represents the investment associated with the water control measures, minus additional economic benefits due to the further development of the Vlissingen harbor area. Furthermore, the number of lives saved estimate in the South West Netherlands case was based on the number of fatalities caused by the 
flooding disaster in 1953. For the Central Holland case we were not able to retrieve the literature sources providing the estimated number of lives saved. Both, the investment and number of live saved estimates, were reported on an annual basis assuming an interest rate of 4 percent and administration costs of 1 percent.

\section{Consumer safety: Measures to reduce mortality risk from contamination of pharmaceutical products}

In 1996, patients with a new variant of Creutzfeldt Jakob disease (CJD) representing a bovine-to-human transmission of BSE (bovine spongiform encephalopathy) were for the first time discovered. Because there is no cure available for this disease, the Dutch government took a series of measures to protect consumers from contracting it. These included tracking down and slaughtering diseased cattle, banning the import of cattle from Great Britain and testing cattle older than 30 months for BSE. ${ }^{13}$ In addition, changes in regulations were made to reduce the transmission risk of the disease by pharmaceutical products containing animal derivates. To adhere to these new regulations, pharmaceutical companies had to change production processes, conduct additional analyses and use other raw materials. The costs and benefits of these measures were recently estimated for the companies SynCo Bio Partners, Sobel, Sanquin and Centocor using data from interviews with company representatives and additional literature. $^{13}$

The investment estimates reported consist of structural and once only costs made by the companies in an 8-year period and include both costs made to comply with the legislation and voluntary costs made to reduce the transmission risk. ${ }^{13}$ The number of lives saved were estimated based on a hypothetical population at risk for contracting the disease of 1 billion and on an estimated initial mortality risk, that was calculated as cumulative risk of the separate protection moments (i.e. each time patients take the pharmaceutical product under consideration).

\section{Transport sector: Measures to reduce mortality risk from road accidents}

Every year, a considerable number of people get injured or die in road accidents due to the limited field of view truck drivers have when turning right. In response to this problem, the Dutch government introduced a legal obligation to equip trucks with field of view improving systems (i.e. blind spot mirror or camera) in 2003. Shortly after this legislation was implemented, Langeveld \& Schoon (2004) ${ }^{14}$ conducted an economic evaluation of this measure from a societal perspective. The investment estimate they report includes the costs made by the government for law making and educational campaigns and the costs made by truck owners for equipping their vehicles with field of view improving systems. The number of lives saved estimate used in the report was 
derived from previous research. ${ }^{15}$ It was calculated using accident statistics and was based on two main assumptions: (i) the differences between the number of casualties caused by trucks turning right and trucks turning left can be accounted for by the blind spot; and (ii) field of view improving systems have a $40 \%$ lower effectiveness than direct view. Both the investment and the number of lives saved concerned an 8-year period and were discounted to present value using a 4 percent discount rate.

\section{Health care: Measures to reduce mortality risk from pandemic influenza}

Based on WHO recommendations the Dutch Ministry of Health, Welfare, and Sports developed an Influenza Pandemic Preparedness Plan with the objective to minimize the effects of a possible influenza pandemic on population and society. In the framework of this plan, the National Institute for Public Health and the Environment (RIVM) assessed the impact of different intervention measures on health services in terms of resources needed and health consequences, including mortality. ${ }^{16}$ The intervention measures concerned two possible scenarios: (i) the situation in which an influenza vaccine is available at the beginning of the pandemic and (ii) the situation in which such a vaccine is not available. For the latter case two intervention options were assessed. First, pneumococcal vaccination of groups at risk for influenza to prevent the complications associated with influenza, and second a therapeutic strategy administering neuraminidase inhibitors (i.e. antiviral agents) to people with influenza-like symptoms. Prophylactically administering neuraminidase inhibitors was another intervention option examined, but this was not included in this study as it did not meet our selection criteria. To date, the Netherlands have not been confronted with an influenza pandemic. However, the Dutch government has already invested in influenza vaccines (4 million units), pneumococcal vaccine (1 million units), and antiviral agents (5 million cures) to ensure rapid action in case a pandemic outbreak occurs. ${ }^{16,17}$

The investment associated with the alternative intervention options was not reported by the RIVM, but it could be calculated due to the detailed description provided of the resources needed for the different intervention options. Given that only health care resources were described in the report, we conducted the analysis from a health care perspective. The investment estimate includes drug costs, pharmacy prescription fees and the costs of GP visits for the number of patients that is expected to receive the interventions. ${ }^{18-21}$ The numbers of lives saved were estimated using a mathematical model synthesising data from various literature sources, including GP registries and Statistics Netherlands. The model was based on several assumptions regarding age dependency of attack rates, the spreading time of influenza and the conversion of death rates in the normal epidemic to the pandemic situation and was validated by an expert panel. Due to the uncertainty regarding the extent of a possible pandemic, the estimates 
of the investment and the number of lives saved were reported for the situation in which the pandemic hits 30 percent and 50 percent of the population. Given the lack of knowledge regarding the efficacy of neuraminidase inhibitors when used for therapeutic purposes, the investment made and the number of lives saved was also calculated for different degrees of efficacy ( 25 percent and 75 percent).

Table 3.1 IVSL Estimates and Input Parameters for the IVSL Calculation

\begin{tabular}{|c|c|c|c|c|c|}
\hline \multirow[b]{2}{*}{ Case (per sector) } & \multirow[b]{2}{*}{$\begin{array}{l}\text { Investment } \\
(* € 1000)\end{array}$} & \multirow[b]{2}{*}{$\begin{array}{l}\text { Lives Saved } \\
\text { (N) }\end{array}$} & \multicolumn{3}{|c|}{$\operatorname{IVSL}(€)$} \\
\hline & & & Min & $\begin{array}{c}\text { Point } \\
\text { estimate }\end{array}$ & Max \\
\hline \multicolumn{6}{|l|}{ Water control } \\
\hline Central Holland & 300000 & $100-5440$ & 55147 & & 3000000 \\
\hline South West Netherlands & 700000 & 64 & - & 10937500 & - \\
\hline \multicolumn{6}{|l|}{ Consumer safety } \\
\hline SynCo Bio Partners & 50 & 28908 & - & 2 & - \\
\hline Sobel & 113200 & 11095 & - & 10203 & - \\
\hline Sanquin & 191000 & 192719815 & - & 1 & - \\
\hline Centocor & 36000 & 73000 & - & 493 & - \\
\hline \multicolumn{6}{|l|}{ Transport } \\
\hline Field of view improving systems & 13610 & 12 & - & 1134167 & - \\
\hline \multicolumn{6}{|l|}{ Health care/Public Health } \\
\hline \multicolumn{6}{|l|}{ Influenza vaccination } \\
\hline pandemic hits $30 \%$ & 69825 & 2251 & - & 31020 & - \\
\hline pandemic hits $50 \%$ & 69825 & 3752 & - & 18610 & - \\
\hline \multicolumn{6}{|l|}{ Neuraminidase inhibitors } \\
\hline pandemic hits $30 \%$; efficacy $25 \%$ & 294690 & 1010 & - & 291772 & - \\
\hline pandemic hits $50 \%$; efficacy $25 \%$ & 501600 & 1600 & - & 313500 & - \\
\hline pandemic hits $30 \%$, efficacy $75 \%$ & 294690 & 3030 & - & 97257 & - \\
\hline pandemic hits $50 \%$, efficacy $75 \%$ & 501600 & 5000 & - & 100320 & - \\
\hline \multicolumn{6}{|l|}{ Pneumococcal vaccination } \\
\hline pandemic hits $50 \%$ & 63884.4 & 230 & - & 277758 & - \\
\hline
\end{tabular}

Notes: All estimates presented in this table were rounded to absolute numbers. 


\section{Discussion}

This study aimed to provide insights into the magnitude of the Implicit Value of Statistical Life (IVSL) by means of 10 cases of life saving interventions implemented in different societal sectors in the Netherlands. Our findings show that IVSL estimates differ considerably between the intervention cases and range from $€ 1$ to almost $€ 11$ million per statistical death prevented. This indicates that society's investments for mortality risk reductions vary extremely. However, one can question whether the IVSL estimates in this study give a good indication of which of life saving interventions represent a better investment than others in terms of efficiency. The IVSL estimates derived in this study have the advantage that they were calculated according to a uniform method and express the efficiency of different types of interventions in the same terms. Ideally, such a common efficiency parameter allows for a comparison of different types of interventions. However, the differences existing between crucial input parameters for the IVSL calculation (i.e. the investment and number of lives saved estimates) hamper valid comparison of the interventions in this study. The differences have several reasons.

First, the investment and number of lives saved estimates derived from the intervention cases were determined using different perspectives. In the pharmaceutical sector cases the perspective of individual companies was applied, while in the other intervention cases a health care, societal or public payer perspective was used. As a result the types of costs included in the investment estimate and the population at risk used to estimate the number of lives saved are not comparable across cases.

Second, discounting is not applied consistently. In the transport sector case discounting is used to adjust future monetary and health effects for their differential timing. In all other cases discounting was not applied or not reported. Due to the preventive nature of the interventions in this study, benefits are generally produced in the future, while costs are generated immediately. Therefore, the choice whether or not to use discounting and the choice for the method of discounting can have profound effect on the costeffectiveness of these interventions. ${ }^{22,}{ }^{23}$ Although there is still ongoing discussion regarding whether or not to discount the benefits of preventive interventions, the methods used should at least be consistent in order to allow for a comparison. ${ }^{24}$

Third, additional economic benefits produced by the interventions are not consistently included in the investment estimate. As part of the water control measures in South West Netherlands, the Vlissingen harbor area was further developed. The additional economic benefits resulting from these measures were subtracted from the total investment made for the intervention. In the remaining intervention cases, benefits other than mortality risk reduction were either not accounted for or this was not reported. 
Finally, the investment and number of lives saved estimates vary in the accurateness by which they were estimated. This is due to differences in the quality and scope of the economic evaluations performed in relation to the intervention cases. The estimates derived from the consumer safety cases are for instance based on a short explorative study, whereas the estimates derived from the health care sector cases are based on a decent and comprehensive analysis. The estimates in the transport sector case appear to be based on a rather global estimation and for the water control cases we could not reconstruct how estimates were calculated. These accuracy differences may for instance explain why IVSL estimates derived from the consumer safety cases are so low compared to IVSL estimates of other cases. The mortality risks in the consumer safety cases were largely based on ad hoc estimates made by company managers. As people generally have difficulties appraising small risks, ${ }^{25}$ it is possible that this approach has resulted in an overestimation of the initial mortality risk and the risk reductions achieved by the intervention and hence in biased IVSL estimates.

Given the potential bias introduced by studies with a rather limited scope and suboptimal research methods, it would have been advisable to use the quality of the data as an additional selection criterion for the cases included in this study. However, as the availability of intervention cases meeting the requirements for the IVSL calculation was limited, we chose not to use the quality of the data as a separate selection criterion. In addition to the limited comparability of IVSL estimates, there are also some conceptual problems inherent to the IVSL. The IVSL is based on investment decisions that have often been taken by policy makers in an ad hoc manner. As a result the tradeoff between wealth and mortality risk may be a highly imperfect process not adequately reflecting policy preferences. ${ }^{11}$

Furthermore, the IVSL only gives an indication of the lower bound of society's willingness to pay for a statistical death prevented. It reveals the amount society has paid in the past, while it would be more relevant to know what society would be willing to pay as a maximum.

A third problem of the IVSL is related to the fact that it has to be determined retrospectively based on secondary data sources. Hence, data about the decision contexts of the wealth-risk trade-offs is not readily available, which limits the opportunity to systematically examine possible determinants of IVSL estimates. Meta-analyses of empirical VSL studies, suggest that VSL estimates are influenced by a variety of factors, including characteristics of the sample (e.g. income), characteristics of the affected population at risk (e.g. life expectancy and average mortality risk) and context-specific factors (e.g. country of origin, year of publication or "unionization" in labour market studies). ${ }^{26,27}$ Insights into these factors and their relationship with the VSL are important 
as they contribute to our understanding of the variations found between VSL estimates from different studies.

Forth, it may be argued that the IVSL concept does not reflect preferences of society, but rather the revealed preferences of policy makers themselves, which is in contrast to the widely shared opinion among economists that the monetary value of safety in public sector cost-benefit analyses should reflect the preferences of those affected by the measure. $^{9}$

Finally, the IVSL assumes that decisions to implement life saving interventions are solely based on the trade-off between wealth and mortality risk. However, this trade-off is only one of the many factors that may be considered by decision-makers. Additional factors taken into account include for instance the broader benefits the intervention has for society, the potential unrest or panic that may be reduced by the intervention, and the consideration that we can be better safe than sorry, which is referred to as the precautionary principle. ${ }^{28,29}$ Moreover, policy decisions are not only based on a rational weighing of arguments, but often represent a political compromise. Decision-makers have to argue with different stakeholders and have to sell their decisions in the light of being re-elected. ${ }^{30}$ Hence, the IVSL does not provide an adequate reflection of the complex reality of decision-making.

\section{Conclusion}

This study has demonstrated that an IVSL derived by means of an ex post investment analysis is not an adequate means to compare the efficiency of different life saving interventions. This is due to the incomparability of input data for the IVSL calculation when these are derived from secondary data sources, but primarily, due to conceptual problems inherent to the IVSL. Despite the limitations of this approach, the IVSL estimates derived in this research suggest that there are great imbalances between society's investments for avoiding a statistical death. At this moment we lack information about the possible reasons of these imbalances. This highlights the need for further deliberation about how policy decisions can be made more transparent. A decisionmaking approach explicitly and ex ante taking the VSL into account could be a step forward. When determined by means of empirical methods and based on societal preferences, the VSL might circumvent the problems associated with the implicit VSL approach and might provide a useful decision aid for policy-makers. Further research efforts are needed to examine applications of this method in the practice setting. 


\section{References}

1. Fuchs VR, Zeckhauser R. Valuing health: A "priceless" commodity. American Economic Review 1987;77: 263-8.

2. Van Velden ME, Severens JL, Novak A. Economic evaluations of healthcare programmes and decision making: The influence of economic evaluations on different healthcare decisionmaking levels. Pharmacoeconomics 2005;23:1075-82.

3. Drummond MF, Sculpher MJ, Torrance GW, O'Brien BJ, Stoddart GL. Methods for the Economic Evaluation of Health Care Programmes. New York: Oxford University Press; 2005.

4. CVZ. Richtlijnen voor farmaco-economisch onderzoek. Diemen: CVZ; 2006.

5. De Blaeij $\mathrm{A}$. The value of statistical life in road safety: Stated preference methodologies and empirical estimates for the Netherlands [Dissertation]. [Amsterdam]: Vrije Universiteit; 2003.

6. Evans MF, Smith VK. Do we really understand the age-VSL relationship? Resource and Energy Economics. 2006;28:242-61.

7. Rabl A, Spadaro JV. Environmental impacts and costs of energy. Annals of the New York Academy of Sciences. 2006;1076: 516-26.

8. Johansson P, Kriström B. Introduction. Resour Energy Econ. 2006;28:193-8.

9. De Blaeij A, Florax RJGM, Rietveld P, Verhoef $E$. The value of statistitical life in road safety: A meta-analysis. Accident Analysis \& Prevention 2003;35:973-86.

10. Card WI, Mooney GH. What is the monetary value of human life? British Medical Journal 1977;2:1627-9.

11. Viscusi WK, Harrington JE, Vernon JM. Economics of regulation and antitrust. Cambridge: MIT Press; 2005.

12. Ten Brinke WMBJ, Bannink BA. Risico's in bedijkte termen: Een thematische evaluatie van het Nederlandse veiligheidsbeleid tegen overstromen. Bilthoven: RIVM; 2004 Report No.: 500799002.

13. Van der Baan F, Donk S, Jansen H, Kleine Staarman I, Luchtenburg P, Mostert B, Smits M. The price of precaution: measures to reduce the risk of contamination with $v C J D$ via pharmaceutical products. Utrecht: University of Utrecht (Faculty of Geosciences):2006.

14. Langeveld PMM, Schoon CC. Kosten-batenanalyse van maatregelen voor vrachtauto's en bedrijven. Leidschendam: SWOV; 2004. Report No.: R-2004-11.

15. Van Kampen LTB, Schoon CC. De veiligheid van vrachtauto's: Een ongevals- en maatregelanalyse in opdracht van Transport en Logisitiek Nederland. Leidschendam: SWOV; 1999. Report No.: R-99-31.

16. Genugten MLL, Heijnen MLA, Jager JC. Scenario analysis of the expected number of hospitalisations and deaths due to pandemic influenza in the Netherlands. Bilthoven: RIVM; 2002.

17. Ministry of Health Welfare and Sports. Hoogervorst tekent contract levering antivirale middelen. Press Report. 2005 Sept 9.

18. CVZ. Farmacotherapeutisch Kompas. [cited 2007 May 22]; Available from: http://www.fk.cvz.nl.

19. CVZ. Medicijnkosten. [cited 2007June 28]; Available from: http://www.medicijnkosten.nl.

20. NZA. Tarievenlijst Huisartsenzorg-Bijlage bij tariefbeschikking 5000-1900-07-1. Utrecht: NZA; 2006.

21. Postma MJ, Novak A, Scheijbeler HWKFH, Gyldmark M, Van Genugten MLL, Wilschut JC. CostEffectiveness of Oseltamivir treatment for patients with influenza-like illness who are at increased risk for serious complications of influenza: Illustration for the Netherlands. Pharmacoeconomics 2007;25:497-509.

22. Bos JM, Beutels P, Annemans L, Postma MJ. Valuing prevention through economic evaluation: Some considerations regarding the choice of discount model for health effects with focus on infectious diseases. Pharmacoeconomics 2004;22:1171-9. 
23. Claxton K, Sculpher M, Cuyler A, McCabe C, Briggs A, Akehurst R, Buxton M, Brazier J. Discounting and cost-effectiveness in NICE - stepping back to sort out a confusion. Health Economics 2006;15:1-4.

24. Severens JL, Milne RJ. Discounting health outcomes in economic evaluation: The ongoing debate. Value in Health 2004(7):397-401.

25. Miller TR. Variations between countries in values of statistical life. Journal of Transport Economics and Policy. 2000;34:399-416.

26. Bellavance $F$, Georges $D$, Lebeau $M$. The value of a statistical life: A meta-analysis with a mixed effects regression model. Montreal: Canada Research Chair in Risk Management 2006. Working paper No.:06-12.

27. Viscusi WK, Aldy JE. The value of a statistical life: A critical review of market estimates throughout the world. Journal of Risk and Uncertainty. 2003;27:5-76.

28. Alban S. The 'precautionary principle' as a guide for future drug development. European Journal of Clinical Investigation 2005;35(Suppl 1):33-44.

29. Mathijssen J, Petersen A, Besseling P, Rahman A, Don H. Omgaan met onzekerheid in beleid. Den Haag: CPB, MNP \& RAND Europe; 2007.

30. Brownson RC, Royer C, Ewing R, McBride TD. Researchers and policymakers: Travellers in parellel universes. American Journal of Preventive Medicine. 2006;30:167-72. 


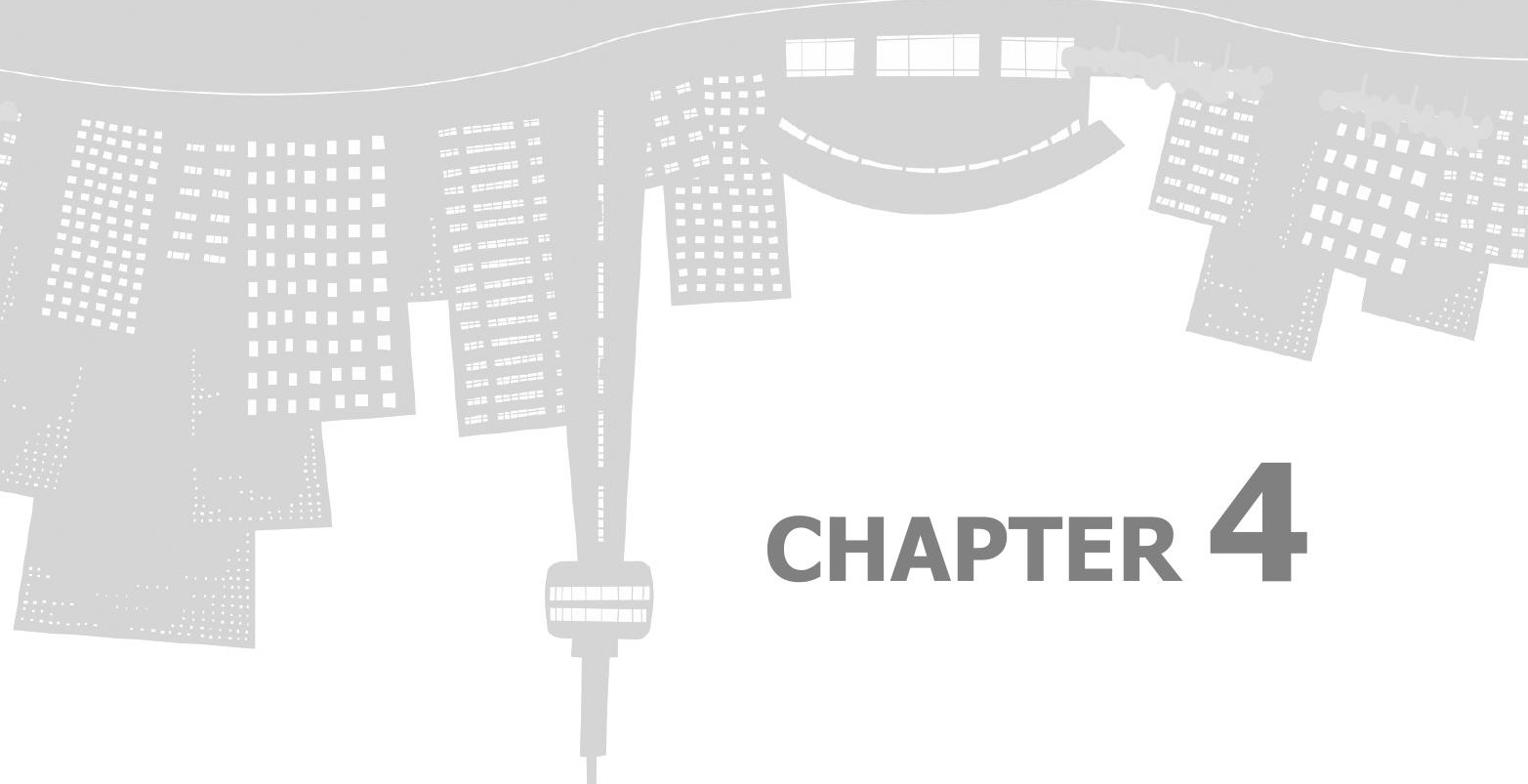

Exploring non-health outcomes of health promotion: the perspective of participants in a lifestyle behavior change intervention

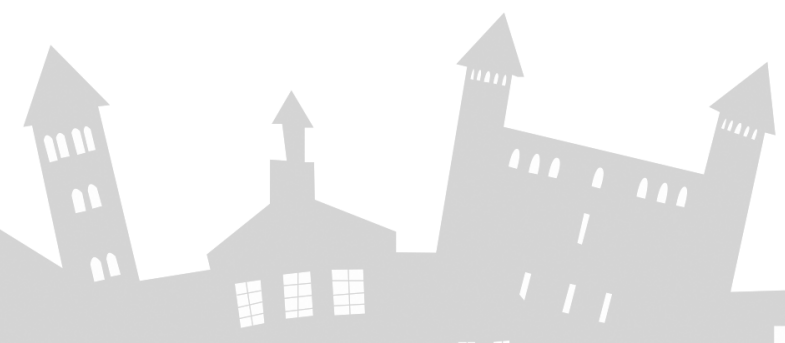

mase
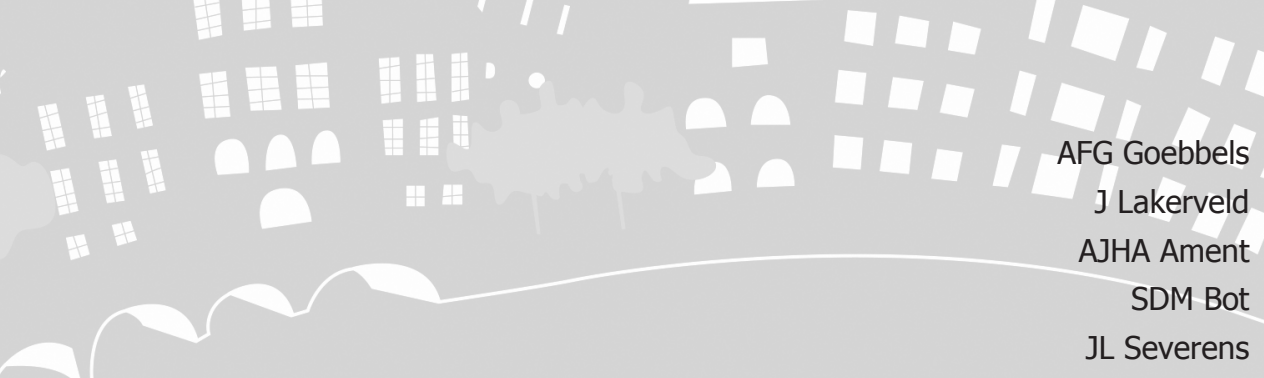

Health Policy 2012;106:177-186 


\section{Abstract}

\section{Objective}

To provide insights into health promotion outcomes that are not captured by conventional measures of health outcome used in economic evaluation studies, such as EQ-5D based QALYs.

\section{Methods}

Twelve semi-structured interviews and five focus group discussions were conducted with participants of a randomized controlled trial $(n=52)$ evaluating the effectiveness of a theory-based lifestyle intervention in Dutch adults at risk for diabetes mellitus and/or cardiovascular disease. Transcripts were analysed by two independent researchers using a thematic analysis approach.

\section{Results}

In total we identified twelve non-health outcome themes that were important from the participant perspective. Four of these were reported as direct outcomes of the lifestyle intervention and eight were reported as consequences of lifestyle behavior change. Our findings also suggest that lifestyle behavior change may have spillover effects to other people in the participants' direct environment.

\section{Conclusion}

This study provides evidence that in the context of lifestyle behavior change EQ-5D based QALYs capture health promotion outcomes only partially. More insights are needed into non-health outcomes and spillover effects produced by health promotion in other contexts and how participants and society value these. Methods to account for these outcomes within an economic evaluation framework need to be developed and tested. 


\section{Introduction}

Health promotion (HP) interventions are increasingly regarded as a way to tackle the growing global burden of chronic diseases. ${ }^{1-3}$ The need to invest in HP interventions is also recognized at the policy level, which is demonstrated by a wide range of HP policies implemented by governments and international organisations, worldwide. ${ }^{4}$ Economic evaluation studies provide a comparative analysis of costs and consequences of alternative intervention options and can support decisions about which interventions to include in such policies. ${ }^{5}$ To date, economic evaluation studies are hardly used for decision making about HP. ${ }^{6}$ First, because in most countries there are no systematic procedures for considering economic evaluation evidence in HP decision-making ${ }^{7}$ and second, because economic evaluation evidence is scarce for HP interventions. ${ }^{8}$ Even when economic evaluation studies are available, the adequacy of the evidence they provide is questionable. There is growing recognition that the methods, which have been developed to evaluate clinical health interventions (e.g. drugs, medical procedures and devices), do not adequately deal with challenges posed by complex HP interventions. ${ }^{9-11}$ The broad number of outcomes HP interventions intend to produce constitutes one of the key challenges. ${ }^{9,10}$ A common objective of HP is, for instance, to improve individuals' ability to make informed decisions and control their personal life. To achieve such empowerment, individuals have to undergo a personal development process which may include consciousness raising and the acquisition of problem solving skills. ${ }^{12-14}$ Changes to such broader outcomes are usually not captured by economic evaluation studies, which tend to focus on health outcomes only. Health outcomes are increasingly measured using a cost-utility framework and expressed in Quality Adjusted Life Years (QALYs). ${ }^{15-17}$ QALYs are a measure of a person's (expected) length of life weighted by the health-related quality of life (HRQOL) experienced over that period. ${ }^{5}$ The HRQOL weight is mostly derived using generic preference based instruments (such as the EQ5D). The use of such off the shelf instruments for evaluating HP interventions is problematic, because they neglect relevant broader outcomes of HP, which may lead to suboptimal allocation of public resources. ${ }^{10,18}$ Intended broader outcomes of health promotion are, however, not well-defined and theoretically underpinned outcome measures for use in evaluation studies not readily available. ${ }^{12,19-22}$ More insights are needed into the types and nature of non-health outcomes of HP to advance the discussion about adequate ways to consider these within an economic evaluation framework in a healthcare decision-making context. The present research aimed to identify non-health outcomes from the perspective of participants in a lifestyle behavior change (LBC) intervention. 


\section{Methods}

A combination of semi-structured interviews (SIs) and focus group discussions (FGDs) was used, because previous research suggests that this type of triangulation of qualitative methods may enhance understanding of the phenomenon studied (here: nonhealth outcomes). ${ }^{23,24}$ SIs give respondents the opportunity to elaborate on their experiences more in detail and share information they find too personal to discuss in a group, while FGDs provide a greater breadth of perspectives. ${ }^{25,26}$

\section{Study population and recruitment procedure}

Respondents were recruited from participants in the Hoorn Prevention Study (HPS), a randomized controlled trial evaluating the effectiveness of a theory-based lifestyle intervention in adults with an increased risk for type 2 diabetes mellitus (T2DM) and/or cardiovascular disease (CVD). ${ }^{27}$ The intervention was directed at improving motivation and self-empowerment of individuals to make sustainable changes in their lifestyle behaviors. Participants received a median of 2 face-to-face counselling sessions (interquartile range: $1-3$ ) and a median of 2.3 follow up sessions by phone (interquartile range: 1-3). The sessions were provided by trained practice nurses using evidencebased counseling techniques (i.e. motivational interviewing and problem solving treatment). ${ }^{27,28}$ Participants in the intervention group $(n=314)$ could choose to focus on smoking cessation, physical activity, diet or a combination of these lifestyle behaviors. The control group $(n=308)$ received written information about their risk to develop T2DM and CVD and existing brochures containing information about how to stop smoking and about health guidelines regarding physical activity and diet. ${ }^{27}$ For this qualitative study we recruited intervention group participants only, because familiarity with the HP intervention was regarded as crucial in order to talk about intervention consequences based on personal experiences. ${ }^{29}$

Respondents for SIs were recruited in January and February 2009, one year after commencement of the HPS. Participants, who had a research visit for physical measurements of the HPS scheduled during this period $(n=20)$, were contacted by phone. They were asked whether they were willing to give an interview after the research visit. This resulted in a final sample of 13 participants (see Figure 4.1).

Two of these were a couple and interviewed together. So, 12 SIs were held in total. To maximise diversity in perspectives and experiences all intervention group members still participating in the HPS in March 2009 ( $n=282,90 \%)$ were invited for FGDs. The invitation was send by mail and included a response form $(n=282)$. In case this form was not returned within two weeks, participants were contacted by phone. This resulted in a sample of 40 participants (see Figure 4.1). Five FGDs (with 6 to 12 participants) 
were held in March and April 2009. Background characteristics of both SI and FGD participants are presented in Table 4.1 and were measured at baseline of the HPS (between December 2007 and April 2008).
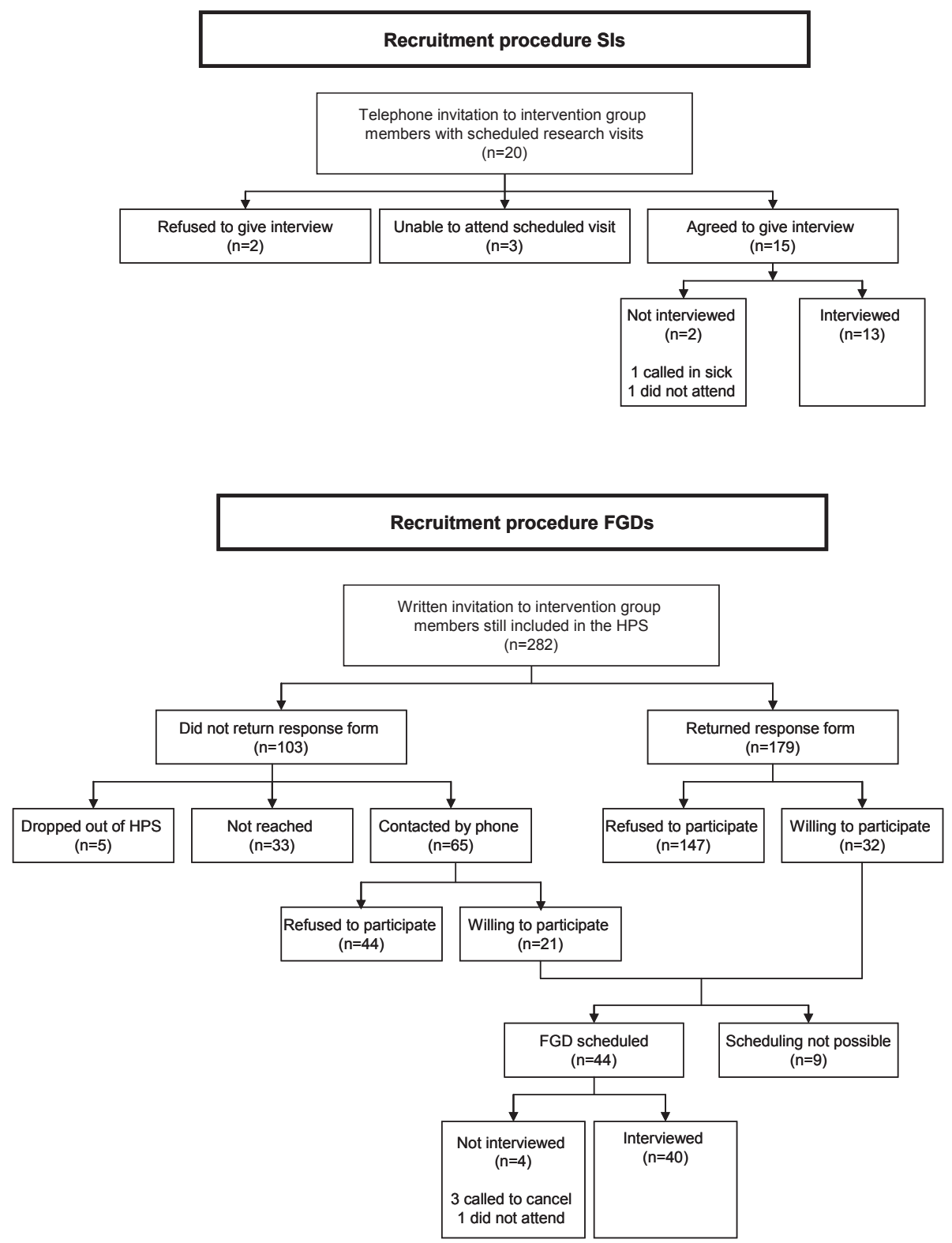

Figure 4.1 Recruitment procedures 
Table 4.1 Characteristics of study participants $(n=52)$

\begin{tabular}{lll}
\hline Variables & & $\mathrm{N}(\%)$ \\
\hline Type of interview & FGD & $12(23.1)$ \\
& SI & $39(75.0)$ \\
Gender & Both & $1(1.9)$ \\
Age & Male & $22(42.3)$ \\
& $30-35$ years 5 (9.6) & $5(9.6)$ \\
& $36-40$ years 13 (25.0) & $13(25.0)$ \\
& $41-45$ years 12 (23.1) & $12(23.1)$ \\
Education level & $46-50$ years 21 (40.4) & $21(40.4)$ \\
& $>50$ years 1 (1.9) & $1(1.9)$ \\
Income (gross per month) & Primary education & $1(1.9)$ \\
& Secondary education & $36(69.2)$ \\
& Higher education & $13(25.0)$ \\
Work status & $<€ 2500$ & $14(26.9)$ \\
& $€$ 2500-3000 & $11(21.1)$ \\
Country of birth & $>€$ 3000 & $12(23.1)$ \\
Living arrangement & Prefer not to tell & $8(15.4)$ \\
& Having paid work & $44(84.6)$ \\
EQ5D visual analogue scale score & Working full-time $(\geq 36$ h/week) & $21(40.4)$ \\
Smoking status & Working part-time & $21(40.4)$ \\
& The Netherlands & $49(94.2)$ \\
Having any problems on EQ5D dimensions & Lobility & $4(7.7)$ \\
& Self care & $6(11.5)$ \\
& Usual activities & $39(75.0)$ \\
& Piving with partner & $1(1.9)$ \\
& Anxiety/depression & $25(48.1)$ \\
& Mean (SD) 76.21 (10.94) & $8(15.4)$ \\
& Othing with partner and child(ren) & $17(32.7)$ \\
& Non-smoker & $7(13.5)$ \\
& Smoker & $1(1.9)$ \\
& & $5(9.6)$ \\
& & $24(46.1)$ \\
& & $10(19.2)$ \\
& & $76.21(10.94)$ \\
\hline
\end{tabular}

Notes: Percentages do not always add up to 100 , because there were missing values for several items: education level $(n=2)$, income $(n=7)$, having paid work $(n=2)$, working full- or part-time $(n=10)$, country of birth $(n=2)$, living arrangements $(n=2)$, smoking status $(n=2)$, and all EQ5-D dimensions $(n=2)$.

\section{The interview process}

SIs and FGDs both commenced with a general introduction about the purpose, procedure and confidentiality of the interviews. SIs proceeded with a broad opening question (You are participating in the Hoorn Prevention Study. Can you tell me how you experience this?). Respondents were then asked how they experienced the counseling sessions and to describe any consequences the counseling had for them. We also asked specifically whether respondents had made changes to any of the three lifestyle 
behaviors due to the counseling and if so, which consequences these had for them. In case respondents did not change lifestyle behavior due to the intervention, we asked them whether they could describe experiences with changing the three lifestyle behaviors of interest in other situations (e.g. self-accomplished changes in absence of an intervention, such as becoming a member in a gym and exercising regularly). We asked about these experiences, because the RCT study was still ongoing when this qualitative research was conducted and intervention effectiveness was unclear. So, in case that the intervention was not effective in changing behavior, participants' previous experiences with LBC could nevertheless provide useful insights into non-health outcomes of LBC.

Probing questions were used to encourage participants to elaborate on their views and experiences (e.g. Can you explain what you mean by feeling good?). The interviewer used a topic guide to ensure that all relevant issues were covered. For FGDs the same topic guide was used as for SIs, but topics were introduced in a different way using techniques to encourage interaction and equal participation of respondents. ${ }^{30} \mathrm{~A}$ whiteboard was used to gather different ideas put forward by respondents. Post its were used on which respondents could first list items individually and then share them with the group. All interviews were conducted by the same interviewer (AG), a health economics researcher with a background in public health. SIs lasted between 30 and 60 minutes and FGDs between 1.5 and 2 hours. Participants' travel and parking costs were reimbursed. Additionally, SI participants received a breakfast and FGD participants received refreshments and a USB stick. Ethical approval for the study was obtained from the VU University Medical Centre Research Ethics Committee.

\section{Data processing and analysis}

All SIs and FGDs were audio-taped, transcribed and entered into QSR Nvivo 8.0. Each transcript was analyzed by two researchers (AG and JL or AA or JS) using thematic analysis. ${ }^{31}$ Text fragments were identified referring to any outcomes participants experienced as a consequence of the counseling or LBC. From these we selected fragments referring to non-health outcomes. Non-health outcomes were defined as all outcomes not incorporated in EQ-5D based QALYs. Consequently, text fragments referring to changes in life expectancy and outcomes covered by the five HRQOL dimensions of the EQ-5D instrument (i.e. mobility, self-care, usual activities, pain/discomfort, and anxiety/depression) were excluded from further analyses. ${ }^{32}$ From the included text fragments non-health outcome themes were identified. Regular meetings were held to compare identified themes and reach consensus about coding. Based on the final coding a tree structure was developed in Nvivo. The non-health outcome themes were indicated as tree nodes and divided into nodes referring to themes of non-health outcomes experienced as a consequence of the counseling and 
themes of non-health outcomes experienced as a consequence of LBC. This distinction was made, because the outcomes were not necessarily experienced simultaneously. Respondents may have participated in the counseling intervention and experienced consequences of the counseling without acting upon it by performing lifestyle changes, while other respondents may have performed behavior changes independent of participating in the intervention (see Box 4.1 for a more detailed description of the impact of the counseling on LBC). All coded text fragments in the transcripts were linked to the tree nodes allowing to analyze all interview data simultaneously. These final analyses were conducted by the first author and consisted of three steps: (1) identifying key non-health outcome themes across all interviews (2) determining relevance of nonhealth outcomes of LBC for each of the lifestyle behaviors of interest and (3) selecting citations to support key themes. Results of the analyses were presented to the project team to check whether they gave a good representation of the data.

Box 4.1 The impact of the counselling on lifestyle behavior change

Participants in the SIs and FGDs had mixed experiences with and views about the counseling intervention. Several respondents clearly indicated that the counseling encouraged them to change their lifestyle behaviors. The changes they reported concerned for example smoking cessation, using the bike more frequently instead of the car, eating more regularly and having breakfast, drinking less alcohol, using healthier fats for cooking and using low fat sandwich fillings.

"Well, I stopped smoking because of this [the counseling]. Well, I managed this and now it is also a matter of physical activity. It goes alright, but it could be more. I just need to do this better." (Woman, FGD 3)

Such changes in lifestyle behaviors induced by the counseling were reported by 3 of the 13 respondents in the SIs and were discussed by respondents in all 5 FGDs. Other respondents found the counseling useful, but they did not change their lifestyle behaviors.

"I don't change my life because of it [the counseling]. Well, but it reminds you that you should watch out a little bit, that you have to live healthy." (Woman, SI 3)

And a third group of respondents did not appreciate counseling sessions at all.

"Well, I have my experience. I had a conversation and it was nothing new actually. And then I stopped immediately in fact. It was a conversation and it was not worthwhile in my situation." (Man, FGD 3) 


\section{Results}

In total we identified 12 themes of non-health outcomes, which are not incorporated in EQ-5D based QALYS (see Figure 4.2). The identified non-health outcome themes were identical across SIs and FGDs and therefore presented together.

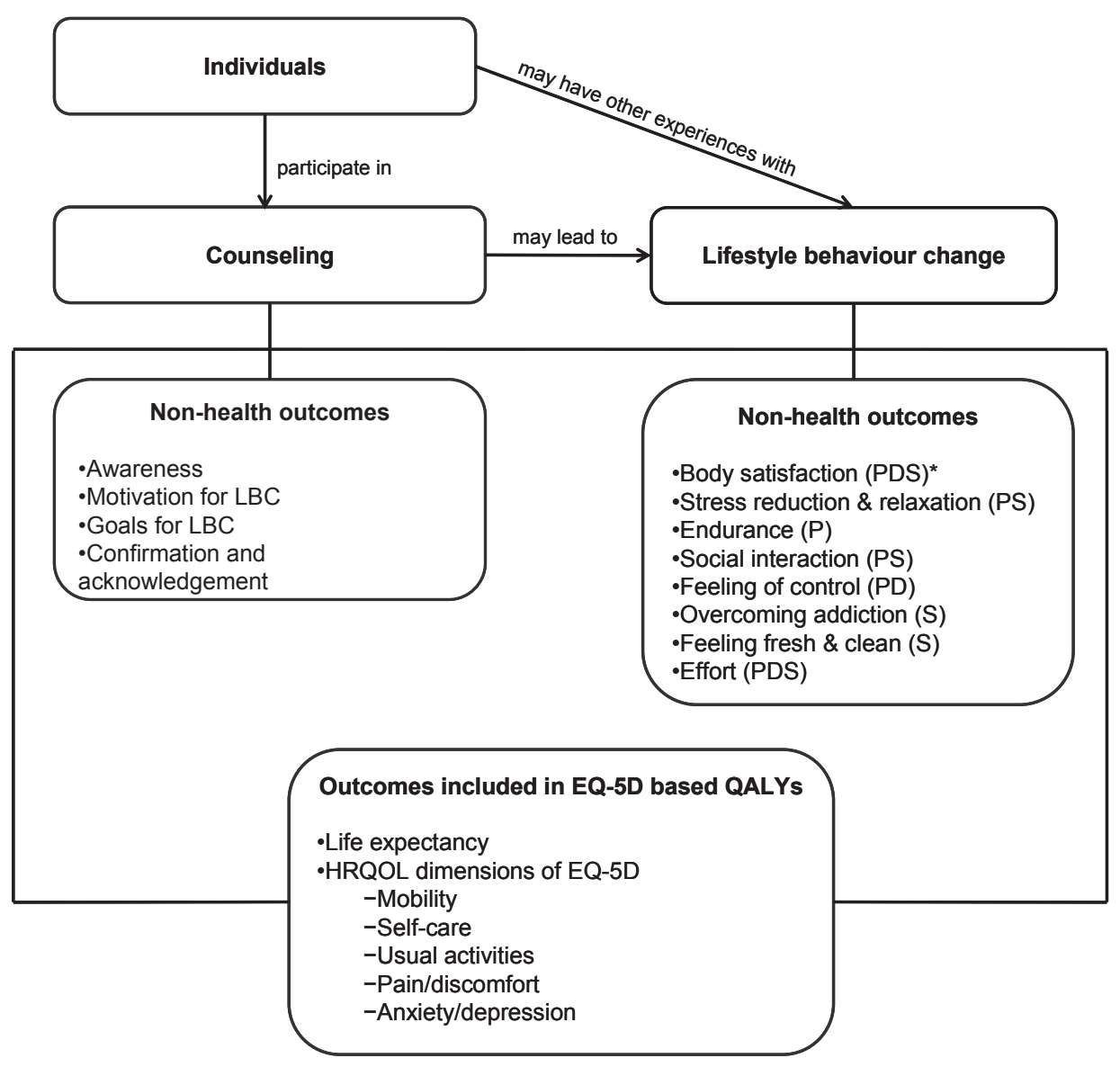

Figure 4.2 Non-health outcomes identified that are not incorporated in EQ-5D-based QALYS Notes: *Outcomes were relevant for: Physical activity (P), diet (D) and smoking cessation (S). 


\section{Non-health outcomes of the counseling}

Four of the identified themes concerned outcomes reported as consequence of the counseling.

\section{Awareness}

One of the most frequently discussed benefits of the counseling was increased awareness of health risks respondents are facing and awareness that these can be reduced by means of $\mathrm{LBC}$.

"Otherwise it just goes by, because it doesn't bother you, you are feeling well (...) you have to wait until you have health complaints and then you are actually too late, so I think for me this is very positive in particular that you are now very aware of what you can do." (Man, FGD 2)

The conversations with the counselor also raised awareness of respondent's own unhealthy behavior patters and pitfalls they encounter while trying to change their lifestyle.

"Well, I become more aware of it (...) what I struggle with, every time. Because I want to change my lifestyle, but I don't manage to." (Woman, FGD 1)

Awareness of their own behavior patterns helped respondents also to see new possibilities for LBC.

"Well, what it brings is that you are more actively aware of physical activity, with the patterns that you have (...). When I look at myself then that is the gain. Like you can simply take the stairs in stead of the lift." (Man, FGD 3)

\section{Motivation for $\angle B C$}

Many respondents felt that the counseling sessions increased their motivation for LBC. Some already had the intention to perform lifestyle changes before participating in the counseling, but did not find the motivation to actually do so.

"I did nothing [sport] anymore, and then [when participating in the HPS], I started again. I just needed this kick, you know." (Man, FGD 4).

The counseling sessions provided the opportunity to discuss progress with LBC on a regular basis. This motivated respondents to continue with lifestyle changes. Some 
respondents were only externally motivated, however. They felt the need to justify failure to progress with lifestyle changes otherwise.

"When I know that I have to go to such a person to have a conversation, I don't do it (...) I can't do it, because next week the scales have to go down. If I put a cookie into my mouth, it's not going to work." (Woman, FGD 4)

Therefore, when the counseling finished not all participants were able to maintain motivation for LBC.

"When this moment of control is not there anymore, yes then it [motivation] is likely to abate. I really need a little bit of control." (Woman, FGD 3)

A possible way to improve the potential of the counseling to increase participants' motivation for LBC was also discussed. Several respondents had the expectation that the results of the physical measurements conducted during the HPS (i.e. anthropometric measurements, blood pressure and blood tests) would be addressed during the counseling. They were disappointed that this was not the case and some pointed out that they perceive this as a lost opportunity for monitoring the impact of their lifestyle changes. Incorporating regular monitoring of the impact of LBC on physical indicators of health risks was suggested as a way to improve the counseling and to increase motivation for LBC.

"When I go exercising what does this actually mean for what changes for me? What about the blood values, what about the cholesterol? Because I think that this could be the gain, the extra gain. (...) it could certainly improve, could be very motivating, because you see that your cholesterol goes down or you see that your cholesterol goes up. Then you can say what happens to you." (Man, FGD 3)

\section{Goals for $L B C$}

The counseling sessions also helped respondents to set more concrete and realistic goals for LBC. Together with the counselor they broke intended lifestyle changes down into smaller steps that can be implemented more easily. Respondents described for instance that as a first step to LBC they started to rearrange their daily life schedules to create rest and time for themselves.

"You simply make a choice now, like, I do this and that. Before that, I wanted everything, I wanted everything and I did nothing (...). Now it is simply structure, bringing structure into your whole life". (Woman, FGD 4) 


\section{Confirmation and acknowledgement}

SIs and FGDs revealed that participants appreciated the positive feedback they received during the counseling sessions regarding lifestyle changes they made. It gave them confirmation and acknowledgement of their achievements. As answer to the question how the counselling has helped her, one respondent said:

"Well, in the sense that you feel supported, not only that, but also that you have actually achieved something, that it is acknowledged again. That it is good." (Woman, SI 11)

\section{Non-health outcomes of LBC}

From the identified non-health outcomes of $\operatorname{LBC}(n=8)$, two were reported only for $L B C S$ in other situations (i.e. 'feeling fresh and clean' and 'overcoming addiction'). All other non-health outcomes themes were concordant for both LBCs performed during the intervention and LBCs in other situations and therefore described together. Most nonhealth outcomes $(n=6)$ were relevant for one or two of the behaviors of interest (see Figure 4.2). Only two non-health outcome themes (i.e. 'body satisfaction' and 'effort') were relevant for all three lifestyle behaviors.

\section{Body satisfaction}

Many respondents experienced a change in their body shape as consequence of LBC. Most of them reported that increased physical activity levels and/or changes in dietary behavior lead to a slimmer body. This resulted in greater body satisfaction, which respondents described as finding themselves more attractive and being less ashamed about their body. Several respondents also mentioned to be happy that they are able to wear a smaller clothing size, which was associated with the possibility to find prettier clothes.

"I am so happy with this [weight loss], that I think for myself I do not want to go back to that $[82.5 \mathrm{~kg}]$. So, I want to keep these 74 [kilos]. (...) I find my body acceptable with 74 kilo's. And of course it can always be better, it can always be more beautiful, but I can do what I want and I feel happy with this." (Woman, SI 7)

Some respondents reported that they gained body weight due to LBC. They became less satisfied with their body. This happened mostly to people who stopped smoking and then started eating more unhealthy snacks, but also to a woman who went to a fitness centre. She explained that she stopped going, because she was unhappy with extra weight she had gained. 
"I go to looking dapper in your clothes [name of a training program]. That's what I want, too. (...) Then you go there [fitness centre] and you get a whole program of what you have to do. I say to this man, this is not going well, the scales are only going up. (...) He says you don't loose weight, but you get muscles (...). I left and never went back." (Woman, FGD 4)

The body satisfaction aspect was not equally important to respondents. Some found outer appearance very important, whereas others considered it less important and attached more value to health risk reduction.

"I sometimes look into the mirror and see love handles developing and so forth, that you think: but I actually absolutely don't want this. But then you rather push this aside, too easily. For me it was only that I said ok, I apparently have a health risk that I thought oh dear." (Man, FGD 4)

\section{Stress reduction and relaxation}

According to several respondents increased physical activity levels contributed to stress reduction and relaxation. They described this as being able to clear their mind and feeling calmer. Some respondents also explained that through relaxation they gained new mental strength to deal with life challenges.

"When you have stress, things, I also notice it when I had a busy day at work. Then I enjoy these 25 minutes on the bike. Because I know when I come home it starts with 'mum, mum, mum' and then the other 'mum, mum, mum'. Listening stereo and answering in stereo. Well, then it is pleasant that your mind is clear" (Woman, SI 7)

Relaxation was also identified as a non-health outcome theme in relation to smoking cessation. One female respondent reported that smoking has always been a way for her to relax and that she experiences less moments of relaxation since she quit smoking.

"Then [when you don't smoke] you simply continue. And this is a moment, a fag really is a little moment for yourself." (Woman, SI 10)

\section{Endurance}

Improved endurance was commonly reported as a positive consequence of increased physical activity. Respondents explained that regular physical activity made them feel stronger, fitter and more energetic. Some respondents described the improvement in endurance also as the experience that physical activity became gradually easier and less tiresome. 
"I feel simply less tired, now. Yes, because of the fitness [training]. So, if you have a big job in the garden or so, then you are broken after a day of hard work in the garden. But now I don't have this anymore." (Man, SI 8)

\section{Social interaction}

Several respondents described that they enjoyed being physically active, because it provided them with an opportunity for social interaction. In this context respondents also mentioned the value of feeling part of a team, which they experienced when engaging in team sport, such as volleyball.

"When you go exercising, you also go there partly for fun. I mean you get some enjoyment out of it. (...) So that you say I get a pleasant evening and social contact and such things and that is an enrichment of your life." (Man, FGD 1)

The benefit of social interaction was also mentioned with respect to smoking cessation. Despite the overall benefit derived from cessation, two respondents noted that they had fewer or less pleasant interactions with other people since they stopped smoking.

"When you stop smoking you miss all internal communication. All that happens in the hospital, all departments, such as his relationship ended and he got married. Smokers come really everywhere, I really missed the gossip." (Woman, FGD 3)

\section{Feeling of control}

The FGDs and SIs revealed that due to their experiences with LBC respondents learned that achievements, such as weight loss or increased endurance are a result of their own efforts to change behavior. This gave them a feeling of control over their lifestyle choices.

"This [loosing weight] is pleasant, yes. That's why I also think that I can simply manage to get rid of it [weight gained again].You see?" (Woman, SI 4)

\section{Overcoming addiction}

Respondents who stopped smoking reported that they were happy to have overcome tobacco addiction. They described this as not having a constant urge for a cigarette anymore, which enabled them to focus better on work or other activities.

"Now, after 8.5 years [of cessation] I can only say yes I simply don't have this urge anymore and everything (...) and I simply hope that I never do it [smoking] again." (Woman, FGD 2) 


\section{Feeling fresh and clean}

Another benefit of smoking cessation experienced by respondents was that they felt fresher and cleaner. A woman who stopped smoking recently mentioned that she liked the idea that her lungs will get completely clean again. But generally this theme concerned getting rid of tobacco odor in respondents' clothes, hair, skin and house.

"No, I find it good for now [that I stopped smoking]. It [the odor] stays in your hair and in your skin. I just didn't want it anymore." (Woman, SI 10)

\section{Effort}

A negative consequence of LBC many respondents mentioned was the effort associated with it. For example respondents found it hard to get up early in the morning and go out into the cold in order to exercise. With respect to changing dietary patterns, some respondents described that they had to resist the temptation of buying fast food or ready-made meals. Others reported that they had to make an effort to prepare separate meals for other family members, who were not willing to adapt to the new diet. Denying yourself sweet or fat snacks was also a commonly reported topic.

"I hope that I loose another thirteen kilos, but I find it difficult. Yes, because you really have to abstain from things." (Woman, FGD 1)

Respondents who quit smoking also described that they had to make an effort, first to overcome withdrawal symptoms and subsequently to handle the risk of relapse.

"It's so easy for me to start [smoking] again (....). I never have it that I think, yuck the first cigarette. Yes, I just instantly like the taste again. So, it will always remain a weakness for me." (Woman, SI 10)

\section{Differentiating between non-health and health outcomes}

The research team agreed that the above described non-health outcome themes concern distinct aspects of wellbeing not covered by EQ5D-based QALYs. The dividing line between the non-health and health outcomes was however not always clear-cut. To provide transparency about outcomes excluded from further analysis, some examples of text fragments referring to health outcomes are presented in Box 4.2.

\section{Spillover effects}

As the lifestyle intervention evaluated in the HPS was directed at individuals, this research focused on identifying non-health outcomes experienced by individual 
participants of the intervention. The FGDs and SIs suggested, however, that LBC of individual participants also had spillover effects on the broader social and family environment. Respondents described for example that becoming more physically active encouraged LBC in their partners and colleagues.

"My partner went to this gym together with me and also at work my colleagues see that I am pretty active and that stimulates them, too (...) I see everybody walking more and using the stairs more." (Man, FGD 3)

The impact of changing grocery habits and cooking patters on dietary behavior of other household members was also frequently discussed.

"(...) and we do the groceries. Then I simply don't buy it [unhealthy snacks]. Things that are not in the house are not going to be eaten." (Woman, FGD 2)

Box 4.2 Examples of text fragments referring to health outcomes

Several respondents mentioned increased life expectancy as an expected benefit of LBC.

"I also think now I should not become any bigger, because I would like to see my children grow old, and I simply know, heart failure is in our family. My father had one with 50, my grandmother with 45 and her brothers and sisters, too, all around the same age. So, I believe: yes, I should, hmm well yes, when you have a lot of overweight you have a risk to get something like this, a heart attack. "(Woman, FGD 1).

Respondents also indicated that losing weight reduced difficulties they had while being physically active. This outcome was coded as pertaining to mobility dimension of the EQ5D.

"It all goes a bit slower (...) a bit more difficult, you know. I still did it, because I am doing sports already for years, but I was quite fat of course (...) you see, when I lift one leg now, I lift six kilos instead of 10 kilos, you understand? (...) the lighter you become, the easier it gets, of course." (Woman, SI 5)

In many interviews respondents mentioned the physical measurements that were conducted during the HPS. They had hoped that the results of these tests were used in the counseling sessions. Although this was not the case, respondents still benefitted from the test results, because they provided them with information on their personal health risk and reduced anxiety. Text fragments referring to anxiety reduction were coded as pertaining to the anxiety/depression dimension of the EQ5D.

"Then you know your blood pressure is good, your blood sugar is good, you name it. If it is good, then it is a confirmation that it goes fine (...) than you know in any case how you perform physically. Personally, that calms me down." (Man, SI 9) 


\section{Discussion}

This research explored non-health outcomes produced by HP that are not captured by EQ5D-based QALYs. By means of SIs and FGDs we identified in total 12 non-health outcome themes from the perspective of participants in a LBC intervention directed at changing smoking, physical activity and dietary behaviors. As the existing evidence regarding non-health outcomes of HP is very limited, most of the identified themes have to our knowledge not previously been described in the health economics literature. Only three of the identified themes confirmed earlier research findings. Increased 'social interaction' was previously reported as a non-health outcome of HP by Borghi and Jan. ${ }^{33}$ They found that participants in a community based HP intervention directed at maternal and newborn health in Nepal were willing to pay for the opportunity of social interaction the intervention provided. A study by Weimer et al. ${ }^{34}$ provides support for the non-health outcome theme 'overcoming addiction'. Their findings show that current smokers in the US were willing to pay for a smoking cessation intervention that eliminates addiction. The non-health outcome theme 'feeling of control' (in our study: over lifestyle choices) previously received attention in the context of social care. A discrete choice experiment by Ryan et al. ${ }^{35}$ showed that older people attach importance to the outcome 'control over daily life'. The concordance between non-health outcomes identified in this study and non-health outcomes identified in other research, suggests that the identified nonhealth outcomes may also be relevant for both other HP interventions and healthcare interventions. Our analyses comparing the relevance of non-health outcome themes of LBC for each of the lifestyle behaviors of interest indicate, that the non-health outcomes that were experienced differed according to the type of the LBC made by respondents. For example the non-health outcome theme 'overcoming addiction' and 'endurance' were only relevant for respondents who changed smoking behavior and physical activity, respectively. So, whether a non-health outcome is relevant for a specific HP intervention may depend on the intervention focus (e.g. changing smoking behavior vs. encouraging safe sexual practices). More research is needed to explore non-health outcomes produced by other HP interventions, in other settings and among other populations to provide an overview of the range of non-health outcomes relevant for consideration within an economic evaluation framework and to categorize outcomes according to their relevance for different types of HP interventions.

The combination of SIs and FGDs was useful in providing different insights into nonhealth outcomes experienced by participants. SIs were more likely than FGDs to provide information about sensitive topics, such as body satisfaction, while FGDs generated more information about similar and contrasting views and experiences. 
The results of this research suggest that HP can also produce spillover effects to others in participants' social environment. This finding confirms previous research showing that HP and other health care interventions have spillover effects to family members. ${ }^{36-38}$ Future research should provide more insights into the nature and value of such spillover effects.

Several limitations of this study are worth mentioning. First, our study population was a selected sample. Ethical approval to conduct this research was obtained when the HPS had already commenced and only provided under the condition that participants, who had dropped out of the study, were not approached again. Findings may therefore not apply to dropouts. A dropout analysis suggests, however, that there were no significant differences in baseline variables (i.e. lifestyle behaviors and risk of type 2 diabetes mellitus or cardiovascular disease) between participants who completed the study and those who dropped out. ${ }^{28}$ Second, the distinction between health and non-health outcomes made in this study is not decisive. Non-health outcomes were defined as all outcomes not captured by EQ5D-based QALYs. The EQ5D is one of the most frequently used HRQOL measures ${ }^{32,39}$ and represents current economic evaluation practice. However, health outcomes could also be defined by means of a different generic preference-based instrument (e.g. SF-6D, 15D or AQOL), which may result in shifting boundaries between non-health and health outcomes. We currently lack clear definitions distinguishing between health and non-health outcomes. Such definitions need to be developed to guide future research aiming to identify relevant outcomes for use in decision-making. Third, this study focused on non-health outcomes representing actual consequences for individual participants of a HP intervention. Outcomes derived from intervention characteristics (e.g. duration or location) or provider characteristics (e.g. attitude, occupation), which are also referred to as non-health (or process) outcomes, were not considered. Previous research examining preferences towards such outcomes suggests that these are also important to participants of HP interventions. ${ }^{40-42}$ Fourth, we did not address relative importance of the identified non-health outcomes compared to each other and to health outcomes captured by EQ5D-based QALYs (i.e. changes in life expectancy and outcomes covered by the HRQOL dimensions of the EQ5D instrument), which have also been mentioned by respondents. Future research should provide insights into relative importance by means of discrete choice modelling or ranking exercises to enable attachment of weights to different outcomes that are considered in decision-making. ${ }^{35}$ Non-health outcomes may be accounted for in decisionmaking in various ways. They could be incorporated directly within economic evaluation studies or considered separately in the appraisal phase of decision-making process. For direct incorporation several approaches are possible. New generic preference-based measures for constructing QALYs could be developed including HRQOL dimensions 
relevant for HP or using capabilities. ${ }^{9,10}$ Contingent valuation may be used for monetary valuation of both health and non-health outcomes within cost-benefit analysis. And a third alternative is to describe all outcomes in separate units using cost-consequence analysis. ${ }^{43}$ Each of the approaches provides a useful source of information for decisionmakers and requires further development and testing. 


\section{References}

1. World Health Organization. 2008-2013 Action plan for the global strategy for the prevention and control of noncommunicable diseases. Geneva: WHO, 2008.

2. Ceccini M, Sassi F, Lauer JA, Lee YY, Guajardo-Barron V, Chisholm D. Tackling of unhealthy diets, physical inactivity, and obesity: health effects and cost-effectivenss. The Lancet 2010;376: 1775-84.

3. Asaria P, Chisholm D, Mathers C, Ezzati M, Beaglehole R. Chronic disease prevention: health effects and financial costs of strategies to reduce salt intake and ontrol tobacco use. The Lancet 2007; 370:2044-53.

4. Catford J. Ottawa 1986: The fulcrum of global development. Promotion \& Education 2007; 14:6-7.

5. Drummond MF, Sculpher MJ, Torrance GW, O'Brien BJ, Stoddard GL. Methods for the Economic Evaluation of Health Care Programmes. New York 2005.

6. Garrido MV, Kristensen FB, Nielsen CP, Busse R. Health technology assessment and health policy-making in Europe: Current status, challenges and potential. Copenhagen: World Health Organization, 2008.

7. Allin S, Mossialos E, McKee M, Holland W. Making decisions on public health: a review of eight countries. Copenhagen: World Health Organization on behalf of the European Observatory on Health Systems and Policies, 2004.

8. McDaid D, Needle J. What use has been made of economic evaluation in public health? A systematic review of the literature. In: Dawson S, Morris ZS, editors. Future Public Health: Burdens, Challenges and opportunities. Basingstoke: Palgrave Macmillan, 2009.

9. Weatherly H, Drummond M, Claxton K, Cookson R, Ferguson B, Godfrey C, Rice N, Sculpher $M$, Sowden A. Methods for assessing the cost-effectiveness of public health interventions: Key challenges and recommendations. Health Policy 2009;93:85-92.

10. Lorgelly PK, Lawson KD, Fenwick AL, Briggs AH. Outcome measurement in economic evaluations of public health interventions: a role for the capability approach?. International Journal of Environmental Research and Public Health 2010;7:2274-2289.

11. Kelly M, Morgan A, Ellis S, Younger T, Huntley T, Swann C. Evidence based public health: A review of the experience of the National Institute of Health and Clinical Excellence (NICE). Social Science \& Medicine 2010;71:1056-1062.

12. Rootman I, Goodstadt M, Potvin L, Springett J. A framework for health promotion evaluation. In: Rootman I, Goodstadt M, Hyndman B, McQueen DV, Potvin L, Springett J, Ziglio E, editors. Evaluation in health promotion: Principles and perspectives: WHO Europe, 2001.

13. World Health Organization. Health Promotion Glossary. Geneva, 1998.

14. Rissel C. Empowerment: the holy grail of health promotion? Health Promotion International 1994;9:39-47.

15. Donaldson C, Shackley P. Does "process utility" exist? A case study of willingness to pay for laparoscopic cholecystectomy. Social Science \& Medicine 1997;44:699-707.

16. Ryan M, Shackley P. Assessing the benefits of health care: how far should we go? Quality in Health Care 1995;4:207-213.

17. Mooney G. What else do we want from our health services? Social Science \& Medicine 1994; 39:151-154.

18. Hale J. What contribution can health economics make to health promotion? Health Promotion International 2000;15:341-347.

19. De Leeuw E, Skovgaard T. Utility-driven evidence for healthy cities: Problems with evidence generation and application. Social Science \& Medicine 2005;61:1331-1341.

20. Nutbeam D, Smith C, Catford J. Evaluation in health education. A review of progress, possibilities, and problems. Journal of Epidemiology \& Community Health 1990;44:83-9.

21. Erikson C. Learning and knowledge-production for public health: a review of approaches to evidence-based public health. Scandinavian Journal of Public Health 2000;28:298-308. 
22. Banta D. Considerations in Defining Evidence for Public Health. The European Advisory Committee on Health Research World Health Organization Regional Office for Europe. International Journal of Technology Assessment in Health Care 2003;19:559-572.

23. Lambert SD, Loiselle CG. Combining individual interviews and focus groups to enhance data richness. Journal of Advanced Nursing 2007;62:228-237.

24. Wackerbarth SB, Streams ME, Smith MK. Capturing the insights of family caregivers: Survey item generation with coupled interview/focus group process. Qualitative Health Research 2002;12: 1141-1154.

25. Lucassen PLBJ, Olde-Hartman TC. Kwalitatief onderzoek: Praktische methoden voor de medische praktijk. Houten: Bohn, Stafleu en van Loghum, 2007.

26. Hesse-Biber SN, Leavy P. The practice of qualitative research Thousand Oaks: Sage Publications, 2011.

27. Lakerveld J, Bot DM, Chinapaw MJ, van Tulder MW, van Oppen P, Dekker JM, Nijpels G. Primary prevention of diabetes mellitus type 2 and cardiovascular diseases using a cognitive behavior program aimed at lifestyle changes in people at risk: Design of a randomized controlled trial. BMC Endocrine Disorders 2008;8:1-11.

28. Lakerveld J, Bot SDM, Chinapaw MJ, van Tulder MW, Kingo L, Nijpels G. Process Evaluation of a Lifestyle Intervention to Prevent Diabetes and Cardiovascular Diseases in Primary Care. Health Promotion Practice 2012;13:696-706.

29. Lucassen PLBJ, olde Hartman TC. Kwalitatief onderzoek: Praktische methoden voor de medische praktijk. Houten: Bohn Stafleu van Loghum 2007.

30. Colucci E. "Focus groups can be fun": The use of activity-oriented questions in focus group discussions. Qualitative Health Research 2007;17:1422-1433.

31. Braun V, Clarke V. Using thematic analysis in psychology. Qualitative Research in Psychology 2006;3:77-101.

32. Brazier J, Ratcliffe J, Salomon JA, Tsuchiya A. Measuring and Valuing Health Benefits for Economic Evaluation. New York Oxford University Press, 2007.

33. Borghi J, Jan S. Measuring the benefits of health promotion programmes: Application of the contingent valuation method. Health Policy 2008;87:235-248.

34. Weimer DL, Vining AR, Thomas RK. Cost-benefit analysis involving addictive goods: contingent valuation to estimate willingness-to-pay for smoking cessation. Health Economics 2009;18:181-202.

35. Ryan M, Netten A, Skåtun D, Smith P. Using discrete choice experiments to estimate a preference-based measure of outcome-An application to social care for older people. Journal of Health Economics 2006;25:927-944.

36. Basu A, Meltzer D. Implications of spillover effects within the family for medical costeffectiveness analysis. Journal of Health Economics 2005;24:751-773.

37. Falba TA, Sindelar JL. Spousal concordane in health behaviour change. Health Services Research 2008;43:96-116.

38. Gorin AA, Wing RR, Fava JL, Jakicic JM, Jeffery R, West DS, Brelje K, DiLillo V, Look Ahead Home Environment Research Group. Weight loss treatment influences untreated spouses and the home environment: evidence of a ripple effect. International Journal of Obesity 2008; 32:1678-1684.

39. Weinstein MC, Torrance G, Mc Guire A. QALYs: The Basics. Value in Health 2009; 12:S5-S9.

40. Roux L, Ubach C, Donaldson C, Ryan M. Valuing the benefits of weight loss programs: An application of the Discrete Choice Experiment. Obesity Research 2004;12:1342-1351.

41. Owen K, Pettman T, Haas M, Viney R, Misan G. Individual preferences for diet and exercise programmes: changes over a lifestyle intervention and their link with outcomes. Public Health Nutrition 2009;13:245-252.

42. Brown DS, Finkelstein EA, Brown R, Buchner DM, Johnson FR. Estimating older adults' preferences for walking programs via conjoint analysis. American Journal of Preventive Medicine 2009;36:201-207.

43. de Salazar L, Jackson S, Shiell A, Rice M. Guide to Economic Evaluation in Health Promotion. Washington: Pan American Health Organization, 2007. 


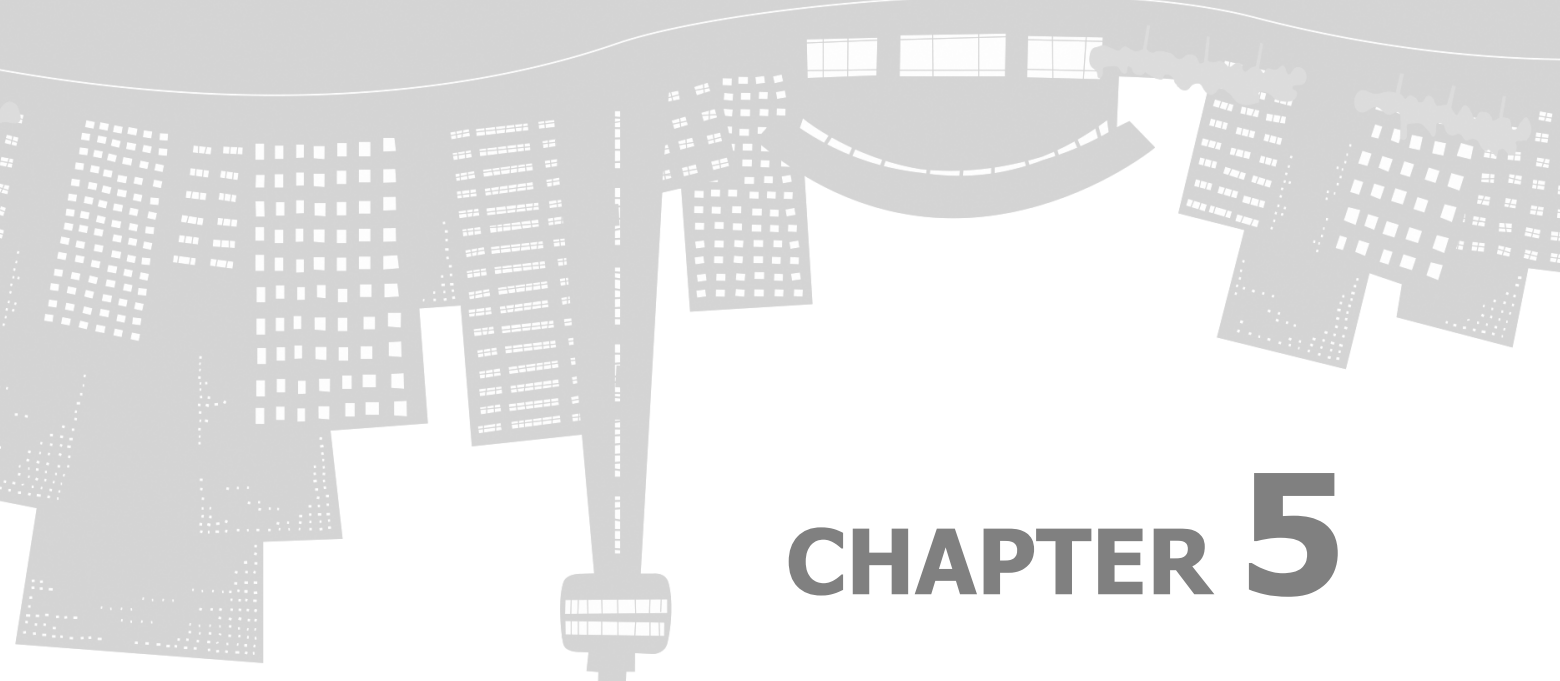

Consumer preferences for health and nonhealth outcomes of health promotion: results from a discrete choice experiment

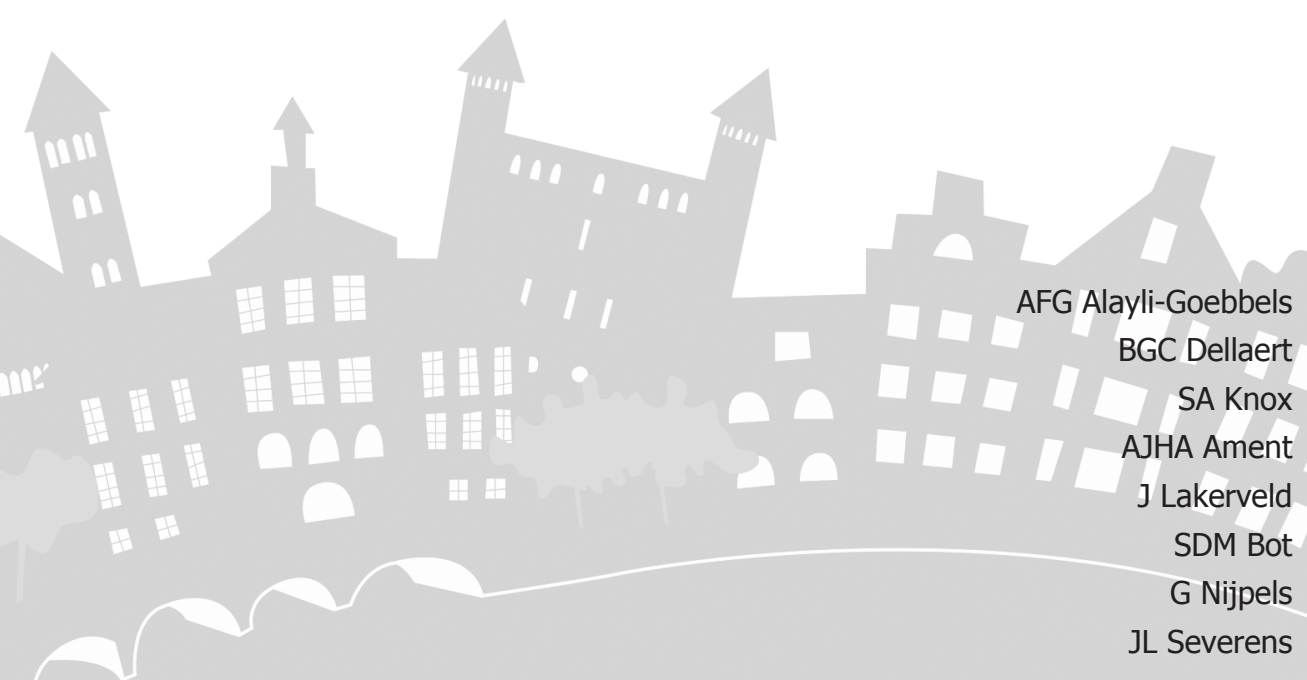




\section{Abstract}

\section{Objective}

Health promotion (HP) interventions have outcomes that go beyond health. Such broader non-health outcomes are usually neglected in economic evaluation studies. To allow for their consideration, insights are needed into the types of non-health outcomes that HP interventions produce and their relative importance compared to health outcomes. This study explored consumer preferences for health and non-health outcomes of HP in the context of lifestyle behavior change.

\section{Methods}

A discrete choice experiment was conducted among participants in a lifestyle intervention $(n=132)$ and controls $(n=141)$. Respondents made 16 binary choices between situations that can be experienced after lifestyle behavior change. The situations were described by 10 attributes: future health state value, start point of future health state, life expectancy, clothing size above ideal, days with sufficient relaxation, endurance, experienced control over lifestyle choices, lifestyle improvement of partner and/or children, monetary cost per month and time cost per week.

\section{Results}

With the exception of time cost per week and start point of future health state, all attributes significantly determined consumer choices. Thus, both health and non-health outcomes affected consumer choice. Marginal rates of substitution between the price attribute and the other attributes revealed that the attributes endurance, days with sufficient relaxation and future health state value had the largest impact on consumer choices. The life expectancy attribute had a relatively low impact and for increases of less than 3 years respondents were not willing to trade.

\section{Conclusion}

Health outcomes and non-health outcomes of lifestyle behavior change were both important to consumers in this study. Decision-makers should respond to consumer preferences and consider non-health outcomes when deciding about health promotion interventions. 


\section{Introduction}

Health promotion (HP) interventions aim to improve health and wellbeing through a process of enabling individuals and communities to increase control over their health. ${ }^{1} \mathrm{~A}$ large variety of activities take place under the name of $\mathrm{HP}$, including mass-media campaigns to increase awareness of the dangers of smoking and drink-driving, schoolbased comprehensive health education programs, fluoridation of water, introducing seatbelt legislation and community development projects to enable disadvantaged mothers to strengthen their parenting skills. ${ }^{2}$ Modern HP interventions are increasingly complex, multi-factorial interventions, which take place on various levels (e.g. individual, policy and physical environment) and have multiple outcomes. ${ }^{3,4}$ This complexity poses a number of methodological challenges to economic evaluation studies. ${ }^{5-7}$ One of the key challenges is that outcome measures commonly used in economic evaluation studies do not capture all outcomes health promotion interventions aim to achieve. Outcome measurement in economic evaluation studies focuses on individual health outcomes, which are increasingly measured using Quality Adjusted Life Years (QALYs). ${ }^{8,9}$ QALYs measure the improvement in life expectancy obtained through a specific intervention adjusted for the health-related quality of life (HRQOL) experienced in that period. ${ }^{10,11}$ While improving life expectancy and HRQOL is clearly an important goal of HP, it is not the only goal. Empowerment of individuals and communities is also a central objective of HP. ${ }^{2}$ This may involve for instance consciousness raising, increased self-esteem and participation in a group to experience mutual support or engage in collective political action. Life skills, such as health literacy, problem solving and communication skills, stress management and skills to cope with emotions ${ }^{12-14}$ can also be acquired during the empowerment process. ${ }^{12-14}$ Neglecting changes to such broader non-health outcomes in economic evaluation studies leads to incomplete information about the relative value of HP interventions and may hamper efficient allocation of public resources to such interventions.

To improve evidence for future decision-making relevant non-health outcomes of HP should also be examined. For an adequate consideration of non-health outcomes, insight is needed into a) the range and types of broader outcomes relevant to include in economic evaluation studies, and b) the relative importance of health and non-health outcomes of HP programs. ${ }^{6,15}$ The latter is crucial to determine the relative weight that should be given to the different outcomes in economic evaluation studies. Previous research identified several non-health outcomes that are important to participants of HP and other stakeholders, ${ }^{15,16}$ but the available evidence is scarce and relates to HP interventions in the field of women's health only. Studies examining relative consumer preferences towards non-health outcomes of HP interventions are also scarce ${ }^{17,18}$ and 
have so far focused on non-health outcomes reflecting the design or process of the intervention (e.g. travel time, extent of physician involvement, intensity of the intervention and group vs. individual focus). Evidence on consumer or societal preferences towards non-health outcomes representing actual consequences of HP interventions is currently lacking.

The present study contributes to the evidence by assessing consumer preferences towards health outcomes and non-health outcomes experienced as a consequence of a lifestyle behavior change intervention.

\section{Methods}

A discrete choice experiment (DCE) was conducted among participants of the Hoorn Prevention Study (HPS). The HPS is a randomized controlled trial evaluating the effectiveness of a HP intervention aiming to change lifestyle behaviors (i.e. physical activity, smoking and dietary behaviors) in adults with an increased risk for developing type 2 diabetes and/or cardiovascular disease. ${ }^{19}$ DCE surveys are increasingly used in health economics to elicit preferences towards health interventions, policies and services. ${ }^{20,21}$ The methods involved in DCEs are well-described in the literature ${ }^{20-23}$ and usually consist of five steps: 1) establishing the attributes and levels to be included in the experiment; 2) selecting the experimental design; 3) developing the questionnaire and actual choice tasks presented to respondents; 4) data collection; and 5) analysis of the discrete choice data.

\section{Establishing attributes and levels}

DCEs in health care have used as many as 12 attributes. ${ }^{22}$ In the present study the DCE consisted of 10 attributes (Table 5.1). Three attributes represented health outcomes measured within the QALY framework (i.e. life expectancy, future health state and timing of future health state) and reflect current economic evaluation practice. The life expectancy attribute was based on the current average life expectancy in the Netherlands at birth. ${ }^{24}$ It was varied by a maximum of three years, because research evidence suggest that a healthier lifestyle can increase life expectancy within this range. ${ }^{25}$ Life expectancy was used as an attribute instead of risk of premature death, because research evidence shows that people have difficulties in understanding risk information. ${ }^{26}$ The future health state attribute was based on the EQ-5D instrument, a widely applied generic preference based measure of health, ${ }^{27,28}$ which is used to obtain the health-related quality of life (HRQOL) weight for calculating QALYs based on 5 dimensions of health (i.e. mobility, self-care, usual activities, pain/discomfort and anxiety/depression). ${ }^{28}$ The attribute was defined in terms of four HRQOL weights 
representing four of 243 possible EQ-5D health states. First, we selected four HRQOL weights that seemed plausible given the sample's EQ-5D scores at baseline of the HPS. Then we identified the corresponding EQ-5D health states using Dutch population Time Trade Off value sets. ${ }^{29}$ These states were presented in the DCE together with the HRQOL weights. Given that consumers of health promotion were essentially healthy at the time of participation in the intervention, they would not experience an improvement in their HRQOL immediately. The benefit of health promotion rather lies in preventing deterioration of their future health state. To account for the long time horizon required to achieve changes in HRQOL we included a third attribute representing different start points of the future health state.

Due to a lack of literature on non-health outcomes of lifestyle behavior change, nonhealth outcome attributes were derived from semi-structured interviews $(n=12)$ and focus group discussions $(n=5)$ with HPS intervention group members $(n=52)$. Respondents were asked to describe any consequences they experienced from lifestyle behavior changes they made as a result of participating in the HP intervention. Reported consequences included both health outcomes (captured by EQ-5D based QALYs) and broader non-health outcomes. From the reported non-health outcomes, four attributes were selected for inclusion in the experiment based on their relevance for the total sample. The four non-health outcome attributes included body satisfaction, relaxation, endurance and experienced control over lifestyle choices. In the interviews a higher body satisfaction was frequently associated with the ability to wear a smaller clothing size. As clothing size can be quantified more easily than body satisfaction, we used clothing size as a proxy attribute for body satisfaction. To allow for the subjective dimension of body satisfaction, clothing size was further specified according to the degree of deviation from the respondent's ideal size from the respondent's perspective. The degree of relaxation was quantified as varying number of days per week during which people experience sufficient relaxation. We did not find useful existing measures to express the attributes endurance and experienced control over lifestyle choices in quantitative terms. Therefore, qualitative levels were used to describe these attributes ranging from poor to very good for endurance and from little to much for experienced control over lifestyle choices. 


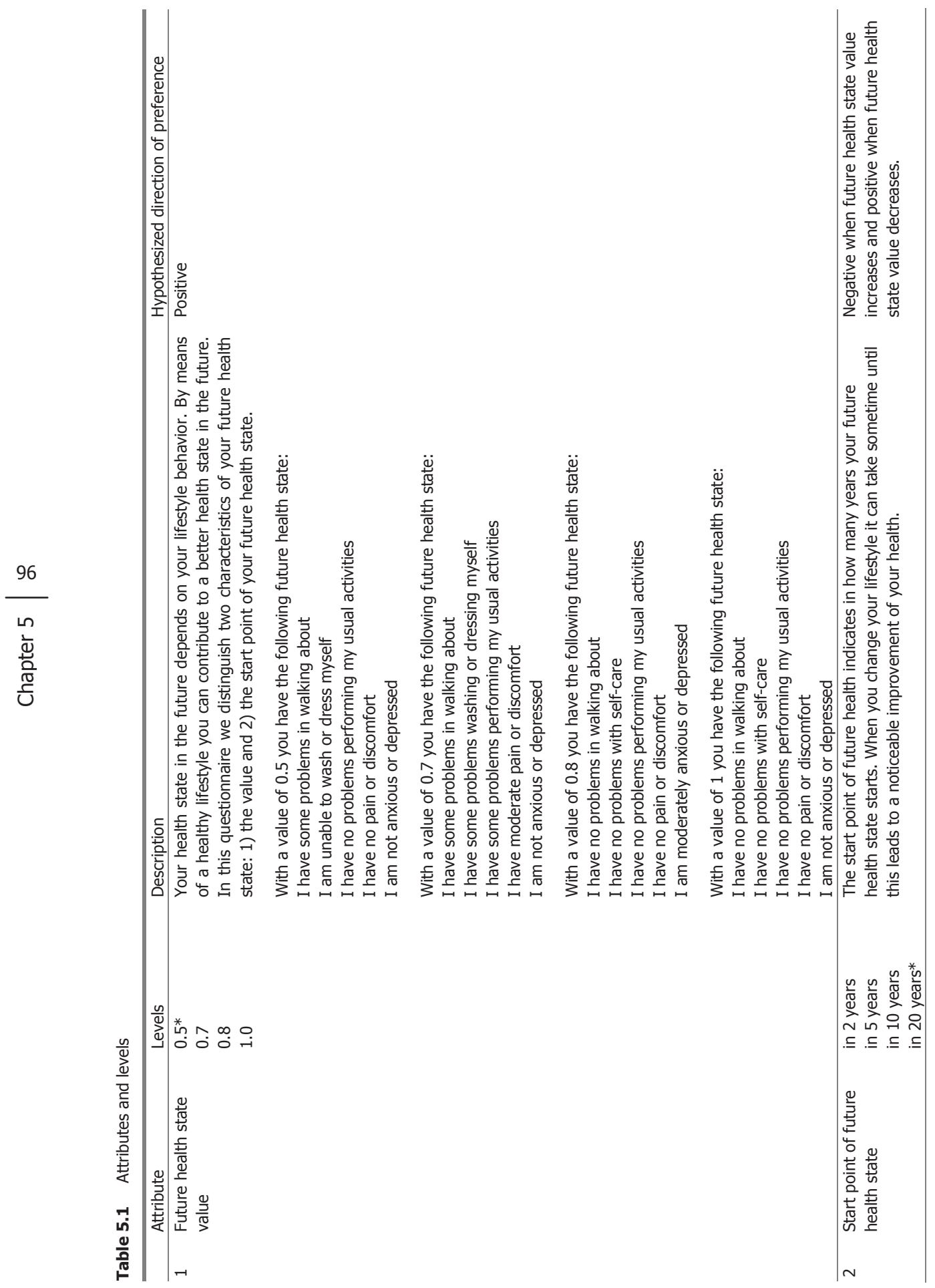




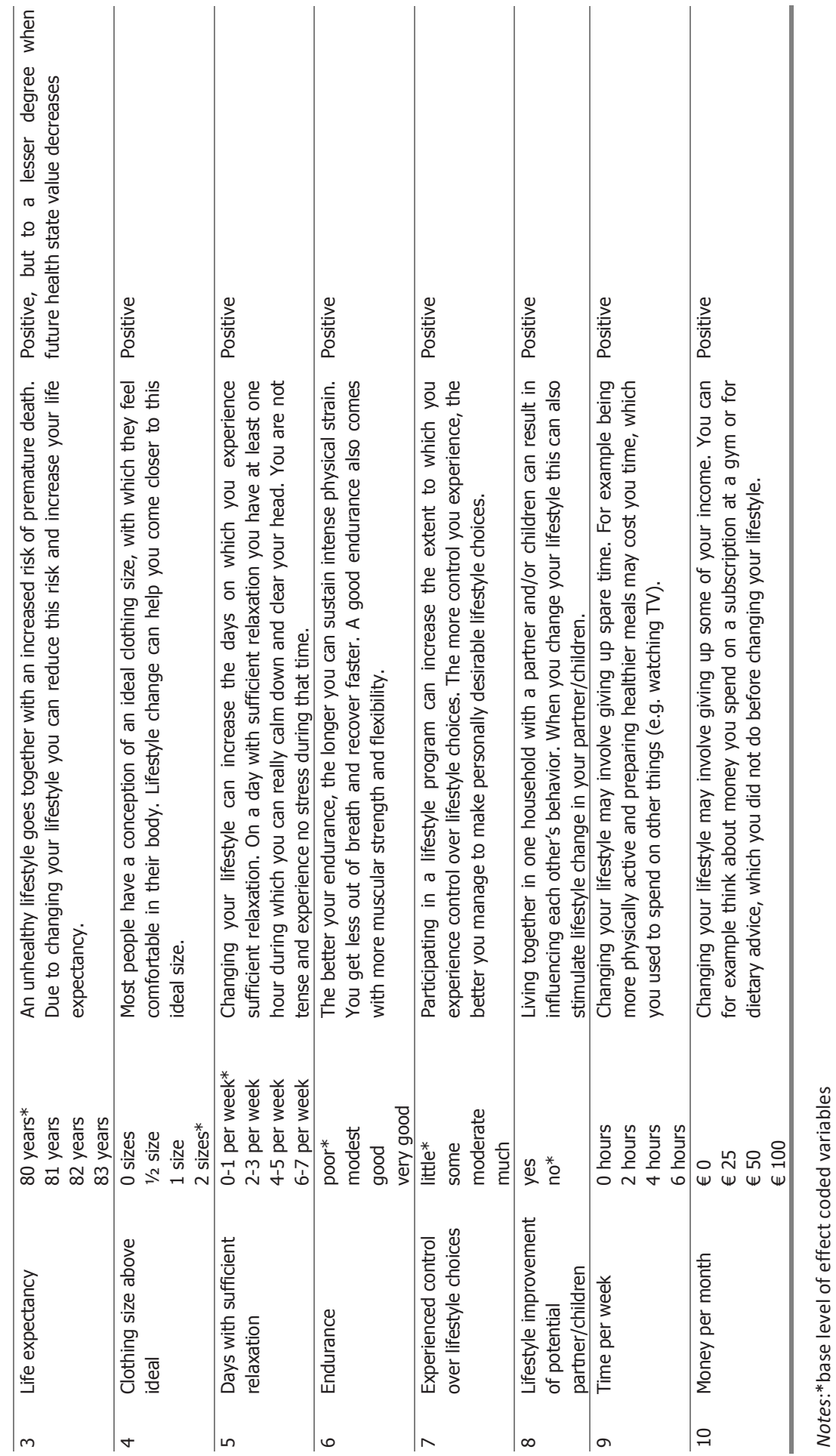


Given that many participants in the interviews and focus group discussions described spillover effects of their own lifestyle changes to lifestyle behaviors of their partners and children, we also included an attribute representing these spillover effects. Finally, two attributes were included to reflect the monetary and time costs associated with lifestyle behavior change. The monetary cost attribute was based on willingness to pay for effective lifestyle change interventions reported during interviews and focus group discussions, as well as market prices for gym subscriptions. The time cost attribute had levels ranging from 0-6 hours per week, which we considered as a realistic maximum time investment. For each attribute, except for lifestyle improvement of partner/children, we defined four levels to create sufficient variation in the attribute levels to produce meaningful choices. ${ }^{21}$

\section{Experimental design}

Using a full factorial design, containing all possible combinations $\left(4^{9} \times 2^{1}\right)$ of attribute levels for the selected attributes was not feasible. Hence, a fractional factorial design was created following design principles of Street and Burgess (2007). ${ }^{30}$ An orthogonal main effects starting design was selected from a design catalogue. ${ }^{31}$ The starting design had level balance and consisted of 32 rows and nine attributes, of which eight had four levels and one had eight levels. The eight-level attribute was collapsed into a two level attribute. An additional four-level attribute was created by adding a new column to the design. The design was then repeated three times, so that each of the four levels of the new attribute occurred together with all attribute level combinations of the starting design. This resulted in a design with 128 rows. Expanding the design in this way allowed us to estimate two-factor interactions between the new attribute (here: future health state value) and all other attributes.

Based on this design choice sets with two options were generated using design software developed by Burgess (2007). ${ }^{32}$ Generators were used to create the second option by shifting the attribute levels of the starting design a specified number of levels. ${ }^{30}$ One set of shift generators was required to estimate main effects and a second to estimate the 2 -factor interactions of interest. This resulted in a final design with 256 choice sets. The D-efficiency of the constructed 256 choice sets for estimating main effects was $87.9 \%$. The D-efficiency of the design for estimating main effects plus specified two - factor interactions could not be calculated. All main and interaction effects, however, were orthogonal (i.e. the levels of each attribute varied independently of each other and of their 2-way interactions) and could be estimated. ${ }^{30}$ The design was blocked into 16 versions to achieve a number of choice tasks $(n=16)$ respondents can handle without problems. $^{33-35}$ 


\section{Questionnaire and choice tasks}

To increase flexibility in the presentation of the choice tasks an online questionnaire was used. $^{36}$ This allowed for instance the use of hyperlinks, which could be used by respondents to look up EQ-5D health state descriptions (i.e. definitions of the levels of the attribute future health state value) throughout the experiment. Online administration of the survey also facilitated the use of a flexible random allocation procedure to ensure equal representation of the 16 versions among respondents. The questionnaire commenced with a number of background questions. Then the choice task was introduced. Each respondent was asked to make 16 forced choices involving two unlabeled alternatives (see Table 5.2). A generic context was used to be concordant with the generic approach to outcome evaluation in EQ-5D based QALYs. The alternatives were presented as potential situations that may be experienced after lifestyle change and characterized by different consequences (i.e. the attributes and levels). Respondents were asked to imagine themselves in these situations and to choose the situation they preferred most.

A forced choice approach was used in this exploratory study to encourage respondents to make trade-offs between the attributes of interest and ensure that they cannot choose the opt-out option to avoid making difficult choices. ${ }^{37}$ This approach was also in line with our objective to study preferences for outcomes experienced given that lifestyle behavior changes have taken place. Respondents were instructed to assume that they have to spend the money and time continuously for the rest of their lives and that they could not spend this time and money for other purposes anymore. It was emphasized that all consequences of lifestyle change would be experienced immediately, except for future health state, which would be experienced only after some years indicated by the attribute start point of future health state. To neutralize the potential impact of attribute ordering on the relative importance of attributes, which has been suggested by previous research, ${ }^{38}$ the ordering of health and non-health attributes was varied across the different versions of the experiment. The monetary and time cost attributes were always presented last, because this is regarded the most realistic place for a cost attribute in DCEs. ${ }^{38}$

After completion of the choice tasks respondents were asked how difficult they perceived the choice task on a 5-point scale ranging from very easy to very difficult. Respondents were also asked to indicate any other consequences of lifestyle change not being included in the choice task, which they considered while making the choices. The final questionnaire, which is available upon request from the authors, was piloted $(n=7)$ to assess understandability and possible ambiguity in interpretations. This led to minor adaptations of survey layout, and wording of questions and instructions. 
Table 5.2 Example choice task

\begin{tabular}{lll}
\hline & Situation A & Situation B \\
\hline Future health state: start point and value & in 2 years $\rightarrow 0.8$ & in 5 years $\rightarrow 0.7$ \\
Life expectancy & I become 81 years & I become 80 years \\
Clothing size & $1 / 2$ size above my ideal & 1 size above my ideal \\
Sufficient relaxation & $2-3$ days per week & $0-1$ days per week \\
Endurance & good & modest \\
$\begin{array}{l}\text { Experienced control over lifestyle choices } \\
\text { Lifestyle improvement potential }\end{array}$ & some & little \\
partner/children & no & yes \\
$\begin{array}{l}\text { I spend on lifestyle change: } \\
\quad \text { Time }\end{array}$ & & \\
$\quad$ Money & 6 hours per week & 4 hours per week \\
\hline
\end{tabular}

Which situation do you prefer?

\section{Data collection and participants}

Respondents were recruited from participants of the HPS. The HPS started in February 2008 and included men and women aged between 30 and 50 years living in the semirural region of West-Friesland in the Netherlands. Study participants had an increased risk for type 2 diabetes and/or cardiovascular disease. They were selected by means of a two-step screening procedure, which is described in more detail elsewhere. ${ }^{19}$ Participants included in the study were randomly assigned to an intervention and control group. The intervention group received a theory-based cognitive behavioral program delivered by trained practice nurses applying counseling techniques of motivational interviewing and problem solving treatment. The control group received written information about their risk of developing type 2 diabetes and cardiovascular disease, and existing brochures containing guideline recommendations for a healthy diet and physical activity as well as advice on smoking cessation. ${ }^{19}$

Invitations for participation in the present study were mailed to all participants still included in the HPS cohort in June $2010(n=515)$. In this sample, intervention $(49.3 \%)$ and control group were equally distributed (50.7\%). Participants with known e-mail addresses $(n=499)$ also received an invitation by e-mail including a direct link to the survey. Participants who did not complete the survey nor indicated that they did not wish to participate received a reminder after one week and in case of non-response a second reminder after two weeks. Ethical approval for this research was granted by the VU University Medical Centre Research Ethics Committee. 


\section{Data analyses}

The discrete choice data were analyzed using Nlogit Version 4. The effect of changes in attribute levels on consumer preferences was initially estimated by means of a multinomial logit (MNL) model. Using this model we tested for hypothesized interactions between attributes (see Table 5.1) and interactions between attributes and intervention experience, socio-demographics and attribute ordering. To account for the panel nature of the data and allow for possible preference heterogeneity across respondents a random parameter logit (RPL) model was estimated. ${ }^{22}$ First, the RPL model was estimated with the constant term as only random parameter. This is a common way of capturing heterogeneity in repeated measures or panel data ${ }^{39}$ and provides a test for left-to-right bias (i.e. the tendency to consistently choose either the first or second alternative in the choice task). Since respondents differed regarding their free time and available income, it is likely that their preferences for investing time and money for lifestyle change differ as well. So, an RPL model including additional random parameters for the attributes time and money was also estimated. Finally, we estimated an RPL model including additional random parameters for the attribute clothing size above ideal, because respondents disagreed most on the importance of this attribute during qualitative interviews and focus groups.

For all three models the estimation was conducted using 2000 Halton draws. The random parameter of the constant was drawn from a normal distribution. All other random parameters were drawn from a constrained triangular distribution. Following recommendations in the literature effects coding was applied for categorical attributes. ${ }^{23,40,41}$ Linear coding was used for the attributes time per week [( 0 hours $\left.=0\right)$, ( 2 hours $=2)$, ( 4 hours $=4)$, ( 6 hours $=6)$ ] and money per month spend on lifestyle change $[(€ 0=0),(€ 25=0.25),(€ 50=0.5),(€ 100=1)]$. To investigate the relative impact of each attribute on the utility respondents derived from the alternatives, we calculated willingness to pay (WTP) estimates based on marginal rates of substitution (MRS) between the cost attribute and all other attributes. ${ }^{42}$ Confidence intervals for WTP values were derived using the Delta method. ${ }^{43}$

\section{Results}

In total 273 respondents (53\%) completed the DCE survey. The majority had performed all 16 choice tasks $(n=264)$. Nine respondents did not fully complete the choice tasks, leading to 42 missing observations. The 16 different versions of the survey were spread fairly evenly across respondents. Most versions $(n=14)$ were completed by 13 to 20 respondents and two versions were completed by 23 and 24 respondents, respectively. 
A summary of respondent background characteristics is presented in Table 5.3. As can be seen from this table, responders were similar to non-responders.

Table 5.3 Background characteristics of responders and non-responders

\begin{tabular}{|c|c|c|}
\hline \multirow[b]{2}{*}{ Characteristic } & \multicolumn{2}{|c|}{$\mathrm{N}$ (valid \%) } \\
\hline & Responders $(n=273)$ & Non-responders $(n=242)$ \\
\hline \multicolumn{3}{|l|}{ Intervention experience } \\
\hline yes & $132(48.4)$ & $122(50.4)$ \\
\hline \multicolumn{3}{|l|}{ Gender } \\
\hline female & $163(59.7)$ & $132(55.0)$ \\
\hline \multicolumn{3}{|l|}{ Age } \\
\hline $30-39$ & $33(12.1)$ & $33(13.6)$ \\
\hline $40-49$ & $140(51.3)$ & $145(60.0)$ \\
\hline $50-59$ & $100(36.6)$ & $64(26.4)$ \\
\hline \multicolumn{3}{|l|}{ Household income (net/month) } \\
\hline low $(\leq € 1100)$ & $13(4.8)$ & - \\
\hline middle $(\leq € 3500)$ & 79 (28.9) & - \\
\hline high $(>3500)$ & $135(49.5)$ & - \\
\hline do not want to tell & $46(16.8)$ & - \\
\hline \multicolumn{3}{|l|}{ Work situation } \\
\hline having paid work & $233(85.4)$ & $211(88.3)$ \\
\hline \multicolumn{3}{|l|}{ Living circumstances } \\
\hline Living alone & $17(6.2)$ & $14(5.9)$ \\
\hline Living with partner & $36(13.2)$ & $24(10.1)$ \\
\hline Living with child(ren) & $13(4.8)$ & $12(5.0)$ \\
\hline Living with partner and child(ren) & $207(75.8)$ & $188(79.0)$ \\
\hline EQ5D health state utility (mean; SD) & $0.89(0.137)$ & $0.92(0.132)$ \\
\hline
\end{tabular}

Notes: Background characteristics of non-responders were derived from questionnaire data collected at baseline of the HPS. Several items of the HPS questionnaire differed from items used in the present study. Hence, income data were not comparable.

Table 5.4 provides a comparison of model fit across the alternative models that were estimated. The Likelihood ratio (LR) test shows that the MNL model including parameters for the attributes has significantly more explanatory power than the constant only model. This indicates that the attributes contribute to the capability of the model to predict choices of respondents. The RPL model with the constant term as only random parameter in turn performed significantly better than the MNL model, demonstrating the presence of preference heterogeneity. Even when adjusting for the loss of degrees of freedom that occurs when a model is expanded, the RPL model performed best. This appears from reductions in the Akaike information criterion (AIC) and Bayesian information criterion (BIC) ${ }^{44}$ (see Table 5.4). 
Specifying additional random parameters did not significantly improve the model fit. Hence, the RPL model with the constant term as only random parameter was used to estimate the effect of the attributes on consumer choices. We only present results of the main effects RPL model here, as most of the tested interaction terms were nonsignificant and including significant interactions did not improve the model.

Table 5.4 Goodness-of-fit statistics for alternative models

\begin{tabular}{llllll}
\hline Summary statistics & PseudoR $^{2}$ & Log-likelihood & $X^{2}$ LL ratio-test (df) & AIC & BIC \\
\hline RPL clothing size above ideal & 0.169 & -2490.799 & $1.24(3)$ & 1.16 & 1.20 \\
RPL time and money & 0.170 & -2489.131 & $5.16(2)$ & 1.16 & 1.20 \\
RPL constant & 0.169 & -2491.71 & $74.14(1)^{*}$ & 1.16 & 1.20 \\
MNL & 0.157 & -2528.78 & $939,49(24) *$ & 1.18 & 1.22 \\
Constant only & - & -2998.53 & - & 1.39 & 1.39 \\
\hline
\end{tabular}

Notes: The constant only MNL model was used as null model for Pseudo R2; $x 2$ LL ratio-test statistic is presented for comparisons with the next less sophisticated model; *exceeds critical value for $\alpha=0.05$.

The health outcome attributes future health state and life expectancy significantly determined consumer choices in the expected direction (Table 5.5). Furthermore, all non-health outcomes attributes (i.e. clothing size above ideal, days with sufficient relaxation, endurance and experienced control over lifestyle choices), spillover effects to partner/children as well as the monetary cost attribute had a significant impact on consumer choices. Two attributes were found to be non-significant. These were start point of the future health state and time per week required for lifestyle behavior change. Estimates of willingness to pay (WTP) for changes in attribute levels obtained from MRS are displayed in Table 5.5. They show that the endurance attribute had the largest impact on utility respondents derived from alternative post lifestyle change situations. For an improvement from 'poor' to 'very good' endurance respondents were willing to trade $€ 298.94$ per month and for an improvement from poor to modest endurance respondents were willing to trade $€ 159.75$ per month. The attribute days with sufficient relaxation had the second largest impact on utility, with respondents being willing to trade $€ 117.98$ per month for an increase from $0-1$ to $6-7$ days with sufficient relaxation per week. The attribute future health state value is on third place with respondents being willing to trade $€ 110.85$ per month for an improvement of the future health state value from 0.5 to 1.0. WTP for changes in life expectancy was relatively low. Respondents were willing to pay $€ 31.98$ per month for an increase in life expectancy from 80 to 83 years. For smaller increases in life expectancy respondents were not willing to trade. 


\section{Validity of the findings}

The majority of respondents (97\%) filled in the DCE survey completely. However many respondents perceived the choice tasks as difficult or very difficult (59.1\%), which raises the question whether respondents gave valid answers. Theoretical validity was tested by examining signs and significance levels of parameter estimates. With the exception of the attribute start point of future health state and time per week all attributes significantly determined choices (see Table 5.5). Generally, attributes in the estimated utility function behaved in line with a priori expectations (see hypothesized direction of preferences in Table 5.1). There was only one exception. We found that a reduction in clothing size to zero sizes above ideal was somewhat less preferred than a reduction to half a size above ideal.

Interactions between respondents' income and the two cost attributes also provided support for the validity of our findings. As could be expected, a higher income was associated with a less negative preference for an increase in money respondents had to spend per month on lifestyle behavior change $(\beta=0.423, t=3.173)$. As the time cost attribute itself, the interaction between income and time spent on lifestyle change per week was non-significant $(\beta=0.003, t=0.140)$. Tested interactions between trial arm and attributes (data not shown) did not provide clear evidence for differences in preferences between members of the intervention and control group of the HPS. Tested interactions between the ordering variable and the attributes (data not shown) indicated that attribute ordering did not systematically affect the relative importance of the attributes.

The constant term was not significant, which suggests that, on average, respondents considered the attributes described in the choice task and did not simply choose the same alternative repeatedly. In concordance with this finding, qualitative data from open questions suggest that only three respondents did not trade between all attributes. One of them did not trade in order to simplify the choice task, but the other two respondents behaved rationally. They only considered attributes they found personally relevant. So, their choices reflect actual preferences. Qualitative data also suggest that only few respondents considered additional attributes not included in the experiment. These were personal attainability on the long term $(n=1)$, the possibility to have a comfortable way of life without the need to consider all sorts of things $(n=1)$, current health state $(n=2)$ and more specific outcomes for respondents' partner and/or children $(n=3)$. In line with recommendations in the literature we did not remove respondents from the analyses based on their decision strategies. ${ }^{45}$ 
Table 5.5 Results from the main effects RPL model

\begin{tabular}{|c|c|c|c|c|}
\hline \multirow{2}{*}{ Attribute } & \multirow{2}{*}{ Coefficient } & \multirow[t]{2}{*}{ SE } & \multicolumn{2}{|c|}{ WTP (in € per month) } \\
\hline & & & Mean & CI \\
\hline \multicolumn{5}{|l|}{ Random parameters: } \\
\hline Constant & 0.000 & 0.050 & - & - \\
\hline SD & $0.578+$ & 0.055 & & \\
\hline \multicolumn{5}{|l|}{ Non-random parameters: } \\
\hline \multicolumn{5}{|l|}{ Future health state value } \\
\hline 0.5 (referent) & - & - & - & - \\
\hline 0.7 & -0.042 & 0.056 & $45.54 *$ & $9.96-81.12$ \\
\hline 0.8 & 0.029 & 0.056 & $59.82+$ & $17.98-101.65$ \\
\hline 1.0 & $0.283+$ & 0.056 & $110.85+$ & $67.98-153.71$ \\
\hline \multicolumn{5}{|c|}{ Start point of future health state } \\
\hline in 2 years (referent) & - & - & - & - \\
\hline in 5 years & 0.008 & 0.040 & 16.77 & $-8.39-41.94$ \\
\hline in 10 years & 0.064 & 0.040 & 27.92 & $-1.15-56.98$ \\
\hline in 20 years & 0.003 & 0.041 & 15.63 & $-10.54-41.80$ \\
\hline \multicolumn{5}{|l|}{ Life expectancy } \\
\hline 80 years (referent) & - & - & - & - \\
\hline 81 years & 0.006 & 0.043 & 13.85 & $-11.82-39.52$ \\
\hline 82 years & -0.039 & 0.040 & 4.86 & $-23.09-32.81$ \\
\hline 83 years & $0.096 *$ & 0.041 & $31.98 *$ & $6.28-57.68$ \\
\hline \multicolumn{5}{|l|}{ Clothing size above ideal } \\
\hline 2 sizes (referent) & - & - & - & - \\
\hline 1 size & 0.017 & 0.042 & $56.67+$ & $29.20-84.13$ \\
\hline $1 / 2$ size & $0.130+$ & 0.041 & $79.29+$ & $44.04-114.53$ \\
\hline 0 sizes & $0.118+$ & 0.039 & $77.01+$ & $46.05-107.97$ \\
\hline \multicolumn{5}{|l|}{ Days with sufficient relaxation } \\
\hline 0-1 per week (referent) & - & - & - & - \\
\hline 2-3 per week & -0.059 & 0.040 & $53.68+$ & $26.63-80.73$ \\
\hline 4-5 per week & $0.125+$ & 0.041 & $90.61+$ & $55.11-126.11$ \\
\hline 6-7 per week & $0.261+$ & 0.041 & $117.98+$ & $82.05-153.91$ \\
\hline \multicolumn{5}{|l|}{ Endurance } \\
\hline poor (referent) & - & - & - & - \\
\hline modest & $-0.130+$ & 0.040 & $159.75+$ & $114.04-205.46$ \\
\hline good & $0.491+$ & 0.039 & $284.26+$ & $211.12-357.39$ \\
\hline very good & $0.564+$ & 0.041 & $298.94+$ & $223.55-374.32$ \\
\hline \multicolumn{5}{|l|}{$\begin{array}{l}\text { Experienced control over } \\
\text { lifestyle choices }\end{array}$} \\
\hline little (referent) & - & - & - & - \\
\hline some & -0.021 & 0.039 & 22.86 & $-1.91-47.63$ \\
\hline moderate & 0.009 & 0.044 & 28.88 & $-3.02-60.78$ \\
\hline much & $0.146+$ & 0.041 & $56.22+$ & $28.07-84.37$ \\
\hline \multicolumn{5}{|c|}{$\begin{array}{l}\text { Lifestyle improvement of potential } \\
\text { partner/children }\end{array}$} \\
\hline no (referent) & - & - & & - \\
\hline yes & $0.181+$ & 0.018 & $72.75+$ & $50.48-95.03$ \\
\hline Time per week & 0.004 & 0.010 & 0.85 & $-3.22-4.91$ \\
\hline Money per month & $-0.498+$ & 0.063 & - & - \\
\hline
\end{tabular}

${ }^{*} p<0.05,+p<0.01$ 


\section{Discussion}

The present DCE study provides evidence that, in the context of lifestyle behavior change, consumers of health promotion are concerned with a broader number of benefits than health benefits only. In addition to the health outcome attributes life expectancy and future health state value, the following non-health outcome attributes significantly influenced consumer choices: clothing size above ideal, the number of days with sufficient relaxation, endurance and the degree of experienced control over lifestyle choices. Lifestyle changes that occur in consumer's partners and/or children were also found to significantly influence consumer choices. This is concordant with earlier research by Basu \& Melzer (2005), ${ }^{46}$ suggesting that spillover effects to family members affect patient preferences. Additional qualitative data provided by respondents in the present study suggest that consumers value spillover effects because they provide both health and non-health effects to their loved ones. But more targeted research is needed to unravel why individual consumers value spillover effects.

Overall, we found that health and non-health improvements in health promotion outcomes both influenced consumer choices. Marginal rates of substitution between the price attribute and other attributes revealed that consumers' WTP for non-health outcomes and spillover effects was in a similar range as WTP for health outcomes. This finding suggests that consumers attach value to outcomes that are not captured by economic evaluation studies using EQ-5D based QALYs as outcome measure. It also has important implications for HP practice. Since consumers attach value to non-health outcomes, emphasizing non-health benefits in HP interventions may increase uptake and motivation for behavior change.

Respondents were willing to pay most for improvements in endurance, second most for an increase in days with sufficient relaxation and third most for improvements in future health state value. Willingness to pay for life expectancy was relatively low and for increases smaller than three years respondents were not willing to trade. This finding confirms results of a recent Norwegian study, showing that people attach little value to small gains in life expectancy. ${ }^{47}$

This study also investigated the impact of costs induced by lifestyle behavior change. As expected, respondents had a lower preference for situations with higher monetary costs than for situations with lower monetary costs. It was striking however, that time investment for lifestyle change did not influence consumer choices, since consumers reported time investment as an important negative consequence of and barrier to lifestyle behavior change during interviews conducted prior to the choice experiment. It is possible that although time investment was not relevant on average, latent classes of respondents can be distinguished: one consisting of respondents who are willing to 
invest time for lifestyle change and second one consisting of respondents who are averse to do so.

A number of limitations of this study are worth mentioning. First, we defined health outcomes as pertaining to life expectancy and EQ-5D health state dimensions. While this definition represents current economic evaluation practice, health outcomes could also be defined in a broader fashion. Additionally, we can't preclude the possibility that there is a relation or overlap between the non-health outcomes examined and EQ-5D dimensions (e.g. between endurance and the mobility dimension of the EQ-5D). More research is required to disentangle relationships between the different outcomes produced by HP interventions and to clarify definitions of health, non-health and process outcomes.

Second, the study sample consisted of participants in a lifestyle intervention trial aged between 30 and 50 years. Therefore, the study results may not be generalized to regular consumers of HP, other HP interventions or other age groups.

Third, due to the generic context used in the study, preferences towards outcomes of lifestyle behavior change were assessed without considering the process by which outcomes are produced. Respondents may value outcomes differently depending on whether these are produced by for instance physical activity or dietary changes.

Fourth, by not including an opt-out option in the choice task, we implicitly assumed that respondents would always choose to make lifestyle changes. This may not be realistic and limits the possibility to use our findings to predict adoption of lifestyle changes and participation in HP interventions. ${ }^{22,37}$

Fifth, although attributes in the estimated discrete choice model significantly contribute to the prediction of consumer choices, the explanatory power of the model was only moderate with a Pseudo $\mathrm{R}^{2}$ of 0.17 . According to Hensher et al. (2005) ${ }^{23}$ a decent $\mathrm{R}^{2}$ would be around 0.3 . The moderate explanatory power may be due to the fact that we failed to include some key attributes having an impact on consumer choices. It is natural that a DCE cannot cover every attribute that is important to every respondent, because it generates a model of preferences over a group. ${ }^{45}$ Additional qualitative data suggest, however, that only few respondents considered omitted attributes. The low model fit may also be caused in part by scale heterogeneity in the data set (i.e. choice behavior of some respondents is more random than that of others). ${ }^{48}$ In situations, where scale heterogeneity is important the RPL model is likely to provide suboptimal approximation of discrete choice data. Hence, alternatives have been proposed describing heterogeneity either as pure scale effect or using a Generalized MNL model, which can accommodate both scale and residual taste heterogeneity. ${ }^{48}$ The application of such models should be tested in future research, as it may yield a more accurate representation of the data and a better model fit. Recent research suggests, however, 
that failure to account for taste heterogeneity has greater consequences for behavioral outputs, such as willingness to pay, than failure to account for scale heterogeneity. ${ }^{49}$ Finally, we used qualitative levels for two non-health attributes that were difficult to quantify (i.e. endurance and experienced control). If not well defined, qualitative levels may be interpreted differently by respondents. ${ }^{21}$ Overall qualitative attributes behaved in line with a priori expectations in this study. Further testing is needed, however, to optimize description of non-health attributes in the future. Quantifying non-health outcomes is a challenging task, which has so far received little attention and needs further exploration. ${ }^{15}$

Discrete Choice Experiments only provide stated preference data. Therefore it would be helpful for cross-validation to collect additional revealed preference data on actual lifestyle choices of consumers. Such research is challenging and rare in the health sector, but out-of-pocket payments for lifestyle changes make it possible. ${ }^{50}$

\section{Conclusion}

The present study used a discrete choice experiment to explore consumer preferences for different outcomes of lifestyle behavior change. The findings show that previously identified non-health outcomes and spillover effects of lifestyle behavior change were as important to participants of a HP intervention trial as health outcomes. This has potentially important implications for decision makers, who should respond to consumer preferences and consider relevant non-health outcomes and spillover effects when deciding about health promotion interventions. Non-health outcomes and spillover effects could either be incorporated directly within economic evaluations or considered as separate source of evidence during the appraisal phase of the decision-making process. Future research needs to provide insights into relevant non-health outcomes and spillover effects in other application areas of HP and test methods to account for them in decision-making. 


\section{References}

1. Ottawa Charter for Health Promotion. WHO/HPR/HER/95.1. Geneva: World Health Organization, 1986.

2. Rootman I, Goodstadt M, Potvin $L$, et al. A framework for health promotion evaluation. In: Rootman I, Goodstadt M, Hyndman B, et al., eds., Evaluation in health promotion: Principles and perspectives. Copenhagen: WHO 2001.

3. Smith RD, Petticrew M. Public health evaluation in the twenty-first century: time to see the wood as well as the trees. Journal of Public Health 2010;32:2-7.

4. Eriksson C. Learning and knowledge-production for public health: a review of approaches to evidence-based public health. Skandinavian Journal of Public Health 2000;28:298-308.

5. Lorgelly PK, Lawson KD, Fenwick EAL, et al. Outcome measurement in economic evaluations of public health interventions: a role for the capability approach?. International Journal of Environmental Research and Public Health 2010;7:2274-89.

6. Weatherly $\mathrm{H}$, Drummond $\mathrm{M}$, Claxton $\mathrm{K}$, et al. Methods for assessing the cost-effectiveness of public health interventions: Key challenges and recommendations. Health Policy 2009;93: 85-92.

7. Chalkidou K, Culyer A, Naidoo B, et al. Cost-effective Public Health Guidance: Asking questions from the Decision-Maker's viewpoint. Health Economics 2008;17:441-48.

8. Lipscomb J, Drummond M, Fryback D, et al. Retaining, and Enhancing, the QALY. Value in Health 2009;12 (Supplement 1): S18-S26.

9. Ryan M. Using conjoint analysis to take account of patient preferences and go beyond health outcomes: an application of in vitro fertilisation. Social Science \& Medicine 1999;48:535-46.

10. Drummond M, Sculpher MJ, Torrance GW, et al. Methods for the Economic Evaluation of Health Care Programmes New York: Oxford University Press, 2005.

11. Sassi F. How to do (or not to do)...Calculating QALYS, comparing QALY and DALY calculations. Health Policy and Planning 2006;21:402-08.

12. Rissel C. Empowerment: the holy grail of health promotion? Health Promotion International 1994;9:39-47.

13. Peerson A, Saunders M. Health literacy revisited: what do we mean and why does it matter? Health Promotion International 2009;24:285-95.

14. World Health Organization. Health Promotion Glossary. Geneva, 1998.

15. Borghi J, Jan S. Measuring the benefits of health promotion programmes: Application of the contingent valuation method. Health Policy 2008;87:235-48.

16. Liamputtong P, Haritavorn N, Kiatying-Angsulee N. HIV and AIDS, stigma and AIDS support groups: Perspectives from women living with HIV and AIDS in central Thailand. Social Science \& Medicine 2009;69:862-68.

17. Roux L, Ubach C, Donaldson C, et al. Valuing the Benefits of Weight Loss Programs: An Application of the Discrete Choice Experiment. Obesity Research 2004;12:1342-51.

18. Owen $\mathrm{K}$, Pettman $\mathrm{T}$, Haas $\mathrm{M}$, et al. Individual preferences for diet and exercise programmes: changes over a lifestyle intervention and their link with outcomes. Public Health Nutrition 2009;13:245-52.

19. Lakerveld J, Bot DM, Chinapaw MJ, et al. Primary prevention of diabetes mellitus type 2 and cardiovascular diseases using a cognitive behavior program aimed at lifestyle changes in people at risk: Design of a randomized controlled trial. BMC Endocrine Disorders 2008;8:1-11.

20. De Bekker-Grob E, Ryan M, Gerard K. Discrete choice experiments in health economics: A review of the literature. Health Economics 2012;21:145-72.

21. Ryan M, Gerard K, Amaya-Amaya M. Using Discrete Choice Experiments to Value Health and Health Care Dordrecht Springer, 2008.

22. Lanscar E, Louviere J. Conducting Discrete Choice Experiments to Inform Healthcare Decision Making: A User's Guide. Pharmacoeconomics 2008;26:661-67.

23. Hensher DA, Rose JM, Greene WH. Applied Choice Analysis: A Primer. New York: Cambridge University Press, 2005. 
24. Centraal Bureau voor de Statistiek. Statline Kerncijfers. Available from: http://cbs.nl/nl-NL/ menu/cijfers/statline/zelf-tabellen-maken/default.htm. [Accessed March 5, 2010].

25. Franco $\mathrm{OH}$, de Laet $\mathrm{C}$, Peeters $\mathrm{A}$, et al. Effects of Physical Activity on Life Expectancy with Cardiovascular Disease. Archives of Internal Medicine 2005;165:2355-60.

26. Lloyd A. The extent of patients' understanding of risk of treatments. Quality in Health Care 2001; 10:i14-i18.

27. Rabin R, de Charro F. EQ-5D: a measure of health status from the EuroQol Group. Annals of Medicine 2001;33:337-43.

28. Brazier J, Ratcliffe J, Salomon JA, et al. Measuring and Valuing Health Benefits for Economic Evaluation. New York: Oxford University Press, 2007.

29. Szende A, Oppe M, Devlin N. EQ-5D value sets: Inventory, comparative review and user guide. Dordrecht: Springer 2007.

30. Street DJ, Burgess L. The construction of optimal stated choice experiments. New Jersey: John Wiley \& Sons, 2007.

31. Kuhfeld WF. Orthogonal Arrays. Available from: http://support.sas.com/ techsup/ technote/ts723.html. [Accessed February 1, 2010].

32. Burgess L. Discrete Choice Experiments [computer software] Department of Mathematical Sciences, University of Technology, Sydney. Available from: http://crsu.science.uts.edu.au/ choice/ 2007. [Accessed March 12 ${ }^{\text {th }}, 2010$ ]

33. Bech M, Kjaer T, Lauridsen J. Does the number of choice sets matter? Results from a web survey applying a discrete choice experiment. Health Economics 2011;20:273-86.

34. Hensher DA, Stopher PR, Louviere JJ. An exploratory analysis of the effect of numbers of choice sets in designed choice experiments: an airline choice application. Journal of Air Transport and Management. 2001;7:373-79.

35. Carlsson F, Martinsson P. How much is too much? An investigation of the effect of the number of choice sets, starting point and the choice of bid vectors in choice experiments. Working Papers in Economics no 91. 2006: Department of Economics, School of Business, Economics and Law, Göteborg University.

36. Couper MP, Traugott MW, Lamias MJ. Web Survey Design and Administration. Public Opinion Quarterly 2001;65:230-53.

37. Ryan M, Skåtun D. Modelling non-demanders in choice experiments. Health Economics 2004;13:397-402.

38. Kjær T, Bech M, Gyrd-Hansen D, et al. Ordering effect and price sensitivity in discrete choice experiments: Need we worry?. Health Economics 2006;15:1217-28.

39. King MT, Hall J, Lanscar $E$, et al. Patient preferences for managing asthma: results from a discrete choice experiment. Health Economics 2007;16:703-17.

40. Louviere J, Hensher DA, Swait JD. Stated Choice Methods: Analysis and Application. Cambridge Cambridge University Press, 2000.

41. Bech M, Gyrd-Hansen D. Effects coding in discrete choice experiments. Health Economics 2005;14:1079-83.

42. Lanscar E, Louviere J, Flynn T. Several methods to investigate relative attribute impact in stated preference experiments Social Science \& Medicine 2007;64:1738-53.

43. Hole AR. A comparison of approaches to estimating confidence intervals for willingness to pay measures. Health Economics 2007;16:827-40.

44. Greene W. Econometric Analysis Fifth Edition Upper Saddle River: Prentice Hall, 2002.

45. Lanscar E, Louviere J. Deleting 'irrational' responses from discrete choice experiments: a case of investigating or imposing preferences? . Health Economics 2006;15:797-811.

46. Basu A, Meltzer D. Implications of spillover effects withing the family for medical costeffectivenss analysis. Journal of Health Economics 2005;24:751-73.

47. Kvamme MK, Gyrd-Hansen D, Olsen JA, et al. Increasing marginal utility of small increases in life-expectancy? Results from a population survey. Journal of Health Economics 2010;29:54148.

48. Fiebig DG. The Generalized Multinomial Logit Model: Accounting for scale and coefficient heterogeneity. Marketing Science 2010;29:393-421. 
49. Greene $\mathbf{W H}$, Hensher DA. Does scale heterogeneity across individuals matter? An empirical assessment of alternative logit models. Transportation 2010;37:413-28.

50. Louviere J, Lanscar E. Choice experiments in health: the good, the bad, the ugly and toward a brighter future. Health Economics Policy and Law 2009;4:527-46. 


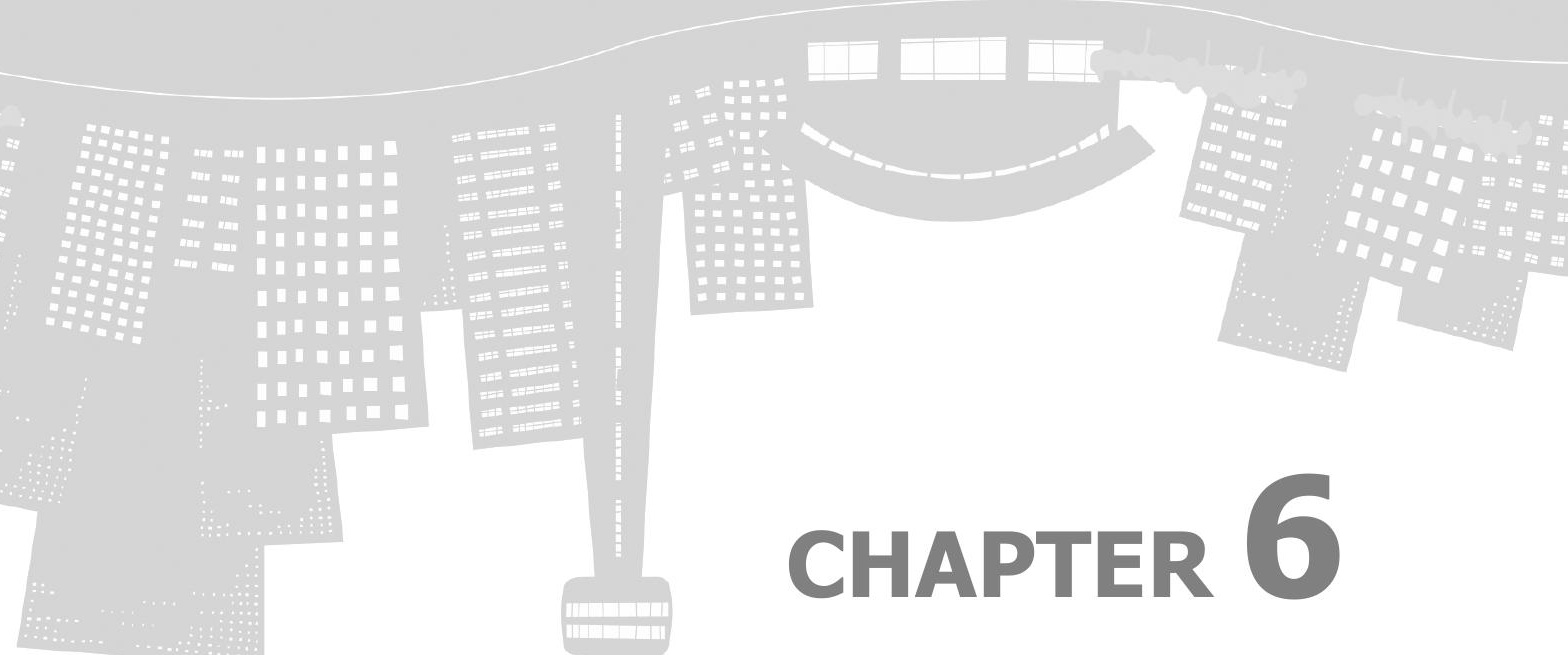

Consumer willingness to invest money and time for benefits of lifestyle behavior change: an application of the contingent valuation method

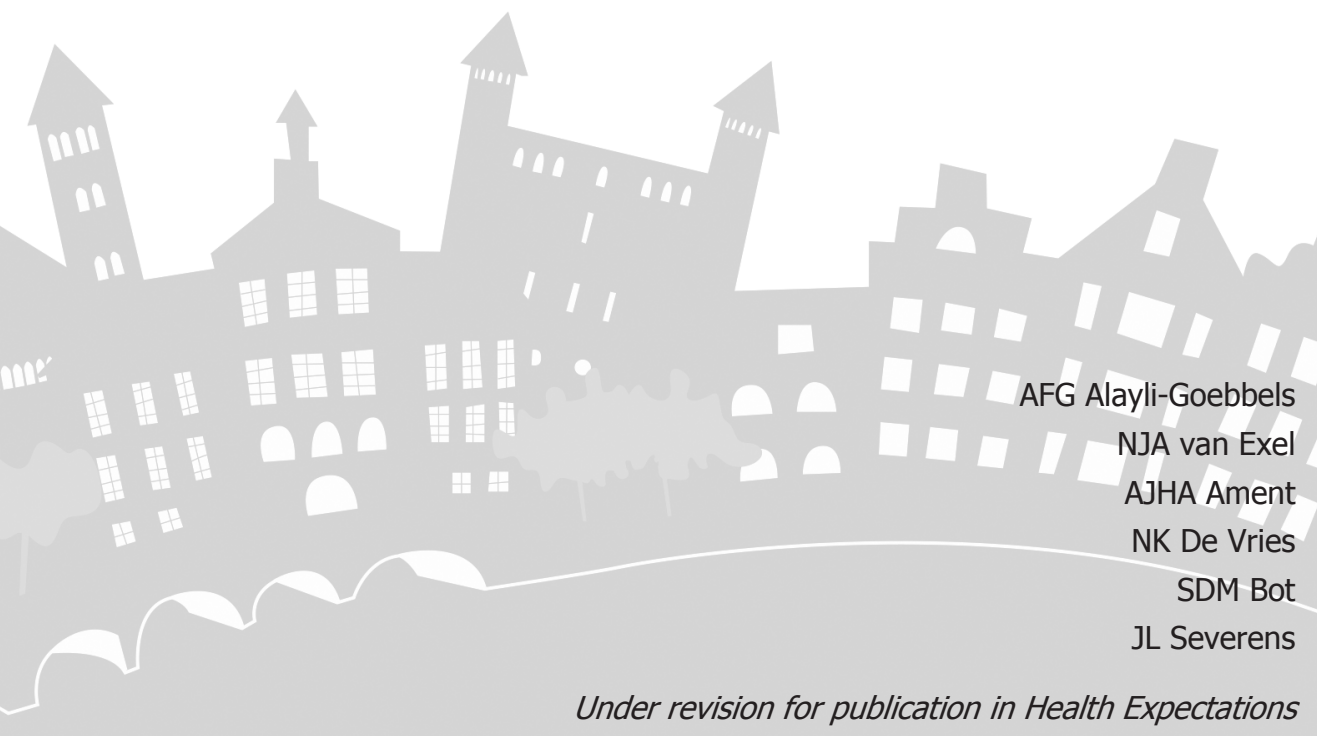




\section{Abstract}

\section{Objective}

To use contingent valuation (CV) to derive individual consumer values for both health and broader benefits of a public health intervention directed at lifestyle behavior change $(\mathrm{LBC})$, and to examine feasibility and validity of the method.

\section{Methods}

Participants of a lifestyle intervention trial $(n=515)$ were invited to complete an online CV survey. Respondents ( $n=312$ ) expressed willingness to invest money and time for changes in life expectancy, health-related quality of life (HRQOL) and broader quality of life aspects. Internal validity was tested for by exploring associations between explanatory variables (i.e. income, paid work, experience and risk factors for cardiovascular diseases) and willingness to invest, and by examining respondents' sensitivity to ordering and scope of the benefits presented.

\section{Results}

The majority of respondents (94.3\%) attached value to benefits of LBC and $87.4 \%$ were willing to invest both money and time. Respondents were willing to invest more for improvements in HRQOL ( $€ 42 /$ month; 3 hours/week) and broader quality of life aspects (€40/month; 2.6 hours/week) than for improvements in life expectancy (€24/month; 2 hours/week). Protest answers were limited (3\%) and findings regarding internal validity were mixed.

\section{Conclusion}

The importance of broader quality of life outcomes to consumers suggests that these outcomes are relevant to consider in decision-making. Our research showed that CV is a feasible method to value both health and broader outcomes of LBC, but generalizability to other areas of public health still needs to be examined. Mixed evidence regarding internal validity pleads for caution to use CV as only base for decision-making. 


\section{Introduction}

Economic evaluation studies provide insights into the relative costs and benefits of alternative intervention options and can be a useful tool for policy makers. ${ }^{1}$ They are increasingly used to support decisions about funding of clinical health interventions, including pharmaceuticals, medical devices and diagnostic or surgical procedures. ${ }^{2,3}$ For decision-making on public health, economic evaluations are hardly used yet, because procedures for decision-making in the field of public health are less well established ${ }^{(4)}$ and because the available economic evaluation evidence is limited, especially for public health interventions addressing wider social or economic determinants of health. ${ }^{3,5}$ The lack of economic evaluation studies can be attributed to both limited funding available to conduct these studies ${ }^{3}$ and the fact that evaluation methods are insufficiently developed to deal with the challenges posed by complex modern public health interventions. ${ }^{2,6-9}$

The wide range of benefits produced by public health interventions is one of the key challenges. Modern public health interventions do not only aim to improve health, but seek to impact also on broader aspects of quality of life and wellbeing. They aim for instance to empower people and increase their capacity to live a full and productive life by improving health literacy, self-awareness, stress management, problem solving skills and access to education. ${ }^{10-12}$ To achieve these broad objectives public health interventions address multiple factors on different operational levels. ${ }^{10,13,14}$ At the individual level educational interventions may be implemented to promote healthy lifestyle choices and enhance people's life skills. At the community level interventions may be directed at developing systems to strengthen public participation in health matters $^{12}$ and societal level interventions may address social, economic and environmental determinants of wellbeing by means of fiscal measures (e.g. alcohol tax), legislation (e.g. smoke free work place legislation) or organizational changes (e.g. changing food offerings in schools). ${ }^{14-16}$ The wide range of interventions also results in a wide range of benefits both inside and outside the domain of health for the individual, the community and society as a whole. ${ }^{17}$ Outcome measurement in economic evaluation however, tends to capture only individual benefits and focuses on health only.

Cost-effectiveness analyses, which have been most frequently used to evaluate public health interventions ${ }^{3}$, measure outcomes in a single unit of effect relevant for the interventions under evaluation, such as infections averted or life years saved. Intermediate outcomes (e.g. behavior change or cholesterol reduction) are also often used, which may or may not be translated to health outcomes using modeling. This approach is limited by the fact that it is not based on public or consumer preferences and allows only for comparison of interventions with the same type of (health) outcome. ${ }^{18}$ Therefore, cost-utility analyses are increasingly used, which measure 
intervention outcomes in Quality Adjusted Life Years (QALYs). QALYs incorporate changes in life expectancy and health-related quality of life in a single generic preference-based measure, allowing for comparisons across different health interventions. ${ }^{18}$ They are a useful measure when the objective is to maximize health, but they do not capture broader benefits for individual consumers or benefits that accrue to the wider social environment. ${ }^{2,6,19}$

Cost-benefit analysis (CBA) using Contingent Valuation (CV) to value outcomes in monetary terms, has been presented in the literature as a potential solution to capture intended broader benefits of public health. 2,20,21 The CV method is a survey-based technique eliciting willingness to pay (WTP) for non-market goods. It is rooted in welfare economic theory and has two major advantages: (a) it does not pose restrictions on the number and types of outcomes to be valued and (b) it provides a monetary value for intervention benefits, which allows for comparison with other societal sectors also using CBA frameworks to evaluate for example road safety measures or interventions to improve air quality. ${ }^{22-24}$

Despite these advantages, CV is not used much to support healthcare decision-making, due to uncertainty regarding the feasibility and ability of the method to derive valid WTP values. ${ }^{23,25,26}$ Respondents may have (ethical) objections against expressing monetary values for outcomes of health interventions and either refuse to complete the survey or give strategic answers, which do not reflect their true WTP (e.g. protest zeros). ${ }^{23}$ Another issue of concern is that respondents may not have clear and ready-made preferences for non-marketed goods. Hence, elicited WTP values are suggested to be both inconsistent and invalid. 27,28

The aim of this study was to apply the CV method to derive individual consumer values for both health and broader outcomes of a public health intervention directed at improving lifestyle behaviors, and to examine the feasibility and validity of the method.

\section{Methods}

A contingent valuation (CV) survey was conducted among participants of the Hoorn Prevention Study (HPS), a randomized controlled trial evaluating the effectiveness of a public health intervention aiming to change physical activity, smoking and dietary behaviors in adults with an increased risk for developing type 2 diabetes (T2D) and/or cardiovascular disease (CVD). ${ }^{29}$ Study participants were recruited from the semi-rural region of West-Friesland in the Netherlands and selected by means of a two-step screening procedure, which is described in more detail elsewhere. ${ }^{29}$ In February 2008 participants were randomly allocated to an intervention $(n=314)$ or a control group $(n=308)$. The intervention group received a theory-based cognitive behavioral program 
delivered by trained practice nurses using counseling techniques of motivational interviewing and problem solving treatment. The control group received written information about their risk of developing T2D and CVD, and existing brochures containing guideline recommendations for a healthy diet and physical activity, as well as advice on smoking cessation.

Participants still included in the HPS cohort $(n=515)$ in June 2010, were invited to complete the contingent valuation survey. Invitations were sent by mail and if e-mail addresses were available $(n=499)$ also by e-mail, including a direct link to the onlinesurvey. Non-responders received up to six reminders during the 6-week period after invitations were received. The VU University Medical Centre Research Ethics Committee granted approval for this research (Protocol no: 2007/107).

\section{The survey instrument}

An online survey format was used, because evidence suggests that survey-based CV studies have higher participation rates than personal interviews and are less likely to produce socially desirable answers than telephone interviews. ${ }^{30}$ The survey commenced with general background questions and an introduction about potential benefits of lifestyle behavior change (LBC). Benefits of LBC presented in the survey were based on literature and qualitative research among intervention group members of the Hoorn prevention study. ${ }^{19}$ They included benefits captured within the QALY framework (i.e. life expectancy and HRQOL) and broader quality of life aspects (i.e. changes in clothing size, relaxation, endurance and experienced control over lifestyle choices). HRQOL was defined according to the EQ-5D instrument, which is commonly used in economic evaluation studies, and includes the following five HRQOL dimensions: mobility, selfcare, usual activities, pain/discomfort and anxiety/depression.

After the introduction, respondents were presented with the CV exercise. As LBC may require both monetary (e.g. subscription in a gym) and time investments (e.g. hours spend on exercise), the CV exercise was designed to derive both maximum willingness to pay (WTP) and maximum willingness to invest time (WTIT) to achieve any or all of three types of potential benefits of LBC: life expectancy, HRQOL and broader quality of life.

Each respondent was presented with two scenarios (see Appendix 6.1). Scenario A elicited WTP and WTIT for one of the three types of benefits of LBC and Scenario B elicited WTP and WTIT for all benefits of LBC together. For Scenario A a split sample design was used, dividing respondents at random into the following three groups: Respondents valuing life expectancy benefits (Group 1), respondents valuing EQ-5D based HRQOL benefits (Group 2) and respondents valuing broader quality of life benefits 
(Group 3). To neutralize potential ordering effects, the order in which respondents received scenario $A$ and $B$ was also randomized.

WTP values were elicited by means of a payment scale, because this approach is regarded most appropriate for the health care context. ${ }^{23,31-33}$ Respondents were first asked to choose the maximum amount they would pay per month on LBC to achieve the presented benefits on a scale ranging from $€ 0$ to $>€ 250$. Between these boundaries, there were ten range categories, each increasing with $€ 25$. Respondents selecting one of the range categories were subsequently asked to indicate a more accurate maximum WTP. For example, if they had selected $€ 1-25$, they were asked to select the WTP amount closest to the amount they would maximally pay from the following options: $€ 1-5, € 6-10, € 11-15, € 16-20$ and $€ 21-25$. Payment scale values were based on market prices for gym subscriptions and WTP values for effective lifestyle interventions expressed by HPS participants during the previously mentioned qualitative research. ${ }^{19}$ Immediately after answering WTP questions, respondents were presented with a scale to elicit the maximum amount of time they would spend on LBC per week to achieve the same benefits. The scale ranged from 0 to $>10$ hours per week. Between these boundaries, there were ten range categories, each increasing with one hour. These categories were based on assumptions of the research team regarding a realistic maximum time investment.

Respondents expressing zero WTP and/or WTIT amounts were asked to indicate reasons using eight answer categories: (1) My household income does not allow me to pay more; (2) I already spend enough on lifestyle behavior change; (3) I find it more important to enjoy my life now than to have a good health in the future; (4) I would not succeed in achieving the described consequences anyway; (5) I find that the government should pay for this; (6) I find that my health insurance should pay for this; (7) I find that my employer should pay for this; (8) Other reason, please indicate. The survey instrument was piloted $(n=7)$ to assess understandability and acceptability of the questions. This led to minor adaptations of survey layout, wording and instructions.

\section{Data analyses}

The primary outcome variables in the analyses were WTP and WTIT values for scenarios A1, A2, A3 and B. To facilitate statistical data analyses categorical WTP and WTIT variables were transformed to continuous variables by recoding WTP and WTIT categories to category mean values. The upper boundary value of the WTP scale (>€250/month) was recoded to $€ 298 /$ month and the upper boundary value of the WTIT scale (>10 hours/week) was recoded to 11.75 hours/week. For lower boundaries of the WTP and WTIT scale (i.e. zero values), we assessed reasons provided by respondents, to distinguish between real and protest zero answers. Answer categories five to seven 
(see above) were always regarded as protest zero answers and for answer category eight open-ended responses were further examined.

Descriptive analyses were conducted to examine WTP and WTIT values for each scenario, their distributions and correlations with each other.

Concordance of WTP and WTIT values with economic theory was explored using three common tests of internal validity. We examined whether WTP and WTIT values were (1) sensitive to the scope of the benefits to be valued, whether they were (2) sensitive to the order in which benefits of LBC were presented to respondents and (3) whether associations between explanatory variables and WTP/WTIT were in line with theoretical expectations.

Sensitivity to scope was examined by comparing means of scenario A with means of scenario B for each split sample group. Wilcoxon Signed-Rank tests were used, because all WTP and WTIT values were non-normally distributed (Kolmogorov-Smirnov test: $\mathrm{P}<0.001)$. Ordering effects were tested for by performing stratified comparisons for respondents who received scenario $A$ and respondents who received scenario $B$ first.

To examine associations between explanatory variables and WTP/WTIT values three linear regression models were tested. The first model used basic background characteristics as predictors (see Table 6.1). Income was entered into the analyses as dichotomous variable with categories high income (high and middle high categories) and low income (low and middle low categories). Answers in the 'do not want to tell' income category were treated as missing values in the regression. It was hypothesized that a higher income is associated with a higher WTP. While differences in ability to pay are expected to translate into differences in WTP, this is not necessarily the case for WTIT. People with a limited ability to pay may for instance compensate a low WTP by means of a higher WTIT. As a proxy for availability of time, we used the variable paid work in the regression model. It was hypothesized that respondents who have paid work will express lower WTIT than respondents without paid work.

The second model used risk factors for developing T2D and CVD as predictors. These included the following variables: smoking status; having a parent with T2D; highly increased waist circumference; and elevated blood pressure. These variables were obtained from data collected for the baseline assessment of the HPS (performed by Lakerveld et al. $2008^{29}$ ) and consist of a combination of physical measurements and selfreport data. Cut-off values for waist circumference and blood pressure were based on national treatment guidelines of the Dutch College of General Practitioners (NHG). ${ }^{34,35}$ Our hypothesis was that WTP and WTIT would increase with presence of each of the risk factors in the model.

The third model used experience factors as predictors. Two of these were measured for the whole sample. They included the group into which respondents had been 
randomized (intervention vs. control group) and whether or not respondents had completed all follow up measurements of the HPS. The remaining four predictorvariables (i.e. respondent satisfaction with the counseling program, the number of faceto-face counseling sessions received, the number of booster phone counseling sessions received, and the extent to which respondents perceived counseling sessions as helpful regarding improving their lifestyle behaviors) were only measured for intervention group members and therefore entered into the model as interaction effects with the intervention group variable. The experience factor variables were obtained from data collected during the process evaluation of the HPS (see Lakerveld et al., 2012). ${ }^{36}$ It was hypothesized that WTP and WTIT would be higher for respondents who have positive previous experiences with the lifestyle behavior change intervention of the HPS. More specifically we expected that WTP and WTIT would increase with increases in satisfaction with the intervention and with perceiving the counseling as more helpful. The other predictor variables were only included to control for potential confounding.

To increase statistical power of the regression analyses WTP and WTIT values for the three A scenarios were combined in one variable. Two dummy variables were added to correct for the different A-scenarios. The outcome variables were transformed, because WTP and WTIT were non-normally distributed. Squared-root transformation approached the normal distribution better than log transformation and was therefore applied before the regression analyses. All data analyses were performed using SPSS 18.

\section{Results}

\section{Study participants}

Completed surveys were returned by 312 of the participants still enrolled in the HPS $(60.6 \%)$. From these we excluded respondents, who had missing values on the primary WTP or WTIT questions $(n=1,0.3 \%)$ or gave protest zero answers $(n=10,3.2 \%)$. Protest zero answers included two of the previously provided closed-ended answers: 'I find that the government should pay for this' $(n=6)$; 'I find that my health insurance should pay for this' $(n=6)$ and four additional open-ended answers: 'I find this a nonsensical question' $(n=1)$; 'I already pay enough for my health insurance' $(n=1)$; 'I don't understand what you want, I find the question indefinable' $(n=1)$; 'Yet another expenditure, I already pay like crazy for the health insurance premiums and do not get back for it since years' $(n=1)$. Exclusion of these respondents resulted in a final sample of 301 respondents for further analyses. Table 6.1 presents background characteristics of study participants and shows that the three split-sample groups for scenario A were comparable. 
Respondents included in this study were similar to non-responders with respect to background characteristics, risk factors and experience factors (data not shown). It is worth noting that even HPS participants who were not satisfied with the counseling program or did not complete all follow up measurements of the HPS have participated in this research ( $18.6 \%$ and $2.3 \%$ of included respondents respectively).

Table 6.1 Background characteristics of study participants

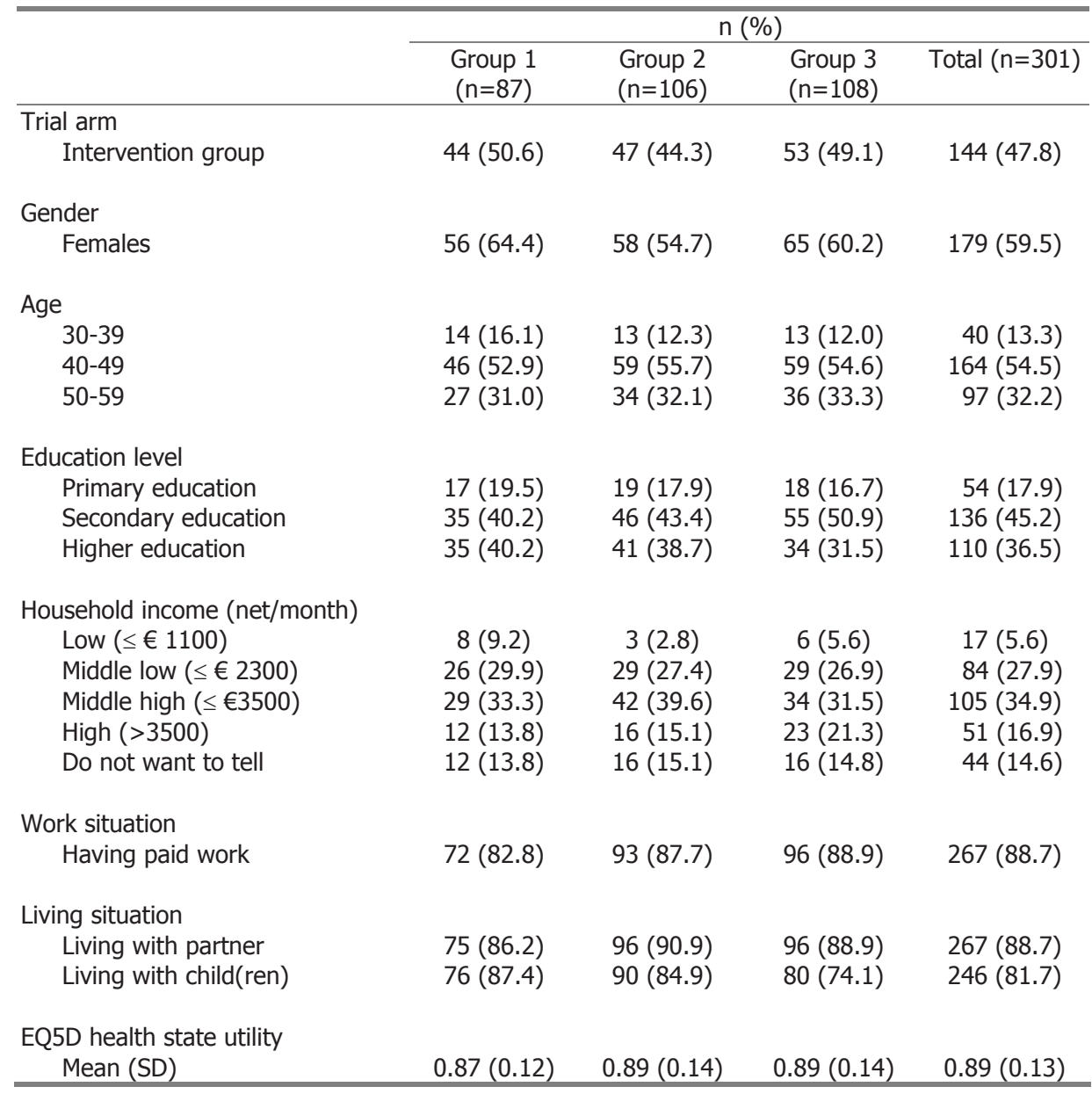

Notes: Group 1= Respondents valuing life expectancy benefits, group 2= respondents valuing EQ$5 \mathrm{D}$ based HRQOL benefits and group $3=$ respondents valuing broader quality of life benefits. Percentages for education level do not add up to $100 \%$ for group 3 and the total, because of missing values. 


\section{WTP and WTIT for benefits of LBC}

The majority of respondents attached at least some value to benefits of LBC: $94.3 \%$ of respondents $(n=284)$ were willing to pay either money or time and $87.4 \%$ of respondents $(n=263)$ were willing to pay both money and time for at least one of the two scenarios presented. Average WTP and WTIT values for scenario A and B in each split sample group are presented in Table 6.2. These show that respondents were willing to invest most for HRQOL benefits ( $€ 42 /$ month; 3 hours/week) and broader QOL benefits ( $€ 40 /$ month; 2.6 hours/week). For life expectancy benefits respondents were willing to invest considerably less ( $€ 24 /$ month; 2 hours/week). Zero answers were less frequent for WTIT (8.5-18.4\%) than for WTP (12.3-27.6\%) and less frequent for HRQOL outcomes and broader QOL outcomes than for life expectancy outcomes. Correlations between WTP and WTIT in all split sample groups consistently showed significant positive associations between WTP and WTIT (Spearman's $\rho$ ranged between 0.30 and $0.62)$.

\section{Scope sensitivity and ordering effects}

The results of the Wilcoxon Signed Rank Tests indicate that respondents were overall sensitive to differences in scope (see Table 6.2). For instance, respondents were willing to invest significantly more money and time for all benefits together (scenario B) than for only life expectancy (scenario A1) or broader QOL benefits (scenario A3). Differences were however not significant for the comparison of WTP and WTIT values between all benefits (scenario $B$ ) and HRQOL benefits (scenario A2).

Stratified analyses comparing subgroups of respondents receiving scenario A first and respondents receiving scenario $B$ first (not shown) suggest that WTP and WTIT answers were sensitive to the order in which outcomes were presented. When Scenario A was presented first, the differences in WTP and WTIT between the A scenarios and scenario $B$ became smaller and non-significant. The only exception was the difference in WTIT for scenario A2 (HRQOL outcomes) and scenario $B$, which became significant in this subgroup, suggesting a higher WTIT for scenario A2 than for scenario B. When Scenario $B$ was presented first, we found the opposite effect. The differences in WTP and WTIT between the A scenarios and scenario B became larger for all spilt sample groups. Significance of differences did not change in most cases. The difference between scenario $\mathrm{A} 2$ and scenario $\mathrm{B}$ is the only exception. It was non-significant in the analyses for the total sample (see Table 6.2) and became significant when Scenario B was presented first.

Given this evidence for ordering effects on a univariate level, we also included an ordering variable in the multivariate regression model testing associations of WTP and 
WTIT with background variables (see Table 6.3 and 6.4). This has the advantage of a larger sample size and allows controlling for other variables.

Table 6.2 Average willingness to invest money and time (SD) for outcomes of life style behavior change and Wilcoxon Signed-Rank tests comparing the A scenarios with scenario B

\begin{tabular}{llccccc}
\hline & & $\begin{array}{c}\text { Life } \\
\text { expectancy } \\
(\mathrm{A} 1)\end{array}$ & $\begin{array}{c}\text { HRQOL } \\
\text { EQ-5D based } \\
(\mathrm{A} 2)\end{array}$ & $\begin{array}{c}\text { Other QOL } \\
\text { aspects } \\
(\mathrm{A3})\end{array}$ & $\begin{array}{c}\text { All } \\
\text { outcomes } \\
(\mathrm{B})\end{array}$ & Test $(\mathrm{Z})$ \\
\hline Money per & Group 1 $(\mathrm{n}=87)$ & $23.90(27.89)$ & - & - & $35.03(43.03)$ & $3.20^{* *}$ \\
month ( $€$ ) & Group 2 $(\mathrm{n}=106)$ & - & $41.78(51.93)$ & - & $43.56(54.58)$ & 0.73 \\
& Group 3 $(\mathrm{n}=108)$ & - & - & $40.08(45.41)$ & $45.41(45.98)$ & $2.56^{*}$ \\
\hline & $\mathrm{n}(\%)$ real zeros & $24(27.59)$ & $13(12.26)$ & $15(13.89)$ & $48(15.95)$ & - \\
\hline Time per & Group 1 $(\mathrm{n}=87)$ & $1.98(1.80)$ & - & - & $2.57(2.29)$ & $3.36^{* *}$ \\
week (h) & Group 2 $(\mathrm{n}=106)$ & - & $3.00(2.45)$ & - & $2.69(2.26)$ & -1.62 \\
& Group 3 $(\mathrm{n}=108)$ & - & - & $2.63(2.17)$ & $2.89(2.26)$ & $1.98^{*}$ \\
\hline & $\mathrm{n}(\%)$ real zeros & $16(18.39)$ & $9(8.49)$ & $11(10.19)$ & $34(11.30)$ & - \\
\hline
\end{tabular}

*significant at the 0.05 level, $* *$ significant at the 0.01 level

\section{Results of the regression analyses}

The results of regression analysis using squared-root transformed outcomes were comparable to results of the analysis without transformed outcomes. Hence, for ease of interpretation we also present results of analyses with untransformed outcomes here. In line with our hypotheses, we found that WTP was positively associated with income (see Table 6.3). The dummies included to correct for the different Scenario A-groups were also significant, confirming that respondents were willing to pay more for outcomes in scenario A2 (HRQOL) and A3 (broader QOL) than for A1 (life expectancy). Three additional covariates had consistent significant associations with WTP (i.e. gender, age and education level) and two had significant associations, which were not consistent across all models tested (i.e. paid work and living with children).

The regression results provided limited support for our hypothesis that having paid work is associated with a lower WTIT (see Table 6.4). We found a negative association between paid work and WTIT across all models tested, the association was however only significant for Scenario $A$ in the model with the untransformed outcome variable. In concordance with the findings for WTP the dummies for the different Scenario A-groups are also significant for WTIT, suggesting that respondents are willing to invest significantly more time for HRQOL and broader QOL than for life expectancy. 
Table 6.3 Associations between background characteristics and WTP

\begin{tabular}{lcccccccc}
\hline & \multicolumn{3}{c}{ SQRT transformed } & \multicolumn{4}{c}{ Untransformed } \\
\cline { 2 - 9 } & \multicolumn{2}{c}{ WTP } & \multicolumn{2}{c}{ WTP } & \multicolumn{2}{c}{ WTP } & \multicolumn{2}{c}{ WTP } \\
& \multicolumn{2}{c}{ Scenario A } & \multicolumn{2}{c}{ Scenario B } & Scenario A & \multicolumn{2}{c}{ Scenario B } \\
\cline { 2 - 9 } & St. Coef. & S.E. & St. Coef. & S.E. & Coef. & S.E. & Coef. & S.E. \\
\hline Gender_female & $-0.22^{* *}$ & 0.42 & $-0.28^{* *}$ & 0.44 & $-17.21^{* *}$ & 5.80 & $-26.73^{* *}$ & 6.17 \\
Age & $0.12^{*}$ & 0.04 & $0.15^{*}$ & 0.04 & $1.28^{*}$ & 0.55 & $1.74 * *$ & 0.58 \\
Education_secondary & 0.12 & 0.59 & $0.20^{*}$ & 0.60 & 9.58 & 8.07 & 15.95 & 8.57 \\
Education_higher & $0.28^{* *}$ & 0.62 & $0.38^{* *}$ & 0.64 & $23.53^{* *}$ & 8.53 & $32.46 * *$ & 9.06 \\
Income_high & $0.14^{*}$ & 0.47 & $0.15^{*}$ & 0.49 & $12.98^{*}$ & 6.50 & $17.16^{*}$ & 6.91 \\
Paid work & -0.10 & 0.68 & $-0.07^{*}$ & 0.70 & $-22.22^{*}$ & 9.33 & $-21.70^{*}$ & 9.92 \\
Living with partner & 0.05 & 0.70 & 0.10 & 0.72 & 7.36 & 9.55 & 14.01 & 10.15 \\
Living with child(ren) & -0.06 & 0.56 & -0.12 & 0.58 & -9.13 & 7.71 & $-17.13^{*}$ & 8.20 \\
EQ5D utility & 0.01 & 1.60 & -0.09 & 1.67 & -1.68 & 21.99 & -38.82 & 23.38 \\
Intervention & -0.04 & 0.40 & -0.07 & 0.41 & -2.19 & 5.51 & -4.43 & 5.86 \\
Ordering & -0.10 & 0.41 & 0.03 & 0.42 & -7.55 & 5.63 & -1.93 & 5.98 \\
Group_A2 & $0.20 * *$ & 0.50 & 0.04 & 0.52 & $16.50^{*}$ & 6.89 & 5.41 & 7.32 \\
Group_A3 & $0.19 * *$ & 0.51 & 0.12 & 0.52 & $14.35^{*}$ & 6.95 & 9.28 & 7.39 \\
Constant (not standardized) & 0.62 & 2.37 & 1.95 & 2.45 & -17.69 & 32.64 & 1.40 & 34.70 \\
\hline F & $4.07 * *$ & $4.98^{* *}$ & $3.37 * *$ & $4.67 * *$ \\
\hline $\mathrm{R}^{2}$ adjusted & 0.14 & 0.17 & 0.11 & 0.16 \\
\hline
\end{tabular}

*significant at the 0.05 level, $* *$ significant at the 0.01 level

Table 6.4 Associations between background characteristics and WTIT

\begin{tabular}{|c|c|c|c|c|c|c|c|c|}
\hline & \multicolumn{4}{|c|}{ SQRT transformed } & \multicolumn{4}{|c|}{ Untransformed } \\
\hline & \multicolumn{2}{|c|}{$\begin{array}{c}\text { WTIT } \\
\text { Scenario A }\end{array}$} & \multicolumn{2}{|c|}{$\begin{array}{c}\text { WTIT } \\
\text { Scenario B }\end{array}$} & \multicolumn{2}{|c|}{$\begin{array}{c}\text { WTIT } \\
\text { Scenario A }\end{array}$} & \multicolumn{2}{|c|}{$\begin{array}{c}\text { WTIT } \\
\text { Scenario B }\end{array}$} \\
\hline & St. Coef. & S.E. & St. Coef. & S.E. & Coef. & S.E. & Coef. & S.E. \\
\hline Gender_female & -0.08 & 0.10 & -0.12 & 0.10 & -0.21 & 0.29 & -0.58 & 0.30 \\
\hline Age & -0.00 & 0.01 & 0.05 & 0.01 & 0.00 & 0.03 & 0.04 & 0.03 \\
\hline Education_secondary & 0.08 & 0.13 & 0.15 & 0.13 & 0.31 & 0.40 & 0.50 & 0.41 \\
\hline Education_higher & 0.13 & 0.14 & $0.24 *$ & 0.14 & 0.40 & 0.42 & 0.77 & 0.44 \\
\hline Income_high & 0.07 & 0.11 & -0.02 & 0.11 & 0.32 & 0.32 & 0.02 & 0.33 \\
\hline Paid work & -0.10 & 0.15 & -0.05 & 0.15 & $-0.92 *$ & 0.46 & -0.79 & 0.48 \\
\hline Living with partner & -0.01 & 0.16 & 0.02 & 0.16 & 0.03 & 0.47 & -0.13 & 0.49 \\
\hline Living with child(ren) & -0.01 & 0.13 & 0.01 & 0.13 & -0.28 & 0.39 & -0.03 & 0.40 \\
\hline EQ5D utility & -0.05 & 0.36 & -0.09 & 0.36 & -0.24 & 1.08 & -1.33 & 1.13 \\
\hline Intervention & -0.10 & 0.09 & -0.05 & 0.09 & -0.48 & 0.27 & -0.15 & 0.28 \\
\hline Ordering & $-0.17 * *$ & 0.09 & 0.05 & 0.09 & $-0.75^{*}$ & 0.28 & 0.03 & 0.29 \\
\hline Group_A2 & $0.26 * *$ & 0.11 & 0.04 & 0.11 & $1.13 * *$ & 0.34 & 0.14 & 0.35 \\
\hline Group_A3 & $0.20 * *$ & 0.11 & 0.13 & 0.12 & $0.76 *$ & 0.34 & 0.54 & 0.36 \\
\hline Constant (not standardized) & 1.73* & 0.53 & $1.45^{* *}$ & 0.54 & $3.28^{*}$ & 1.60 & 2.42 & 1.68 \\
\hline $\mathrm{F}$ & \multicolumn{2}{|c|}{$2.36 * *$} & \multicolumn{2}{|c|}{1.09} & \multicolumn{2}{|c|}{ 2.14* } & \multicolumn{2}{|c|}{0.97} \\
\hline $\mathrm{R}_{\text {adjusted }}^{2}$ & \multicolumn{2}{|c|}{0.06} & \multicolumn{2}{|c|}{0.00} & \multicolumn{2}{|c|}{0.06} & \multicolumn{2}{|c|}{-0.00} \\
\hline
\end{tabular}

*significant at the 0.05 level, $* *$ significant at the 0.01 level 
Multivariate regression analyses provided weaker evidence for ordering effects than univariate analyses. Ordering did not have a significant impact on WTP and for WTIT the impact of ordering was only significant for scenario A, suggesting that respondents' WTIT was lower for scenario A, when scenario $B$ was presented first.

In contrast to the regression model with background variables, which contributed significantly to the explained variance in WTP and WTIT (for Scenario A), the models with experience and risk factors had poor explanatory power and did not reach statistical significance. Therefore these results are not presented here.

\section{Discussion}

The present paper reports on a study using CV to value benefits of a LBC intervention from an individual consumers perspective. Benefits included benefits incorporated within the QALY framework (i.e. life expectancy and HRQOL) and impacts on broader quality of life aspects (i.e. clothing size, relaxation, endurance and experienced control over lifestyle choices). Our results indicate that the majority of respondents (94.3\%) attach value to benefits achieved by LBC. In concordance with previous CV studies, ${ }^{37-39}$ we found consistent positive associations between monetary and time investments, indicating that respondents, who are willing to invest time to achieve benefits of LBC are generally also willing to invest money. However, zero willingness to invest was somewhat more frequent for WTP than for WTIT questions suggesting that some respondents only want to invest time for $\mathrm{LBC}$, but no money. Respondents were willing to invest more for improvements in HRQOL and other QOL benefits than for life expectancy benefits. This finding is consistent with results of a discrete choice experiment conducted among a smaller sample of HPS participants, ${ }^{40}$ providing some evidence for external validity of our findings.

Our findings regarding the internal validity of the CV method were mixed. Respondents were overall sensitive to the qualitatively different scope of benefits presented to them. They were willing to invest significantly more money and time for all types of benefits together than for improvements in only life expectancy or broader QOL aspects. However, this was not the case for HRQOL outcomes. Our findings regarding scope sensitivity contrast earlier research by Olsen et al. (2004), ${ }^{41}$ who reported that respondents were insensitive to both the size of health programs as well as the size of the benefits. Our findings are concordant however with findings by Smith $(2001)^{42}$ and Yeung et al. (2003), ${ }^{43}$ showing that sensitivity to scale decreases with increasing utility of the benefit being valued. In both studies diminishing sensitivity to scale was ascribed to a budget constraint, which becomes increasingly relevant as the benefit increases. The budget constraint could either be an actual budget constraint, referring to inability 
to pay more, ${ }^{44}$ or a psychological budget constraint, referring to the possibility that respondents construct their own purpose-specific budgets. ${ }^{45}$

The environmental economics literature has shown that CV applications comprising multiple valuation questions are vulnerable to question ordering effects. ${ }^{46}$ Kartman et al. $(1996)^{47}$, who tested for ordering effects within the healthcare setting, did not find evidence for ordering effects. In our study we found ordering effects, but these became weaker after controlling for other explanatory variables. Ordering effects are problematic, because they suggest that preferences of respondents are unstable and not clearly defined. Several techniques have been suggested to minimize ordering effects, such as giving respondents the opportunity to revise their answers after all questions have been completed. ${ }^{25}$ However, there is evidence that ordering bias cannot be fully eliminated. It is not a problem inherent to $\mathrm{CV}$, but rather a fundamental property of human decision-making, which raises questions about which benchmarks to use when examining the validity of $\mathrm{CV}$ in future research. ${ }^{48}$

Associations between exploratory variables and WTP/WTIT outcomes also provided mixed evidence for internal validity. In line with theoretical assumptions and previous research, we found that respondents' income was consistently positively associated with WTP. ${ }^{49}$ Having paid work, which was used as a proxy for availability of time, only showed a weak negative association with WTIT in one of the four models presented. This could have several reasons. The proxy measure used for availability of time could have been suboptimal, availability of time may not determine WTIT, or the weak association between paid work and WTIT is due to bias related to the CV method. Only two other studies have to our knowledge examined potential predictors of WTIT so $\mathrm{far}^{38,39}$ while predictors of WTP have received considerable attention in previous research. This highlights the need for more research to identify and test relevant predictors for WTIT.

Against our hypotheses, associations between WTP/WTIT and respondent's health risk factors, as well as intervention experiences were not significant. This may be explained by a number of reasons. First, the time difference of 2.5 years between measuring risk factors and conducting the CV study could have been too long for risk factors to have any impact. Second, although respondents had different types of health risk factors, they all had an increased risk for T2D, CVD or both. Hence, it is possible that there was not sufficient variation in perceived importance of risk between respondents. Third, the fact that we did not find a significant impact of experience factors may be due to limited power in the analyses, since experience factors were only measured among half of the study participants.

A number of limitations of this research need mentioning. The study sample consisted of participants in a trial evaluating a LBC intervention. Hence, results may not be 
generalized to other populations, such as consumers of regular LBC interventions and consumers in other application areas of public health.

Another limitation is related to the definition of life expectancy gains used in our research (i.e. 2.6 years). This definition was based on results of a study quantifying life expectancy gains that may be achieved by changing physical activity levels. ${ }^{50}$ Recent Canadian research quantifying life expectancy gains for multiple lifestyle factors, suggests however that LBC may achieve considerably larger gains (of up to 7.5 years). ${ }^{51}$ Although the Canadian estimate represents life expectancy gains that may be achieved when all lifestyle factors are improved at the same time and participants of the HPS often only worked on improving one of these factors, we cannot preclude that we may have underestimated possible life expectancy gains and hence their perceived importance to respondents.

Our research also had several strengths. It adds to the limited number of CV studies applied to broader public health programs. ${ }^{20,52-54}$ Applications of CV to public health are increasing, but the majority has concentrated on clinical public health programs, such as screening $^{55}$ vaccinations, ${ }^{56,57}$ preventive dental care $^{38,58}$ or drugs for smoking cessation. ${ }^{27,59}$ Additionally, we are aware of only two studies valuing both health and broader benefits of a public health program. ${ }^{20,53}$ An important limitation of these studies was that broader benefits were not well defined or quantified and that health outcomes were not described in terms of their impact on HRQOL. Our research addresses this limitation by providing detailed definitions of three types of public health outcomes to be valued.

Another advantage of our study was the simultaneous use of WTP and WTIT to value consequences of LBC. Given that LBC may require both time and monetary investments, this approach seems more realistic in the context of behavior change interventions than only using WTP. Experience with deriving preferences using WTIT questions is to date very limited. Few studies have measured WTIT so far $^{37-39,60}$ and none of these addressed the question how both measures could be used simultaneously within a CBA framework. Van Helvoort - Postulart et al. (2009) ${ }^{37}$ and Johanneson (1992 $)^{60}$ suggested converting WTIT values into monetary units using opportunity costs of leisure time, but it is still unclear which method to use for this purpose and whether monetary values of WTP and WTIT can simply be added up for CBA.

The importance of broader quality of life benefits of LBC to consumers has implications for decision-makers, who wish to respond to consumer preferences. To support this process, research needs to develop methods for considering such broader benefits in decision-making. The CV method has been suggested as a possible way to capture broader benefits of public health within an economic evaluation framework. It has proven to be a feasible method in our study, which appears from a limited number of 
protest zeros $(3 \%)$, as well as from the $61 \%$ response rate achieved, which is regarded reasonable for survey-based research. ${ }^{61}$ Feasibility of the $\mathrm{CV}$ method also needs to be tested in other application areas of public health and among general population samples, for which lifestyle changes are less urgent.

\section{Conclusion}

The results of this study have shown that consumers are willing to invest both time and money to achieve benefits of lifestyle change. In addition to benefits incorporated within the QALY framework, they are also willing to invest for broader individual-level benefits. This highlights the need to develop methods to consider such benefits in decisionmaking about LBC. The CV method has shown to be a feasible approach to value both health and broader benefits of a public health intervention, but generalizability to other areas of public health still needs to be examined. Given mixed evidence for internal validity, we recommend using CV not as the sole method to support decision-making, but rather it in conjunction with other methods, such as discrete choice experiments, ranking exercises and qualitative research. 


\section{References}

1. Drummond M, Sculpher MJ, Torrance GW, O'Brien BJ, Stoddart GL. Methods for the Economic Evaluation of Health Care Programmes New York: Oxford University Press; 2005.

2. Weatherly H, Drummond M, Claxton K, Cookson R, Ferguson B, Godfrey C, et al. Methods for assessing the cost-effectiveness of public health interventions: Key challenges and recommendations. Health Policy 2009;93:85-92.

3. McDaid D, Needle J. What use has been made of economic evaluation in public health? A systematic review of the literature. In: Dawson S, Morris ZS, editors. Future Public Health: Burdens, Challenges and Opportunities. Basingstone: Palgrave Macmillan; 2009:248-64.

4. Allin S, Mossialos E, McKee M, Holland W. Making decisions on public health: a review of eight countries. Copenhagen: World Health Organization; 2004.

5. Rush B, Shiell A, Hawe P. A census of economic evaluations in health promotion. Health Education Research 2004;19:707-19.

6. Lorgelly PK, Lawson KD, Fenwick EAL, Briggs AH. Outcome measurement in economic evaluations of public health interventions: a role for the capability approach?.International Journal of Environmental Research and Public Health 2010;7:2274-89.

7. Kelly M, Morgan A, Ellis S, Younger T, Huntley J, Swann C. Evidence based public health: A review of the experience of the National Institute of Health and Clinical Excellence (NICE) of developing public health guidance in England. Social Science \& Medicine 2010;71:1056-62.

8. Chalkidou K, Culyer A, Naidoo B, Littlejohns P. Cost-effective Public Health Guidance: Asking questions from the Decision-Maker's viewpoint. Health Economics 2008;17:441-8.

9. Shiell A. In search of social value. International Journal of Public Health 2007;52:333-4.

10. Fielding JE, Teutsch S, Breslow L. A Framework for Public Health in the United States. Public Health Reviews 2010;32:174-89.

11. WHO. Health Promotion Glossary. Geneva: World Health Organization; 1998.

12. WHO. Milestones in Health Promotion: Statements from Global Conferences. Geneva: World Health Organization; 2009.

13. Awofeso N. What's New About the "New Public Health"? American Journal of Public Health 2004;94:705-9.

14. McLeroy KR, Bibeau D, Steckler A, Glanz K. An Ecological Perspective on Health Promotion Programs. Health Education Quarterly 1988;15:351-77.

15. Allwright S, Paul G, Greiner B, Mullally BJ, Pursell L, Kelly A, et al. Legislation for smoke-fee workplaces and health of bar workers in Ireland: before and after study. British Medical Journal 2005;331:1117-20.

16. Wagenaar AC, Tobler AL, Komro KA. Effects of Alcohol Tax and Price Policies on Morbidity and Mortality: A Systematic Review. American Journal of Public Health 2010;100:2270-8.

17. Smith RD, Petticrew M. Public health evaluation in the twenty-first century: time to see the wood as well as the trees. Journal of Public Health 2010;32:2-7.

18. Brazier J, Ratcliffe J, Salomon JA, Tsuchiya A. Measuring and Valuing Health Benefits for Economic Evaluation. New York: Oxford University Press; 2007.

19. Goebbels AFG, Lakerveld J, Ament AJHA, Bot SDM, Severens JL. Exploring non-health outcomes of health promotion: The perspective of participants in a lifestyle behaviour change intervention. Health Policy 2012;106:177-86.

20. Borghi J, Jan S. Measuring benefits of health promotion programmes: Application of the contingent valuation method. Health Policy 2008;87:235-48.

21. Hale J. What contribution can health economics make to health promotion? Health Promotion International 2000;15:341-8.

22. O'Brien B, Gafni A. When Do the "Dollars" Make Sense? Toward a Conceptual Framework for Contingent Valuation Studies in Health Care. Medical Decision Making 1996;16:288-99.

23. Hanley N, Ryan M, Wright R. Estimating the monetary value of health care: lessons from environmental economics. Health Economics 2003;12:3-16. 
24. Olsen JA. Aiding priority setting in health care: Is there a role for the contingent valuation method? Health Economics 1997;6:603-12.

25. Venkatachalam L. The contingent valuation method: a review. Environmental Impact Assessment Review 2004;24:89-124.

26. de Meijer C, Brouwer W, Koopmanschap M, van den Berg B, van Exel J. The value of informal care - a further investigation of the feasibility of contingent valuation in informal caregivers. Health Economics 2010;19:755-71.

27. Olsen JA, Røgeberg OJ, Stavem K. What explains willingness to pay for smoking-cessation treatments - addiction level, quit-rate effectiveness or the opening bid?. Applied Health Economics and Health Policy 2012;10:1-9.

28. van Exel NJA, Brouwer WBF, van den Berg B, Koopmanschap MA. With a little help from an anchor: Evidence of starting point bias in contingent valuation of informal caregiver time inputs. Journal of Socio-Economics 2006;35:836-53

29. Lakerveld J, Bot DM, Chinapaw MJ, van Tulder MW, van Oppen P, Dekker JM, et al. Primary prevention of diabetes mellitus type 2 and cardiovascular diseases using a cognitive behavior program aimed at lifstyle changes in people at risk: Design of a randomized controlled trial. BMC Endocrine Disorders 2008;8:1-11.

30. Maguire KB. Does mode matter? A comparison of telephone, mail, and in-person treatments in contingent valuation surveys. Journal of Environmental Management 2009;90:3528-33.

31. Donaldson C, Thomas R, Torgerson DJ. Validity of open-ended and payment scale approaches to willingness to pay. Applied Economics 1997;29:79-84.

32. Frew EJ, Whynes DK, Wolstenholme JL. Eliciting Willingness to Pay: Comparing Closed-Ended and Payment Scale Approaches. Medical Decision Making 2003;23:150-9.

33. Bobinac A, van Exel NJA, Rutten FFH. Willingness to pay for a QALY: the individual perspective. Value in Health 2010;13:1046-55.

34. van Binsbergen JJ, Langens FNM, Dapper ALM, Van Halteren MM, Glijsteen R, Cleyndert GA, et al. NHG-Standaard Obesitas. Huisarts Wet 2010;53:609-25.

35. NHG. NHG-Standaard Cardiovasculair risicomanagment (eerste herziening). Huisarts Wet 2012;55:14-28.

36. Lakerveld J, Bot S, Chinapaw M, van Tulder M, Kingo L, Nijpels G. Process Evaluation of a Lifestyle Intervention to Prevent Diabetes and Cardiovascular Diseases in Primary Care. Health Promotion Practice 2012;13:696-706.

37. van Helvoort-Postulart D, Dirksen CD, Kessels AGH, van Engelshoven JMA, Hunink MGM. A comparison between willingness to pay and willingness to give up time. European Journal of Health Economics 2009;10:81-91.

38. Vermaire JH, van Exel NJA, Van Loveren C, Brouwer WBF. Putting your money where your mouth is: Parents' valuation of good oral health of their children. Social Science \& Medicine 2012;75:2200-6.

39. Barner JC, Mason HL, Murray MD. Assessment of Asthma Patients' Willingness to Pay for and Give Time to an Asthma Self-Managment Program. Clinical Therapeutics 1999;21:878-94.

40. Alayli-Goebbels AFG, Dellaert BGC, Knox SA, Ament AJHA, Lakerveld J, Bot SDM, et al. Consumer preferences for health and non-health outcomes of health promotion: results from a discrete choice experiment. Value in Health 2013;16:114-23.

41. Olsen JA, Donaldson C, Pereira J. The insensitivity of 'willingness-to-pay' to the size of the good: New evidence for health care. Journal of Economic Psychology 2004;25:445-60.

42. Smith RD. The relative sensitivity of willingness-to-pay and time-trade-off to changes in health status: an empirical investigation. Health Economics 2001;10:487-97.

43. Yeung RYT, Smith RD, McGhee SM. Willingness to pay and size of health benefit: an integrated model to test for 'sensitivity to scale'. Health Economics 2003;12:791-6.

44. Smith RD. Sensitivity to scale in contingent valuation: the importance of the budget constraint. Journal of Health Economics 2005;24:515-29.

45. Thaler R. Mental Accounting Matters. Journal of Behavioural Decision Making 1999;12:183206. 
46. Powe NA, Bateman IJ. Ordering effects in nested 'top-down' and 'bottom-up' contingent valuation designs. Ecological Economics 2003;45:255-70.

47. Kartman B, Stålhammar NO, Johanneson M. Valuation of health changes with the contingent valuation method: A test of scope and question order effects. Health Economics 1996;5:53141.

48. Clark J, Friesen L. The causes of order effects in contingent valuation surveys: An experimental investigation. Journal of Environmental Economics and Management 2008;56:195-206.

49. Kling $\mathrm{CL}$, Phaneuf $\mathrm{DJ}$, Zhao J. From Exxon to BP: Has some number become better than no number? Journal of Economic Perspectives 2012;26:3-26.

50. Franco $\mathrm{OH}$, de Laet $\mathrm{C}$, Peeters A, Jonker J, Mackenbach J, Nusselder W. Effects of Physical Activity on Life Expectancy with Cardiovascular Disease. Archives of Internal Medicine 2005; 165:2355-60.

51. Manuel D, Perez R, Bennett C, Rosella L, Taljaard M, Roberts M, et al. Seven more years: The impact of smoking, alcohol, diet, physical activity and stress on health and life expectancy in Ontario. Toronto: Institute for Clinical Evaluative Sciences and Public Health Ontario; 2012.

52. Cawley J. Contingent valuation analysis of willingness to pay to reduce childhood obesity. Economics and Human Biology 2008;6:281-91.

53. Haines TP, McPhail S. Patient preference for falls prevention in hospitals revealed through willingness-to-pay, contingent valuation survey. Journal of Evaluation in Clinical Practice 2011;17:304-10.

54. Sorenson SB. Funding Public Health: The Public's Willingness to Pay for Domestic Violence Prevention Programming. American Journal of Public Health 2003;93:1934.

55. Yasunaga $\mathrm{H}$. Willingness to pay for mass screening for prostate cancer: A contingent valuation survey. International Journal of Urology 2008;15:102-5.

56. Heinzen RR, Bridges JFP. Comparison of four contingent valuation methods to estimate the economic value of a pneumococcal vaccine in Bangladesh. International Journal of Technology Assessment in Health Care 2008;24:481-87.

57. Palanca-Tan R. The demand for a dengue vaccine: A contingent valuation survey in Metro Manila. Vaccine 2008;26:914-23.

58. Oscarson N, Lindholm L, Källestål. The value of caries preventive care among 19-year olds using the contingent valuation method within a cost-benefit approach. Community Dentristry and Oral Epidemiology 2007;35:109-17.

59. Weimer DL, Vining AR, Thomas RK. Cost-benefit analysis involving addictive goods: Contingent valuation to estimate willingness-to-pay for smoking cessation. Health Economics 2009;18:181-202.

60. Johanneson M. Economic evaluation of lipid lowering - A feasibility test of the contingent valuation approach. Health Policy 1992;20:309-20.

61. Baruch Y. Response rate in academic studies - A comparative analysis. Human Reations 1999;52:421-38. 

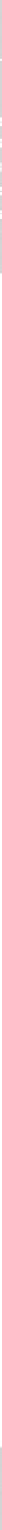

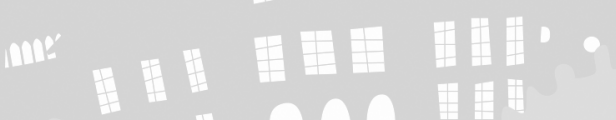

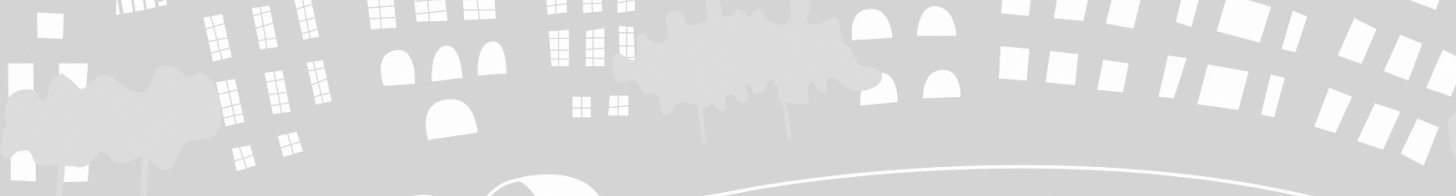

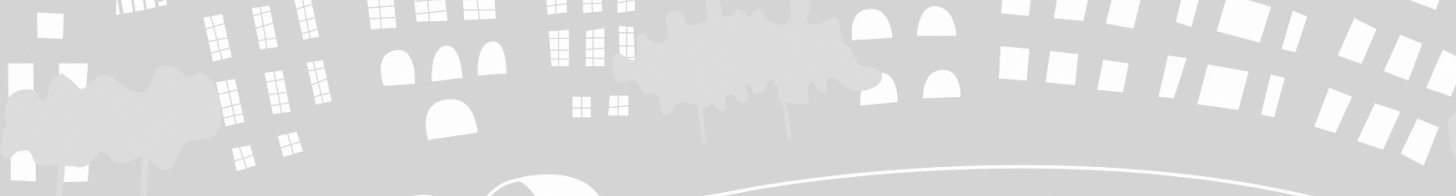

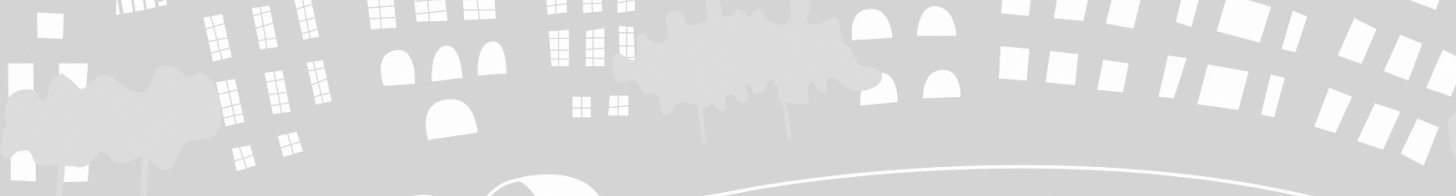

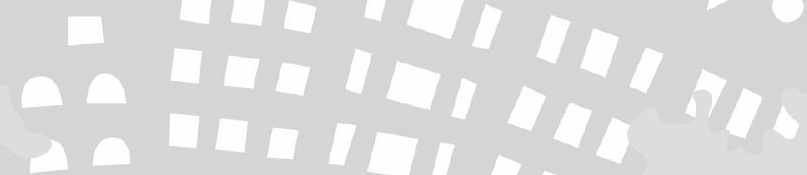




\section{Introduction}

Economic evaluation studies are a useful tool to support decisions on allocation of limited health care resources. They integrate information about both costs and effectiveness of alternative technologies and are a key source of evidence to consider in the health technology assessment process. Economic evaluation evidence is increasingly used in decision-making about funding of health technologies, such as pharmaceuticals, medical devices, diagnostic and surgical procedures. For public health programs economic evaluation evidence is still relatively scarce. One key reason for the lack of economic evaluation studies is that public health programs pose methodological challenges to economic evaluation. The research in this dissertation contributes to improving the evidence-base for decision-making in public health by addressing methodological challenges and questions that have been raised regarding the methodological quality of existing studies. This chapter provides an overview of the main findings of the studies described in this thesis. Based on a systematic literature review assessing the methodological quality and progress of economic evaluations of behavior change programs remaining challenges for evaluation were identified. As a next step, we discuss the findings of four empirical studies exploring potential solutions to overcome challenges associated with a) comparing efficiency across multiple societal sectors and b) considering impacts of public health interventions on broader domains of wellbeing not captured within the QALY framework. Based on the overall research findings, we conclude with a description of the state of scientific progress in applying economic evaluation methods to public health and the resulting implications for practice, decisionmaking and future research.

\section{State of the art and what this research adds}

The systematic literature review reported in Chapter 2 identified 142 economic evaluations of public health programs directed at behavior change. These studies provide evidence to support funding decisions. Methodological quality of the studies showed several weaknesses, however, which limits their usefulness for decision-making. These weaknesses included for instance insufficient reporting of essential study details and lack of compliance with methodological standards, such as performing an incremental analysis, sensitivity analyses and the use of discounting.

Based on an analysis of economic evaluation studies published before April 2009, the progress with addressing methodological challenges for evaluation was overall limited. Mathematical modeling techniques to extrapolate intermediate outcomes to long-term health outcomes have the potential to overcome the challenge caused by the long time 
horizon of public health programs. More than half of the economic evaluations included in our systematic review made use of modeling techniques. The time horizon of many of these studies was however insufficiently long to capture all health outcomes and costs relevant to the decision problem. Another finding was that lacking data often hampered modeling of underlying causal relationships.

Our review also shows that it remains challenging to consider impacts on broader domains of wellbeing not captured by the QALY. Very few economic evaluations identified or measured such broader outcomes, and validated methods or instruments for their consideration have not yet been developed (see Chapter 2). The qualitative research described in Chapter 4 contributed to the limited evidence about broader impacts of public health interventions in the context of lifestyle change. The discrete choice experiment described in Chapter 5 provides evidence that the identified broader outcomes of lifestyle behavior change are equally important to consumers as health outcomes captured by QALYs. This finding underlines the importance to develop methods to consider broader outcomes in decision-making. Contingent valuation (CV) has been suggested as a potential method for capturing both health and broader outcomes of public health programs. In the present research CV has been a feasible method for monetary valuation of health and broader benefits of a public health intervention from an individual consumer perspective (see Chapter 6). Evidence regarding the internal validity of the method was inconclusive, however.

Several studies included in our systematic review incorporated consequences for individuals not directly targeted by the program under evaluation. The progress in this area was mainly limited to studies evaluating programs directed at sexual behaviors, which considered health outcomes (e.g. HIV or other infections averted), life years or QALYs gained among sexual partners of targeted individuals. Hardly any efforts have been made to consider consequences on a community or societal level and suitable measures for capturing community-level changes (e.g. increased sense of community) are not yet available.

Despite the fact that reducing health inequities is an important public health objective, not a single study examined the impact of behavior change programs on equity outcomes.

The majority of economic evaluations examined in our review used effectiveness evidence from RCTs. Only few studies used evidence from alternative designs, such as quasi-experiments or comparisons with historical data. It is currently unclear which study design to use in situations in which RCT designs are not feasible and in which evidence from RCTs insufficient to inform decision-making.

Non-health sector costs (e.g. costs of violent crimes and law enforcement) were considered in several economic evaluations in our review (see Chapter 2), but methods 
used to identify, measure and value these were not described in much detail. Hence, there still is no clear guidance regarding the types of non-heath sector costs public health programs produce and how to incorporate them within an economic evaluation framework.

Using a common parameter of efficiency may be a potential solution to overcome the challenge associated with comparing investments in public health with investments in other societal sectors. Chapter 3 describes a study exploring the possibility of using the Value of Statistical Life (VSL) for this purpose. Study findings show that, when determined by means of a retrospective investment analysis, the VSL is not an adequate method for multi-sector comparison. Even when determined empirically using an ex-ante stated preference approach, it would not be an ideal parameter of efficiency, as reduction in risk of premature death is the only outcome it captures. Our findings suggest that other outcomes are also relevant to consider within an economic evaluation framework. This is not only the case for public health programs, but also for interventions in other societal sectors. For instance, transport interventions may lead to a reduction of non-lethal road accidents, and hence to improved health and quality of life outcomes for people who would otherwise have been injured. On the contrary, the CV method does not pose restrictions on the number of types of outcomes to be valued. It is commonly used to determine efficiency of interventions in other societal sectors (e.g. transport and environment), and hence may be an alternative approach to multisector comparisons given that the validity issues surrounding the method can be resolved.

\section{Implications for economic evaluation practice}

Our research identified a number of steps that evaluators may take to improve future economic evaluation evidence for decision-making in public health. Compliance with methodological standards could be improved through more use of good practice guidelines (e.g. Ramsey et al. ${ }^{1}$ and Caro et al. $^{2}$ ) when planning and designing new economic evaluation studies.

Reporting of studies could be improved by using quality assessment checklists, which identify methodological aspects that are essential to report in economic evaluation (e.g. Drummond et al. ${ }^{3}$, Evers et al. ${ }^{4}$ or Philips et al. ${ }^{5}$ ). Davidson et al. ${ }^{6}$ could be used to identify program characteristics essential to report, and Abraham and Michie $^{7}$ for describing conceptually distinct behavior change techniques that are used in the program.

Long-term costs and outcomes should be considered more often in economic evaluation studies to provide insights into all relevant costs and outcomes of interest to decision- 
makers. This requires more use of mathematical modeling to extrapolate costs and translate short-term intermediate outcomes to long-term outcomes. Given that performing an intervention trial and a subsequent model-based study to extrapolate the trial findings can be both time consuming and costly, we suggest that evaluators engage more in joint modeling projects where a basic model structure is developed for use across a wide range of research projects that require modeling of the same processes. The chronic disease model of the Dutch National Institute for Public Health and the Environment (RIVM) is a good example. ${ }^{8}$ It describes the relationship between several risk factors (e.g. smoking, body mass index and blood pressure) and the development of chronic diseases (e.g. lung cancer, coronary heart disease and diabetes mellitus) and has been applied to a wide range of public health programs, including obesity prevention, smoking prevention and cessation and interventions against alcohol abuse. $^{9-11}$

In situations where specific data for populating model parameters are not available, we recommend using scenario analyses to examine impacts of these parameters and to use sensitivity analyses in case values exist but are uncertain. ${ }^{12}$ In situations where too many parameters are lacking to build a model, we recommend to conduct costeffectiveness analysis using a measurable intermediate outcome or a more descriptive cost-consequence analysis approach, in which both quantifiable and non-quantifiable outcomes can be presented simultaneously. Together with the results of this analysis, evaluators could present a logic model of the program under evaluation to provide insights to decision-makers about processes and outcomes that are expected to occur based on theoretical models used for program development. ${ }^{13}$

Modeling requires skills, which are often not part of the standard toolbox of evaluators. Hence, providing more training in model building is another measure likely to contribute to more use of modeling.

Our research also highlighted the need to consider a wider range of outcomes of public health programs, including impacts on broader domains of wellbeing for targeted individuals, outcomes for individuals not directly targeted and the wider community or society. Given that methods to incorporate such broader outcomes directly within economic evaluation are currently not well developed, we suggest that evaluators identify, describe, and where possible measure relevant broader outcomes that cannot be directly incorporated in summary measures of cost-effectiveness. Presenting program outcomes in a disaggregated manner does not provide decision-makers with a clear decision rule. However, it gives them a more complete picture of the programs under evaluation and the possibility to define and apply their own decision criteria. It also creates the opportunity to adopt a multi-criteria decision-analysis approach to priority setting, which applies weights to different decision criteria. ${ }^{14}$ 
Methods for incorporating non-health sector costs are also uncertain. Hence, the same recommendations apply as for broader outcomes. Evaluators could present both identified costs and outcomes that were not incorporated in the economic analysis in a table, which describes their expected impact on cost-effectiveness (i.e. direction and size). It would also be helpful to indicate the analytical levels on which these costs and outcomes are produced as well as the analytical perspective from which they would be relevant to consider. This might help decision-makers to determine which of the costs and outcomes that have not been incorporated are relevant for them to consider or require further research.

Based on previous literature, our research has identified several systematic methods evaluators could use to consider equity within economic evaluation. These include reviewing background information on equity, presenting cost-effectiveness for equityrelevant subgroups, and systematic assessment of expected distributional effects of implementing interventions under evaluation. ${ }^{15,16}$ Results of these methods provide useful information to decision-makers who want to consider the impact of public health programs on equity outcomes. The need to consider equity outcomes is likely to be the highest for public health programs that target disadvantaged populations and lifestyle behavior change programs, which may be less effective among 'hard-to-reach disadvantaged groups. ${ }^{15}$

To facilitate improvements of future economic evaluation evidence using the steps outlined above it is important that health economists and public health experts collaborate. Public health experts need to help health economists understand the programs being evaluated, while health economists need to communicate the possibilities and impossibilities of economic evaluation to public health experts and assist them in designing, conducting and reporting economic evaluations.

\section{Implications for decision-making}

The findings of this research have implications for two aspects of decision-making: a) the scope of scientific evidence considered and b) the infrastructure to support decisionmaking in public health.

\section{Scope of evidence considered}

Our research highlighted that economic evaluation studies of public health programs are generally based on evidence from a limited number of sources. The majority of economic evaluations use RCTs as only source of evidence on effectiveness (see Chapter 2). RCTs are an important source of information on effectiveness of a program under ideal circumstances, but they cannot provide insights into other determinants of effectiveness 
of public health programs in the real world, such as the intervention process, local context circumstances, participant experiences and stakeholder views. ${ }^{13,17}$ Economic evaluation studies also tend to focus on health outcomes and do not consider broader impacts on quality of life and wellbeing (see Chapter 2). However, our research shows that participants of a public health program aimed at changing lifestyle behavior also experience broader non-health outcomes (see Chapter 3 ) and attach value to them (see Chapter 4 and 5). This finding suggests that decision-makers who wish to respond to consumer preferences should consider such broader outcomes of public health programs.

In practice technology assessments supporting healthcare decision-making tend to consider only a limited scope of scientific evidence. ${ }^{14,18}$ The scientific evidence most commonly considered is evidence regarding effectiveness, safety, costs and costeffectiveness. ${ }^{19}$ This evidence tells decision-makers whether a program works in general, but it does not provide insights into how a program works and whether it could be implemented in a particular local context. ${ }^{20}$ The latter insights are essential for decisionmaking in public health because public health programs often need to be tailored to specific local and organizational circumstances. So far, however, information regarding the specific local circumstances in which a program is implemented is usually considered only in the appraisal phase of the technology assessment process and not based on scientific methods. To provide better information to decision makers regarding local implementability of public health programs, we recommend broadening the scope of the scientific evidence produced and examined during technology assessments.

Lomas et al. ${ }^{20}$ have identified two forms of scientific evidence relevant to decisionmakers: context-free and context-sensitive evidence. Context-free evidence pertains to evidence that reveals universal truths about what might be achieved under ideal circumstances. This type of evidence is closely linked to the evidence-based medicine concept and is based on a clear hierarchy of evidence, with meta-analyses and systematic reviews representing the highest level of evidence. Context-free evidence is derived using clinical research methods such as epidemiology and biostatistics. Contextsensitive evidence relates to evidence about the context relevant to a particular decision. It is embedded more strongly in the social sciences and includes evidence about attitudes, implementation, organizational capacity, forecasting, economics/finance and ethics. Given the potentially diverse context elements, the methods to derive contextsensitive evidence are diverse as well. They may include experimental evidence, quasiexperimental evidence, qualitative research, survey-based research, regression analyses, time series, econometric methods, economic evaluation, public consultation and distributional analyses. The appropriate methods for obtaining evidence on context 
factors are not the same as those for obtaining evidence on efficacy of a program under ideal circumstances, but both methods are equally scientific. ${ }^{20}$

Figure 7.1 depicts how context-free and context sensitive evidence can complement each other in the technology assessment process. This figure is a simplified version of a figure developed by Davies ${ }^{21}$ and adapted by Lomas et al. ${ }^{20}$ Given the importance of reducing health inequities in the field of public health and the availability of scientific methods to examine equity impacts of public health programs in specific local settings, we added 'equity evidence' as form of context-sensitive evidence to this figure.

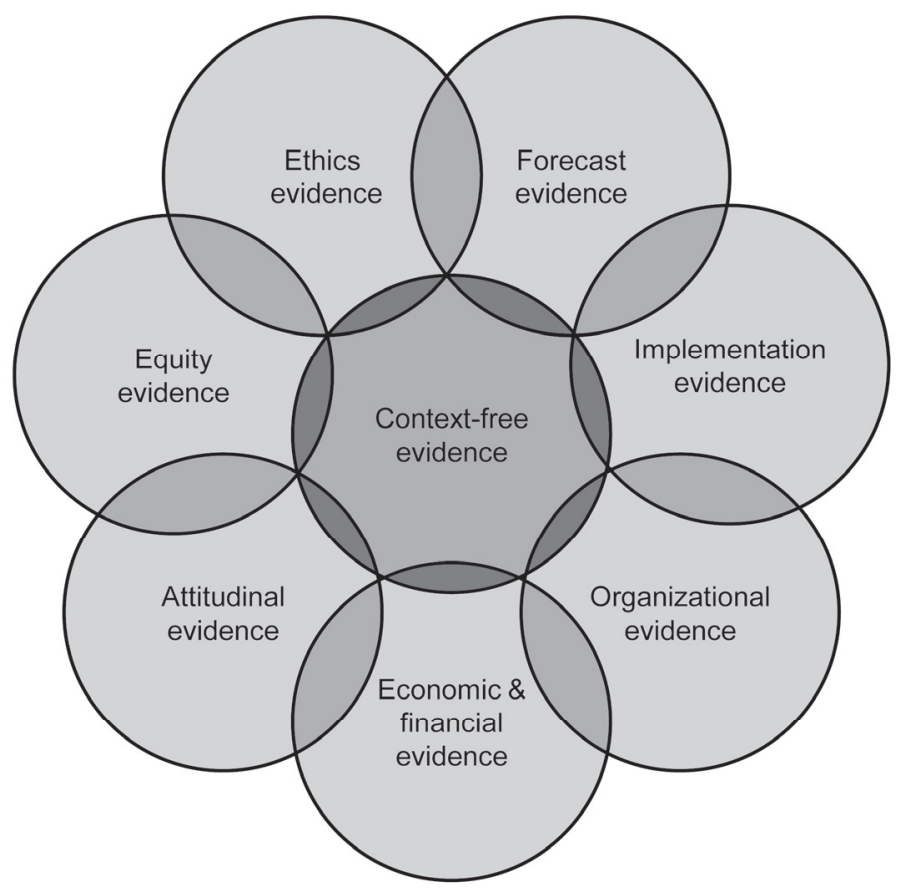

Figure 7.1 Technology assessment: context-sensitive evidence complements context-free evidence (adapted from Davies ${ }^{21}$ and Lomas et al. ${ }^{20}$ )

Health technology assessments to date predominantly produce context-free scientific evidence (i.e. efficacy and safety evidence) and some context-sensitive evidence (i.e. economic evaluation evidence using context-free efficacy data and context-sensitive cost data).

Based on the findings of this research, we recommend broadening the scope of contextsensitive scientific evidence examined and produced in technology assessments that 
inform decisions about funding and implementation of public health programs. The type of context-sensitive evidence relevant to incorporate in a technology assessment will depend on both the public health program in question and the specific decision-making context.

Scientific evidence derived by systematic and replicable methods is not the only factor determining decision-making in public health. Funding decisions are inherently political and involve the appraisal of other types of information such as values and judgments from a range of stakeholders. ${ }^{22}$ Lomas et al. ${ }^{20}$ refer to this information as colloquial evidence. They define it as "anything that establishes a fact or gives reason for believing something", and divide it into evidence about available resources, expert and professional opinion, political judgment, values, habits and traditions, lobbyists and pressure groups, and the particular pragmatics and contingencies of the situation. To develop appropriate, feasible and realistic public health policies, both scientific and colloquial evidence need to be considered by decision-makers. Figure 7.2 shows how colloquial evidence can complement scientific evidence in the deliberative technology appraisal process. It may also act as substitute for scientific evidence in situations where scientific evidence on context is missing. ${ }^{20}$

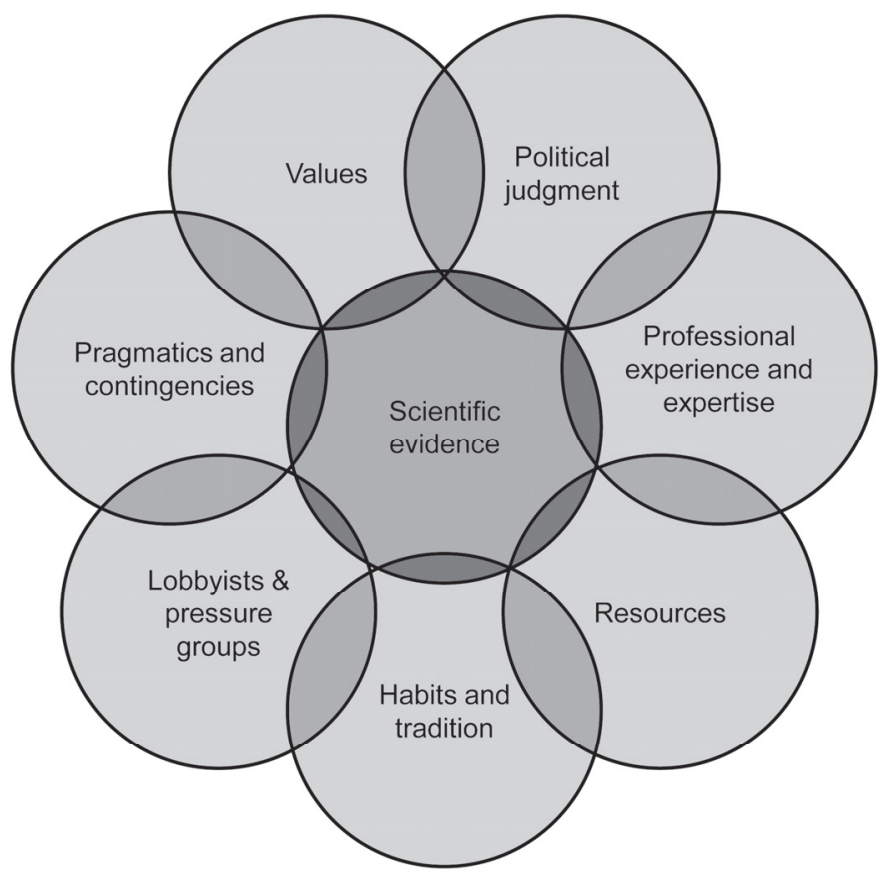

Figure 7.2 Technology appraisal: colloquial evidence complements scientific evidence (based on Davies ${ }^{21}$ and Lomas et al. ${ }^{20}$ ) 
The National Institute for Health and Care Excellence in the UK has adopted such a pluralistic perspective to scientific evidence in their new methods guide for developing public health guidance. ${ }^{23}$ How diverse forms of evidence will actually be integrated into decision-making in practice still remains to be seen. There is currently little insight into best practices of deliberative processes for appropriately combining and weighting diverse forms of evidence for decision-making ${ }^{20}$. A recent study by Marsh et al. ${ }^{14}$ successfully applied multi-criteria decision analysis to combine and weight both different types of scientific evidence and stakeholder values for priority setting in public health. This method provides a possible way forward, but still requires further development and testing. Hence, at this point, we recommend that decision-makers document in a transparent manner how they combined diverse forms of evidence in arriving at a decision.

\section{Infrastructure to support decision-making}

The systematic use of evidence to inform decisions on public health in the Netherlands and many other countries is currently hampered by a lack of formal structures to support decision-making. ${ }^{24}$ To encourage more use of economic evaluation evidence and thereby efficient allocation of public resources, clearer decision-making structures need to be developed.

England was one of the first countries worldwide to introduce formal organizational structures for systematic and transparent consideration of evidence in decision-making about public health programs. ${ }^{25}$ Since 2006 the Centre for Public Health Excellence and Public Health Guidance, which is located at the National Institute for Health and Care Excellence (NICE), provides recommendations on a wide range of public health programs focusing on smoking cessation, family planning, creation of safe open spaces for physical activity, controlling the number of fast food restaurants and alcohol outlets in inner city zones, as well as programs addressing health inequalities. ${ }^{25}$ Recommendations are made at the population, community, organizational, group, family and individual level, recognizing the wide spectrum of determinants of population and individual health. Independent advisory committees develop guidance according to clear processes and methods using the best available evidence. ${ }^{23}$ Throughout the development of the guidance views of different stakeholders are considered, including professionals, academic institutions, industry and interest groups from the general public. Topics for guidance development are identified by the Department of Health. ${ }^{25,26}$ The guidance applies in England and may selectively be applied in Northern Ireland, Scotland and Wales. ${ }^{27}$ It is developed for a wide range of audiences, including the National Health Service (NHS), local government, a range of central government departments responsible for taxation, transport, housing and criminal justice, and the 
voluntary and private sectors. ${ }^{23,25}$ Once a guidance is finalized, it is made publicly available on the NICE website together with the evidence on which it was based. ${ }^{25}$

This approach is innovative and could provide direction to other countries wishing to develop more formal structures to support evidence informed decision-making in public health.

When developing new decision-making structures, it is important to consider that decisions about funding and implementation of public health programs tend to take place on multiple levels, including the international, national, regional and local level. Decisions at an international level are required, because determinants of disease and behavior do not obey national boundaries (e.g. food contamination, availability of condoms and hand washing behaviors in one country can impact on global transmission of infectious diseases). Hence, prevention strategies need to be coordinated between countries. Decisions at the national level are required for the development of national public health policies, such as legislation to promote population health. Regional leveldecisions are needed, because public health priorities may differ across regions. Finally, decisions need to be taken at the local level, to coordinate implementation of policies locally, where there is direct access to populations. ${ }^{24}$ The method of funding of a health care system plays an important role in defining decision-making authority on each of these levels. In tax-funded systems, such as the UK, there is generally more authority and infrastructure for public health on a central level, ${ }^{24}$ which makes it easier to establish systematic procedures to support decisionmaking on a national level. In health care systems, which are predominantly social health insurance-based, such as the Netherlands or Germany, authority tends to be more decentralized and national level infrastructure for public health is less developed. ${ }^{24}$ In the Netherlands there is considerable autonomy on the local (municipal) level for funding, priority setting and implementing of public health activities. ${ }^{24}$ Hence, it may require more time and effort to create structures to support evidence-informed decisionmaking. These might require a more complex multi-level structure consisting of an overarching national-level organization which determines general methodological guidelines for evidence informed decision-making, as well as a regional- and/or locallevel structure being closely connected to the national level. The national-level structure could focus on producing recommendations for national-level programs (e.g. the national immunization program in the Netherlands) and consider context-free scientific evidence for public health programs requiring regional or local decision-making. The evidence assessed at the national level could be integrated at the regional/local level with contextsensitive scientific evidence, as well as colloquial evidence relevant for the specific application context of the program. 


\section{Implications for research}

Our research provides insights into how economic evaluations of behavior change interventions have tackled methodological challenges for evaluation so far. It also gives several directions on how to overcome the challenges associated with comparing efficiency across multiple societal sectors and considering impacts of public health programs on broader domains of quality of life and wellbeing. Given that this research is one of the first studies exploring potential solutions to overcome these challenges, there is still more work required. Based on our findings, we have outlined a number of priority areas for future research.

\section{Impacts on broader domains of quality of life and wellbeing}

Measures to examine health outcomes achieved by public health programs are plentiful and relatively straightforward. They include measures of mortality, life expectancy, disease incidence or prevalence and health-related quality of life. By combining changes in life expectancy and health-related quality of life (HRQOL) in a single measure, QALYs provide a useful summary measure of health outcome for use in economic evaluation. However, they do not capture impacts public health programs may have on broader domains of an individual's quality of life or wellbeing (e.g. improvements in knowledge, skills, and opportunities for personal development or access to services and resources). Impacts on broader domains of quality of life and wellbeing are not well understood and theoretically underpinned measures to capture them in economic evaluation lacking.

This research has contributed to the identification of broader outcomes experienced by participants of a lifestyle behaviour change intervention implemented in a primary care setting (see Chapter 3). Future research should continue to identify and define broader outcomes of public health programs in other settings and among other populations, and examine how these are related to existing measures of HRQOL. An overview and categorisation of broader outcomes and their relevance for different areas of public health would help evaluators identify outcomes to consider in a specific (economic) evaluation study.

Developing validated instruments for considering impacts on broader domains of wellbeing within economic evaluation is also a priority for future research. Lorgelly et al. ${ }^{28}$ explored the possibility to develop an instrument based on Sen's capability approach. ${ }^{29}$ According to this approach wellbeing is determined by what people can do (i.e. their capabilities), rather than by what they actually do (i.e. their functioning), which forms the basis of generic preference-based measures currently used to calculate QALYs. Al-Janabi et al. ${ }^{30}$ took this work further and developed a first brief self-report measure of capability wellbeing for the general adult population. This instrument is 
referred to as ICECAP-A and consists of the following five domains: stability, attachment, achievement, autonomy and enjoyment. Acceptability and validity of the instrument still needs to be assessed and index values generated to allow for expressing a participant's capability score in a single number for use within economic evaluation.

A quality of life (QOL) model developed by a research group at the Centre for Health Promotion at the University of Toronto may provide a useful alternative to the capability approach and also requires further exploration and validation. ${ }^{31,32}$ The model is consistent with modern public health in two ways: it regards health as a resource for daily living rather than the objective of living and takes a holistic approach to conceptualizing QOL, stressing the importance of personal control and opportunities to improve QOL by changing the environment. ${ }^{31}$ It defines QOL as degree to which a person enjoys possibilities in three major domains of life: (1) being, (2) belonging, (3) becoming. Being refers to who a person is, belonging refers to how a person fits with environments and becoming refers to self-expressing, achievement of personal goals and aspirations. A number of validated instruments have been developed to measure QOL using these domains among different target groups, ${ }^{33-35}$ but so far no algorithms are available that allow transforming responses into a utility score (i.e. quality weight) for use within a QALY framework or single-index score for use within cost-effectiveness analysis. Until such algorithms are available QOL outcomes can only be presented in a disaggregated manner. Consequently, there is no clear decision-rule and decisionmakers need to apply their own weighting to each outcome.

Finally, instead of using generic instruments capturing broader domains of wellbeing that could be used across a variety of public health programs, it is also possible to develop program-specific utility measures using a discrete choice experiment (DCE). In an application to a social care intervention for older people Ryan et al. ${ }^{36}$ have shown how DCEs can be used to derive utility (or: quality) weights for individuals based on previously identified intervention outcomes. Based on results of a DCE asking respondents to trade between the different intervention outcomes, they estimated an algorithm from which they could obtain quality weights for use in QALY calculations. Their exploratory study suggests that the DCE approach can produce both valid and reliable quality weights. However, several methodological issues remain to be solved, including which anchor to use when creating a utility scale and how to account for different scales of attributes.

The DCE study reported in Chapter 5 suggests that it is feasible to apply a DCE approach to a lifestyle behaviour change intervention. More applications are needed across a broader range of public health interventions and testing of the method for the purpose of economic evaluation. The DCE-based approach has the advantage that it is flexible and allows for comparison with investments in other areas of healthcare, where QALYS 
have become the standard approach. However, a potential disadvantage of developing a program-specific utility measure may be that it is costly and time consuming.

\section{Impacts on the wider community}

Impacts public health programs have on the wider community fall into two broad categories: those that occur at an individual level and those that occur at a system or community level. Individual-level outcomes can be summed up to determine a total for an entire population or community (e.g. the total number of infections averted or QALYs gained). Economic evaluation studies in the area of sexually transmitted disease prevention have used such aggregate values for example to capture the number of HIV infections averted among sexual partners of program participants (see Chapter 2). This approach is not so much used yet in other areas of public health (e.g. smoking cessation or physical activity), partly because data on social diffusion effects are not available, but in principle this is possible.

It is methodologically more challenging to capture outcomes that occur at a community or system level, such as changes in structures, policies, decision-making or organizational processes, community capacity or the build environment. These cannot be measured or integrated in a single parameter and added up across individuals. ${ }^{37}$ Health economists need to develop novel methods to allow for their consideration in economic evaluation. These could build on the health promotion literature, which has already developed approaches to measure community or system-level changes. ${ }^{38}$ These include qualitative and quantitative research methods as well as the use of system-level population indicators ${ }^{38,39}$. Evaluators use qualitative research to understand for example policy changes or subjective perceptions of changes by vulnerable populations, ${ }^{38}$ and quantitative methods, such as household surveys, to measure community social dynamics (e.g. sense of community and community participation). ${ }^{40}$ Population indicators of system-level wellbeing and social functioning used in evaluation research include for instance unemployment rates, women rates in offices, income distributions, family life measures (e.g. divorce and birth rates), immigration rates and government spending on education. ${ }^{38,41}$ Indicators used to describe a neighborhood's physical environment include for example walkability, accessibility, connectivity, transportation network characteristics, traffic safety, presence of sidewalks and aesthetics (e.g. cleanliness and the availability of natural or commercial sights). ${ }^{42}$

Given the large variety of potential methods and measures to examine community or system-level changes, it would be quite challenging to apply all of them at once. This raises the question of how to find the right mix. Based on experiences with the WHO Healthy Cities Initiative, which represents a typical example of a complex modern public health program, de Leeuw ${ }^{39}$ suggests using 'Realist Evaluation' as a framework to guide 
the composition of the methods toolbox. The key assumption of Realist Evaluation is that each program has its own unique program theory that can be tested. Evaluation should address the unique specifics and underlying causal mechanisms pertaining to the program under evaluation. Consequently, the choice of evaluation methods should be driven by the purpose of a program in its local context. ${ }^{39}$ If this is the new direction for measuring system-level changes in public health, health economists need to respond to this with tools that allow for sufficient flexibility in the sort of outcome measures these can consider. Available tools health economists could use for this purpose are cost consequence analysis (CCA) and contingent valuation (CV). In CCA different types of costs and outcomes are again presented in a disaggregated manner, while CV could in principle value different outcomes in a single monetary measure. Both approaches need to be further tested and future research needs to explore ways to overcome challenges associated with them (i.e. a lack of a clear decision rule in CCA and validity issues associated with CV).

\section{Using cost-benefit analysis}

Cost-benefit analysis (CBA) has the potential to capture a broad number of benefits and enable comparisons of cost-effectiveness across multiple sectors. Our research suggests that the VSL is not an adequate parameter to use in CBA of public health programs. However, the use of CBA in public health could be facilitated through solving methodological issues surrounding CV. Our research showed that CV was a feasible method to elicit monetary values for individual benefits of lifestyle behavior change (see Chapter 6). Feasibility of CV should also be examined for valuing other benefits of public health programs, including those occurring at a community of system level. In the environmental economics literature CV is commonly used to value system level benefits, such as expansion of open access woodlands. ${ }^{43,44}$ Similar approaches should also be tested in public health applications. Future research should also explore how to value both individual and system-level outcomes within a single study.

The application of CV described in Chapter 6 highlights the need to further investigate the validity of the method. Two questions need to be answered in this context: a) what are the reasons that $\mathrm{CV}$ results are inconsistent with neo-classical economic theory?; and b) what is the size of the problem? Underlying reasons for results that are inconsistent with neo-classical economic theory (e.g. scope insensitivity and ordering effects) could be assessed using qualitative interviews, focus groups and think aloud approaches conducted simultaneously to the CV task. These can help understand how respondents arrive at WTP values. ${ }^{45}$ Such studies may also provide further evidence regarding the correctness of the 'neo-classical paradigm of rational agents'. This paradigm has been challenged by behavioral economics research, which provides alternative theories and 
hypotheses to explain departures from neoclassical assumptions. ${ }^{46}$ Given that evidence regarding internal validity tests is mixed, ${ }^{47}$ it would also be helpful to gain better knowledge of the size of the problem through systematic reviews of recent literature. ${ }^{48}$

\section{Other areas for future research}

The systematic literature review reported in Chapter 2 identified several other knowledge gaps that need to be addressed in future research. These relate to input data and methods for modelling, consideration of non-health sector costs and equity outcomes, as well as study designs used to determine effectiveness.

Many economic evaluation studies in public health currently focus only on intermediate outcomes of individual program participants. Mathematical models can translate intermediate outcomes into long-term outcomes. This requires a good understanding of the processes, by which intermediate outcomes lead to long-term outcomes. Some of the processes involved in public health interventions are well understood and can be modeled well, such as the relationship between smoking and cardiovascular disease, COPD or lung-cancer. ${ }^{49,50}$ For other relationships empirical data are missing and it is currently impossible to build an appropriate model structure and populate model parameters. ${ }^{51}$ Our findings suggests that there is a lack of data for modeling regarding program outcomes that go beyond the unidirectional effect on targeted individuals (e.g. interactions of the program with the wider social and structural environment) and for intermediate outcomes other than behavior changes (e.g. unwanted pregnancies prevented or increased knowledge and skills). Future research needs to address these knowledge gaps and provide further insights into complex processes involved in modern public health programs.

Modeling complex processes may also require departing from Markov models, which are commonly used in economic evaluation. These models represent changes in terms of (health) state transitions and may not provide an adequate reflection of change processes involved in public health programs, for example interactions between individuals and interactions between individuals and the environment. Hence, alternative model types, such as discrete-event simulation or system dynamics need to be tested. ${ }^{52,53}$ A recent application of system dynamics simulation modeling to assess costeffectiveness of alternative policy options in the US healthcare system, suggests that these types of models could be a way forward. ${ }^{54}$

It is important that researchers make models available to other researchers, ${ }^{55}$ who can adapt them to fit circumstances in other settings or countries. Orme and colleagues ${ }^{56}$ developed a model that calculates health and economic consequences of smoking related disease and made this widely accessible through an interactive software tool. This is an innovative approach, which should be taken up by other researchers. 
Future research should also give attention to non-health sector costs. Given that we lack insights into the type of costs public health programs pose on non-health sector budgets, it would be helpful to compile an overview of relevant non-health sector costs for different areas of behavior change and for other public health programs. At the same time there is a need for more methodological guidance regarding how to identify, measure and value these costs. Clear methodological guidance may contribute to more consistency in the methods used by economic evaluation studies and thus to better comparability. Gold et al. ${ }^{57}$ have conducted one of the first studies to systematically identify costs of a community-based health promotion program. They used a systemlevel approach to identifying costs and tracked a wide range of resource inputs from around the community. This work may give directions to other researchers, who seek to identify costs of complex modern public health programs or want to develop methodological guidance.

To better reflect the objectives of public health programs, economic evaluation studies should consider equity outcomes. Our research has identified several methods, which evaluators can use to provide information to decision-makers regarding actual or anticipated equity outcomes (i.e. reviewing background information on equity, presenting cost-effectiveness for equity-relevant subgroups and systematic assessment of expected distributional effects of implementing interventions under evaluation). ${ }^{15,16}$ These methods can be readily applied using standard methods of health technology assessment, when suitable data are available. ${ }^{15}$ Equity weighting analysis is another method that could be used to consider equity within economic evaluation. This method is still in development and has not been used to support decision-making in practice, yet. It explicitly attaches a value to reducing inequalities. Program benefits (e.g. QALYs gains) are weighted based on characteristics of the people who experience the benefits. Appropriate weights can be determined from relevant stakeholders, such as the general public or policy-makers. ${ }^{15}$ Different methods have been suggested to derive equity weights, including discrete choice experiments. Two recent studies using a DCE to determine equity weights in the $\mathrm{UK}^{58}$ and Australia ${ }^{59}$ produced contradictory findings regarding equity weights based on population preferences. More research is needed to further test these methods and address open methodological questions, for instance regarding the number and types of equity dimensions to be considered. ${ }^{58}$ Related to this is the need for a clear definition of 'equity'. There are different philosophical underpinnings of the equity concept, which determine how to operationalize equity outcomes. $^{60}$

The clear hierarchy of evidence adopted for biomedical and clinical health interventions, does not apply in the same way to public health programs. ${ }^{61,62}$ This has two main reasons: a) RCTs are not always a feasible and appropriate design option in public 
health and b) RCTs cannot provide all information relevant to decision-making. Our research highlighted for example the importance of context-sensitive evidence in public health. Currently, clear guidance is lacking regarding best practices for producing context-sensitive evidence. Future research needs to develop evaluation standards and methods for answering 'why' and 'how' public health programs work. ${ }^{63}$ At the same time research must continue to explore how RCTs can be used most optimally in public health. ${ }^{63}$ Hawe et al. ${ }^{64}$ suggest for instance to adapt RCT designs when applying them to complex public health programs by changing how these define standardization. Standardization usually means that all program components are the same. For complex programs it would make more sense to standardize only the function and process of the program, while the program form or components are tailored to local circumstances. The feasibility and validity of this approach needs to be tested. Usually a single study design will not provide sufficient evidence for public health decision-making. ${ }^{63}$ Hence, a variety of evidence sources may need to be used. Methods to synthesize diverse sources of evidence for the purpose of decision-making need to further developed.

Finally, in order to develop innovative solutions to overcome challenges in the economic evaluation of public health programs, it is essential to increase dialogue and collaboration between health economics and public health researchers. To date relatively few public health specialist are trained in economic evaluation methods and relatively few health economists are familiar with the specific characteristics of modern public health programs that create challenges for economic evaluation. Additional training is needed to increase understanding of each other's language and make this dialogue more fruitful. Given that all innovations ultimately aim to assist decision-makers, it is important to engage decision-makers in the process of their development. A key task that lies ahead for a collaborative working group is the development and regular update of good practice guidelines for the economic evaluation of public health programs. 


\section{References}

1. Ramsey S, Willke R, Briggs A, Brown R, Buxton M, Chawla A, et al. Good Research Practices for Cost-Effectiveness Analysis Alongside Clinical Trials: The ISPOR RCT-CEA Task Force Report. Value in Health 2005;8:521-533.

2. Caro JJ, Briggs A, Siebert U, Kuntz KM. Modeling Good Research Practices - Overview: A Report of the ISPOR-SMDM Modeling Good Research Practices Task Force-1. Medical Decision Making 2012;32:667-677.

3. Drummond MF, Sculpher MJ, Torrance W, O'Brien BJ, Stoddard GL. Methods for the Economic Evaluation of Health Care Programmes New York: Oxford University Press; 2005.

4. Evers S, Goosens $M$, de Vet $H$, van Tulder M, Ament A. Criteria list for assessment of methodological quality of economic evaluations: Consensus on Health Economic Criteria. International Journal of Technology Assessment in Health Care 2005;21:240-245.

5. Philips Z, Bojke L, Sculpher M, Claxton K, Golder S. Good practice guidelines for decisionanalytic modelling in health technology assessment: a review and consolidation of quality assessment. Pharmacoeconomics 2006;24:355-371.

6. Davidson KW, Goldstein M, Kaplan RM, Kaufmann PG, Knatterud GL, Orleans CT, et al. Evidence-Based Behavioral Medicine: What is it and how do we achieve it? Annals of Behavioral Medicine 2003;26:161-171.

7. Abraham C, Michie S. A taxonomy of behavior change techniques used in interventions. Health Psychology 2008;27:379-387.

8. Hoogenveen RT, de Hollander AEM, van Genugten MLL. The chronic diseases modelling approach, Report no. 266750001. Bilthoven National Institute of Public Health and the Environment (RIVM); 1998.

9. van Baal PHM, van den Berg M, Hoogenveen RT, Vijgen SM, Engelfriet PM. Cost-Effectiveness of a Low-Calorie Diet and Orlistat for Obese Persons: Modeling Long-Term Health Gains through Prevention of Obesity-Related Chronic Diseases. Value in Health 2008;11:1033-1040.

10. Tariq $L$, van den Berg $M$, Hoogenveen RT, van Baal PHM. Cost-Effectiveness of an Opportunistic Screening Programme and Brief Intervention for Excessive Alcohol Use in Primary Care PLOS One 2009;4:e5696.doi:5610.1371/journal.pone.0005696.

11. Vijgen SMC, van Baal PHM, Hoogenveen RT, de Wit GA, Feenstra TL. Cost-effectivenss analyses of health promotion programs: a case study of smoking prevention and cessation among Dutch students. Health Education Research 2008;23:310-318.

12. Briggs A. Handling uncertainty in economic evaluation. British Medical Journal 1999;319:120.

13. Baxter S, Killoran A, Goyder E. Synthesizing diverse evidence: the use of primary qualitative data analysis methods and logic models in public health reviews. Public Health 2010;124:99106.

14. Marsh $\mathrm{K}$, Dolan $\mathrm{P}$, Kempster $\mathrm{J}$, Lugon $\mathrm{M}$. Prioritizing investments in public health: a multicriteria decision analysis. Journal of Public Health 2013;35:460-466.

15. Cookson R, Drummond $M$, Weatherly $H$. Explicit incorporation of equity considerations into economic evaluation of public health interventions. Health Economics, Policy and Law 2009;4:231-245.

16. Sassi F, Archard L, Le Grand J. Equity and the economic evaluation of healthcare. Health Technology Assessment 2001;5:1-138.

17. Rychetnik $L$, Frommer $M$, Hawe $P$, Shiell $A$. Criteria for evaluating evidence on public health interventions. Journal of Epidemiology and Community Health 2002;56:119-127.

18. Rosen R, Gabbay J. Linking health technology assessment to practice. British Medical Journal 1999;319:1-3.

19. Stephens JM, Handke B, Doshi JA. International survey of methods used in health technology assessment (HTA): does practice meet the principles proposed for good research? Comparative Effectiveness Research 2012;2:29-44.

20. Lomas J, Culyer T, McCutcheon C, McAuley L, Law S. Conceptualizing and combining evidence for health system guidance. Ottawa: Canadian Health Services Research Foundation 2005. 
21. Davies P. Evidence-based government: how can we make it happen? [oral presentation]. CHSRF 7th invitational workshop -- leveraging knowledge: tools and strategies for action March 3rd; Montreal 2005.

22. Abelson J, Giacomini M, Lehoux P, Gauvin F. Bringing 'the public' into health technology assessment and coverage policy decisions: From principles to practice. Health Policy 2007;82:37-50.

23. NICE. Methods for the development of NICE public health guidance (third edition). London NHS; 2012.

24. Allin S, Mossialos E, McKee M, Holland W. Making decisions on public health: a review of eight countries. Copenhagen: WHO Regional Office for Europe; 2004.

25. Kelly MP, McDaid D, Ludbrook A, Powell J. Economic appraisal of public health interventions. London: NHS Health Development Agency 2005.

26. NICE. Developing NICE Public Health Guidance. [accessed on April 14th 2013]; Available from:http://www.nice.org.uk/aboutnice/howwework/developingnicepublichealthguidance/deve loping_nice_public_health_guidance.jsp

27. NICE. Where NICE guidance applies. [accessed on April 14th 2013] ; Available from: http://www.nice.org.uk/aboutnice/ whatwedo/niceandthenhs/nice_and_the_nhs.jsp.

28. Lorgelly PK, Lawson KD, Fenwick EAL, Briggs AH. Outcome measurement in economic evaluations of public health interventions: a role for the capability approach?. International Journal of Environmental Research and Public Health 2010;7:2274-2289.

29. Sen A. Commodities and Capabilities. New York: Elsevier; 1985.

30. Al-Janabi H, Flynn TN, Coast J. Development of a self-report measure of capability wellbeing for adults: the ICECAP-A. Quality of Life Research 2012;21:167-176.

31. Renwick R, Brown R. Being, belonging, becoming: the Centre for Health Promotion model of quality of life. In: Renwick R, Brown I, Nagler M, editors. Quality of Life in Health Promotion and Rehabilitation: Conceptual Approaches, Issues and Applications. Thousand Oaks: Sage 1996:75-88.

32. Raphael D, Steinmetz B, Renwick R, Rootman I, Brown I, Sehdev H, et al. The Community Quality of Life Project: a health promotion approach to understanding communities. Health Promotion International 1999;14:197-210.

33. Renwick R, Nourhaghighi N, Manns PJ, Rudman DL. Quality of life for people with physical disabilities: a new instrument. International Journal of Rehabilitation Research 2003;26:279287.

34. Raphael D, Waalen J, Karabanow A. Factor analytic properties of the Quality if Life Profile: examination of the nine subdomain Quality of Life Model. Psychological Reports 2001;88:265276.

35. Raphael D, Rukholm E, Brown I, Hill-Bailey P, Donato E. The Quality of Life Profile Adolescent Version: Background, Description, and Initial Validation. Journal of Adolescent Health 1996;19:366-375.

36. Ryan M, Netten A, Skåtun D. Using discrete choice experiments to estimate a preferencebased measure of outcome - An application to social care for older people. Journal of Health Economics 2006;25:927-944.

37. Shiell A, Hawe P. Health promotion community development and the tyranny of individualism. Health Economics 1996;5:241-247.

38. Raphael D. Evaluation of quality-of-life initiatives in health promotion. WHO Regional Publications European Series No 92. 2001:123-147.

39. de Leeuw E. Do Healthy Cities Work? A Logic of Method for Assessing Impact and Outcome of Healthy Cities. Journal of Urban Health 2011;89:217-231.

40. Parker EA, Lichtenstein RL, Schulz AJ, Israel BA, Schork MA, Steinman KJ, et al. Disentangling Measures of Individual Perceptions of Community Social Dynamics: Results of a Community Survey. Health Education and Behavior 2001;28:462-486.

41. Wallerstein $\mathrm{N}$. What is the evidence on effectiveness of empowerment to improve health? Kopenhagen: WHO Regional Office for Europe; 2006. 
42. McCormack G, Giles-Corti B, Lange A, Smith T, Martin K, Pikora TJ. An update of recent evidence of the relationship between objective and self-report measures of the physical environment and physical activity behaviours. Journal of Science and Medicine in Sport. 2004; 7:Supplement: 81-92.

43. Bateman IJ. Household Willingness to Pay and Farmers' Willingness to Accept Compensation for Establising a Recreational Woodland. Journal of Environmental Planning and Management. 1996;39:21-44.

44. Bennet RM, Tranter RB, Blaney RJP. The Value of Countryside Access: A Contingent Valuation Survey of Visitors to the Ridgeway National Trail in the United Kingdom. Journal of Environmental Planning and Management. 2003;46:659-671.

45. Baker R, Robinson A, Smith R. How do respondents explain WTP responses? A review of the qualitative evidence. The Journal of Socio-Economics. 2008;37:1472-1442.

46. Kling $\mathrm{CL}$, Phaneuf $\mathrm{DJ}$, Zhao J. From Exxon to BP: Has some number become better than no number? Journal of Economic Perspectives. 2012;26:3-26.

47. Venkatachalam L. The contingent valuation method: a review. Environmental Impact Assessment Review. 2004;24:89-124.

48. Whitty JA. Insensitivity to Scope in Contingent Valuation Studies: New Direction for an Old Problem. Applied Health Economics and Health Policy. 2012;10:361-363.

49. Ezzati M, Lopez AD. Estimates of global mortality attributable to smoking in 2000. Lancet. 2003;362:847-852.

50. Pichon-Riviere A, Augustovski F, Bardach A, Colantonio L. Development and Validation of a Microsimulation Economic Model to Evaluate the Disease Burden Associated with Smoking and the Cost-Effectiveness of Tobacco Control Interventions in Latin America. Value in Health. 2011;14:S51-S59.

51. Levy DT, Bauer JE, Hye-ryeon L. Simulation Modeling and Tobacco Control: Creating More Robust Public Health Policies. American Journal of Public Health. 2006;96:494-498.

52. Stahl J. Modelling Methods for Pharmacoeconomics and Health Technology Assessment: An Overview and Guide. Pharmacoeconomics. 2008;26:131-148.

53. Barton P, Bryan S, Robinsion S. Modelling in the economic evaluation of health care: selecting the appropriate approach. Journal of Health Services Research and Policy 2004;9:110-118.

54. Milstein B, Homer J, Hirsch G. Analyzing National Health Reform Strategies With a Dynamic Simulation Model. American Journal of Public Health. 2010;100:811-819.

55. Eddy DM, Hollinworth W, Caro JJ, Tsevat J, McDonald K, Wong JB. Model Transparency and Validation: A Report of the ISPOR-SMDM Modeling Good Research Practices Task Force - 7. Medical Decision Making. 2012;32:733-343.

56. Orme ME, Hogue SL, Kennedy LM, Paine AC, Godfrey C. Development of the health and economic consequences of smoking interactive model. Tobacco Control. 2001;10:55-61.

57. Gold L, Shiell A, Hawe P, Riley T, Rankin B, Smithers P. The costs of a community-based intervention to promote maternal health Health Education Research. 2007;22:648-657.

58. Lanscar E, Wildman J, Donaldson C, Ryan M, Baker R. Deriving distributional weights for QALYs through discrete choice experiements. Journal of Health Economics. 2011;30:466-478.

59. Norman R, Hall J, Street D, Viney R. Efficiency and Equity: A Stated Preference Approach Health Economics. 2013;22:568-581.

60. Braveman P, Gruskin S. Defining equity in health. Journal of Epidemiology and Community Health. 2003;57:254-258.

61. Godfrey C. Economic evaluation of health promotion. WHO Regional Publications European Series No 92. 2001:149-170.

62. Macdonald G, Veen $C$, Tones $K$. Evidence for success in health promotion: suggestions for improvement. Health Education Research. 1996;11:367-376.

63. Victora CG, Habicht J, Bryce J. Evidence-Based Public Health: Moving Beyond Randomized Trials. American Journal of Public Health 2004;94:400-405.

64. Hawe $P$, Shiell A, Riley T. Complex interventions: how "out of control" can a randomized controlled trial be? British Medical Journal. 2004;328:1561-1563. 

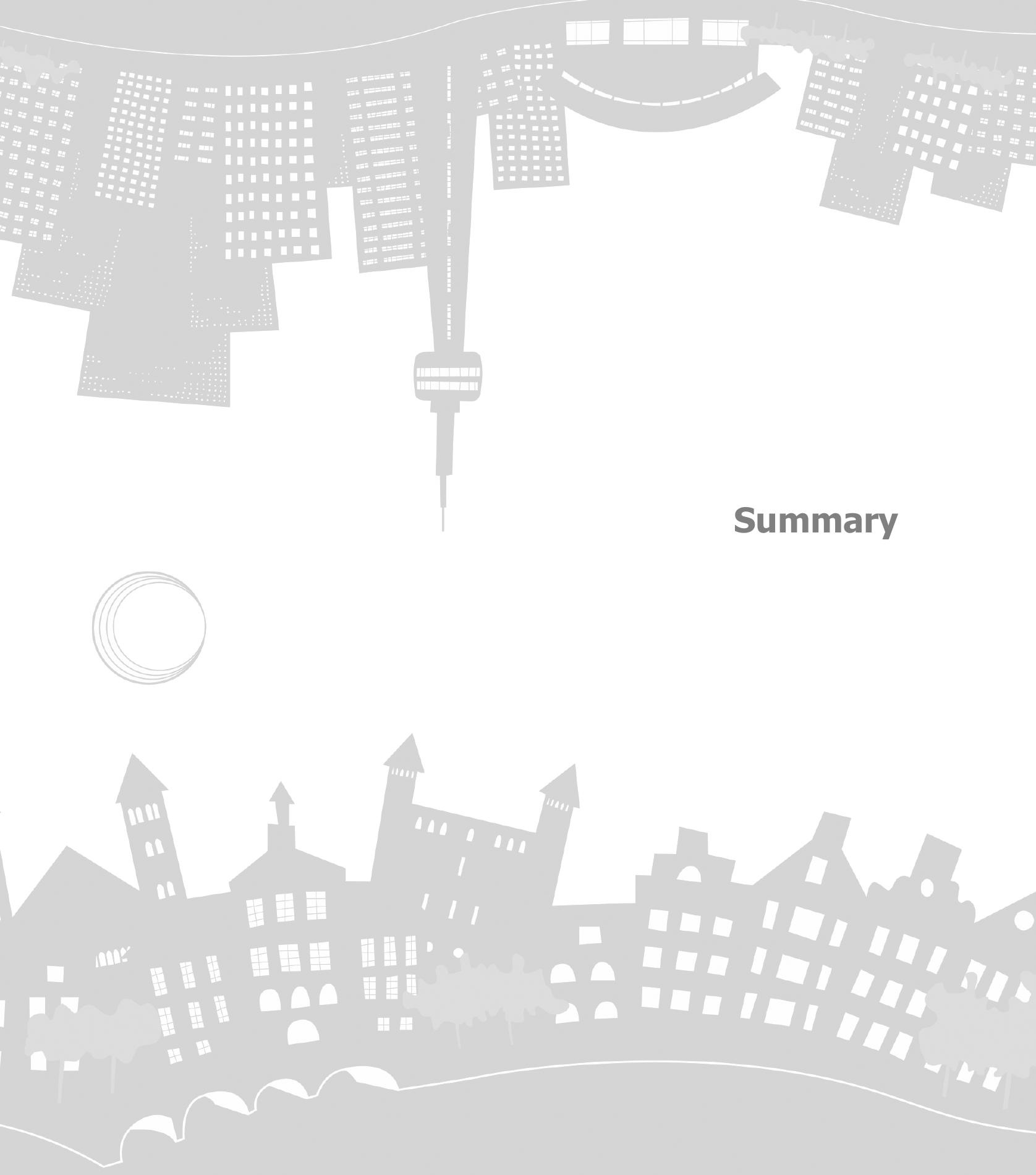
苞 


\section{Summary}

Economic evaluation studies of health programs provide insights into the costs and benefits of decision alternatives. They are increasingly used to support decisions about health technologies, such as pharmaceuticals, medical devices, diagnostic and surgical procedures. Economic evaluation methods have not yet been much applied to modern public health programs. These programs are challenging for evaluation, because they tend to address multiple determinants of health and behavior, consist of multiple strategies and produce multiple outcomes on the individual and societal or system level. This research provides insights into the state of the art of applying economic evaluation to public health programs in the area of behavior change and presents potential solutions to overcome key methodological challenges. Seven methodological challenges are addressed in this research: 1) the long time horizon needed to achieve all benefits of public health programs; 2) the impacts public health programs may have on broader domains of individual quality of life or wellbeing that are not captured by the QALY; 3 ) the outcomes public health programs may produce on a community or societal level; 4) the objective of many public health programs to achieve more health equity; 5) the fact that evidence in public health does not always fit into the hierarchy of evidence adopted for biomedical and clinical health interventions; 6) the non-health sector costs public health programs may produce; and 7) the need for comparing public health programs with interventions in other societal sectors, due to multi-sector collaboration.

Chapter 2 presents a systematic review of existing economic evaluations of lifestyle behavior change programs. It demonstrates that the number of economic evaluations has considerably increased over the past decade. However, methodological quality of the studies shows several weaknesses, including insufficient reporting of essential study details and limited adherence to good practice guidelines. Progress with addressing methodological challenges has also been limited. These shortcomings in the existing evidence impede efficient resource allocation to public health programs.

Chapter 3 reports a study exploring the possibility to use the Value of Statistical Life (VSL) as efficiency parameter in multi-sector comparisons. Our study determined and compared implicit VSL estimates for life saving interventions implemented by the Dutch government in the health, water control, consumer safety and transport sector. The study findings suggest that the VSL is not an ideal parameter to compare public health programs with interventions in other societal sectors, because reduction in risk of premature death is the only outcome it captures. Nevertheless, the cost-benefit framework, on which the VSL is based, may still be a useful approach to encourage multi-sector comparisons. 
Chapter 4 provides further insights into outcomes that may be relevant to consider in addition to reductions in risk of premature death. Based on a qualitative study using a combination of focus groups and individual interviews, we identified outcomes experienced by participants of a randomized controlled trial evaluating the effectiveness of a theory-based lifestyle intervention in adults at risk for diabetes mellitus and/or cardiovascular disease. By means of a thematic analysis approach identified outcomes were coded into outcomes that are captured by EQ-5D based QALYs (i.e. changes in life expectancy and health-related quality of life dimensions measured by the EQ-5D instrument) and other outcomes usually not considered in economic evaluations. Other outcomes included direct consequences of the lifestyle intervention (e.g. increased awareness and motivation for behavior change) and consequences of lifestyle behavior change (e.g. increased feeling of control and body satisfaction). The study findings also indicate that lifestyle behavior change may have social spillover effects to other people in participants' direct social environment.

Chapter 5 describes a discrete choice experiment (DCE), which explores the relative importance health outcomes have to consumers compared to broader outcomes of lifestyle behavior change. Respondents were asked to make a series of binary choices between situations that can be experienced after lifestyle behavior change. The situations were described in terms of ten attributes. Three of these represented health outcomes measured within the QALY framework (i.e. life expectancy, future health state and timing of future health state). Five attributes were based on broader outcomes identified in the qualitative research reported in Chapter 4 (i.e. clothing size above or conform ideal, days with sufficient relaxation, endurance, experienced control over lifestyle choices and lifestyle improvement of partner and/or children). Finally, two attributes were included to reflect the monetary and time costs associated with lifestyle behavior change (i.e. monetary cost per month and time cost per week). With the exception of time cost per week and timing of future health state, all attributes significantly determined consumer choices. Marginal rates of substitution between the monetary cost attribute and the other attributes suggest that respondents attached most value to improvements in endurance, days with sufficient relaxation and future health state value. These findings suggest, that decision-makers, who wish to respond to consumer preferences, should consider both health and non-health outcomes when deciding about lifestyle behavior change interventions.

Chapter 6 presents an application of the contingent valuation (CV) method to support decision-making that requires consideration of both health and non-health outcomes. The CV task asked participants of a lifestyle intervention trial to express their willingness to invest money and time for changes in three benefits of lifestyle change: improved life 
expectancy, health-related quality of life and broader quality of life aspects. Our findings indicate that the majority of respondents attached value to all three benefits and that most were willing to invest both money and time. The CV method is controversial, because there is uncertainty regarding the feasibility and ability of the method to derive valid WTP values. In the present research CV has proven to be a feasible approach for monetary valuation of a range of benefits from an individual consumer perspective. Three tests of internal validity produced mixed results, however. Thus, at present CV cannot be recommended as sole base for decision-making.

The overall findings of this research lead to a number of recommendations for economic evaluation practice, decision-making and future research, which are described in the general discussion (see Chapter 7). Recommendations for economic evaluation practice focus on improvement of reporting of studies, increasing adherence with good practice guidelines and existing methods that can be used to deal with challenges caused by the long-time horizon of public health programs, non-health sector costs, and broader benefits or equity outcomes they may produce. For decision-making two recommendations are made: a) broadening the scope of scientific evidence produced and examined during technology assessments in the field of public health, and b) establishing better infrastructure to support systematic use of evidence. This research also highlights several areas for future research, including: the identification and definition of broader outcomes in different application areas of public health; developing validated instruments or measures that allow for consideration of impacts on wider domains of wellbeing; development of methods to capture community or system-level changes; further testing of the feasibility and validity of the CV method; producing input data for modeling, testing new approaches for modeling of complex processes; developing methodological guidance regarding how to deal with non-health sector costs; further testing of methods for equity weighting analysis; defining equity outcomes for economic evaluation; establishing best practices for producing context-sensitive evidence; and developing methods to synthesize diverse forms of quantitative and qualitative evidence for use in technology assessment and economic evaluation. Finally, in order to develop innovative solutions to overcome remaining challenges in the economic evaluation of public health programs, it is essential to increase dialogue and collaboration between health economics, public health researchers and decision-makers. The development and regular update of good practice guidelines for the economic evaluation of public health programs is a key task ahead, which requires collaborative action. 


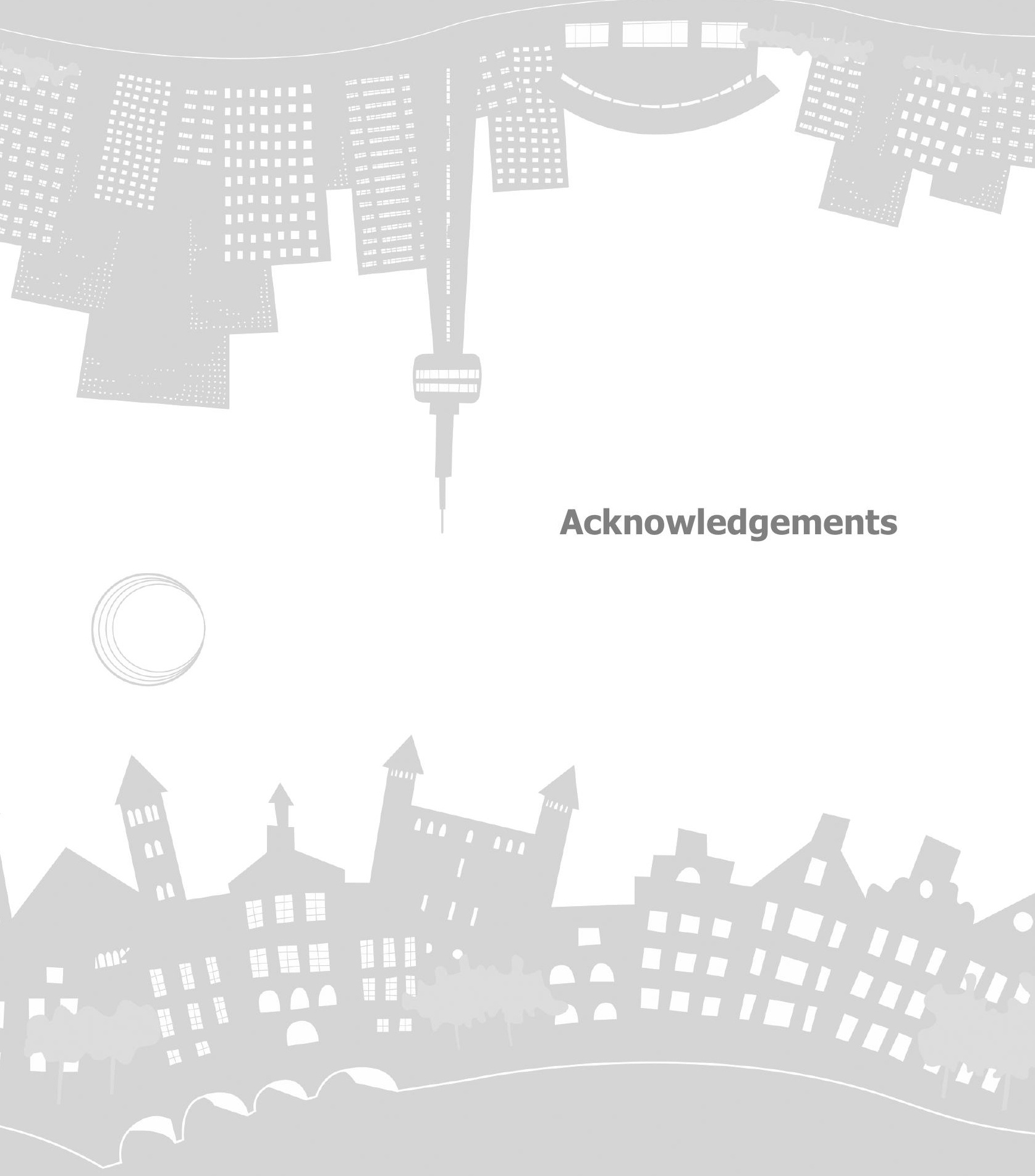


\section{Acknowledgements}

I am grateful for all the support I received on my journey through the hills and valleys of this PhD adventure. During different parts of the journey several people had a special role, which I would like to acknowledge here.

Stepping-stones: First, I want to thank my Master's thesis supervisors Prof. Hans Maarse, Prof. Jan Nicholson, Dr. Kerryann Walsh and Prof. Hein de Vries, who made me enthusiastic about research and stimulated me to start this journey. Hans, thank you for your continuous interest in my research and passing by for regular chats. Jan and Kerryann, thanks for your ongoing support. I enjoyed that we continued working together on an article and book chapter.

Supervision team: I am thankful to Prof. Hans Severens, Prof. Nanne de Vries and Dr. Andre Ament for their support and time over years and distances. I appreciate the many productive discussions, which helped me grow professionally and personally. Hans, you were the most constant factor on a journey full of changes. Nanne, thanks for joining in the final stage of the project. You had a fresh perspective and a great sense of humor, which kept me going with a smile. Andre, I appreciate that your door was always open for scientific and other life questions.

Colleagues in Maastricht: The Department of HOPE (later: HSR) was the home base, where I have spent most of my PhD time. Many colleagues made me actually feel at home there. In particular, my roommates Janneke Grutters and Ellen Leers, who were always helpful and fun. I would also like to acknowledge Professor Silvia Evers, who has given me many opportunities to learn. I enjoyed working with you and Aggie in the Health Economics Course Planning-Group and on the INFORMEH project. Fellow PhD students have enriched my journey through many laughs and activities. I want to thank the folks, who were there when I started: Hanneke, Irma, Lineke, and Ties. I missed you after you flew out as fresh doctors. Federica, Jelena, Marie-Jeanne, Marla and Saskia, thanks for taking over during my final years in Maastricht. I enjoyed our coffee break chats. Fleur, it was an honor to be your paranymph and great to experience the 'paranymphship' together with Irene. I am also thankful to the HTA group (Aukje, Brigitte, Carmen, Iris, Manuela, Marieke, Thea, Valesca et al.) for the inspiring seminars and conference visits. Merel, it was a great to bump into you during my first HTA seminar. Thank you for your friendship and our Sydney experiences. Anil, I am grateful that you invited Marie-Claire and me to stay in your apartment in Mumbai. We are still talking about your in-laws' amazing hospitality and homemade cooking. Last, but not 
least I want to thank the ladies of the secretarial office: Brigitte, Suus, Rietje en Marja. Without your friendly support this research would not have been possible.

Colleagues in Amsterdam: I want to acknowledge Professor Maurits van Tulder, who created the opportunity for me to spend two years as visiting researcher at the Department of Health Sciences, VU University. I appreciate the good collaboration with the team of the 'Leefstijl Onderzoek Westfriesland': Dr. Sandra Bot, Prof. Giel Nijpels, Jolanda Bosman, Marzella Zijlmans, Merlin Zwart and in particular Dr. Jeroen Lakerveld, who had a crucial role during the collaboration. Many thanks also to Nienke Wijnstok and Lucilla Solerno for being such nice roommates, to Trynke Hoekstra for inviting me to so many activities (including the 4-daagse), to Jacqueline Cransberg for answering numerous questions; and to other colleagues for the inspiring chats in the hallways: Dr. Judith Bosmans, Maarten Kok, Dr. France Portrait, Dr. Matthijs Heijmans, Suzanne van der Werff, Dr. Maiza Campos Ponce et al. Finally, I want to thank Bernard van den Berg for contributing many good ideas at the beginning of the project.

The iBMG-team at Erasmus University. Thanks to all of you for being so welcoming and helpful every time I made the journey to Rotterdam to meet my supervisor/co-authors. A big word of thanks to Karin van Oorschot and Liza Moreira, who made these meetings happen. I also want to thank Pepijn Vemer for being so helpful and inspiring. Maybe I should finally consider joining Toastmasters...

Experts and colleagues in Australia: I am grateful to Professor Jane Hall for hosting me at the Centre for Health Economics Research and Evaluation (CHERE). I appreciate your feedback and the introductions you provided to experts at your Centre and in Melbourne. One of these experts was Professor Debbie Street. It was an honor to meet you and to get your advice regarding the design of our discrete choice experiment. I am also thankful to Dr. Stephanie Knox for developing the optimal orthogonal design of the experiment and for helping me understand this complex process. I was lucky to meet plenty of welcoming people at CHERE: Professor Marion Haas, Professor Rosalie Viney, Jody Church, Dr. Rebecca Reeve, Richard Norman, Dr. Stephen Goodall, Bonnie Parkinson et al. In particular, I want to thank Braedon Donald for being a friend when I needed one. I hope we catch up sometime soon, now that we are both in Canada.

I also want to acknowledge the experts, I met during a short-term visit in Melbourne/Geelong: Professor Jeff Richardson, Dr. Liza Gold, Dr. Duncan Mortimer, Professor Tony Scott and Professor Bruce Hollingsworth. Thank you for your time and good ideas. I am especially thankful to Professor Eveline de Leeuw, for her amazing 
hospitality. Last, but not least I want to thank Jean Spinks, who hosted me at her house and showed me the city from an insider perspective.

Support network in Canada: During the last one and a half years of writing in Toronto, I had much unexpected support. First and foremost and want to thank Jenn Veenboer for being a great mentor and friend. I am also thankful to Professor Jeffrey Hoch, who introduced me to the theta rounds and health economics network in Toronto. Martine, I was happy to make a Dutch friend during my first weeks in Canada. Thanks for showing me where to get 'drop' and 'hagelslag'. I also want to acknowledge my new colleagues at Public Health Ontario. I am grateful to Dr. Heather Manson, who gave me the opportunity to experience program evaluation in the real world. This made many of the ideas in my thesis come to life. Thanks also to the ladies of the HBHC team: Anne, Carly, Eunice, Helen, Jenny, Lori and Quynh. Your humor and positive attitude made me forget that I was tired after long nights of writing. Finally, I want to thank Dr. Beate Sander. It is great to have a colleague with similar research and lunch interests.

Co-authors: I want to acknowledge all co-authors, who have contributed to articles in this thesis. Thank you for your valuable comments and suggestions.

- $\quad$ Professor Benedict Dellaert, Department of Business Economics, Erasmus University.

- Dr. Job van Exel, Institute of Health Policy and Management (iBMG), Erasmus University.

- Dr. Stephanie Knox, Centre for Health Economics Research and Evaluation, University of Technology, Sydney (Australia).

- Professor Silvia Evers, Department of Health Services Research, Maastricht University.

- Dr. Jeroen Lakerveld, Department of General Practice, EMGO Institute, VU University Medical Center.

- Dr. Sandra Bot, Department of General Practice, EMGO Institute, VU University Medical Center.

- Professor Giel Nijpels, Department of General Practice, EMGO Institute, VU University Medical Center.

- Christiaan Veraart, Merck Serono, Schiphol-Rijk.

- Annoesjka Novák, Anovák Services, Apeldoorn.

- Jan Christoph-Tilly, GlaxoSmith Kline GmbH \& Co KG, München (Germany).

- Daria Alexseeva, Dance 4 Life International, Amsterdam. 
The reading committee: I want to thank Prof. Dirk Ruwaard, Prof. Carmen Dirksen, Prof. Maurits van Tulder, Prof. Hein de Vries and Dr. Ardine de Wit for assessing the scientific content of this dissertation.

Funding: This research would not have been possible without the generous support of the Netherlands Organisation for Scientific Research (NWO) and the School of Public Health and Primary Care (CAPHRI).

Study participants: I am thankful to all study participants, who shared their views and experiences. Their input was indispensible for this research.

PhD Academy: The PhD Academy Maastricht was a great place to meet interesting people and look beyond the boarders of my research. I am particularly thankful to Daniel Vertesy, Erik Pot and Marco Zinzani for the wonderful board time we had together. Siu Hing Lo and Stephanie van Nispen, thanks for taking over from us. The board couldn't have been in better hands.

Paranymphs: Marie-Claire and Carolina, I am glad that you'll stand by my side during the defence in the same way you did during the PhD journey.

Friends: I feel blessed for the distractions and support my friends provided. Anke, Nicola, Petra, Rebecca, Sabine, Sylvia and Vicky, thanks for being such good friends for almost 20 years; Julia, thank you for making my Rotterdam trips so pleasant; Dorit, I am happy that we shared some of our PhD time in Maastricht; Esther, I admire your positive spirit; Adele, thank you for helping me find a place to stay in Sydney; Chantal, Kim Marloes and Nienke I am glad that we keep up our 'jaarclub' traditions. Special thanks to Kim for being such a good friend and for everything you have done - from taking notes during Epi-classes and providing a bed and breakfast during my Amsterdam times to visiting us in Toronto.

Family: Papa and Mama, thank you for creating such a safe harbor. Without your love and support I would not be where I am. Fatima, Mahmoud and Aseel, I consider myself lucky to be part of such a wonderful family. Omar, you give me the courage to follow our dreams, no matter how unachievable or crazy they may seem. Thank you for your love and tremendous patience, and for designing the cover of this book. Last, but not least, I am glad that Hazel joined our little family. I didn't know dogs could teach us so much. 

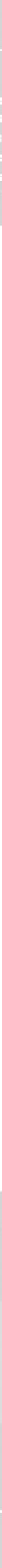


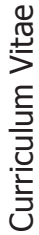




\section{Curriculum Vitae}

Adrienne Alayli-Goebbels was born on April $4^{\text {th }} 1980$ in Heerlen, the Netherlands. After completing her A-levels at Gymnasium Herzogenrath (Germany) in 1999, she worked for 12 months at the General Hospital Marienhöhe in Würselen (Germany), first as intern and subsequently as assistant nurse.

In 2006, Adrienne obtained a Master's degree in Health Sciences (MSc) from Maastricht University with double majors in Health Promotion and Education; and Health Policy, Economics and Management (both cum laude). During her study period, she spent a semester at Humboldt University in Berlin (Erasmus program) and a six-month research placement at Queensland University of Technology in Brisbane, Australia.

From April 2006 to October 2007, she was employed as junior researcher at the Department of Health Promotion and Education and the Department of Health Organization, Policy and Economics (HOPE).

Adrienne stayed at the Department of HOPE (now: Health Services Research) to conduct her doctoral research under supervision of Professor J.L. Severens, Professor N.K. de Vries and Dr. A.J.A.H. Ament. The research focused on methodological challenges in the economic evaluation of public health programs and was funded by a Toptalent scholarship from the Netherlands Organisation for Scientific Research (NWO).

Adrienne carried out parts of the doctoral research at VU University in Amsterdam, where she was a visiting researcher for two years. In 2010, she spent three months in Sydney (Australia) to conduct a work visit at the Centre for Health Economics and Research Evaluation (CHERE) and complete course work at the University of Sydney, both funded by a travel grant from the School of Public Health and Primary Care (CAPHRI). CAPHRI also provided funding to follow a postgraduate program in Epidemiology (MSc), from which Adrienne graduated in 2011.

In her role as doctoral researcher she jointly applied for a research grant, which was awarded by The Netherlands Organisation for Health Research and Development (ZonMW) in 2011 (Project title: INFORMEH - An INstrument FOR outcome Measurement in Economic evaluations of Health promotion). Adrienne continues to be involved in this project as co-project leader and supervisor.

Since, February 2013 Adrienne holds a position as Evaluation Specialist at Public Health Ontario in Toronto, Canada. Her current research at the Department of Health Promotion, Chronic Disease and Injury Prevention contributes to the evaluation of the provincial implementation of recent enhancements to the Healthy Babies, Healthy Children Program. 



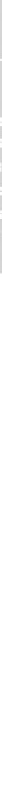

List of publications and presentations
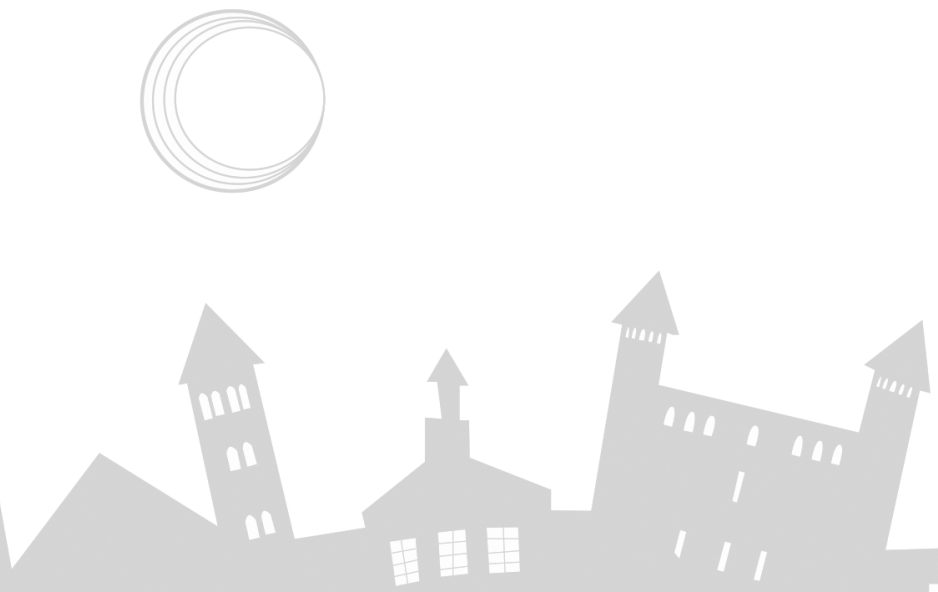

Mne H H H H

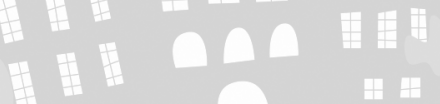
H 패

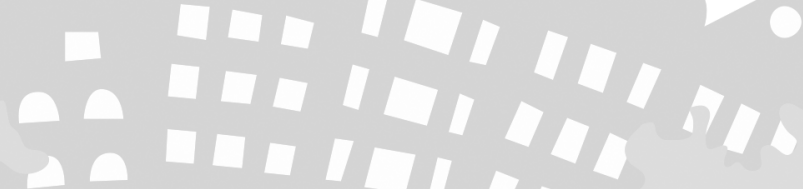


$\frac{0}{0}$
음
$\frac{0}{\overline{0}}$
$\frac{3}{2}$ 


\section{List of publications}

\section{Peer-reviewed publications}

Alayli-Goebbels AFG, Dellaert BGC, Knox SA, Ament AJHA, Lakerveld J, Bot SDM, Nijpels G, Severens JL. Consumer preferences for health and non-health outomes of health promotion: results from a discrete choice experiment. Value in Health. 2013;16:114-123.

Alayli-Goebbels AFG, Evers SMAA, Alexeeva D, Ament AJHA, De Vries NK, Tilly JC, Severens JL. A review of economic evaluations of behaviour change interventions: setting an agenda for research methods and practice. Journal of Public Health. 2013 [Epub ahead of print].

Goebbels AFG, Lakerveld J, Ament AJHA, Bot SD, Severens JL. Exploring non-health outcomes of health promotion: the perspective of participants in a lifestyle behavior change intervention. Health Policy. 2012;23:177-186.

Goebbels AFG, Nicholson JM, Walsh K, de Vries H. Teachers' reporting of suspected child abuse and neglect: behaviour and determinants. Health Education Research. 2008;23:941-951.

Goebbels AFG, Ament AJHA, Novak A, Veraart CPWM, Severens JL. Estimating the Implicit Value of Statistical Life based on public interventions implemented in the Netherlands. International Journal of Technology Assessment in Health Care. 2008;24:495-501.

\section{Manuscripts submitted for publication}

Alayli-Goebbels AFG, van Exel NJA, de Vries NK, Ament AJHA, Bot SD, Severens JL. Consumer willingness to invest time and money for benefits of lifestyle behavior change: an application of the contingent valuation method. (Under revision for publication in Health Expectations).

Aarts M, Alayli-Goebbels AFG, Lawson KD, Evers SMAA. Do we need to widen the scope of economic evaluation? The importance of non-health outcomes in health promotion.

Benning TM, Alayli-Goebbels AFG, Aarts M, de Wit GA, Prenger R, Braakman A, Stolk E, Evers SMAA. Exploring outcomes to consider in economic evaluations of health promotion programs: what broader non-health outcomes matter most? 


\section{Other publications and reports}

Evers SMAA, Aarts MJ, Alayli-Goebbels AFG. Measuring health and wellbeing for economic evaluation of public health interventions. In: The Economics of Chronic Disease Prevention: Making the economic case for investing in public health, health promotion and disease prevention interventions across Europe. Paris: OECD, (forthcoming).

Walsh K, Goebbels AFG, Nicholson J. Teachers' detecting and reporting child abuse and neglect: Research into the determinants of complex professional behaviour. In: J. O'Dea \& Crawford, L. (Eds.), Current Issues and Controversies in School and Community Health education. New York: Nova Science Publishers, 2012.

Goebbels AFG, Ament AJHA, Severens JL. The value of statistical life: A promising efficiency parameter for health care? Final project report for NWO, 2012.

Aarts M, Goebbels AFG, Evers SMAA. An Instrument for Outcome Measurement in Economic Evaluation of Health Promotion (the INFORMEH project). Progress report for ZonMW, 2012.

Goebbels AFG, Ament AJHA, Severens JL. The value of statistical life: A promising efficiency parameter for health care? Midterm project report for NWO, 2010.

Goebbels AFG, Severens JL, Ament AJHA. Estimating the implicit value of statistical life in different societal sectors in the Netherlands. Project report for Roche Netherlands B.V., 2007.

Goebbels AFG, Ament AJHA, Severens JL. Economic evaluation of alternative cholesterollowering strategies in patients with varying LDL-c baseline values. Project report for AstraZenca, 2007.

Eiling E, Goebbels AFG, De Vries NK. Effect evaluation of Find Out. Project report for ZonMW. Maastricht: Maastricht University, 2006.

\section{Presentations}

Aarts MJ, Goebbels AFG, Evers SMAA. A theoretical framework for measuring non-health outcomes of health promotion for economic evaluations. Lowlands Health Economists' Study Group, May 24-25 2012 in Almen. Discussion paper. 
Goebbels AFG, Dellaert BGC, Knox SA, Ament AJHA, Lakerveld J, Bot SDM, Nijpels G, Severens JL. Incorporating non-health outcomes in economic evaluations of health promotion? An exploratory DCE-based analysis. 25th Conference of the European Health Psychology Society, September $20^{\text {th }} 2011$ to 24 th in Crete, Greece. Poster presentation.

Goebbels AFG, Dellaert BGC, Knox SA, Ament AJHA, Lakerveld J, Bot SDM, Nijpels G, Severens JL. Incorporating non-health outcomes in economic evaluations of health promotion? An exploratory DCE-based analysis. $8^{\text {th }}$ World Congress on Health Economics, July 10-13 2011 in Toronto, Canada. Oral presentation.

Goebbels AFG, Dellaert BGC, Knox SA, Ament AJHA, Lakerveld J, Bot SDM, Nijpels G, Severens JL. Incorporating non-health outcomes in economic evaluations of health promotion? An exploratory DCE-based analysis. Seminar on May $17^{\text {th }} 2011$ at the Institute of Health Policy and Management at the Erasmus University, Rotterdam. Invited oral presentation.

Goebbels A, Lakerveld J, van den Berg B, Ament A, Nijpels G, Severens J. The (dis)benefits of health promotion: experience and perspective of programme users. European Conference on Health Economics, July 7-10 2010 in Helsinki, Finland. Oral presentation.

Goebbels AFG, van den Berg B, Ament AJHA, Severens JL. Lives, health related QOL, costs and what else to consider in economic evaluation of health promotion interventions. Seminar on March $11^{\text {th }} 2010$ at the Centre for Health Economics Research and Evaluation, Sydney, Australia. Invited oral presentation.

Goebbels AFG, Ament AJHA, Novak A, Veraart CPWM, Severens JL. Estimating the Implicit Value of Statistical Life based on life saving interventions implemented in the Netherlands. ISPOR European Congress, November 8-1 $1^{\text {th }} 2008$ in Athens, Greece. Poster presentation.

Goebbels AFG, van den Berg B, Ament AJHA, Severens JL. Economic evaluation of health promotion programmes: A review of current practice and assessment of potential problems. Health Technology Assessment and Health Economics meeting, October $14^{\text {th }}$ 2008 at VU University in Amsterdam. Invited oral presentation. 
